\title{
BIBLIOGRAFÍA
}

OBSERVACIONES: Las reseñas se consignan a continuación del libro (o artículo) reseñado. Cuando éste se ha descrito en una entrega anterior de la Bibliografía, se pone entre paréntesis el número de ficha correspondiente. También se hacen referencias a ediciones anteriores de una obra, a tomos anteriores de una obra en curso de publicación, etc. En estos casos, la cifra que precede al número de referencia indica el volumen de la NRFH en que figura la ficha en cuestión. Así, el "núm. 3939695 " corresponde a la ficha 39695, la cual está en el volumen 39 de la NRFH. Cuando no hay cifra inicial, ha de entenderse que el número remite a una ficha incluida en el presente fascículo.

\section{OBRAS GENERALES}

42-1. Fernández Catón, José María - Colección documental de la catedral de León (775-1230). T. 6: (1188-1230). Centro San Isidoro, León, 1991. xxx + 571 pp. || CCM, 36 (1993), 306 (Gautier Dalché).

42-2. LOzaNO LÓPEZ, Garcia (ed.) Leyes de Toro. Sección de Pergaminos, Archivo de la Real Chancillería de Valladolid. Introd. de Carlos Petit. The Hispanic Seminary of Medieval Studies, Madison, 1990. microficha.

42-3. MACKENZIE, ANN L., \& MARIA GUTERRES - Hispanic articles in scholarly periodicals. Annual bibliography, 1990. - Liverpool University Press, Liverpool, 1991. 34 pp.

42-4. MARTín ABAD, Julián - "La biblioteca manuscrita de José Amador de los Ríos adquirida en 1908 por la Biblioteca Nacional de Madrid', CuLH, 1992, núm. 15, 169-194.

42-5. Martín ABAD, Julián - La imprenta en Alcalá de Henares (1501-1600). - Arco, Madrid, 1991. 1536 pp. ॥
$C D, 206$ (1993), 288-289 (Andrés); CuLH, 1992, núm. 16, 241-243 (Delgado).

42-6. ROMERO ROJAS, FRANCISCO (comp.) - Anuario Bibliográfico Colombiano "Rubén Pérez Ortiz», 1988-1989. - Instituto Caro y Cuervo, Bogotá, 1992. xix +455 pp.

42-7. ROMERO ROMERO, CATALINA "Tres bibliotecas jesuitas en pueblos de misión: Buenavista, Paila y Santa Rosa, en la región de Moxos"' RIM, 52 (1992), 889-921.

\section{LINGÜÍSTICA}

\section{TEORÍA LINGÜÍSTICA HISPÁNICA}

42-8. AdRadOS, FRancisco R. - "Semántica y sintaxis en la Gramática funcional de Dik'. - REL, 21 (1991), 1-10.

42-9. BEUCHOT, MAURICIO - "El pensamiento y su relación con el signo en Peirce y la escolástica"'. - Morphé, 1993, núm. 8, 133-142. 
42-10. Blas ARroyo, JosÉ LUIS "Problemas teóricos en el estudio de la interferencia lingüística". - $R E L$, 21 (1991), 265-289.

42-11. Cabrillana Leal, Concepción - "Aproximación al concepto de 'dinamismo comunicativo' '. - $-R E L$, 22 (1992), 397-405.

42-12. Contreras, Heles - "Principios y parámetros sintácticos". - $R e$ flexiones lingüísticas y literarias, t. 1, ed. R. Barriga Villanueva, y J. García Fajardo (México, 1992), 139-154.

42-13. Derisi, Octavio N. - "Reflexiones filosóficas sobre el concepto, el juicio y el lenguaje". - $B A A L, 56$ (1991), 83-93.

42-14. LARA, LuIS FERnANDO - "Sobre la naturaleza de los lenguajes"'. $P S M, 1993$, núm. 1, 105-111.

42-15. Rosal, Gerardo del - "Discurso, cultura y cognición". - PSM, 1993, núm. 1, 139-146.

42-16. Serrano, Sebastià - "Elementos verbales y no verbales en la interacción lingüística"' - Morphé, 1993, núm. 8, 7-25.

42-17. Smith Stark, Thomas C. "El método de Sapir para establecer relaciones genéticas remotas". - $R \boldsymbol{e}$ flexiones lingüisticas y literarias, t. 1, ed. R. Barriga Villanueva, y J. García Fajardo (México, 1992), 17-42.

V. también núm. 124.

\section{LINGÜÍSTICA HISPÁNICA OBRAS GENERALES}

42-18. Barriga VillanueVa, Rebeca, y Josefina García Fajardo (eds.) - Reflexiones lingüisticas y literarias. $T$. 1: Lingüística. - El Colegio de México, México, 1992. xiii +283 pp.

42-19. "Bibliografía lingüística española 1989 y complemento de años anteriores'". - REL, 21 (1991), 399-505.

42-20. "Bibliografía lingüística española 1990 y complemento de años anteriores". - REL, 22 (1992), 489-592.

42-21. BOzAL, VAleriano - "Lenguaje clásico y modernidad. Tres notas".
- LBM, 1993, núm. 25, 100-106.

42-22. Maldonado-Denis, Manuel - "Aprecio y defensa de la lengua española en Puerto Rico". - CuA, 1992, núm. 32, 88-102.

42-23. Marcos Marín, Francisco "Corpus lingüístico de referencia de la lengua española". - BAAL, 56 (1991), 129-155.

42-24. Naranjo Villegas, Abel "El español y la transferencia de tecnología”. - BACol, 1992, núm. 175, 6-9.

42-25. Pamo Reyna, Óscar G. - Medicina y lenguaje. - Universidad Peruana Cayetano Heredia, Lima, 1991. 141 pp. || LexisL, 16 (1992), 267-269 (Cisneros).

42-26. Quezada Pacheco, Jorge ARTURO - "Lingüística y otras profesiones". - Imágenes, 1992, núm. 1, 19-30.

42-27. SAPORITI, Esteban C. - Aprender el lenguaje. - Doméstica, Río Negro (Argentina), 1993.

42-28. ZIERER, ERnESTo - "Glosario de sistemas lectales". - $L y C, 30$ (1990), 29-40.

\section{HISTORIA DE LA LINGÜÍSTICA HISPÁNICA}

42-29. Allaigre, Claude - "Jerigon$z a$ : le témoignage de Nebrija'. $B H i, 94$ (1992), 463-478.

42-30. Alvar, Manuel - "Molinos y otras máquinas en el Vocabulario de Nebrija". - ALM, 31 (1993), 5-19.

42-31. Álvarez de Miranda, Pedro - "En torno al Diccionario de Terreros". - BHi, 94 (1992), 559-572.

42-32. Arias Álvarez, BEATriz "La forma amaría en Nebrija". ALM, 31 (1993), 21-30.

42-33. ARIZA, MANUEL - "Nombre propio y diccionario (Breve estudio de los lexicógrafos clásicos españoles)'”. - ALM, 31 (1993), 415-430.

42-34. BENIERs, ElizABeTh - "La morfología derivacional en la Gramática Castellana de Nebrija"'. - ALM, 31 
(1993), 31-52.

42-35. BEUCHOT, MAURICIO - "Algunas ideas filosóficas aristotélicoescolásticas en la Gramática Castellana de Nebrija". - ALM, 31 (1993), 5363.

42-36. BOUZY, CHRISTIAN - "El Tesoro de la lengua castellana o española: Sebastián de Covarrubias en el laberinto emblemático de la definición". Criticón, 1992, núm. 54, 127-144.

42-37. BRASELMANN, PETRA - "Nebrija und die spanische Grammatikographie"'. - VR, 52 (1993), 243-278.

42-38. Breva Claramonte, Manuel - "El uso y la copia en el método de Pedro Simón Abril (1530-1600)"'. REL, 21 (1991), 47-64.

42-39. Breva Claramonte, Manuel - "Las traducciones literales y la identificación de 'morfemas' en Lorenzo Hervás (1735-1809): El estado de las lenguas en el mundo". $-A L M$, 31 (1993), 497-523.

42-40. Cano Aguilar, Rafael "Antonio de Nebrija y Mateo Alemán: Los orígenes de la gramática en España y América". - ALM, 31 (1993), 65-95.

42-41. Checa Beltrán, José - "Paralelos de lenguas en el siglo Xvin: de Feijoo a Vargas Ponce (1726-1793)'. - RLit, 53 (1991), 485-512.

42-42. COLOMBO Airoldi, Fulvia "Nebrija, precursor de la enseñanza del español como lengua extranjera". - ALM, 31 (1993), 93-120.

42-43. CRistina Carbonell, Marta - "Las Exequias de la lengua castellana de Juan Pablo Forner, "sátira menipeas". - $A L E, 1992$, núm. 8, 37-52.

42-44. García-Macho, María LourDES - "Sobre los vocablos suprimidos en la edición de $\mathbf{1 5 1 6}$ del Vocabulario español-latino de Nebrija'. - $A L M$, 31 (1993), 135-159.

42-45. Guitarte, Guillermo L. "La crítica de Valdés a las equivalencias latinas de cecear, ceceoso que da $\mathrm{Ne}-$ brija". - $A L M, 31$ (1993), 161-182.

42-46. Hernández Alonso, CÉSAR "El concepto de norma lingüística en Nebrija: pervivencia y superación'. - ALM, 31 (1993), 183-204.
42-47. HERNÁNDEZ DE LEÓN-PORTILLA, ASCENSIÓN - "Nebrija y el inicio de la lingüística mesoamericana". ALM, 31 (1993), 205-223.

42-48. HERNÁNDEZ DE LEÓN-PORTILLA, ASCENSIÓN - "Nebrija y las lenguas compañeras del imperio". - CuA, 1993, núm. 37, 135-147.

42-49. HiLdEBRANT, MARTHA - "Mestizaje lingüístico en un vocabulario del siglo XVII'. - BAAL, 57 (1992), 930. [Vocabulario (1608) de González Holguín].

42-50. Lliteras, Margarita-'Benito de San Pedro frente a la tradición nebrisense". - BHi, 94 (1992), 503-527. 42-51. Lope Blanch, JuAN M. - "De Nebrija a Ménage a través de Covarrubias"'. - BHi, 94 (1992), 479-497.

42-52. LOPE BlanCH, JUAN M. - "Nebrija, fuente y puente de conocimientos gramaticales". - ALM, 31 (1993), 225-250.

42-53. Martínez, JosÉ LuIS - "Nebrija en México". - NRFH, 41 (1993), 1-17.

42-54. Martínez Alcalde, María JosÉ - "La doctrina ortográfica de Benito de San Pedro y su impugnación por Benito Martínez Gómez Gayoso". - BHi, 94 (1992), 529-557.

42-55. MORENO DE AlBA, José G. "Antonio de Nebrija en España y América". - CuA, 1992, núm. 35, 134-144.

42-56. MORENO DE ALBA, JOSÉ G. "Eugenio de Zeballos y el Vocabulario Geográfico de Nebrija". - ALM, 31 (1993), 251-263.

42-57. NIEDEREHE, HANS-JOSEF - "Corrientes primarias y secundarias en la prehistoria de la Gramática de la lengua castellana de Nebrija". - ALM, 31 (1993), 265-293.

42-58. PÉREZ RODRÍGUez, ESTRELlA - El Verbiginale. Una gramática castellana del siglo xiii. (Estudio y edición crítica). - Universidad de Valladolid-Caja de Ahorros, Salamanca-Valladolid, 1990. (Lingüística y Filología, 9).

42-59. POLO, JosÉ - "Noticia sobre la labor nebrisense de Antonio Sánchez Moguel''. - ALM, 31 (1993), 295306. 
42-60. Polo, José - "Presencia de Saussure en el mundo hispánico". CuIF, 18 (1992), 189-196.

42-61. POLO, JOSÉ - "Traducciones al español del CLG de Saussure". CuIF, 18 (1992), 183-187.

42-62. Polo, José, y JuAN R. LODARES - "En torno a un trabajo inédito de Vicente García de Diego; señales del camino". - ALM, 31 (1993), 307311.

42-63. PORTOLÉS, JOSÉ - "Las ideas gramaticales de los discípulos de $\mathrm{Me}$ néndez Pidal". - BHi, 94 (1992), 573-601.

42-64. POTTIER, Bernard - "Miguel Navarro (1599)". — BHi, 94 (1992), 499-503.

42-65. Ramajo Caño, antonio "La huella del Brocense en el Arte del P. La Cerda (1560-1643)". - REL, 21 (1991), 301-321.

42-66. Ramajo Caño, ANTONIO - "La norma lingüística y las autoridades de la lengua: de Nebrija a Correas'". ALM, 31 (1993), 333-377.

42-67. Ramajo Caño, ANTONIO "Notas sobre la recepción del Poliziano latino en España: una "monodias del catedrático salmantino Blas López''. - Criticón, 1992, núm. 55, 41-52.

42-68. RODRÍGUEZ-IZQUIERDO Y GAVALA, Fernando - "Aspectos de la personalidad de Rufino José Cuervo". - BICC, 45 (1990), 747-757.

42-69. RoJas, Elena M. - "El pensamiento lingüístico de Juan B. Terán". - BAAL, 56 (1991), 395-413.

42-70. Ruiz PÉrez, PEDRo (ed.) Gramática y humanismo: perspectivas del Renacimiento español. - Libertarias, Madrid, 1993. 230 pp.

42-71. SARMIENTO, RAMÓN - "La teoría de la corrupción en Antonio de Nebrija (1492)". — BHi, 94 (1992), 405409.

42-72. SARMiEnTO, RAMÓN - "Lo que sabemos de Nebrija (1492)"'. - ALM, 31 (1993), 379-393.

42-73. Soler AREchalde, María ÁNGELES - "Nebrija, Villalón y la concordancia gramatical en nuestra lengua"'. - $A L M, 31$ (1993), 395-414.
42-74. TOLLIS, FRANCIS - "Remarques sur l'approche et la présentation des noms dérivés dans la Gramática de la lengua castellana de Nebrija: vers une (re)lecture linguistique". - $\mathrm{BHi}, 94$ (1992), 411-462.

42-75. WARD, Michael T. - "Bernardo Aldrete and Celso Cittadini: Shared Sophistication in Renaissance linguistic investigation"'. - HR, 61 (1993), 65-85.

\section{LATÍN Y LINGÜÍSTICA ROMÁNICA}

42-76. Anglada, E., y M. Bargallo (eds.) - El cambio lingüístico en la Romania. - Publicacions de l'Estudi General de Lleida-Virgili \& Pagès, Lleida, 1990. 126 pp. (El Fil d'Ariadna, Sèrie Lingüística). \| $R E L, 21$ (1991), 386-388 (Clavería Nadal).

42-77. ASTEY, LUIS - Dramas litúrgicos del Occidente medieval. - El Colegio de México-CONACYT-ITAM, México, 1992. 682 pp. || Estudios, 1993, núm. 34, 111-114 (Frost); 115-118 (Beuchot).

42-78. Bezler, Francis - " ¿El ogro y el niño o El arco y la pala?"' RLitMed, 4 (1992), 43-46.

42-79. BIRKEN-SILVERMAN, GABRIELE - "Le vocabulaire représentatif des langues romanes: sur le patrimoine latin'. - RRL, 37 (1992), 117-123.

42-80. BîRLAdEANU, M. et al. - Vocabularul reprezentativ al limbilor romanice (N. 41-73). \| RLiR, 57 (1993), 198-200 (Zafiu).

42-81. Calboli, Gualtiero (ed.) Latin vulgaire - latin tardif II. Actes deu IIème Colloque international sur le latin vulgaire et tardif (Bologne, 29 août - 2 septembre 1988). - M. Niemeyer, Tübingen, 1990. xii +286 pp. \| $Z R P h, 107$ (1991), 662-674 (Kramer). 42-82. Camus Bergareche, Bruno "El estudio de la lingua franca: cuestiones pendientes'. - RLiR, 57 (1993), 433-454.

42-83. CATALÁN, D. - Las lenguas cir- 
cunvecinas del castellano (N. 41-77). $B I C C, 45$ (1990), 758-765 (Villarreal Vásquez); Anthropos, 1992, núm. 132, 91-92 (Abad).

42-84. CHACÓN GÓMEZ-MONEDERO, ANTONIO - "El códice escurialense del Forum Conche. Estudio codicológico y paleográfico"'. - CD, 206 (1993), 365-398.

42-85. ColóN, G. - El español y el catalán, juntos y en contraste (N. 41-79). \| REL, 22 (1992), 262-265 (Terrado Pablo).

42-86. Corriente, Federico - Arabe andalusí y lenguas romances. - Mapfre, Madrid," 1992. 270 pp. \|CD, 206 (1993), 283-284 (Justel).

42-87. CORRIENTE, FEDERICO - "Expresiones bajo tabú social en árabe andalusí y sus relaciones con el romance". - VR, 52 (1993), 282-291.

42-88. DAHMEN, WOLFGANG et al. (Hrsg.) - Die romanischen Sprachen und die Kirchen. Romanistisches Kolloquium III. - G. Narr, Tübingen, 1990. (Tübinger Beiträge zur Linguistik, 343). I ASNS, 229 (1992), 440-442 (Elwert).

42-89. DAHMEN, WOLFGANG et al. (Hrsg.) - Zum Stand der Kodifizierung romanischer Kleinsprachen. Romanistisches Kolloquium V.. - G. Narr, Tübingen, 1991. xxix + 410.pp. (Tübinger Beiträge zur Linguistik, 348). \|| ASNS, 229 (1992), 444-446 (Elwert).

42-90. DAHMEN, WOLFGANG et al. (Hrsg.) - Zur Geschichte der Grammatiken romanischer Sprachen. Romanistisches Kolloquium IV. - G. Narr, Tübingen, 1991. xxx + 298 pp. (Tübinger Beiträge zur Linguistik, 357). "| $A S N S$, 229 (1992), 442-444 (Elwert).

42-91. DARDEL, ROBERT DE, et JAKOB WÜEST - "Les syștèmes casuels du protoroman. Les deux cycles de simplification". - VR, 52 (1993), 25-65.

42-92. DI SaIUllo, ANNE-MARIE \& ANNE ROCHETTE (eds.) - Binding in Romance. Essays in honour of Judith McA'Nulty. - The Canadian Linguistic Association, Ottawa, 1990. x + 305 pp. || Lan, 68 (1992), 655-656 (Ishikawa).

42-93. Díaz de Bustamante, José MaNUEL - "Ingenua lectio. Reflexión so- bre la lectura y los lectores de la Vulgata". - CuN, 51 (1991), 223-240.

42-94. Díaz de Bustamante, José MANUEL - "Nota a los prolegómenos del Virgilio de Nebrija". - ALM, 31 (1993), 121-133.

42-95. García LeAL, AlFonso - " $A d$ denda a la colección de documentos de la Catedral de Oviedo (un diploma recuperado del obispo Pelayo)'" BIEA, 47 (1993), 331-336.

42-96. García Leal, Alfonso - "Nota al diploma de Fakilo de la Catedral de Oviedo"'. - BIEA, 46 (1992), 715720.

42-97. GuITER, HENRI - "Sur la distribution des prépositions de, in, ad dans la Romania continue". - RLiR, 57 (1993), 67-78.

42-98. Holtus, GÜNTER, MiahaEL METZELTIN, und CHRISTIAN SCHMITT (Hrsg.) - Lexikon der Romanistischen Linguistik (LRL). Bd. VI, 1: Aragonesisch/Navarresisch, Spanisch, Asturianisch/ Leonesisch - Aragonés/Navarro, Español, Asturiano/Leonés. - M. Niemeyer, Tübingen, 1992. xxxviii +708 pp. +1 mapa: || $R L i R, .57$ (1993), 536-539 (Thibault).

42-99. HOLTUS, GÜNTER, und WOLFGANG SCHWEICKARD - "Zum Stand der Erforschung der historischen Dimension gesprochener Sprache in der Romania". - ZRPh, 107 (1991), 547 574.

42-100. ILIESCU, MARI, et DAN SLUSAN SKI (éds.) - Du latin aux langues romanes. Choix de textes traduits et commentés (du ïe siècle avant J.C. jusqu'au xe siècle après J.C.). - Gottfried Egert, Wilhelmsfeld, 1991. xix + 301 pp. . RLiR, 57 (1993), 193-198 (Tekavcic). 42-101. Lleal GarceráN, Coloma La formación de las lenguas romances peninsulares. - Barcanova, Barcelona, 1990. 383 pp. || RFilR, 9 (1992), 332333 (Ortega Román).

42-102. OSORIO ROMERO, IGNACIO, TARCISIO. HERRERA ZAPIÉN et al. La tradición clósica en México. UNAM, México, 1991. 219 pp. \| Morphé, 1993, núm. 8, 167-173 (Campos).

42-103. Pagés H., Gerardo - 'El bifronte Jano y la prefijación latino- 
castellana". - $B A A L, 55$ (1990), 225236.

42-104. Pharies, DAVID - "The IberoRomance reflexes of Greco-Latin $s \bar{y}$ ringa"'. - HR, 61 (1993), 247-269.

42-105. PRICE, S. - Comparative constructions in Spanish and French syntax (N. 4193). \| Lan, 69 (1993), 431-432 (Gómez Díaz).

42-106. REINHEIMER RîPEANU, SANDA - "Linguistique romane et registres de langue"'. - RRL, 37 (1992), 125129.

42-107. RIIHO, TIMO, y LAURI JUHANI EERIKÄINEN - Crestomatía iberorrománica. Textos paralelos de los siglos xiii-xvi. - Suomalainen Tiedeakatemia, Helsinki, 1993. 269 pp. (Annales Academiae Scientiarum Fennicae, $B, 268)$. \| RLiR, 57 (1993), 547-548 (Roques).

42-108. Ruiz Asencio, José Manuel - Colección documental del archivo de la catedral de León (775-1230). IV: 1032 1109. - Centro San Isidoro, León, 1990. xxiii + 703 pp. \|CCM, 36 (1993), 325 (Lignage Conde).

42-109. Ruiz de la PEÑa Solar, J. IGNACIO - "Documentos medievales del desaparecido archivo del monasterio de San Salvador de Celorio"'. BIEA, 46 (1992), 437-452.

42-110. Sevilla MuÑoz, Julia "Fuentes paremiológicas francesas y españolas en el siglo XVI". - RFilR, 9 (1992), 103-123.

42-111. ValdÉs Gallego, JosÉ anToNIO - "Perspectiva lingüística del Liber Testamentorum de la Catedral de Oviedo". - BIEA, 45 (1991), 751 765.

42-112. Vernay, Henri - Dictionnaire onomasiologique des langues romanes (DOLR). - M. Niemeyer, Tübingen, 1991-1992. 2 ts. \| RLiR, 57 (1993), 191-193 (Gorcy).

42-113. WAGNer, MAX LeOPOLD Sondersprachen der Romania. Hrsg. von Heinz Kröll. Bd. 1: Spanische Sondersprachen. Bd. 2: Sardische, italienische, portugiesische, rumänische und türkische Sondersprachen. - Steiner, Stuttgart, 1990. xxiv $+264+243$ pp. $\|$ ZRPh, 107 (1991), 629-631 (Kramer). 42-114. Walsh, Thomas J. - "New contributions to the study of Romance languages'. - $R P h, 45$ (1991-92), 287-298.

42-115. WANnER, D., \& D. A. KIBBEE (eds.) - New analysis in Romance linguistics (N. 41-100). \| Lan, 68 (1992), 448-449 (Elson).

42-116. WestMoRELAND, MAURICE "The - $r$ - segment in the Romance preterit paradigm'. $-R P h, 45$ (199192), 484-492.

42-117. WRIGHT, ROGER (ed.) - Latin and the Romance Languages in the Early Middle Ages. - Routledge, LondonNew York, 1991. ix + 262 pp. (Romance Linguistics series). \| EHF, 15 (1993), 213-220 (Álvarez Maurín); ZRPh, 107 (1991), 674-683 (Kramer).

42-118. WUNDERLI, P. - "La deixis personnelle dans les langues romanes'. - VR, 49/50 (1990-91), 31-56.

V. también núms. 270, 288, 291, 457, $460,461,725$.

\section{FONÉTICA Y FONOLOGÍA}

42-119. "Acerca de la letra $\tilde{n}$. Informe de la Real Academia Española sobre la consulta relativa a la letra "n̄"»". $B A A L, 57$ (1992), 139-141.

42-120. Albalá, María José - “Análisis y síntesis de las consonantes nasales". - RFE, 72 (1992), 37-55.

42-121. Ávila, RAÚl - "Ortografía española: estratificación social y alternativas'. - NRFH, 40 (1992), 649-672.

42-122. Champion, James J. - “On the distribution of the Spanish palatal nasal"'. $-K R Q, 39$ (1992), 355-359. 42-123. Fidelholtz, James L. "Acerca de la acentuación en español"'. - Morphé, 1992, núm. 7, 109129.

42-124. Halle, Morris, James W. HARRIS, \& JEAN-ROGER VERGNAUD - "A reexamination of the stress erasure convention and Spanish stress". - LI, 22 (1991), 141-159.

42-125. VAQUERO, MARÍA, y LOURDES GUERRA DE LA FUENTE - "Fonemas vocálicos de Puerto Rico". - RFE, 
72 (1992), 555-582.

V. tambiên núms. $177,267,271,278$, $286,287,289,314,323,331,336$, $346,370,376,416,417$.

\section{MORFOLOGÍA Y SINTAXIS}

42-126. Albano de VÁzQUEZ, HILdA, y LAURA FERRARI DE EgÜES - "Presencia y ausencia del pronombre en caso objetivo en el español hablado de Buenos Aires". - Fil, 25 (1990), 2538.

42-127. ÁlVAREZ MENÉNDEZ, AlFREDO - "Conectores y grupos oracionales consecutivos". - LEA, 13 (1991), 117-132.

42-128. BAUHR, G. - El futuro en "-ré" $\ell$ "ir a" + infinitivo en español peninsular moderno (N. 41-124). \| REL, 21 (1991), 175-178 (Herrero Ruiz de Loizaga).

42-129. BENIERS, ELISABETH - "Supletivismo vernáculo como profilaxis de la pérdida de transparencia derivacional"'. - NRFH, 40 (1992), 637-648.

42-130. BERENGUER SÁNCHEZ, José A. - "Distintos conceptos de partícula en la descripción lingüística". $R E L, 22$ (1992), 55-76.

42-131. Bogard, SERGIO - "El estatus del clítico de complemento indirecto en español". - Reflexiones lingüísticas y literarias, t. 1, ed. R. Barriga Villanueva, y J. García Fajardo (México, 1992), 171-186.

42-132. BOLINGER, D. - Essays on Spanish: Words and grammar, ed. J. H. Silverman (N. 41-130). \| $H, 75$ (1992), 345 (Ishikawa).

42-133. BRUYNE, JACQUES - "Acerca de sombreros nonísimos y nuevísimos. Complemento III al Esbozo de una nueva gramática de la lengua española". - I, 1993, núm. 37, 91-105.

42-134. CAMPOS, HÉCTOR - "Los bearneses que quequean, ¿y nosotros qué?". - HL, 4 (1992), 329-349.

42-135. CAMPOS, HÉCTOR - "Preposition stranding in Spanish?', - LI, 22 (1991), 741-750.

42-136. Camus Bergareche, BRuno
- "Negación doble y negación simple en español moderno". - RFilR, 963101.

42-137. Castro, JuAN - "Las relaciones morfosintácticas". - BdFS, 33 (1992), 11-26.

42-138. Contreras, Heles - "Descripción y explicación en la teoría lingüística: la sintaxis de los cuantificadores". - RLA, 30 (1992), 17-38.

42-139. DE KOCK, JOSSE - "Corpus y norma académica: $a$ con régimen directo". - LEA, 14 (1992), 69-95.

42-140. DE Kock, JossE - Gramática española: enseñanza e investigación. - Universidad, Salamanca, 1990-91. 16 ts. \| QIA, 1993, núm. 73, 134-139 (Ares).

42-141. DeMello, George - "Adjetivos adverbializados en el español culto hablado de diez ciudades". $L E A, 14$ (1992), 225-242.

42-142. DelbecQue, Nicole - "Por qué y cómo integrar la variación en la descripción gramatical". - LEA, 14 (1992), 5-68.

42-143. DeMello, George - "Cuyo y reemplazos por cuyo en el español hablado contemporáneo". - ALHis, 8 (1992), 53-71.

42-144. DeMello, George - "Pronombre relativo con antecedente humano"'. - NRFH, 41 (1993), 75-98.

42-145. Demonte, Violeta - Detrás de la palabra: estudios de gramática del español. - Alianza, Madrid, 1991.

42-146. Dumitrescu, D. - "Preguntas con multiconstituyentes interrogativos en español'. $-H, 75$ (1992), 164-170.

42-147. Español Giralt, M. Teresa - Nominalidad y contexio en español. PPU, Barcelona, 1991. 235 pp. \| Anthropos, 1992, núms. 134/135, 138139 (Domingo).

42-148. FAITELSON-WEISER, Silvia "Los sufijos formadores de adjetivos en español moderno: valores genéricos y valores específicos"'. - NRFH, 41 (1993), 19-53.

42-149. FERnÁndez lagunilla, MariNA, y Francisco Javier de Dios LÓPEZ - "Dos análisis gramaticales de ciertas construcciones completivas de infinitivo en español: a propó- 
sito de los verbos causativos y de percepción". - REL, 21 (1991), 217232.

42-150. Fernández Soriano, Olga (ed.) - Los pronombres átonos. - Taurus, Madrid, 1993. $388 \mathrm{pp}$.

42-151. FonTANA, JOSEP M., \& JoHN MOORE - "VP-internal subjects and se-reflexivization in Spanish". $-L I$, 23 (1992), 501-510.

42-152. García, Érica C. - "Por qué como o porque". - NRFH, 40 (1992), 599-621.

42-153. García-Page, Mario - "Locuciones adverbiales con palabras “idiomáticas»". - REL, 21 (1991), 233-264.

42-154. Gingras, R. - "Études d'un suffixe régulier de l'espagnol moderne". - LanL, 1992, núm. 18, 97-119.

42-155. Girón AlCONCHEL, José LUIS - "Sobre la consideración del adverbio ya como un "conmutador"". REL, 21 (1991), 145-153.

42-156. GÓMEz DE ENTERRÍA, JOSEFA - "Las siglas en el lenguaje de la economía”. - RFilR, 9 (1992), 267-274.

42-157. GÓMEZ MONTIEL, FERNANDO - "Visiones divergentes acerca de la teoría de la transposición sintáctica". - EHF, 15 (1993), 57-63.

42-158. HARRe, Catherine E. - ' $T e$ ner" + past participle: $A$ case study in linguistic description. - Routledge, London-New York, 1991. viii + 213 pp. (Croom Helm Romance Linguistic Series). \| RLiR, 57 (1993), 549-553 (Thibault).

42-159. HARRIS, JAMES W. - "The exponence of gender in Spanish". $-L I$, 22 (1991), 27-62.

42-160. HERMERÉN, INGRID - El uso de la forma en "ra" con valor no-subjuntivo en el español moderno. - Lund University Press, Lund, 1992. 303 pp. \| RLiR, 57 (1993), 222-224 (Eberenz).

42-161. Herrero Ruiz de Loizaga, F. JAVIER - "Algunas consideraciones en torno al complemento agente". $R E L, 22$ (1992), 339-359.

42-162. Hurtado, Alfredo - Los cliticos del español y la gramática universal (N. 41-163). \| Fil, 25 (1990), 230-233 (Solana).

42-163. JONGE, BOB DE - "Pragmatis- mo y gramaticalización en el cambio lingüístico: ser y estar en expresiones de edad". - NRFH, 41 (1993), 99-126.

42-164. KAYNE, RICHARD S. - "Romance clitics, verb movement, and PRO'. - LI, 22 (1991), 647-686.

42-165. KEMPCHINSKY, PAULA - "Syntactic constraints on the expression of possession in Spanish". - $H, 75$ (1992), 697-704.

42-166. LAGO, JESÚS - "Construction endocentrique, construction exocentrique, construction appositive". RLiR, 57 (1993), 421-432.

42-167. LAMIROY, B. - Léxico y gramática del español: estructuras verbales de espacio $y$ del tiempo (N. 41-167). $\| H, 75$ (1992), 580-581 (Moore).

42-168. LANG, M. F. - Spanish word formation: Productive derivational morphology in the modern lexis (N. 41-168). \| Lan, 69 (1993), 210 (Beard); ZRPh, 107 (1991), 806-807 (Lüdtke).

42-169. LORENZO GONZÁLEZ, GUILLERMO - "La teoría temática y las modalidades de descarga argumental: una propuesta restrictiva". - CuIF, 18 (1992), 35-49.

42-170. Losada DURÁN, José R. - “El artículo y el posesivo en español e inglés"'. - AnMal, 14 (1991), 141-157.

42-171. Mallén, EnRIQUe - "Partitive constructions". $-H L, 4$ (1992), 351-388.

42-172. Martinell Gifre, EMma "El uso de las formas un, uno, una, unos, unas en español y de sus equivalentes en inglés"'. - $A L M, 30$ (1992), 29-45.

42-173. Martínez Álvarez, Víctor E. - "Proposiciones para una visión de la voz pasiva en español". $-R L A$, 30 (1992), 183-193.

42-174. Mello, George De - "Duplicación del pronombre relativo de objeto directo en el español hablado culto de once ciudades'. - LexisL, 16 (1992), 23-52.

42-175. NARBona JimÉnez, ANTONIO - "Sintaxis coloquial y análisis del discurso"'. - REL, 21 (1991), 187204.

42-176. NoEmí PADILLA, CRISTIAN JUAN - "Rol de argumentos en la organiza- 
ción del sistema preposicional en sintagmas verbales". - RLA, 30 (1992), 195-218.

42-177. Nuessel, Frank - "A supplementary annotated bibliography of theoretical grammatical analyses of Spanish (1989-1990): Phonology and morphology; syntax and semantics". - HL, 4 (1992), 411-456.

42-178. POOL WESTGAaRd, MarianNa - "Los dativos de posesión y los sujetos posverbales: su funcionamiento en el español y en otras lenguas". Reflexiones lingüisticas y literarias, t. 1, ed. R. Barriga Villanueva, y J. García Fajardo (México, 1992), 155-169.

42-179. PORTOLÉs, JOSÉ - "Atributos con un enfático". - RRo, 28 (1993), 218-236.

42-180. REESE, SUSANNE - Gerundialkonstruktionen im Spanischen: Anstaz zu einer grammatisch-pragmatischen Beschreibung. - G. Narr, Tübingen, 1991. 282 pp. || Ibero, 1992, núm. 45, 93-96 (Veh).

42-181. RINI, JOEL - "The redundant indirect object constructions in Spanish: A new perspective". $-R P h, 45$ (1991-92), 269-286.

42-182. RODRÍGUEZ ESPIÑEIRA, MARÍA JosÉ - "Sobre la codificación informativa de las cláusulas con predicativo en español". - $R R o, 27$ (1992), 30-60.

V. también núms. $103,105,185,189$, $198,204,207,213,246,272,275$, $308,324,331,338,339,345,349$, $355,361,363,369,378,438$.

\section{SEMÁNTICA}

42-183. Gasas Gómez, Miguei - "A propósito del concepto lingǘstico de eufemismo como sincretismo léxico: su relación con la sinonimia y la homonimia". - 1, 1993, núm. 37, 7090.

42-184. DIAMOND, CORA - " ¿Qué tan viejos son estos huesos? Putnam, Wittgenstein y la verificación". Diánoia, 38 (1992), 115-142.

42-185. FAITELSON-Weiser, Silvia, et
RENÉ GINGRAS - "Homonymie, polysémie, équivalence et concurrence suffixales". - LanL, 1991, núm. 17, 69-98.

42-186. García Fajardo, Josefina "Las variaciones de sentido, los sujetos y el universo del discurso". $-R e$ flexiones lingüisticas y literarias, t. 1, ed. R. Barriga Villanueva, y J. García Fajardo (México, 1992), 231-247.

42-187. HERNÁNDEZ DE MENDOZA, C. - Del significado y su expresión (N. 41216). \| HR, 60 (1992), 341-343 (Moreno Cabrera).

42-188. LaRa, Luis Fernando - "La ecuación sémica con ser y significar: una exploración de la teoría del estereotipo". - Reflexiones lingüisticas y literarias, t. 1, ed. R. Barriga Villanueva, y J. García Fajardo (México, 1992), 211-230.

42-189. MENDOZA, JosÉ G. - "El caso de la causa". - LexisL, 16 (1992), 223-254.

42-190. Morera, MARCial - "La preposición española contra: su evolución semántica". - BICC, 45 (1990), 650-689.

42-191. MORETTI, ALBERTO - "Semántica tarskiana, lenguaje natural y ontología". - Crítica, 24 (1992), 2346.

42-192. MUNIZ RODRÍGUEZ, VICENTE Introducción a la filosofia del lenguaje. T. 2: Cuestiones semánticas. - Anthropos, Barcelona, 1992. 221 pp. (Autores, textos $y$ temas. Filosofia, 41). \||Anthropos, 1992, núm. 137, 80 (Rivera de Ventosa).

42-193. OESTERREICHER, WULF - " $S_{e}$ im Spanischen. Pseudoreflexivität, Diathese und Prototypikalität von semanstischen Rollen". - RJ, 43 (1992), 237-260.

42-194. Padilla Gálvez, Jesús - "La distinción referencialatributiva en las descripciones definidas".. - $E H F, 15$ (1993), 153-165.

42-195. Rodríguez-Consuegra, FranCISCO - "Putnam, Quine y la ufacticidad" de la semántica". - Diánoia, 38 (1992), 171-185.

42-196. SÁNCHeZ SAlor, E. - "Rasgos semánticos de las oraciones finales". - REL, 21 (1991), 205-216. 
42-197. StengaARD, BirTe - Vida $y$ muerte de un campo semántico. Un estudio de la evolución semántica de los verbos latinos stare, sedere e iacere del latín al romance del s. xiii. - M. Niemeyer, Tübingen, 1991. 414 pp. (Beiheft zur Zeitschrift für romanische Philologie, 234). \| RJ, 43 (1992), 336-341 (Busch); RRo, 28 (1993), 133-136 (Henrichsen).

42-198. Velleman, Barry L. - "Extensión semántica del sustantivo posparticipial"'. - NRFH, 41 (1993), 55-73.

V. también núms. 167, 177, 250, 257, 1238.

\section{LEXICOLOGÍA Y LEXICOGRAFÍA}

42-199. AlVAR EZQUERRA, MANUEL "Tradición en los diccionarios del español". - REL, 22 (1992), 1-23.

42-200. ARDAO, ARTURO - "El nombre "América Latina", en Madrid desde 1858''. - CuA, 1992, núm. 36, 104-111.

42-201. ÁVILA, RAÚL - "Diccionarios para nin̄os: un problema de comunicación". - Reflexiones lingüísticas y literarias, t. 1, ed. R. Barriga Villanueva, y J. García Fajardo (México, 1992), 251-259.

42-202. Ayala Castro, Marta C. "Nomenclatures de l'espagnol (15261800). Considérations générales sur la nature et la fonction des nomenclatures'’. - CLex, 1992, núm. 61, 127160.

42-203. BÉDARD, E. - "Cupicupi, furufuru, purruputú, etc. Léxico ictionímico onomatopéyico'" - LanL, 1992, núm. 18, 149-165.

42-204. Bravo, Federico - "La négation antiphonique en espagnol. La formule de renforcement $n i$ insulas $n i$ insulos; étide synchronique et diachronique". - $\mathrm{BHi}, 94$ (1992), 619-672.

42-205. Caro Baroja, Julio - "Sobre nombres propios imaginarios que expresan acción, situación o pensamiento". - RDTP, 47 (1992), 359363.
42-206. Corominas, J., y J. A. PasCUAL - Diccionario crítico etimológico castellano e hispánico. T. 6. - Gredos, Madrid, 1991. 1047 pp. \| $C D, 205$ (1992), 295 (Justel).

42-207. Escandell Vidal, María VicTORIA - "Sobre las reduplicaciones léxicas". - LEA, 13 (1991), 71-86.

42-208. Espejo Muriel, María DEL MAR - Los nombres de los colores en español. Estudio de lexicología estructural. Universidad, Granada, 1990. 291 pp. (Series Lingüistica). \| REL, 21 (1991), 376-378 (Martinell Gifre).

42-209. Fradejas Rueda, José MANUEL - "Notas léxicas: acetrería, altanería, cetrería, halconería y volateria". $R F E, 72$ (1992), 149-158.

42-210. GÓMEz DE ENTERRÍA, JOSEFA - "Notas sobre neologismos del léxico de la economía". - $L E A, 14$ (1992), 207-224.

42-211. Gómez Renau, María Del MAR - "Léxico castellano en textos aljamiados". - ALHis, 8 (1992), 99115.

42-212. Jensen, Frede - "On the provenance of Spanish blanco and Portuguese branco". - RNo, 33 (199293), 39-43.

42-213. LAMÍQUIZ, VIDAL - “La compleja actividad de una lengua (a propósito de 'harto' en español)'. - REL, 21 (1991), 35-45.

42-214. LAPESA, RAFAEL - Léxico e historia. II. Diccionarios. - Istmo, Madrid, 1992. 120 pp. \| Anthropos, 1993, núm. 145, 74 (Abad).

42-215. MONDÉJAR, JoSÉ - "'Sobre palabras y términos ("Wortfeld" frente a "Sachfeld")". - REL, 21 (1991), 1134.

42-216. Móreno de AlbA, José G. "Revisión de americanismos en el Diccionario de la Academia". - $A L M$, 30 (1992), 165-172.

42-217. MUÑ̃oz, ElVIRA - Diccionario de palabras olvidadas o de uso poco frecuente. - Paraninfo, Madrid, 1993. 409 pp.

42-218. MülleR, BODO - Diccionario del español medieval. Fascículo 5: acabador-acebuche. - Heidelberger Akade- 
mie der Wissenschaften-Garl Winter Universitätsverlag, Heidelberg, 1990. 275-354 pp. || REL, 21 (1991), 388-391 (Clavería Nadal).

42-219. MÜlLER, BODO - Diccionario del español medieval. Fascículo 8 (acordaracreer). - Carl Winter Universitätsverlag, Heidelberg, 1992. 515-594 \|| RLiR, 57 (1993), 539-540 (Thibault). 42-220. Petrecca, Francisco - "La terminología en las Academias. (Perspectiva desde la Argentina)". BAAL, 55 (1990), 211-224.

42-221. POtTIER-NAVARRO, HuguetTe - "El concepto de americanismo léxico". - RFE, 72 (1992), 297-312.

42-222. RAINER, FRANZ - "Argent. $f i$ lodramático: ein verkappter Italianismus". - ZRPh, 107 (1991), 543-546.

42-223. ROSSI, TERESA M. - "Denominar lo nuevo y volver a denominarlo: un problema a raíz del descubrimiento". - LEA, 14 (1992), 243-256.

2-224. SÁNCHEZ VALDERRÁBANOS, ANTONIO, ENRIQUE TORREJÓN PÉREZ, y Miguel Ángel de Pineda Pérez - "Un sistema de consulta automatizada para el Diccionario ideológico de la lengua española de Julio Casares'. - REL, 22 (1992), 135-154.

42-225. Santiago Guervós, Javier DE - El léxico político de la transición española. - Universidad, Salamanca, 1992. 270 pp. (Acta Salmanticensia, Estudios Filológicos, 248). \|| RLiR, 57 (1993), 225 (Colón).

42-226. Satorre GraU, José J. "Un nuevo ejemplo de la expresión dar higas"'. - RFE, 72 (1992), 177178.

42-227. Seguí, Agustín F. - "Precolombino y palabras relacionadas, con sus equivalentes en alemán, inglés, francés, italiano, catalán, portugués, rumano, holandés, danés, polaco, checoslovaco y latín, más algunas referencias al griego, japonés y vietnamita'. - RLiR, 57 (1993), 27-58.

42-228. TIBÓN, GUTIERRE - Diccionario etimológico comparado de los apellidos españoles, hispanoamericanos y filipinos. F.C.E., México, 1992. xxii + 433 pp.

42-229. TRAPERO, MAXIMIANO - "El deporte desde la lengua: algunos tec- nicismos deportivos del español'. LEA, 14 (1992), 127-163.

V. también núms. $30,31,33,44,132$, $156,167,183,250,270,273,274$, $283,301,307,311,313,315,316$, $327,328,330,337,364,383,397$, $414,423,424,1061,1094,1550$.

\section{PRAGMÁTICA}

42-230. Casado VElarde, MANUEL "Los operadores discursivos es decir, esto es, o sea y a saber en el español actual: valores de lengua y funciones textuales"'. - LEA, 13 (1991), 87 116.

42-231. Castaños, Fernando - "Ilocución: intervención deóntica". Discurso, 1992, núm. 13, 25-34.

42-232. ROSAL VARGAS, GERARDO DEL - "Interpretación y representación de la experiencia: una perspectiva pragmalingüística”. - Morphé, 1992, núm. 7, 55-67.

42-233. RUIZ DE MENDOZA IBÁÑEZ, FRANCISCOO JOSÉ - "Descripciones definidas y negociación del significado: un punto de vista conversacional'". - CuIF, 18 (1992), 85-97.

V. también núms. $134,180,238,363$.

\section{LINGÜISTICA TEXTUAL}

42-234. AGUIRRE, JUAN ANTONIO, y EDMUNDO VEGA - "De un discurso que ama y otro que mal-dice". Morphé, 1993, núm. 8, 111-124.

42-235. Agustín Guijarro, Carmen $e t$ al. - "Análisis lingüístico de un texto publicitario". - RFilR, 9 (1992), 275-294.

42-236. Alvar, MANUEL - "Lenguaje político: el debate sobre el estado de la nación (1989)"'. - LEA, 13 (1991), 546.

42-237. BARRIGA VillanUEVA, REBECA - "De Cenicienta a Amor en silencio. Un estudio sobre narraciones infantiles". 
- NRFH, 40 (1992), 673-697.

42-238. BarRiga VillanUeVa, Rebeca - "De las interjecciones, muletillas y repeticiones: su función en el habla infantil'”. - Reflexiones lingüisticas y literarias, t. 1, ed. R. Barriga Villanueva, y J. García Fajardo (México, 1992), 99-113.

42-239. Bubnova, Tatiana - "Parodia como réplica y como recurso de escapatoria'. - Morphé, 1993, núm. 8, 85-97.

42-240. Carbó, TERESA - "Determinaciones discursivas sobre episodios interaccionales en situación de debate'. - Morphé, 1993, núm. 8, 27-51.

42-241. Carbó, Teresa - "La versión de una palabra: ¿propia o ajena?"'. Discurso, 1992, núm. 13, 129-136.

42-242. Ciapuscio, Guionar Elena "Impersonalidad y desagentivación en la divulgación científica". - $-L E A$, 14 (1992), 183-205.

42-243. Downing, ANGela - "La 'metáfora gramatical' de M.A.K. Halliday y su motivación funcional en el texto". - REL, 21 (1991), 109-123.

42-244. FlORES, ROBERTO - "La semiótica del relato histórico”. - $P S M$, 1993, núm. 1, 113-120.

42-245. Forgas Berdet, Esther "El diálogo referido y otras bases de tipologización de la fábula y el coloquio". - REL, 22 (1992), 309-324.

42-246. Garcés Gómez, María Pilar - "El operador discursivo pues en el español hablado". - RJ, 43 (1992), 261-276.

42-247. García-Page, Mario - "Lengua y estilo del Refranero: repetición y (re)creación"'. - ALM, 30 (1992), 89-131.

42-248. GimÉnEz, GilberTo - " Análisis argumentativo y sociocrítica de la ficción literaria: dos aproximaciones al discurso". - PSM, 1993, núm. 1, 35-40.

42-249. LARSEN, KeVIN S. - "The literary background of Dolores Ibárruri's Memorias'. - DLit, 10 (199293), núm. 2, 129-140.

42-250. Marcos-Ortega, José "Evidencia neurofisiológica de los procesos de categorización léxica y acceso al significado'. - Reflexiones lingüisticas y literarias, t. 1, ed. R. Barriga Villanueva, y J. García Fajardo (México, 1992), 187-209.

42-251. Martínez de Merlo, Luis " "Las aleluyas del vino de Jerez". (Ensayo de una análisis semioretórico)", - LBM, 1993, núms. 26/27, 39-55.

42-252. Menéndez, Martín - "Voz y voto. Análisis del discurso de propaganda política'. - Fil, 25 (1990), 133-160.

42-253. Ostria González, Mauricio - "Fundamentos lingüísticos de la intertextualidad en el discurso literario". - RLA, 30 (1992), 219-229.

42-254. PÉrez Castillo, EnriQue "La semiótica y el paradigma interexperencial'. - PSM, 1993, núm. 1, 129-138.

42-255. Quiroz, Gustavo, Denis APOTHÉLOZ, y PIERRE-YVES BRANDT "Argumentación y refutación". Discurso, 1992, núm. 12, 65-74.

42-256. RAMÓN Trives, E. - "Datos para una propuesta de tipología integrada de estilos enunciativos". LEA, 13 (1991), 47-59.

42-257. RASTIER, FRANÇOIS - "El problema del estilo para la semántica del texto'”. - Morphé, 1992, núm. 6, 2343.

42-258. Rodríguez, FÉliX - Prensa $y$ lenguaje político. - Instituto de Cultura Juan Gil-Albert-Fundamentos, Madrid, 1991.308 pp. \|REL, 22 (1992), 466-471 (Battaner Arias).

42-259. SÁnchez CorRal, LUIS "Los marcadores deícticos en la publicidad, una estrategia del discurso". $L E A, 13$ (1991), 133-151.

42-260. Santiago Guervós, Javier de - "Socialismo, socialdemocracia y marxismo en el vocabulario político de la Transición Democrática española (1975-1982)'. - Arb, 1992, núm. 557, 53-67.

42-261. Zavala, LaUro - "Para nombrar las formas de la ironía'. - Discurso, 1992, núm. 13, 59-83.

V. también núm. 175. 
HISTORIA DE LA LENGUA ESPAÑOLA

42-262. Alatorre, A. - Los 1,001 años de la lengua española (N. 41-282). || Ibero, 1992, núm. 45, 96-97 (Berschin); BHi, 94 (1992), 381 (Pottier).

42-263. Álvarez Maurín, María PILAR - "El registro lingüístico especial de los documentos notariales medievales"'. - EHF, 15 (1993), 2341.

42-264. Barrio de la Fuente, CarMEN - "Sacer esto y la pena de muerte en la Ley de las XII Tablas". $E H F, 15$ (1993), 43-56.

42-265. BODElón, SERAFín - "Algunos documentos de San Salvador de Oviedo". - BIEA, 46 (1992), 703713.

42-266. Bonilla, Diego - "Baja California: de la leyenda al acertijo. Antiguos nombres de,la península". - Estudios, 1993, núm. 32, 83-93.

42-267. Cabrera Morales, Carlos - "Las sibilantes medievales: Reflexiones sobre el problema de la desonorización". - Medievalia, 1992, núm. $11,1-18$.

42-268. Camus Bergareche, BRUno - "El dialecto asturiano en el siglo XVII". - BIEA, 46 (1992), 375-392.

42-269. Carrera de la RED, Micaela - "Documentos de criollos de Santo Domingo: estado de lengua (ca. 15291650)". - ALM, 31 (1993), 525-555.

42-270. Clavería NaDal, Gloria El latinismo en español. - Universitat Autònoma de Barcelona, Barcelona, 1991. 294 pp. || Medievalia, 1991, núm. 9, 51-52 (Company Company).

42-271. COMPANY COMPANY, CONCEPCIÓN - "Fonética novohispana a fines del siglo XVII". - ALM, 31 (1993), 557-575.

42-272. COMPANY COMPANY, CONCEP. CIÓN - La frase sustantiva en el español medieval. Cuatro cambios sintácticos. UNAM, México, 1991. 154 pp. ॥ RLiR, 57 (1993), 540-547 (Monjour). 42-273. CONCEPCIÓN SUÁREZ, JULIO "Motivación toponímica: algunos animales domésticos entre los nombres de lugar". - BIEA, 46 (1992),
45-68.

42-274. Dworkin, Steven N. - "The demise of Old Spanish decir: A casestudy in lexical loss". - $R P h, 45$ (1991-92), 493-502.

42-275. EBERENZ, R. - "Construcciones pronominales con verbos intransitivos en el español del siglo XV"'. $V R, 49 / 50$ (1990-91), 371-391.

42-276. FERNÁNDEZ MOLINA, ANA MARÍA - "Una propuesta metodológica para los estudios diacrónicos del español en América"'. - ALHis, 8 (1992), 73-83.

42-277. FonTANELla DE WEINBERG, MARÍA BEATRIZ - "Estudios históricos sobre el español de América". $B A A L, 56$ (1991), 587-596.

42-278. FONTENELLA DE WEINBERG, MARÍA BEATRIZ - "La evolución fonológica del español americano. durante la etapa colonial'. - ALHis, 8 (1992), 85-97.

42-279. FonTANELLA DE WEINBERG, MARÍA BEATRIZ - "Nuevas perspectivas en el estudio de la conformación del español americano". - HL, 4 (1992), 275-299.

42-280. FONTANELLA DE WEINBERG, MARÍA BEATRIZ - "Variedades conservadoras e innovadoras del español de América durante el período colonial"'. - RFE, 72 (1992), 361-378.

42-281. Frago Gracia, Juan A. "Variación dialectal y sociocultural en la documentación indiana del siglo XVI'. - RFE, 72 (1992), 399-428.

42-282. GORDÓN PERAL, MARÍA DE LOS DOLORES - "Materiales documentales para la historia del andaluz. Análisis filológico de textos inéditos guadalcanalenses (1527-1783)"'. - VR, 49/50 (1990-91), 392-420.

42-283. Gordón PERAI, María DOLORES - "Nuevas aportaciones a la lexicología hispánica. Derivados del lat. vg. fictus en castellano y mozárabe". - VR, 51 (1992), 211-219.

42-284. Guitarte, Guillermo L. "Sobre la generalidad del yeísmo porteño en el siglo XIX". - NRFH, 40 (1992), 547-574.

42-285. GUZMÁN BETANCOURT, 'IGNAcro - "La lengua ¿compañera del 
imperio? Destino de un presagio nebrisense en la Nueva España". CuA, 1993, núm. 37, 148-164.

42-286. HARRIS-NORTHALI., RAY "Devoicing, deaffrication, and wordfinal $-z$ in Medieval Spanish'. $-H L$, 4 (1992), 245-274.

42-287. HARRIS-NORTHALL, RAYMOND

- Weakening processes in the history of Spanish consonants. - Routledge, London-New York, 1990. 162 pp. (Croom Helm Romance Linguistic Series). || REL, 21 (1991), 378-380 (Herrero Ruiz de Loizaga).

42-288. HERMAN, JÓzȘEF - Du latin aux langues romanes: études de linguistique historique. Réunies par S. Kiss, avec une préf. de J. Monfrin. - M. Niemeyer, Tübingen, 1990. 392 pp. \| ZRPh, 107 (1991), 604-611 (Kramer); $R P h, 45$ (1992), 507-511 (Wright).

42-289. Hernández, Laura A. - “El sustrato árabe y la evolución de la /f/ latina en aspiración: una nueva hipótesis". - AJMM2, 199-205.

42-290. JAMIESON, MARTIN - "Confusión de sibilantes en el español rioplatense del siglo XVII". - RNo, 33 (1992-93), 217-219.

4<-291. LlOYD, PAUl M. - Del latín al español: fonología y morfología históricas de la lengua española. Trad. de A. Álvarez Rodríguez. - Gredos, Madrid, 1993. xiv + 735 pp.

42-292. LOPE BlaNCH, JUAN M. "Méx. -che, -i(n)che ¿nahuatlismo?". - NRFH, 40 (1992), 623-636.

42-293. Malkiel, YaKoV - Diachronic problems in phonosymbolism. - J. Benjamins, Amsterdam-Philadelphia, 1990. (Edita and Inedita, 1).

42-294. MALKIEL, YAKOV - Diachronic studies in lexicology, affixation, phonology. - J. Benjamins, Amsterdam-Philadelphia, 1992. (Edita and Inedita, 2).

42-295. MALKIEL, YAKOV - "La pérdida del participio pasado en -udo". NRFH, 40 (1992), 11-28.

42-296. Meilán García, Antonio J. - La oración simple en la prosa castellana del siglo $x v$. - Universidad, Oviedo, 1991. 317 pp. \|| REL, 22 (1992), 472475 (Álvarez Martínez).

42-297. Melis, Ghantal - "La pre- posición para del español: un acercamiento a sus orígenes". -- Reflexiones lingüisticas y literarias, t. 1, ed. R. Barriga Villanueva, y J. García Fajardo (México, 1992), 69-86.

42-298. Melis, Chantal - "La sintaxis de las emociones en la época de Nebrija'. - ALM, 31 (1993), 577596.

42-299. MEnÉndez Pidal, Ramón La lengua castellana en el siglo xvii. Pról. de R. Lapesa. - Espasa-Calpe, Madrid, 1991. 225 pp. \| Anthropos, 1992, núms. 134/135, 133-134 (Abad).

42-300. MORIYÓN, CARLOS - "Planificación lingüística ampliadora en la España de los Siglos de Oro'. - ALHis, 8 (1992), 171-188.

42-301. Oliver Pérez, DOlores "Dos arabismos nacidos de un imperativo árabe: jarre! y arriar'. - $A L Q a$, 14 (1993), 163-176.

42-302. Oliver Pérez, Dolores " El nacimiento del sistema genealógico español y sus posibles raíces árabes". - ALHis, 8 (1992), 213-248.

42-303. Pastor de Arozamena, BárBARA - "Overo: La evolución de un tecnicismo latino". - VR, 52 (1993), 279-281.

42-304. PENNY, Ralph $-A$ history of the Spanish language. - Cambridge University Press, Cambridge, 1991. xv + 319 pp. \| HR, 61 (1993), 547549 (Blake); Lan, 69 (1993), 633-634 (Clements).

42-305. Pérez TORal, Marta "Análisis lingüístico de una muestra onomástica asturiana'. - BIEA, 45 (1991), 671-685.

42-306. PerissinotTo, GIORgIO - “El habla de "un caballero de la tierra" novohispano del siglo XVI". - NRFH, 40 (1992), 29-43.

42-307. Perissinotto, Giorgio "Léxico altocaliforniano del siglo XVIII". - ALM, 31 (1993), 597-620.

42-308. RINI, JOEL - Motives for linguistic change in the formation of the Spanish object pronouns. - Juan de la Cuesta, Newark, 1992. 152 pp.

42-309. RINI, JOEL - "On the evolution of Spanish cigüeña and the blending of multiple variants'. $-H R, 61$ 
(1993), 519-529.

42-310. RIVAROLA, J. L. - La formación lingüística de Hispanoamérica (N. 41343). \|ALHis, 8 (1992), 302-307 (Carrera de la Red).

42-311. Rodríguez Fernández, PERFECTO - 'Res = 'ganado' (del latín res)". - BIEA, 46 (1992), 179-181.

42-312. RUHSTALlER, STEFAN - Toponimia de la campiña de Utrera. Estudio lin. güístico e histórico. - Excma. Diputación provincial de Sevilla, Utrera, 1990. x + 141 pp. \| $Z R P h, 107$ (1991), 581-583 (Baldinger).

42-313. SCHWEGLER, ARMIN - "Afrohispanismo mariandá 'tipo de baile (negro)'. Su etimología e importancia para los estudios lingüísticos caribeños". - ALHis, 8 (1992), 259-271.

42-314. TORREBlanca, Máximo "Sobre los orígenes de la distinción fonológica $/ \mathrm{f} /: / \mathrm{h} /$ en el castellano medieval"'. - RPh, 45 (1991-92), 369-409.

42-315. VAllejJOS DE Llobet, PATRICIA - "El vocabulario científico en la prensa iluminista porteña (1800-1825)". - CuA, 1993, núm. 38, 205-224.

42-316. VÁZQUEZ DE BENITO - "Algunos arabismos del léxico médico castellano medieval". - $A L Q a, 14$ (1993), 205-213.

42-317. Zavala, Silvio - "El castellano, ¿lengua obligatoria? Nuevas adiciones". - NRFH, 40 (1992), 45-61.

V. también núms. $30,32,76,86,101$, $107,163,204,206,209,211,212$, $218,219,221-223,226,341,365,378$, $454,1070,1094,1550$.

\section{DIALECTOLOGÍA Y GEOGRAFIA LINGÜÍSTICA}

42-318. Alba, ORLANDO - "El español del Caribe: unidad frente a diversidad dialectal"'. - RFE, 72 (1992), 525540.

42-319. AlMEIDA, MANUEL - "El español hablado en Canarias". - Ibero, 1992, núm. 45, 4-16.

42-320. Alvar, MaNUEL - "El español de los Estados Unidos: diacronía y sincronía'. - RFE, 72 (1992), 469490.

42-321. Alvar, MANUEL - "Encuestas en Estados Unidos'. - LEA, 13 (1991), 273-278.

42-322. Álvarez Nazario, Manuel - "Elogio de la lengua española: El español del Caribe"'. - BACol, 1992 , núms. 176/177, 99-112.

42-323. ARIZA, MANUEl, y ANTONIO SALVADOR - " $/ \mathrm{b} /$ oclusiva y $/ \mathrm{b} / \mathrm{frj}-$ cativa en Serradilla, Cáceres". $A L M, 30$ (1992), 173-176.

42-324. ARJona, Marina, y Fernando RODRÍGUEZ - "Las oraciones objetivas en el habla popular de la ciudad de México". - ALM, 30 (1992), 61-74. 42-325. ARMISTEAD, SAMUEL G. "Tres diälectos españoles de Luisiana'. - LEA, 13 (1991), 279-301.

42-326. BÁEz PinAL, Gloria Estela, María Eugenia Herrera lima, y José Francisco MENdoza - "An. tropónimos en el español de la ciudad de México. Tradición y novedad'". $A L M, 31$ (1993), 431-496.

42-327. BALleRO FlORES, VICENTE De la creatividad lexical. El habla animal chilena. - Romanistischer Verlag, Bonn, 1992. 176 pp.

42-328. BAZÁN C., LUCÍA - "Algunas voces de uso típico en el discurso de Sauce (Provincia de San Martín, Región Autónoma de San Martín, Perú)". - $L y C, 30$ (1990), 14-15.

42-329. BROWN, DOLORES - "El polimorfismo de la /s/ explosiva en el noroeste de México". - NRFH, 41 (1993), 159-176.

42-330. Buesa Oliver, TOMás "Cotejo de los nombres del juego de la comba en los atlas hispánicos". LEA, 13 (1991), 173-198.

42-331. BURDACH, ANA MARÍA, ANA MARÍA MILLÁN, MARISELA TOSELLI, Gladys CePEDA, y M. TERESA POBLETE - "El condicionamiento morfofonológico de /s/ como marcador de plural en el SN del español de Valdivia". - RLA, 30 (1992), 119138.

42-332. BUSSE, WINFRIED (Hrsg.) - Judenspanisch I. - Institut für Romanische Philologie der Freien Universität, 
Berlin, 1991. 289 pp. (Neue Romania, 12). \|RJ, 43 (1992), 343-346 (Kröll). 42-333. Caballero Rubio, María del Carmen, y Julia Beatriz Corral HERNÁNDEZ - "Informatización del Atlas Lingüístico y Etnográfico de Hispanoamérica". - LEA, 13 (1991), 223-250.

42-334. Caravedo, Rocío - "El Atlas Lingüistico Hispanoamericano en el Perú: observaciones preliminares'. - $L E A$, 14 (1992), 287-299.

42-335. Caravedo, Rocío - “¿Restos de la distinción /s/ / $\theta /$ en el español del Perú?". - RFE, 72 (1992), 639654.

42-336. CERDÀ, RAMÓN - "Nuevas precisiones sobre vocalismo del andaluz oriental"'. - LEA, 14 (1992), 165182.

42-337. Coupal, Lysanne $e t$ al. - $R e$ pertorio ictionímico de la República Dominicana. Fascículo 1: Acanthuridae - $\mathrm{Ca}$ rangidae. - Université Laval, Québec, 1992. 306 pp. + 9 pp. de fotografías || RLiR, 57 (1993), 548-549 (Thibault).

42-338. DeMello, George - "Hasta = no hasta / hasta no = hasta en el español hablado de once ciudades". $A L M, 30$ (1992), 5-28. [Habla culta de Bogotá, Buenos Aires, Caracas, La Habana, La Paz, Lima, Madrid, México, San Juan de Puerto Rico, Santiago de Chile y Sevilla].

42-339. DONNI DE MiRANDE, NÉlida ESTHER - "El sistema verbal en el español de Argentina”. - RFE, 72 (1992), 655-670.

42-340. ESPINOSA SANTOS, VICTORIA, y Magdalena CONTARDO LlanOS "La variación diastrática: un tipo de diferenciación interna considerado en el Atlas Lingüístico de la Provincia de Parinacota. A.L.P.A." - $-R L A, 30$ (1992), 145-150.

42-341. Fontanella DE Weinberg, MARÍA BEATRIZ - "Variaciones sincrónicas y diacrónicas en las construcciones con haber en el español americano"'. - BdFS, 33 (1992), 35-46.

42-342. Galindo Oyarzo, LEONEL "Aspectos lingüístico-etnográficos del campo coyhaiquino". - RLA, 30
(1992), 163-170.

42-343. García RiVERón, RaQUEL “'El Atlas Lingüistico de Cuba". - LEA, 13 (1991), 199-221.

42-344. GORdón PERAL, María DOLORES, y STEFAN RUHSTALLER - "Voces de tipificación occidental en el léxico de las hablas de la sierra morena andaluza'". - RLiR, 57 (1993), 337-346.

42-345. Granda, GERMÁN DE "Acerca de la génesis de un rasgo sintáctico del español antillano". $R F E, 72$ (1992), 541-554.

42-346. GRANDA, GERMÁN DE "Acerca del origen de un fenómeno fonético en el español andino. La realización $[\mathrm{Z} / \mathrm{Z}$ Z $]-[y]$ de la oposición /1//y/". - BdFS, 33 (1992), 47-207.

42-347. Granda, Germán DE - "Bibliografia del español de Guinea Ecuatorial'". - ALHis, 8 (1992), 4752.

42-348. Groppy, MiRTA y MARISA MELCUORI - " "Losotro semo canario". El habla rural del noreste de Canelones'. - ALHis, 8 (1992), 127-147.

42-349. Gutiérrez Araus, María LUZ - "Algunos rasgos gramaticales comunes al español actual de Canarias y de las Antillas'. - LEA, 13 (1991), $61-70$.

42-350. Hawayek de Ezcurdia, AN. TOINETTE et al. - "Immigrant languages of Mexico”. - IJSL, 1992, núm. 96, 111-127.

42-351. Hernández, César, Germán DE GRANDA et al. (eds.) - El español de América. - Junta de Castilla y León, Salamanca, 1991. 3 vols. \| Anthropos, 1992, núms. 134/135, 133 (Abad).

42-352. JAMIESON, MARTIN - "Africanismos en el español de Panamá'. ALHis, 8 (1992), 149-170.

42-353. LAPESA, RAFAEL - "Nuestra lengua en España y América”. $R F E, 72$ (1992), 269-282.

42-354. LIPSKI, JOHN M. - The language of the "isleños": Vestigial Spanish in Louisiana. - Louisiana State University Press, Baton Rouge-London, 1990. x + 148 pp. || Lan, 68 (1992), 438-439 (Silva-Corvalán).

42-355. Lope Blanch, JUAN M. - 
"Desde que y (en) donde: sobre geografía lingüística hispánica". - Reflexiones lingüisticas y literarias, t. 1, ed. R. Barriga Villanueva, y J. García Fajardo (México, 1992), 87-96.

42-356. LOPE BLANCH, JUAN M. "Diferenciación dialectal y polimorfismo lingüístico". - $B d F S, 33$ (1992), 71-77.

42-357. LOPE BLANCH, JUAN M. - "El Atlas Lingüístico de México". - LEA, 13 (1991), 153-171.

42-358. LOPE Blanch, JUAN M. - El español hablado en el suroeste de los Estados Unidos. - UNAM, México, 1990.

42-359. LOPE BLANCH, JUAN M. - Investigaciones sobre dialectología mexicana. $2^{a}$ ed. - UNAM, México, 1990. 197 pp. (Publicaciones del Centro de Lingüística Hispánica, 8). I| Anthropos, 1992, núm. 133, 90 (Abad); $A L M, 30$ (1992), 262-265 (Silva Aldrete).

42-360. LOPE BLANCH, JUAN M. "La falsa imagen del español americano". - RFE, 72 (1992), 313-336.

42-361. Montes Giraldo, José JOAQUÍN, y JAIME BERNAL LEONGÓMEZ - "El verbo en el habla culta de Bogotá: frecuencia de categorías tradicionales y creación de otras nuevas". - BICC, 45 (1990), 732-742.

42-362. MONTES, José JOAQUíN "Lingüística, idiomática y español de América". - RFE, 72 (1992), 337 344.

42-363. Morales, Amparo - "Acerca de la topicalidad del objeto en algunos dialectos del español"' - RFE, 72 (1992), 671-686.

42-364. Moreno de AlBA, José G. "Léxico de las capitales hispanoamericanas: propuesta de zonas dialectales". - NRFH, 40 (1992), 575-597.

42-365. MORENO FERNÁNDEZ, FRANCISCO - "El español de Orán: notas históricas, dialectales y sociolingüísticas". - RFE, 72 (1992), 5-35.

42-366. NAVARRo CorREa, MANUEL - "Valóración social de algunas formas verbales en el habla de Valencia". - LEA, 14 (1992), 97-106. [También en ALHis, 8 (1992), 201211].

42-367. NeIRA VÁzQUEZ, Jesús - "Ba- ble central: doble comportamiento de la [-a] de los sustantivos en la alternancia singular/plural' . $-B I E A, 46$ (1992), 137-145.

42-368. NiÑo Murcia, MERcedes -

"El futuro sintético en el español norandino: caso de mandato atenuado". - H, 75 (1992), 705-713.

42-369. OSÁN dE PÉREz Sáez, María FANNY - "Notas sobre el español rural de la provincia de Salta (República Argentina). La composición de palabras'. - ALHis, 8 (1992), 249-257.

42-370. Parker, Steve - "El silabeo del grupo consonántico /tl/ en el castellano peruano"'. - LexisL, 16 (1992), 53-69.

42-371. POTTIER, BERNARD - "La variación lingüística y 'el español de América". - RFE, 72 (1992), 283296.

42-372. QUILIS, ANTONIO - "Situación actual del Atlas Lingüístico de Hispanoamérica". - LEA, 13 (1991), 269271.

42-373. QUilis, ANTONIO, y Celia CASADO - "La lengua española en Filipinas. Estado actual y directrices para su estudio". - ALHis, 8 (1992), 273-295.

42-374. QUILIS, ANTONIO, y MATILdE GraELl STANziola - "La lengua española de Panamá". - RFE, 72 (1992), 583-638.

42-375. RABANALES, AMBRosio "Fundamentos teóricos y pragmáticos del Proyecto de estudio coordinado de la norma lingüística culta del español hablado en las principales ciudades del mundo hispánico"”. - BdFS, 33 (1992), 251-272.

42-376. RANSON, DIANA L, - "Nominal number marking in Andalusian Spanish in the wake of /s/ deletion". - HL, 4 (1992), 301-327.

42-377. SÁEZ GODOY, LEOPOLDO "Economía en el español de Chile (1970-1992). Elipsis, aglutinación, siglificación, reducción y abreviación". - LyL, 1992, núm. 5, 16j-200.

42-378. SCHWARZWALD, ORA (RODRIGUE) - "Morphological aspects in the development of Judeo-Spanish". - FLing, 27 (1993), 27-44.

42-379. SCHWENTER, SCOTT A. - "Di- 
ferenciación dialectal por medio de pronombres: una comparación del uso de tú y usted en España y México". NRFH, 41 (1993), 127-149.

42-380. Simoni-Aurembou, MarieROSE - "Botánica y dialectología en las Islas Canarias". - RDTP; 47 (1992), 255-270.

42-381. Spitzová, Eva - "Estudio coordinado de la norma lingüística culta de las principales ciudades de Iberoamérica y de la Península Ibérica: Proyecto y realización". - ÉRB, 21 (1991), 61-66.

42-382. TORREJÓN, ALFREDO - "Juan Ignacio de Armas y la dialectología hispanoamericana". - NRFH, 41 (1993), 151-158.

42-383. Trapero, Maximiliano "Lengua y cultura: sobre las definiciones de canario 'baile antiguo originario de las Islas Canarias','. RDTP, 48 (1993), 47-79.

42-384. WESCH, ANDREAS - "Grammatische und lexikalische Aspekte des Spanischen von Barcelona'. - I, 1992, núm. 35, 1-14.

V. también núms. 126, 141, 174, 216, $221,268,276-282,284,290,292$, 305$307,310-312,315,395,401,402,412$, 420,424 .

\section{SOCIOLINGÜÍSTICA}

42-385. Almeida, Manuel - Diferencias sociales en el habla de Santa Cruz de Tenerife. - Instituto de Estudios Canarios, La Laguna, Tenerife, 1990. 149 pp. \|| REL, 21 (1991), 373-375 (Medina López).

42-386. BARTOŠ, LUBOMÍR - "El bilingüismo, ¿camino hacia la fragmentación del español en América?". ÉRB, 21 (1991), 53-60.

42-387. BIXLER-MÁrQUEZ, D. J., J. L. Ornstein-Galicia, \& G. K. Green (eds.) - Mexican-American Spanish in its societal and cultural contexts (N. 41-422). || Lan, 68 (1992), 419-420 (Ingle).

42-388. CARAVEDO, R. - Sociolingüistica del español de Lima (N. 41-426). \| ALHis, 8 (1992), 297-302 (Carballera Cotillas).

42-389. Casado Velarde, Manuel Lenguaje y cultura. La etnolingüística. Síntesis, Madrid, 1992. 159 pp. \| RDTP, 48 (1993), 270-272 (Fernández Vallejo).

42-390. Cifuentes, Barbara - "Language policy in Mexico"'. - IJSL, 1992, núm. 96, 9-17.

42-391. Corvalán, Graziella - "El bilingüismo urbano en el Paraguay. El caso de la ciudad de Asunción'. ALHis, 8 (1992), 9-41.

42-392. Guartas, Juan Manuel "En torno al concepto de koiné o interdialecto". - BICC, 45 (1990), 743746.

42-393. DE Fina, ANnA - “Tendencias en la investigación de la alternancia de códigos"'. - Discurso, 1992, núm. 13, 107-128.

42-394. Elizaincín, Adolfo - "His" toria y sociedad: componentes básicos del lenguaje"'. - IJSL, 1993, núms. 100/101, 29-35.

42-395. García Marcos, Francisco J. - "Estratificación social de $-/ \mathrm{r} /$ en el español de la costa granadina". ALM, 30 (1992), 47-59.

42-396. Garvin, Paul L. - "A conceptual framework for the study of language standardization'" - IJSL, 1993, núms. 100/101, 37-54.

42-397. LARA, LUIS FERnANDO - "Para la historia lingüística del pachuco". - ALM, 30 (1992), 75-88.

42-398. LaRa, LUIS Fernando - "'Sociolingüística del Diccionario del español de México". - IJSL, 1992, núm. 96, 19-34.

42-399. Medina López, JAVier - “Esbozo de una guía bibliográfica del tratamiento". - ALM, 30 (1992), 233248.

42-400. Montes, Rosa Graciela "Mecanismos de organización de la interacción verbal". - PSM, 1993, núm. 1, 157-163.

42-401. MORENO FERnÁNDEZ, FrancisCO - "Norma y prestigio en el español de América. Apuntes para una planificación de la lengua española". 
- RFE, 72 (1992), 345-360.

42-402. MORENO FERNÁNDEZ, FRANCISco - "Planificación lingüística y dialectología". - LEA, 13 (1991), 251268.

42-403. Pellicer, Dora - "Storytelling in Mazahua Spanish". - IJSL, 1992, núm. 96, 71-88.

42-404. SAMPER PAdilla, J. A. - Estudio sociolingüístico del español de Las Palmas de Gran Canaria (N. 41-440). \| H, 75 (1992), 341-342 (Lipski); Lan, 68 (1992), 664 (Lorenzino); HR, 60 (1992), 345-347 (Rini).

42-405. SÁNCHEZ, AQUILINO - "Política de difusión del español". - IJSL, 1992, núm. 95, 51-69.

42-406. SÁNKEY García, MaRía DEL RAYO - "Microanálisis de los procesos comunicativos: la interacción familiar como discurso"'. - PSM, 1993, núm. 1, 89-91.

42-407. SIGUÁN, MIGUEL - España plurilingüe. - Alianza, Madrid, 1992. \| RFilR, 9 (1992), 303-305 (López Encinas).

42-408. Tassara Chávez, Gilda "Actitudes lingüísticas ante la variación de /ĉl". - RLA, 30 (1992), 263271.

V. también núms. $142,263,281,285$, $300,317,324,340,342,365,371$, $373,379,413,419$.

\section{LENGUAS EN CONTACTO CON EL ESPAÑOL}

42-409. Albarrán González, BENigno - "Diversidad de lenguas en pueblos de fundación española en las islas Filipinas ( $1^{\text {a }}$ parte)". $-E H F, 15$ (1993), 11-22.

42-410. ARgENTE, JOAN A., y ANXO M. LORENZO - "Reorganización formal y función social en una lengua minoritaria: un ejemplo del contacto gallegocastellano". - NRFH, 41 (1993), 177-199.

42-411. BERNAL LABRADA, EMILIO "Influencias anglicanizantes en el español contemporáneo. La internacio- nalización del español'". - BACol, 1992, núm. 175, 68-75.

42-412. ELIZAincín, AdOlFo - Dialectos en contacto. Español y portugués en España y América. - Arca, Montevideo, 1992. $260 \mathrm{pp}$.

42-413. Escobar, ANNA María - "El español andino y el español bilingüe: semejanzas y diferencias en el uso del posesivo". - LexisL, 16 (1992), 189222.

42-414. GÓMEz CAPUZ, JUAN - "Anglicismos en las noticias sobre la guerra del Golfo Pérsico. Visión actual del problema e intento de clasificación". - LEA, 14 (1992), 301-320.

42-415. GRANDA, GERMÁN DE - El español en tres mundos. Retenciones y contactos lingüísticos en América y África. Universidad, Valladolid, 1991. 285 pp. (Linguística y filologia, 10). \| RJ, 43 (1992), 346-349 (Geckeler).

42-416. HaRe, GÉcilia - "Un cas d'influence des langues amérindiennes sur la phonologie de l'espagnol". - LingP, 29 (1992), 5-16.

42-417. Hualde, José Ignacio "Phonologically unmotivated changes in language contact: Spanish borrowings in Basque". - FLing, 27 (1993), 1-25.

42-418. ITIER, CÉSAR - "Un nuevo documento colonial escrito por indígenas en quechua general: la petición de los caciques de Uyupacha al obispo de Huamanga (hacia 1670)". - LexisL, 16 (1992), 1-21.

42-419. MACKAY, Garolyn J. "Language maintenance in Chipilo: a "Veneto dialect in Mexico". - IJSL, 1992, núm. 96, 129-145.

42-420. MEgENNEY, WiLliam W. África en Santo Domingo: su herencia lingǘstica. - Editorial Tiempo, Santo Domingo, 1990. 252 pp. $\| \cdot$ Lan, 69 (1993), 212-213 (Green).

42-421. MÉNDEZ, JOSÉ LUIS - "Puerto Rico ¿español o inglés? Un debate sobre su identidad". - CuA, 1993, núm. 40, 84-96.

42-422. NAVAS SÁNCHEZ-ÉLEZ, MARÍA VICTORIA - "El barranqueño: un modelo de lenguas en contacto". RFilR, 9 (1992), 225-246. 
42-423. Prieto, LUIS - "Galicismos léxicos en la prensa de Santiago de Chile (1976-1985)"'. - BdFS, 33 (1992), 79-249.

42-424. SCHWEGLER, ARMIN - "Abrakabraka, suebbesuebbe y otras voces palenqueras: sus orígenes e importancia para el estudio de dialectos afrohispanocaribeños". - BICC, 45 (1990), 690-731.

42-425. ZIMMERMANN, KLAUS - Sprachkontakt, ethnische Identität und Identitätsbeschädigung. Aspekte der Assimilation der Otomi-Indianer an die hispanophone mexikanische Kultur. - Vervuert, Frankfurt/M, 1992. 500 pp. \| RJ, 43 (1992), 350-352 (Perl).

V. también núms. $10,49,86,222,313$, $391,403$.

\section{PSICOLINGÜÍSTICA}

42-426. López MORAles, Humberto - "En torno al aprendizaje del léxico. Bases psicolingüísticas de la planificación curricular'. - $R L A, 30$ (1992), 39-50.

42-427. QUESADA, RAúl - “Psicoanálisis y lenguaje”. - Morphé, 1993, núm. 8, 125-131.

42-428. RoDríguez, ORALIA - "Rasgos sui generis en el habla de niños mexicanos de seis años". - Reflexiones lingüisticas y literarias, t. 1, ed. R. Barriga Villanueva, y J. García Fajardo (México, 1992), 115-137.

42-429. Rodríguez, Oralia, y María PAZ BerRuecos - La adquisición del español como lengua materna. Bibliografía descriptiva. - El Colegio de México, México, 1993. 172 pp.

42-430. VAlle Arroyo, F. - Psicolingüistica. - Morata, Madrid, 1991. 232 pp. \| $E M, 1992$, núm. 176, 176 (Vázquez).

42-431. ZIERER, ERNESTO - "La interpretación simultánea: aspectos sicolingüísticos y comunicativos'. $-L y C$, 30 (1990), 1-8.

V. también núms. 237, 238, 250.

\section{LINGÜÍSTICA APLICADA}

42-432. Alarcón, Miguel A., e Irma V. Allarcón H. - "Sistemas de aprendizaje interactivos y adquisición de lenguas"'. - RLA, 30 (1992), 5160 .

42-433. Alcalá Esqueda, Elizabeth - "Problemas y perspectivas en los cursos de redacción". - Escritos, 1992, núm. 8, 103-111.

42-434. Al-Kasey, TAMARA, \& ROSEMARY WESTON - "Why can't Johnny learn Spanish?: A look at Spanish grammar instruction'". - H, 75 (1992), 751-755.

42-435. AraVena, Luz, y ANamaría HARVEY - "Manifestaciones evaluativas en la comunicación de resultados de trabajos de investigación". $R L A, 30$ (1992), 75-84.

42-436. Contreras, HernáN - "Capacidad lectora: experiencias para su evaluación y desarrollo". - RLA, 30 (1992), 139-143.

42-437. Coronado Suzán, Gabriela - "Educación bilingüe en México: propósitos y realidades"'. - IJSL, 1992, núm: 96, 53-70.

42-438. FERREIRA, ANITA, y HUGO MOLINA - "Analizador funcional, diseño e implementación'. $-R L A$, 30 (1992), 151-161.

42-439. Gabbiani, Beatriz, y LEONARDO PELUSO - Lenguaje, pensamiento $y$ educación. Matrices sociales y desarrollo de las habilidades lingüistico-cognitivas. Facultad de Humanidades y Ciencias de la Educación-Amauta, Montevideo, 1993. $166 \mathrm{pp}$.

42-440. GuntermanN, G. - "An analysis of interlangue development over time: Part I, por and para'. $-H, 75$ (1992), 177-187.

42-441. LANGENBACHER-LIEBGOTT, JUTTA - "Sprachkritische Beiträge in französischen und spanischen Zeitungen". - $-R J, 43$ (1992), 17-34.

42-442. Lima MuÑIz, LAURA, y SalvaDOR MORENO KALBTK - " Reflexiones en torno a una periodización de la política educativa en México"'. - Iztapalapa, 1992, núm. 26, 135-150. 
42-443. PANDOLFI, ANA MARÍa, y MA. RÍA OLIVIA HERRERA - "Bases analíticas para la elaboración de un macroperfil de la producción lingüística infantil"'. - RLA, 30 (1992), 231-247.

42-444. PARODI SWEIS, GIOVANNI, y PaUlina NúÑEz LaGos - "Estrategias lectoras en alumnos de educación básica". - RLA, 30 (1992), 249-261.

42-445. Peñalver Castillo, Manuel - La linguística y la enseñanza de la lengua española en el Bachillerato. Pról. de J. Martínez Marín. - Comares, Granada, 1991. 264 pp. || REL, 22 (1992), 453-454 (Rodríguez Baltanás).

42-446. RUIZ DE BRAVO AHUJA, GloRIA - "Educación bilingüe-bicultural en México: criterios de viabilidad"'. - Reflexiones lingüisticas y literarias, t. 1, ed. R. Barriga Villanueva, y J. García Fajardo (México, 1992), 261-283.

42-447. RuIz DE BRavo AhuJa, GloRIA - "The process of bilingualism in a multiethnic context'. - IJSL, 1992, núm. 96, 45-52.

42-448. RYAN, JOHN M., \& BARBARA A. LAFFORD - "Acquisition of lexical meaning in a study abroad environment: Ser and estar and the Granada experience". - H, 75 (1992), 714-722.

42-449. VÁZQUEZ, GRACIELA E. - Análisis de errores y aprendizaje de español/lengua extranjera. Análisis, explicación y terapia de errores transitorios y fosilizables en el proceso de aprendizaje de español como lengua extranjera en cursos universitarios para hablantes nativos de alemán. - Lang, Frankfurt/M, 1992. 286 pp. (Studia Romanica et linguistica, 25). || Ibero, 1992, núm. 45, 99-100 (Navarro).

42-450. VELIZ, MÓNICA, Y BERNARDO RIFFO - "Hacia un perfil de la competencia lectora". - $R L A, 30$ (1992), 273-290.

42-451. VIVANCO, HIRAM, y LARRY SELINKER - "Una experiencia en el uso de las 'reglas confiables' en la redacción en lengua materna". $-R L A$, 30 (1992), 291-301.

42-452. WAGner, Claudio - "La enseñanza del castellano: necesidad de acuerdos básicos". - LyL, 1992, núm.
5, 201-210.

42-453. WALKER DE FÉLIX, JUDITH, \& Sylvia Cavazos PEÑa - "Return home: The effects of study in Mexico on bilingual teachers'. $-H, 75$ (1992), 743-750.

42-454. WOEHR, R. - "The undergraduate meets Spanish language history". - H, 7.5 (1992), 391-397.

42-455. ZiERER, ERNESTO - "Perspectivas de la lingüística aplicada en el Perú". - LyC, 30 (1990), 16-27.

V. también núms. $140,201,426,429$.

\section{HOMENAJES Y ACTAS DE CONGRESOS}

42-456. ANSCHÜTZ, SUZANNE R. (Hrsg.) - Texte, Sätze, Wörter und Moneme. Festschrift für Klaus Heger. - Heidelberg Orientverlag, Heidelberg, 1992. xxiv + 718 pp. \| $R L i R, 57$ (1993), 169-170 (Martin).

42-457. AsHBY, WILLIAM J. et al. - Linguistic perspectives on the Romance languages; selected papers from the Linguistic Symposium on Romance Languages, 21, Santa Barbara, California, 1991. - J. Benjamins, Amsterdam, 1993.

42-458. Demonte, V., y B. Garza GuARÓN (eds.) - Estudios de lingüística de España y México (N. 41-503). II Carav, 1992, núm. 58, 205-212 (Hernández de León-Portilla); RFE, 72 (1992), 749-755 (Martín).

42-459. Garza Cuarón, B., y P. Levy (eds.) - Homenaje a Jorge A. Suárez. Lingüistica indoamericana e hispánica $(\mathbf{N}$. 41-504). \| RFE, 72 (1992), 735-739 (Hernández Hernández); HR, 62 (1994), 105-106 (Moreno Cabrera); BHi, 94 (1992), 381-382 (Pottier).

42-460. HalmDY, ODILE, ARNE HALVORSEN et LISE LORENTZEN (eds.) Actes du onzième congrès des romanistes scandinaves. Trondheim 13-17 août 1990. - Trondheim, 1990. 572 pp. \| RRo, 28 (1993), 131-133 (Pedersen).

42-461. LORENZO, RAMÓN (ed.) - Actas do XIX Congreso Internacional de Lingüistica e Filoloxía Románicas. III: Pragmática e Sociolingüistica. Universi- 
dade de Santiago de Compostela, 1989. - Fundación Pedro Barrié de la Maza, Conde de Fenosa, A Coruña, 1992. 616 pp. \| RLiR, 57 (1993), 485486 (Biermann Fischer).

42-462. MACKENZIE, DAVID, \& IAN MiCHAEL (eds.) - Hispanic linguistic studies in honour of $F$. W. Hodcroft. Dolphin Book, Wales, 1993. xi +223 pp.

42-463. Profesor Francisco Marsá / Jornadas de Filología. - Universidad, Barcelona, 1990. 293 pp. \| REL, 21 (1991), 380-383 (Álvarez Martínez).

\section{LITERATURA TEORÍA LITERARIA HISPÁNICA}

42-464. AlburQUerQue, LUIS - "Producción bibliográfica de la teoría literaria española (I)". - RLit, 55 (1993), 229-258.

42-465. ANDACHT, FERNANDO - Entre signos de asombro: antimanual para iniciarse en la semiótica. - Trilce, Montevideo, 1993. 200 pp.

42-466. ANDERSON-IMBERT, ENRIQUE "Filosofia de la abducción: Peirce y Poe". - NRFH, 40 (1992), 699-705.

42-467. Arriarán, Samuel - "La necesidad de reconsiderar la relación entre el análisis del discurso y el marxismo". - Discurso, 1992, núm. 12, 85-89.

42-468. Bobes Naves, María del CaRMEN - Comentario semiológico de textos narrativos. - Universidad, Oviedo, 1991. \| Anthropos, 1992, núms. 134/135, 138 (Maestro).

42-469. BUENO, RAÚL - Escribir en Hispanoamérica. Ensayos sobre teoria y crítica literarias. - Latinoamericana Editores, Lima-Pittsburgh, 1991. \| RCLL, 1993, núm. 38, 397-399 (Huamán).

42-470. CaIV.ANo, José LUIS - "Semiotics and reality". - Sem, 97 (1993), 231-238.

42-471. Carbonell, Marta Cristina - "Urbano González Serrano, crítico literario (1900-1903)'”. - BBMP, 68 (1992), 177-210.
42-472. CATELLI, N. - El espacio autobiográfico (N. 41-520). \| H, 75 (1992), 110 (Rodríguez-García).

42-473. Chávez Tesser, Carmen " $E$ l discurso literario en el contexto de la "abertura»". - CuA, 1992, núm. 31, 239-245.

42-474. CROS, EDMOND - Ideosemas y morfogénesis del texto. Literaturas española e hispanoamericana. - Vervuert, Frankfurt/M, 1992. $203 \mathrm{pp}$. (Teoría y crítica de la cultura y literatura, 1$)$.

42-475. DOMf́nguez CAPARRós, José - Orígenes del discurso crítico. Teorías antiguas y medievales sobre la interpretación. - Gredos, Madrid, 1993. 254 pp. (Biblioteca Románica Hispánica. II: Estudios $y$ ensayos, 379).

42-476. DOMínguez CaparRós, J. "Razones para la oscuridad poética". - RLit, 54 (1992), 553-573.

42-477. Faulhaber, Charles B. "Textual criticism in the 21 st century"'. - RPh, 45 (1991-92), 123-148.

42-478. Ferman, Glaudia - "Posmodernidad en Latinoamérica: literaturización y desliteraturización en la Argentina contemporánea". - Critical essays on the literatures of Spain and Spanish America, eds. L. T. González del Valle \& J. Baena (Boulder, 1991), 89109.

42-479. Garasa, Delfín L. - “Lo que leen los personajes ficticios". $B A A L, 55$ (1990), 251-277.

42-480. GARCÍA BARRIENTOS, JOSÉ LUIS - "Teatro, drama, texto dramático, obra dramática. (Un deslinde epistemológico)". - RLit, 53 (1991), 371390.

42-481. García-Page Sánchez, Mario - "En torno al encabalgamiento. Pausa virtual y duplicidad de lecturas". RLit, 53 (1991), 595-618.

42-482. GARRIDO DOMínguez, ANTONIO - "El discurso del tiempo en el relato de ficción". - RLit, 54 (1992), 5-45. 42-483. Gómez MARTínez, José LUIS - Teoría del ensayo. - UNAM, México, 1992. 221 pp. \| CuA, 1993, núm. 41, 229-234 (Andueza).

42-484. GómEz MORIANA, ANTONIO Discourse analysis as sociocriticism. The Spanish Golden Age. - University of 
Minnesota Press, Minneapolis, 1993. 179 pp.

42-485. AERMENEGILDO, ALFREDO "Los signos condicionantes de la representación: el bloque didascálico". - Critical essays on the literatures of Spain and Spanish America, eds. L. T. González del Valle \& J. Baena (Boulder, 1991), 121-131.

42-486. HERNÁNDEZ NiETO, HÉCTOR - "Una senda singular: las nuevas teorías poéticas de Caramuel'. RLit, 53 (1991), 655-676.

42-487. Kaliman, Ricardo J. - "Sobre la construcción del objeto en la crítica literaria latinoamericana". RCLL, 1993, núm. 37, 307-317.

42-488. LAUER, M. - El sitio de la literatura (N. 41-552). \| RCLL, 1992, núm. 35, 173-175 (FernándezCozman).

42-489. LÁZARO GARRETER, FERNANDO - De poética y poéticas. - Cátedra, Madrid, 1990. 250 pp. \| $B G E C$, 1993, núm. 6, 62-65 (Genoud de Fourcade).

42-490. LeÓN, Jesús AlberTo - "La narrativa de la adolescencia: ¿signo de crisis social?', - Inti; 1993, núms. 37/38, 117-122.

42-491. LiRA Coronado, SERgIo RENÉ - "Hacia el análisis científico de la literatura". - PSM, 1993, núm. 1, 179-190.

42-492. LLANO, AYMARÁ DE - "Crítica literaria y sociología: dos prácticas argumentativas". - CuLH, 1992, núm. 16, 219-237.

42-493. MALPARTIDA, JUAN - "Sujeto y creación poética". - CuH, 1993, núm. 520, 81-89.

42-494. MANDOKI, KATYA - "Semiótica y estética”. - PSM, 1993, núm. 1, 101-104.

42-495. Millones, LuIS - "El texto andino: las muchas lecturas". - CuA, 1992, núm. 33, 78-90.

42-496. NÚÑEZ RAMOS, RAFAEL - La poesía. - Síntesis, Madrid, 1992. 215 pp. (Teoría de la Literatura y Literatura Comparada ). \| EHF, 15 (1993), 205211 (Marcos Casquero).

42-497. ORDUNA, GERMÁN - "Ecdótica hispánica y el valor estemático de la historia del texto". - $R P h, 45$ (199192), 89-101.

42-498. PAREDES, AlBerTO - Manual de técnicas narrativas. - Grijalbo, México, 1993. 109 pp.

42-499. Pascual Buxó, José - "La semiótica literaria: encuentro y revisiones". - PSM, 1993, núm. 1, 191212.

42-500. Penas Ibáñez, Beatriz "Mímesis y realismos: una discusión relevante para la caracterización del modernismo y postmodernismo". CuIF, 18 (1992), 109-128.

42-501. PÉrez Magallón, J. - En torno a las ideas literarias de Mayans (N. 41560). \| HR, 61 (1993), 104-106 (Dowling); RCEH, 17 (1992-93), núm. 1, 223-225 (Gies).

42-502. PIMENTEI, LUZ AURORA "La dimensión icónica de los elementos constitutivos de una descripción". - Morphé, 1992, núm. 6, 109-144.

42-503. PIMENTEL, LUZ AURORA "Tematología y transtextualidad". NRFH, 41 (1993), 215-229:

42-504. PORQUeras MAYO, A. - La teoría poética en el Manierismo y Barroco españoles (N. 41-561). \| $A L M, 30$ (1992), 296-298 (García-Castañón).

42-505. Prada Oropeza, Renato Análisis e interpretación del discurso narrativo-literario. - Universidad, Zacatecas, 1992. 2 ts.: 205, 175 pp.

42-506. READ, MALCOLM K. - Language, text, subject: $A$ critique of hispanism. Purdue University Press, West Lafayette, 1992. xiii + 209 pp.

42-507. REYZÁBAL, MARÍA VICTORIA, y PEDRO TENORIO - El aprendizaje significativo de la literatura. - La Muralla, Madrid, 1992. II Anthropos, 1993, núms. 142/143, 171-172 (Gabino).

42-508. ROSA, NICOLÁs - "Veinte años después o la "novela familiar" de la crítica literaria": - CuH, 1993, núms. 517/518/519, 161-186.

42-509. Rugueiro ElaM, HELEN "Crítica, negatividad, poesía". $B G E C, 1993$, núm. 6, 15-24.

42-510. RUIz MORENO, LuISA - "Estilos del discurso mítico-religioso": Morphé, 1992, núm. 6, 45-62.

42-511. SÁnchez MECA, DiEgo, y José 
DOMÍNGUEz GAPARRós (coords.) Filosofía y Literatura. Historia de una relación e interna reflexión crítica. - Anthropos, Barcelona, 1992. 95 pp.

42-512. Spadaccini, Nicholas, \& JeNARO TALENS - The politics of editing. - University of Minnesota Press, Minneapolis, 1992. xxii $+181 \mathrm{pp}$.

42-513. SPANG, KURT - Teoría del drama. Lectura y análisis de la obra teatral. EUNSA, Pamplona, 1991. 397 pp. \| $B G E C, 1993$, núm. 6, 65-67 (Galli de Ortega).

42-514. TitTler, Jonathan - "NeoColombian literature: for a loose canon'. - Dispositio, 1991, núm. 41, 121-132.

42-515. TORrES, ANA TERESA - "El escritor ante la realidad política venezolana". - Inti, 1993, núms. 37/38, 37-45.

42-516. VALDECANTOS, ANTONIO "Las trampas de la letra, el ardid de la lectura y el número de maneras en que la memoria puede administrarse. (Tres glosas a dos libros de Emilio Lledó)". - LBM, 1992, núm. 23, 73-93. [El silencio de la escritura y El surco del tiempo. Meditaciones sobre el mito platónico de la memoria y la escritura].

42-517. VARDERI, ALEJANDRO - "Los talleres literarios en la formación de la literatura del fin de siglo". - Inti, 1993, núms. 37/38, 225-232.

42-518. Venier, MARTha Elena "La memoria, iconografía de la retórica". - Reflexiones lingüísticas y literarias, t. 2, ed. R. Olea, y J. Valender (México, 1992), 115-124.

42-519. Villarnovo, ANTONIO - "Teorías explicativas de la coherencia textual"'. - REL, 21 (1991), 125-144.

42-520. Villanueva, Darío - El polen de ideas. Teoria, crítica, historia y literatura comparada. - Promociones y Publicaciones Universitarias, Barcelona, 1991. 406 pp. \| $B G E C, 1993$, núm. 6, 68-72 (Arrigoni de Allamand).

42-521. Villanueva, Darío - Teorias del realismo literario. - Instituto de España-Espasa Calpe, Madrid, 1992. 231 pp. \| $B G E C, 1993$, núm. 6, 72-74 (Granata de Egües); RLit, 55 (1993), 271-276 (Gómez Segade); Anthropos,
1993, núms. 142/143, 167 (Maestro). 42-522. VOLEK, EMIL - "Hacia un concepto cultural postmoderno del realismo mágico en la narrativa hispanoamericana actual". - Critical essays on the literatures of Spain and Spanish Ameri$c a$, eds. L. T. González del Valle \& J. Baena (Boulder, 1991), 235-243.

42-523. ZAVAlA, IRIS MARÍA - La posmodernidad y Mijail Bajtín. Una poética dialógica. Trad. de E. Díaz Navarro. - Espasa-Calpe, Madrid, 1991. \| $A P, 1991$, núm. 12, 179-189 (Bubnova); $B G E C, 1993$, núm. 6, 78-80 (Darré).

V. también núms. 253, 535, 578, 579, 604, 614, 774, 888, 1193.

\section{LITERATURA HISPÁNICA OBRAS GENERALES}

42-524. ADMYTE (Archivo Digital de Manuscritos y Textos Españoles). T. 1. Micronet-Quinto Centenario-Ministerio de Cultura-Biblioteca Nacional, Madrid, 1992.

42-525. Alvar, Carlos - El rey Arturo y su mundo. Diccionario de mitología artúrica. - Alianza, Madrid, 1991. 483 pp. (Alianza Tres, 258).

42-526. AMORÓs, ANDRÉS - Introducción a los estudios literarios. - Rei, México, 1993. 208 pp.

42-527. ANDRÉS, GREGORIO DE - “La colección de manuscritos del literato Serafín Estebánez de Calderón en la Biblioteca Nacional"' - $\mathrm{CuLH}$, 1991, núm. 14, 79-97.

42-528. ANDRÉS, GREGORIO DE - "Vicisitudes de la Real Biblioteca del Monasterio de El Escorial en el siglo XIX". - CuLH, 1992, núm. 15, 59-86.

42-529. AVEnzola, Gemma, y GerMÁN ORDUNA - "Registro de filigranas de papel en códices españoles. (Cont.)". - Incipit, 1991, núm. 11, 1-9.

42-530. BARrio MOYA, JosÉ LUIS "La librería y otros bienes de don Martín Martínez de Medrano. Funcionario del rey Felipe IV (1660)"'. - 
CuLH, 1992, núm. 15, 157-167.

42-531. BÉNASSY-BERIING, MARIE-CÉCILE - "Algunas notas sobre los fondos bibliográficos franceses ubicados en las provincias". - NRFH, 40 (1992), 217-221.

42-532. BÉNASSY-BERIING, MARIE-CÉCIIE - "Notes sur quelques aspects de la vision de l'Amérique hispanique en France pendant la première moitié du XIXe siècle". - Carav, 1992, núm. $58,39-48$.

42-533. Blecua, Alberto - "Los textos medievales castellanos y sus ediciones'. - RPh, 45 (1991-92), 73-88.

42-534. BRIESEMEISTER, DIETRICH, und KLAUS ZIMMERMANN (Hrsg.) - $\mathrm{Me}$ xico heute. Politik, Wirtschaft, Kultur. Vervuert, Frankfurt/M, 1992. 760 pp. (Bibliotheca Ibero-Americana, 43).

42-535. Carrera, Mario Alberto "El rostro de Centroamérica reflejado en su literatura". - Critical essays on the literatures of Spain and Spanish America, eds. L. T. González del Valle \& J. Baena (Boulder, 1991), 47-55.

42-536. ChICHARRO CHAMORRO, ANTONIO - "Acerca del comentario de textos literarios como instrumento docente. (Significación actual y perspectivas de futuro)". - $\mathbb{R}$ Lit, 53 (1991), 585-594.

42-537. CORFIS, IVy A. (ed.) - Ordenanzas Reales. I-1338, Biblioteca Nacional, Madrid. Introd. by C. Petit. The Hispanic Seminary of Medieval Studies, Madison, 1990. microficha.

42-538. Dellepiane, Ángela B. "Proyecto de concordancias de textos gauchescos". - BAAL, 56 (1991), 157-179.

42-539. FORSTER, M. H., \& K. D. JACKSON - Vanguardism in Latin American literature: An annotated bibliographical guide. With the collab. of M. Milleret and J. F. Day (N. 41-594). \| RevIb, 58 (1992), 312-317 (Verani).

42-540. FOSTER, DAVID WILIIAM Mexican literature. $A$ bibliography of secondary sources. 2nd. ed. - Scarecrow, Metuchen, NJ, 1992. xi +686 pp.

42-541. Fradejas Rueda, José MANUEL - Biblioteca cinegética hispónica. Bibliografía crítica de los libros de cetrería y monteria hispano-portugueses anteriores a 1799. - Grant \& Cutler, ValenciaLondon, 1991. 127 pp. \| $A S N S, 229$ (1992), 477-478 (Schmitt).

42-542. Friere LÓPEZ, ANA MARÍA "Cartas inéditas de escritores españoles en la colección de autógrafos de don Antonio Romero Ortiz"' CuLH, 1991, núm. 14, 99-139.

42-543. GARCí́A ORO, JOSÉ - "La cruzada del Cardenal Cisneros". - $A I A$, 51 (1991), 553-766.

42-544. GaRfietd, E. P., \& I. A. SchulMAN - Las literaturas hispánicas: introducción a su estudio (N. 41-598). \| H, 75 (1992), 340-341 (Sackett).

42-545. GOIC, CEDOMIL - Los mitos degradados. Ensayo de comprensión de la literatura hispanoamericana. - Rodopi, Amsterdam-Atlanta, 1992. 368 pp. (Teoria literaria: texto y teoría, B).

42-546. GUTIÉRREZ GIRARDOT, RAFA$\mathrm{EL}$ - La formación del intelectual hispanoamericano en el siglo xix. - LASC, Maryland, 1991. 72 pp. \| RUAn, 1992, núm. 230, 120-126 (Sánchez Lozano).

42-547. JAFFÉ C., VERÓNICA - "Anotaciones sobre la literatura venezolana". - Inti, 1993, núms. 37/38, 245-251.

42-548. Lago Carballo, ANTONIO "La cultura iberoamericana más allá del 92"'. - CuA, 1992, núm. 32, 103113.

42-549. LechNER, JAN - "América en los atlas de humanistas holandeses". - NRFH, 40 (1992), 85-98.

42-550. LEONARD, IRVING G. - Viajeros por la América Latina colonial. F.C.E., México, 1992. 199 pp. \| Estudios, 1992, núm. 30, 114-116 (Bonilla).

42-551. LeÓN-PORTILLA, Miguel "Naturaleza y cultura". - CuA, 1993, núm. 39, 65-71.

42-552. Marcos Marín, Francisco - "Computers and text editing: A review of tools, an introduction to UNI$\mathrm{TE}$ and some observations concerning its application to Old Spanish texts". - $R P h, 45$ (1991-92), 102-122.

42-553. Martínez-Cachero Rojo, MARÍA - "Presencia de escritores asturianos en la revista Índice Literario (19321936)". - BIEA, 47 (1993), 129-143. 
42-554. Marting Diane, E. (ed.) Spanish American women writers: $A$ biobibliographical source book (N. 41-604). ॥ H, 75 (1992), 338 (Foster).

42-555. MÉndez, MaRía ÁGUeda (dir.) - Catálogo de textos marginados novohispanos. Inquisición: Siglos xviii y xix. Archivo General de la Nación (México). Archivo General de la Nación-El Colegio de México-UNAM, México, 1992. 792 pp. || Carav, 1993, núm. 61, 267-268 (Bennassar); LMM, 3 (1992), 203-208 (Trabulse).

42-556. Monero Sorolla, María PILAR - "Los tratados retóricos barrocos y la exaltación de la imagen". RLit, 53 (1991), 445-483.

42-557. Montiveros De Mollo, PerLA - El hilo secreto. Aproximación a la dinámica entre la oralidad y la escritura. Gente de Letras, Buenos Aires, 1990. 137 pp. || Carav, 1992, núm. 58, 227 228 (Mansau).

42-558. Mota Murillo, Rafael "Fuentes para la historia franciscanoamericana del s. XVIII. (Esbozo de bibliografia)"'. - AIA, 52 (1992), 1-80.

42-559. NaharRo Calderón; José MARÍA (coord.) - El exilio de las Españas de 1939 en las Américas: "¿A dónde fue la canción?". - Anthropos, Barcelona, 1991. 431 pp. \| RFilR, 9 (1992), 335-338 (Gómez Íñiguez).

42-560. NARANJo Villegas, ABel "Alternativa de una cultura hispanomericana'. - BACol, 1992, núm. $175,19-31$.

42-561. Olea Franco, Rafael, y JAMES VALENDER (eds.) - Reflexiones lingüisticas y literarias. T. 2: Literatura. - El Colegio de México, México, 1992. xiii + 378 pp.

42-562. PFEIFFER, ERNA - Entrevistas. Diez escritoras mexicanas desde bastidores. - Vervuert, Frankfurt/M, 1992. 170 pp.

42-563. PichóN Rivière, MARCELO "La irrealidad de una literatura". CuH, 1993, núms. 517/518/519, 511513.

42-564. Piglia, Ricardo - " Ficción y política en la literatura argentina". CuH, 1993, núms. 517/518/519, 514516.
42-565. RODRÍGUEZ, RODNEY T., y AMPARO RANCH SALES - "La biblioteca romántica de Eduardo Ranch'. BBMP, 68 (1992), 269-292.

42-566. Rodríguez ReA, Miguel ÁNGEL - El Perú y su literatura. Guía bibliográfica. - Pontificia Universidad Católica del Perú, Lima, 1992. 251 pp. \| LexisL, 16 (1992), 117-119 (González Montes); Carav, 1993, núm. 60, 179-180 (Rozenblat).

42-567. Seres Rodrfguez, Gema “Las Actas Capitulares de la Iglesia Colegial de Antequera en los años 1536-1537. Transcripción y notas". - AnMal, 14 (1991), 87-101.

42-568. Soto PÉREz, JosÉ LuIS "Fuentes documentales para la historia de la provincia franciscana de $\mathrm{Mi}$ choacán en el siglo XVIII'. - $-A I A, 52$ (1992), 81-106.

42-569. VAlis, NÖEL, \& CAROL MAIER (eds.) - In the feminine mode: Essays on Hispanic women writers. - University Press, Bucknell, 1990. 284 pp. \| $K R Q$, 39 (1992), 125-127 (Wietelmann Bauer).

42-570. VÁzQUEz JANEIRo, ISAaC "Documentación americana en el Pontificio Ateneo Antoniano de Roma". - AIA, 52 (1992), 767-809.

42-571. Verdejo SÁNChez, María DoLORES - "La enseñanza de los textos en la universidad". - AnMal, 14 (1991), 167-172.

42-572. WENTZLAFF-EGGEBERT, HARALD - Las literaturas hispánicas de vanguardia. Orientación bibliográfica. - Vervuert, Frankfurt/M, 1991. xv + 229 pp. (Bibliotheca Ibero-Americana, 38).

42-573. WITTSCHIER, HEINZ WILlI Die spanische Literatur. Einführung und Studienführer von den Anfängen bis zur Gegenwart. - M. Niemeyer, Tübingen, 1993. $480 \mathrm{pp}$.

42-574. ZAMORA, HERMENEGILDO "Escritos franciscanos americanos del s. XVIII". - AIA, 52 (1992), 691-766.

42-575. Zavala, Lauro - "Los estudios sobre comunicación y cultura: una aproximación constructivista". - PSM, 1993, núm. 1, 147-155.

42-576. ZEA, LEOPOLDO - Fuentes de la cultura latinoamericana. - F.C.E., Mé- 
xico, 1993. 2 ts.: 577, 593 pp.

\section{HISTORIA LITERARIA}

42-577. AgUiLAR PIÑAL, F. - Introducción al siglo xviii (N. 41-630). \| RLit, 54 (1992), $751-754$ (Checa Beltrán).

42-578. ALBORG, JUAN LUIS - Sobre critica y críticos. Historia de la literatura española. Paréntesis teórico que apenas tiene que ver con la presente historia. - Gredos, Madrid, 1991. 1005 pp. \| Anthropos, 1993, núm. 140, 76-77 (Estepa).

42-579. AldARACA, B., E. BAKER, y J. BEVERLEY (eds.) - Texto y sociedad: problemas de historia literaria (N. 41631). \| H, 75 (1992), 319-320 (Parr).

42-580. AMELL, S. (ed.) - Literature, the arts, and democracy: Spain in the Eighties (N. 41-632). \| H, 75 (1992), 327 (Myers).

42-581. APARICIO, FRANCES R. - Versiones, interpretaciones y creaciones: instancias de la traducción literaria en Hispanoamérica en el siglo $x x$. - Rds. Hispamérica, Gaithersburg, 1991. 193 pp. \| BGEC, 1993, núm. 6, 55-57 (de Zuleta).

42-582. BARNADAS, JOSEPH M. - "La historia literaria de Charcas: legitimidad, problemas, tareas, cuestiones pendientes"'. - QIA, 1993, núm. 73, 65-75. [actual Bolivia].

42-583. BARRIOS, Alba LíA - "Primer costumbrismo venezolano: ¿liberal? ¿conservador?"'. - EUSB, 1993, núm. 1, 5-17.

42-584. Beauregard, Paulette SilVIA - "Democratización, censura y enmascaramientos: el cambio de la intelectualidad venezolana de finales del XIX"'. - EUSB, 1993, núm. 1, 2946.

42-585. Belluzzo, A. M. de M. (ed.) - Modernidade: vanguardas artísticas na América Latina (N. 41-637). \| RevIb, 58 (1992), 312-317 (Verani).

42-586. Bertrand de MuÑoz, Maryse (coord.) - Guerra civil y producción cultural. Teatro, poesia, narrativa. - Anthropos, Barcelona, 1993. 95 pp.

42-587. BEVERLEY, J: M., \& M. ZIM-
MERMAN - Literature and politics in the Central American revolutions (N. 41-640). || $R C L L, 1993$, núm. 37, 380-382 (Higgins); $H, 75$ (1992), 338-339 (Keyck). 42-588. Blasco, Francisco JaVier "La metáfora del cuerpo en la literatura esotérica del Siglo de Oro'. - Le corps comme métaphore dans l'Espagne des xvie et xviie siècles, ed. A. Redondo (Paris, 1992), 235-244.

42-589. BORsò, VITTORIA - "Die Aktualität mexikanischer Literatur: von der Identität zur Heterogenität' . - Ibero, 1992, núm. 46, 84-108.

42-590. BOUZA, FERNANDO - Locos, enanos y hombres de placer en la corte de los Austrias. - Temas de Hoy, Madrid, 1991. 223 pp. \|| Criticón, 1992, núm. 54, 147-148 (Arellano).

42-591. BRIHUEGA, JAIME - "Arte y política en la España del siglo XX". - LBM, 1992, núm. 24, 43-48.

42-592. CALvo SANZ, ROBERTO - Literatura, historia e historia de la literatura. Reichenberger, Kassel, 1993. 166 pp.

42-593. CARDWELL, RICHARD A. "Degeneration, discourse and differentiation: Modernismo frente a noventa $y$ ocho reconsidered"'. - Critical essays on the literatures of Spain and Spanish America, eds. L. T. González del Valle \& J. Baena (Boulder, 1991), 29-46.

42-594. CASTRO KLARÉN, S. - Escritura, transgresión y sujeto en la literatura latinoamericana (N. 41-519). \| RCLL, 1992, núm. 35, 171-173 (Podestá).

42-595. CAUDET, FRANCISCO - El exilio republicano en México. Las revistas literarias (1939-1971). - Fundación Banco Exterior, Madrid, 1992. 652 pp. \| Anthropos, 1993, núm. 150, 73-74 (Ortego Sanmartín).

42-596. COURCELIES, DOMINIQUE DE - "Du corps de cvirtut" des saints au corps d'écriture: ou la métaphore au service du pouvoir dans des feuillets de prière imprimés en Catalogne au XVII siècle". - Le corps comme métaphore dans l'Espagne des xvie et xvïe siècles, ed. A. Redondo (Paris, 1992), 181-190.

42-597. CrÉmoux, FrançOISE - "Le corps du pèlerin comme métaphore spirituelle dans les récit de pèlerinages 
et de miracles". - Le corps comme métaphore dans l'Espagne des xvie et xviie siècles, ed. A. Redondo (Paris, 1992), 191-202.

42-598. Davies, Catharine (ed.) Women writers in Twentieth-Century Spain and Spanish America. - Edwin Mellen Press, Lewiston, 1993. 213 pp.

42-599. Delgado, SAMUel ROMÁN "El atalayismo; innovación y renovación en la literatura puertorriqueña". - RevIb, 59 (1993), 93-100.

42-600. Díaz Diocaretz, Myriam, e IRIS M. Zavala (coords.) - Breve historia feminista de la literatura española (en lengua castellana). I. Teoría feminista: discursos y diferencia. Enfoques feministas de la literatura española. - AnthroposConsejería de Educación de la Comunidad de Madrid-Universidad de Puerto Rico, Barcelona-Madrid-San Juan de Puerto Rico, 1993. 144 pp. (Cultura y Diferencia, 1).

42-601. Díaz Martínez, Manuel “'La generación del 27 e Hispanoamérica'. - CuH, 1993, núms. 514/515, 143-154.

42-602. ESCOBAR, JOSÉ - "Ilustración, romanticismo, modernidad". - $L B M$, 1993, núm. 25, 45-54.

42-603. ÉtIENVRE, J.-P. - Márgenes literarias del juego. Una poética del naipe. Siglos xvi-xviii (N. 41-660). \| HR, 61 (1993), 102-104 (Lozano Marco).

42-604. FLITTER, DEREK - Spanish romantic literary theory and criticism. Cambridge University Press, Cambridge, 1992. $220 \mathrm{pp}$. \| HR, 61 (1993), 418-421 (Iarocci); RHM, 46 (1993), 394-397 (Sebold).

42-605. Foster, D. W. - The Argentine generation of 1880: Ideology and cultural texts (N. 41-663). \| H, 75 (1992), 99 (Daniel); HR, 60 (1992), 249-250 (Ianes).

42-606. GaBILONDO PUjo, ÁNGel - "La mística como lenguaje de la carne". - Edad de Oro, 1992, núm. 11, 59-71.

42-607. García Barragan, María GuaDALUPE - El naturalismo literario en México. - UNAM, México, 1993. $132 \mathrm{pp}$.

42-608. Garfield, E. P., e I. A. SCHULMAN (eds.) - Contextos: literatura y so- ciedad latinoamericanas del siglo xix (N. 41665). \| H, 75 (1992), 570 (Szmetan). 42-609. GelPí, JUAN G. - Literatura $y$ paternalismo en Puerto Rico. - Universidad de Puerto Rico, Río Piedras, 1993. $201 \mathrm{pp}$.

42-610. González STEPHAN, BEATRIZ - "Poder y cultura nacional: estado e historiografía literaria (Venezuela, siglo XIX)"'. - EUSB, 1993, núm. 1, 47-60.

42-611. HerRera NaVARro, JaVIER "Picasso y los escritores del 98: la revista Arte Joven'. - - LBM, 1992, núm. 24, 5-28.

42-612. Hidalgo de Jesús, Amarilis - "Abrapalabra: el discurso desmitificador de la historia colonial venezolana'. - Inti, 1993, núms. 37/38, 163-169.

42-613. INFANTES, VÍcTOR - En el Siglo de Oro. Estudios y textos de literatura áurea. - Scripta Humanistica, Potomac, 1992. xi + 255 pp. (Scripta humanistica, 88).

42-614. JURETSCHKE, HANS - "La actualización de la vida y la obra de Milá y Fontanals en la historiografía literaria y cultural de España. Un comentario a la investigación de Manuel Jorba'. - RLit, 55 (1993), 149-159.

42-615. JARA, R., \& N. SPADACCINI (eds.) - 1492/1992: Re/discovering. Colonial writing (N. 41-686). \|RCEH, 17 (1992-93), núm. 1, 207-209 (Boruchoff).

42-616. Johnson, JULIE GREER - Satire in colonial Spanish America: Turning the New World upside down. Introd. by D. R. Reedy. - University of Texas Press, Austin, 1993. xvii + 203 pp.

42-617. JORDAN, BARRY - "Social realism in the 1950s: The contribution of Revista Española". - BHS, 68 (1991), 281-295.

42-618. JORDAN, BARRY - Writing and politics in Franco's Spain. - Routledge, London-New York, 1990. xiii + 213 pp. \| KRQ 39 (1992), 113-115 (Valis).

42-619. Martínez TORRÓN, Diego El alba del romanticismo español. - Alfar, Sevilla, 1993. 414 pp.

42-620. Meregalli, F. (ed.) - Storia 
della civiltà letteraria spagnola. T. 1: Dalle origini al Seiscento. T. 2: Dal Settecento ai giorni nostri (N. 41-697). \| HR, 60 (1992), 75-79 (Damiani).

42-621. Molloy, S. - At face value. Autobiographical writing in Spanish America (N. 41-699). \|| RevIb, 58 (1992), 281283 (Gelpi); HR, 61 (1993), 596-598 (Ross); MLN, 108 (1993), 376-381 (Shumway).

42-622. PAYeras GraU, M. - La colección "Colliure" y los poetas del medio siglo (N. 41-891). \| $H R, 60$ (1992), 105107 (Debicki).

42-623. PIÑA, CRISTINA - "La narrativa argentina de los años setenta y ochenta"'. - CuH, 1993, núms. 517/518/519, 121-138.

42-624. Salaün, Serge, et Carlos SERRANO (eds.) - Historie de la littérature espagnole contemporaine. xixe-xxe siècles. Questions de méthode. Actes du Colloque organisé à la Sorbonne par le CRID les 2, 3 et 4 mars 1989. - Presses de la Sorbonne Nouvelle, Paris, 1992.158 pp. 42-625. SCHRADER, LUDWIG - "Les yeux de l'âme et de l'esprit, métaphore de la littérature religieuse espagnole du Siècle d'Or'". - Le corps comme métaphore dans l'Espagne des xvie et xviie siècles, ed. A. Redondo (Paris, 1992), 203-219.

42-626. SchWARTZ, J. (ed.) - Las vanguardias latinoamericanas: textos programáticos y críticos (N. 41-716). || RevIb, 58 (1992), 312-317 (Verani).

42-627. SCONZA, M. JEAN - History and literature in fifteenth-century Spain: An edition and study of Pablo de Santa Maria's "Siete edades del Mundo". - The Hispanic Seminary of Medieval Studies, Madison, 1991.

42-628. SEBold, Russell P. - De ilustrados y románticos. - El Museo Universal, Madrid, 1992. xiii + $228 \mathrm{pp}$.

42-629. SUTHERLAND, M: - "The captive's tale retold: High culture and mass culture in Eighteenth-century Spain'". H, 75 (1992), 20-29.

42-630. TOVAR DE Teresa, GuillerMO - Pegaso. $O$ el mundo barroco novohispano en el siglo xviii. - Vuelta, México, 1993. 98 pp.

42-631. Valín, Gema, y Gemma Ave-
NOZA - "Los primeros pasos de la novela en España: Cuatro quentos de exemplos'. - Criticón, 1992, núm. 55, 31 40.

42-632. Videla DE Rivero, G. - Direcciones del vanguardismo hispanoamericano (N. 41-722). || HR, 61 (1993), 451454 (Müller-Bergh); RevIb, 58 (1992), 312-317 (Verani).

42-633. Viña Liste, José María Cronología de la literatura española. T. 1: Edad Media. - Cátedra, Madrid, 1991. 447 pp. || RLit, 54 (1992), 733 739 (Gómez-Redondo).

42-634. YÁÑEZ, ADRIANA - Los románticos: nuestros contemporáneos. Pról. de $\mathrm{R}$. Xirau. - Patria, México, 1993. 125 pp.

V. también núms. 520, 719, 748.

\section{LITERATURA COMPARADA}

42-635. ANDRÈs, ChristiAn - "Nota sobre lo cómico médico en el teatro de Lope de Vega y Molière". - IFE, 1992, núm. 6, 91-104.

42-636. ANGuita, EdUARdo - "Huidobro y Neruda: final". - Atenea, 1993, núm. 467, 145-147.

42-637. Aparicio, Frances R. - "Borges y Whitman: un abrazo panteísta": - DLit, 10 (1992-93), núm. 2, 23-31. 42-638. ANA TORRALBA, JUAN CARLOS - "Víctor Hugo en el fin de siglo español: Ricardo León y la poesía luchadora". - IFE, 1992, núm. 7, 55-69.

42-639. ARCE, ÁNGEles - "Algo más sobre Dante y la narrativa en lengua española". - CuLH, 1992, núm. 15, 7-22.

42-640. Arellano, Ignacio - "Presencia de Góngora en Bances Candamo, poeta oficial de Carlos II'. RLit, 53 (1991), 619-630.

42-641. AREs MonTes, José - “'La influencia española en la obra de Manuel da Veiga Tagarro'". - RFilR, 9 (1992), 11-36.

42-642. ARPINI, ADRIANA - "Ecos martianos en el latinoamericanismo de un argentino: Manuel Ugarte'?. - CuA, 
1992, 34, 164-170.

42-643. BARTOW, JOANNA R. - “Isolation and madness: Collective memory and women in Los recuerdos del porvenir and Pedro Páramo". - RCEH, 18 (1993-94), núm. 1, 1-15.

42-644. BLAZER, BERIT - "Domesticidad y transgresión: Madame Bovary, Effi Briest y La Regenta'". - IFE, 1993, núm. 9, 57-81.

42-645. Bravo, M. Elena - "Herrumbrosas lanzas-bruñidas letras: Juan Benet a la luz de Cervantes". DLit, 11 (1993-94), núm. 1, 9-24.

42-646. BUSH, ANDREW - "On exemplarity and postmodern simulation: Robert Coover and Severo Sarduy'. - CL, 44 (1992), 174-193.

42-647. CAMPo, Angel Esteban P. DEL - “Bécquer y Martí: inspiración y genio poético. Sus simbolizaciones como aspecto de la suprarracionalidad". - CuLH, 1991, núm. 14, 299314.

42-648. Carande, Bernardo - "Jorge Guillén y Night and Death de Blanco White". - CuH, 1993, núms. 514/515, 301-305.

42-649. Cobos Castro, Esperanza "Les relations franco-espagnoles XIXe siècle". - IFE, 1993, núm. 9, 41-55.

42-650. Cobos Castro, Esperanza “Louis Verneuil en España”. - IFE, 1992, núm. 7, 91-104.

42-651. Colomer, José LUIS - "'Traducción y recepción. La lectura europea de la picaresca en $I l$ picariglio castigliano de Barezzo Barezzi (1622)'. - RLit, 53 (1991), 391-443.

42-652. CONCHA, EDMUNDO - "Neruda y Huidobro". - Atenea, 1993, núm. 467, 155-156.

42-653. Corral, Rose - "Onetti/Arlt o la exploración de algunos vasos comunicantes". - Reflexiones lingüisticas $y$ literarias, t. 2, ed. R. Olea, y J. Valender (México, 1992), 251-267.

42-654. D'ANTOUNO, NANCY L. "The evolution of Il Cavaliere perseguitato: Literary interdependence in Bandello, Lope de Vega and the Commedia dell'arte'. - BC, 44 (1992), 103-112.

42-655. Esteban-P. Del Campo, ÁnGEL - "Bécquer y Martí: una au- diencia especial con el sentimiento". - ALM, 30 (1992), 177-189.

42-656. ETREROS, MERCEDES - "Influjo de la narrativa rusa en doña Emilia Pardo Bazán. El ejemplo de La piedra angular". - ALE, 1993, núm. 9, 31-43.

42-657. Fernández díaz, María del CARMEN - "Maurice Scève y Garcilaso de la Vega: paralelismos vitales y literarios". - IFE, 1993, núm. 9, 1122.

42-658. Franklin Lewis, Elizabeth M. - "Huellas en el hielo, Hemingway en Tres tristes tigres". - RHM, 46 (1993), 131-140.

42-659. García Devesa, Consuelo "Cuatro poemas de amor o un poema de Luis Cernuda a la luz de Bécquer, Rosalía y A. Machado'. - RNo, 33 (1992-93), 197-206.

42-660. García Garrosa, María Jesûs - "Diderot y Trigueros: sobre las posibles fuentes de El precipitado". - RLit, 54 (1992), 183-200.

42-661. García Garrosa, María Jesús - "Valladares, adaptador de Marmontel. Una nueva versión española de los Contes moràux". - IFE, 1992, núm. 7, 39-54.

42-662. GlantZ, MARGo - "De Narciso a Narciso o de Tirso a Sor Juana: El vergonzoso en palacio y Los empeños de una casa". - NRFH, 40 (1992), 477 492. [También en El escritor y la escena (1), pp. 29-43].

42-663. Gliemmo, Graciela - "La inscripción de una escritura: Georges Bataille en América Latina". $R U A n, 1992$, núm. 232, 45-58.

42-664. GÓMEZ MONTERO, JAVIER Literatura caballeresca en España e Italia (1483-1542). El "Espejo de cavallerías". - M. Niemeyer, Tübingen, 1992. $330 \mathrm{pp}$.

42-665. González del VAlle, LuIS T. - El canon. Reflexiones sobre la recepción literaria teatral (Pérez de Ayala ante Benavente). - Huerga y Fierro, Madrid, 1993. 104 Pp.

42-666. GrogAN, RuTH A. - "The fall into history: Charles Tomlinson and Octavio Paz'. . - CL, 44 (1992), 144160. 
42-667. GUTIÉRREZ GIRARDÖT, RAFAEL - "César Vallejo y Walter Benjamins"' - CuH, 1993, núm. 520, 5572.

42-668. HAMBROOK, GLYN - "Baudelaire y España". - IFE, 1992, núm. 7, 71-75.

42-669. HANSEN, KeITH. W. - Tragic lucidity: Discourse of recuperation in Unamuno and Camus. - P. 'Lang,' New York, 1993. 187 pp. \& , , , :st?

42-670. HATHERLY, ANA - A égloga Toledo que Manuel de Faria é Sousa fez com versos : de Garcilaso".. - RFilR, 9 (1992), 191-206.

42-671. LIDA, DENAH - "Don Juan en Italia en el siglo XVIu". - NRFH, 40 (1992), 707-717. : :

42-672. LÓPEZ BARALT, LUCE - Islam in Spanish literature. From the Middle Ages to the present. $\mathrm{Tr}$. by A. Hurley. - E. J: Brill, Leiden, 1992. xvii + 323 pp.

42-673. LOURENÇO, EdUARDO - "Camoens y Góngora". - Syntaxis, 1992, núms. ,30/31, 24-29.

42-674. MADRID, L. M. - "Sábato/Borges: sobre el cielo y el infierno"..RevIb, 58 (1992), 207-216.

42-675. MATAMORO, Blas - "Villaurrutia y Cernuda: eros y cosmos". - $\mathrm{CuH}, 1993$, núms. 514/515, 209213.

42:676. MAUTNER. WASSERMAN, RENATA R. - "Mario Vargas Llosa, Euclides da Cunha, and the strategy of intertextuality" - $-P M L A, 108$ (1993), 460-473.

42-677. MaGRadY, DónALD - "Sobre una fuente boccaccesca en un soneto religioso de Lope": - KRQ 39 (1992), 199-203.

42-678. MCGRADY; DONALD \& RONNA FEIT - "Recollections of Juan de Mena in Lope de Vega's Viuda, casada y doncella". - BC, 45 (1993), 7-11.

42-679. Menocal, M: R. - Writing in Dante's cult of thruth: From Borges to Boccaccio: (N. 41-1942). \| MLN, 107 (1992), 406-410 (Teuber).

42-680. MilleR, STEPHEN - Del realismo/naturalismo al modernismo: Galdós, Zola, Revilla y Clarin (1870-1901). Cabildo Insular de Gran Canaria, Las Palmas, 1993: 218 pp.
42:681. Navarro Pastor, SANTIAGo - "Canto y festejo en Giacomo Leopardi y Claudio Rodríguez". . RHM, 46 (1993), 275-288.

42-682. Pacheco, José Emilio " "Birds in the night" (Vallejo y Cernuda se encuentran en Lima)". CuA, 1992, núm. 31, 16-40.

42-683. PRATS SARIOL, JosÉ - "Nuestra América de Martí y Pellicer'. Unión, 1993, núm. 15, 12-16.

42-684. REY HAZAS, ANTONIO - "Cer-

- vantes y Lope ante el personaje colectivo: La Numancia frente a Fuenteovejuna”. - CTC, 1992, núm. 7, 69-91.

42-685. RiBbaNS, GEOFFREY - "A note on Cadalso and Samuel Johnson". BHS, 68 (1991), 47-51.

42-686. RODRÍGUEZ, MARIO, Y MARÍA i. Nieves AlONSO - "Poesía chilena y española: Lihn y Gil de Biedma”. Atenea, 1993, núm. 467, 197-219:

42-687. RODRÍGUEZ FERNÁNDEZ, MARIO - "De Neruda a Lihn. (Tres oposiciones complementarias en la poesía chilena contemporánea)". - Atenea, i 1992, núms. 465/466, 261-268.

42-688. RODRÍGUEZ LUIS; JULIO Contemporary praxis of the fantastic: Borges and Cortázar. - Garland, New York, 1991. || RCLL, 1993, núm. 38, 403404 (Incledon).

42-689. SHAW, PATRICIA - "The presence of Spain in Middle English literature'.. - ASNS, 229 (1992), 41-54.

42-690. VAN MEteR, D. A. - "Rubén Darío and Vicente Huidobro: Two views of language as impregnation". - H, 75 (1992), 294-300.

42-691. VÁZQUEZ ARCE, CARMEN "Los desastres de. la guerra: sobre la articulación de la ironía en los cuentos La recién nacida sangre, de Luis Rafael Sánchez y El momento divino de Caruso Llompart; de Félix Córdova Iturregui'". - RevIb, 59 (1993), 187-201.

42-692. YOUNG, HOWARD T. - "Sombras fluviales: Poeta en Nueva York y The Waste Land"' - FGL, 1992, núms. $10 / 11,165-177$.

42-693. YOUNG, RICHARD A. - "Verano, de Julio Cortázar, The Nightmare; de John Henry Fuseli; $y$ athe judicious adoption of figures in arts" : - 
RCEH, 17 (1992-93), núm. 2, $373-$ 382.

42-694. ZANGRILli, Franco - "Pirandello e Locos di Felipe Alfau'. - QIA, 1993, núm. 73, 95-106.

V. también núms. 520, 1400.

\section{ANTOLOGÍAS Y SELECCIONES}

42-695. Castro KLARÉn, Sara, Sylvia MOLLOY, y BEATRIZ SARLO (eds.) Women's writing in Latin America. An anthology. - Westview Press, Boulder, 1991. || RCLL, 1993, núm. 37, 372374 (Paulino Bueno).

42-696. Cu Cortés, Julio (ed.) - Poesía mexicana de la segunda mitad del siglo $x x$. Antología. - UNAM, México, 1993. 258 pp.

42-697. DeitA, F. (coord.) - Teatro mexicano contemporáneo. Antología. F.C.E., México, 1992. \| Anthropos, 1993, núm. 145, 74-75 (Reyzábal).

42-698. FORN, JUAN (ed.) - Buenos $A i$ res. Una antologia de la nueva ficción argentina. - Anagrama, Barcelona, 1992. 234 pp. || RHM, 46 (1993), 402-402.

42-699. FRANCO, JEAN, et JEAN-MARIE LEMOGODEUC (eds.) - Anthologie de la littérature hispano-américaine du xxe siècle. - Presses Universitaires de France, Paris, 1993. 404 pp.

42-700. GonZÁlez, Cristina (ed.) Antología de la prosa medieval castellana. - Colegio de España, Salamanca, 1993. 184 pp.

42-701. GonzÁlez Rodríguez, SerGIO (comp.) - Los amorosos; relatos eróticos mexicanos. - Cal y Arena, México, 1993.

42-702. Helguera, Luis Ignacio Antología del poema en prosa en México. F.C.E., México, 1993. 479 pp.

42-703. KAPPATOS, RIGAS, y JAVIER SOLOGUREN - Antología del cuento peruano. - Kastanioti, Atenas, 1989. II $R C L L, 1993$, núm. 37, 392-396 (Catzaras).

42-704. Kappatos, Rigas, y PEDRo LASTRA - Antología del cuento chileno. - Kastanioti, Atenas, 1989. \|
RCLL, 1993, núm. 37, 392-396 (Catzaras).

42-705. LITVAK, LILY (ed.) - Antología de la novela corta erótica española de entreguerras (1918-1936). - Taurus, Madrid, 1993. 627 pp.

42-706. PAVÓN, ALFREdo (comp.) - Te lo cuento otra vez. (La ficción en México). - Universidad Autónoma de Tlaxcala-Universidad Autónoma de Puebla, Tlaxcala, 1991. \| LMM, 3 (1992), 228-229 (García).

42-707. RiCCETTO, MARía NÉlida (comp.) - Teatro uruguayo contemporáneo. Antología. - Colihue, Buenos Aires, 1993. $235 \mathrm{pp}$.

42-708. Rosa, Jaime B. (ed.) - Sepharad '92: Antología de autores en lengua judeo-española. - BC Artes Gráficas, Valencia, 1992. 149 pp.

\section{ESTUDIOS MISCELÁNEOS}

42-709. Dunham, Lowell - De Oklahoma a Venezuela. Estudios de literatura venezolana. Comp., pról. y notas de D. Miliani. - Intevep, Venezuela, 1992. $623 \mathrm{pp}$.

42-710. García Gual, Garlos - Lecturas y fantasías medievales. - Mondadori, Madrid, 1990. 184 pp. (Bblioteca Mondadori, 9). I| Medievalia, 1992, núm. 11, 34-38 (Rubio Pacho). [Dedicado a la materia artúrica contiene, sin embargo, dos trabajo sobre el Libro de Alexandre].

42-711. HART, STEPHEN M. - The other scene: Psychoanalytic readings in modern Spanish and Latin-American literature. Society of Spanish and Spanish-American Studies, Boulder, 1992. 144 pp.

42-712. Patán, Federico (ed.) - Perfiles. Ensayos sobre literatura mexicana reciente. - Society of Spanish and Spanish American Studies, Boulder, CO, 1992. xi + 169 pp. 


\section{HOMENAJES $Y$ ACTAS DE CONGRESOS}

42-713. ABELLÁN, CONCEPCión, CONCEPCIÓN COMPANY, AURELIO GONZÁLEZ, y LILLIAN VON DER WALDE (eds.) - Heterodoxia y ortodoxia medieval. (Actas de las Segundas Jornadas Medievales). - UNAM, México, 1992. 205 pp. (Pubs. de Medievalia, 2). || Medievalia, 1992, núm. 10, 38-41 (Rivas).

42-714. BELTRÁN, RAFAEL, JOSÉ LUIS CANET, y JOSEP LLUÍS SiERRA (eds.) - Historias y ficciones: Coloquio sobre la literatura del siglo xv. Actas del Coloquio Internacional organizado por el Departament de Filologia Espanyola de la Universitat de València, celebrado en Valencia los días 29, 30 y 31 de octubre de 1990. - Universitat, València, 1992. $363 \mathrm{pp}$.

42-715. Garza Cuarón, Beatriz, e YVETTE JIMÉNEZ DE BÁEZ (eds.) Estudios de folklore y literatura dedicados a Mercedes Díaz Roig. - El Colegio de México, México, 1992. xxxi + 914 pp. (Serie Estudios de lingüistica y literatura, 20).

42-716. GeRLI, E. MichaEL, \& HaRVEY L. SHARRER (eds.) - Hispanic Medieval studies in honor of Samuel G. Armistead. - Hispanic Seminary of Medieval Studies, Madison, 1992. 301 pp.

42-717. GONZÁLEZ DEL VALLE, LUIS T., y Julio BAENA (eds.) - Critical essays on the literatures of Spain and Spanish America. - Society of Spanish and Spanish American Studies, Boulder, CO, 1991. 243 pp.

42-718. GutTART, JOAN (ed.) - Actes dels Symposion "Tirant lo Blanc".-Quaderns Crema, Barcelona, 1993. 636 pp.

42-719. LuCía MEgías, JosÉ MaNuel, PAlOMA García AlONSO y CARMEN Martín Daza (eds.) - Actas del II Congreso Internacional de la Asociación Hispónica de Literatura Medieval. Universidad de Alcalá, Alcalá, 1992. 2 ts., 923 pp. || Medievalia, 1992, núm. 10, 45-48 (González).

42-720. MACKENZIE, ANN L. (ed.) The Eighteenth century in Spain. Essays in honour of I.L. McClelland. - Liverpool University Press, Liverpool, 1991. 246 pp.
42-721. MACKENZIE, ANN L., \& DoROTHY S. SEVERIN (eds.) - Hispanic studies in honour of Geoffrey Ribbans. Liverpool University Press, Liverpool, 1992. vi + 371 pp.

42-722. POOT HERRERA, SARA (ed.) "Y diversa de mi misma/entre vuestras plumas andom. Homenaje Internacional a Sor Juana Inés de la Cruz. Coordinado por Sara Poot Herrera y Elena Urrutia. El Colegio de México, México, 1993.

42-723. REDONDO, AUGUSTIN (ed.) Le corps comme métaphore dans l'Espagne des xvie et xvii siècles. Colloque International (Sorbonne et Collège d'Espagne, 1-4 octobre 1990). - Presses de la Sorbonne Nouvelle, Paris, 1992. 349 pp. (Travaux du "Centre de Recherche sur l'Espagne des xvie et xvii siècles", 7).

V. también núm. 1590.

\section{TEMAS LITERARIOS}

42-724. AlATORRE, ANTONIO - "Andanzas de Venus y Cupido en tiempos del Romancero nuevo". - HMDR, 337-390.

42-725. Alcina, JUAN F. - "Un fragmento de la Visio Philiberti y la tradición hispana del "Diálogo del alma y el cuerpo"". - NRFH, 40 (1992), 513522.

42-726. ANDIOC, RENÉ - "Goya y el temperamento currutáquico". $B H S, 68$ (1991), 67-89.

42-727. BAUDOT, GEORGES - "Malitzin, imagen y discurso de mujer en el México virreinal"' - CuA, 1993, núm. 40, 181-207.

42-728. Carreras, SANDRA - "Del "reino del terror" al "modelo de desarrollo autocentrado". Las diferentes interpretaciones acerca de la figura histórica del Dictador Supremo del Paraguay, Dr. José Gaspar Rodríguez de Francia"'. - Ibero, 1992, núm. 45, 17-35.

42-729. CARTER, ROBIN - "The concept of human liberty in Golden Age Spain: A theoretical definition". $C D, 205$ (1992), 123-148. 
42-730. Chevalier, Maxime "Cuestiones del aseo: Luis Zapata, Lucas García Dantisco, Alfonso Quijano". - Incipit, 1991, núm. 11, 153160.

42-731. COHEN, EsTHER - "La bruja, el diablo y el inquisidor". $-A P$, 1991, núm. 12, 99-119.

42-732. COHEN, ESTHER - "La sexualidad y la Cábala”. - AJMM2, 8392.

42-733. Delmar, Fernando $-E l$ ojo espiritual. Imagen y naturaleza en la Edad Media. - UNAM, México, 1993. 188 pp. (Publs. de Medievalia, 4).

42-734. Delmar, FERNANDO - "El ojo espiritual". - Medievalia, 1991, núm. 8, 7-12.

42-735. DORRA, RAÚl - "Ciudad culpable, fascinante". - Morphé, 1992, núm. 6, 161-170.

42-736. Feal, Carlos - "Don Juan en la picota". - RHM, 46 (1993), 193197.

42-737. Franco, J. - Plotting women: Gender and representation in México (N. 41-842). \| CL, 45 (1993), 92-94 (Larisch).

42-738. Gascón Vera, Elena - Un nuevo mito: la mujer como sujeto/objeto literario. - Pliegos, Madrid, 1992. 286 pp.

42-739. Gilard, JaCQUES - "Ricas mieles y buen café, le café dans la chanson populaire du pourtour caraibe'" Carav, 1993, núm. 61, 27-48.

42-740. GONZÁlez OCHOA, CÉSAR "En torno a una historia de los demonios". - AP, 1991, núm. 12, 83-98.

42-741. GonzÁlez OCHOA, CÉSAR "La naturaleza en el imaginario medieval". - Morphé, 1992, núm. 6, 145-159.

42-742. GRACIA, Paloma - Las señales del destino heroico. - Montesinos, Barcelona, 1991. $236 \mathrm{pp}$. (Héroes y dioses, 4). $\| E H F, 15$ (1993), 239-241 (Cuesta Torre).

42-743. Guicharnaud-ToluIS, MichèLe - "Le café de San Marcos dans la littérature cubaine du XIXème siècle". - Carav, 1993, núm. 61, 137-154.

42-744. HOOK, DAVID - ' 'Un dato más para la historia de la difusión de la leyenda de la destrucción de Jerusalén". - Medievalia, 1993, núm. 13, 24-25.

42-745. Ilie, Paul - "The literary substrate of Goya's owl iconology". - BHS, 68 (1991), 53-66.

42-746. JOLY, MONIQUE - "La flor de la jacarandina". - NRFH, 40 (1992), 461-475.

42-747. Mandrell, JaMes - Don Juan and the point of honor. Seduction, patriar. chal society, and literary tradition. Pennsylvania State University Press, Pennsylvania, 1992. 310 pp.

42-748. MATEO, EduARDO - "'Segunda generación del exilio español en México: la presencia del exilio en su obra". - CuLH, 1992, núm. 16, 79-104.

42-749. MATZAT, WOLFGANG - "Der lateinamerikanische Roman zwischen Geschichtsentwurf und Negation der Geschichte. Zum Thema der «soledad" bei Ernesto Sábato und Gabriel García Márquez'". - I, 1992, núm. 36, 73-94.

42-750. Miaja, María Teresa - "El matrimonio en la literatura medieval española"' - AJMM2, 141-153.

42-751. Montero, JuAN - "De la Diana de Montemayor al Cántico espiritual: especulaciones en la fuente'. - Edad de Oro, 1992, núm. 11, 113-121.

42-752. MORÁBITO, FABIO - "El vampiro". - Morphé, 1992, núm. 7, 35-53. 42-753. MUÑIz, ANGELINA - "La Morada de Dios (Shejuná) en la cábala medieval'. - AJMM2, 93-100.

42-754. OYARZÚN, KeMY - "Literaturas heterogéneas y dialogismo genérico-sexual'". - $R C L L, 1993$, núm. 38, $37-50$.

42-755. Pailler, Claire - "Le café et l'imaginaire costaricien". - Carav, 1993, núm. 61, 93-101.

42-756. Poot Herrera, Sara - " Nonatos literarios. Búsqueda del origen y gestación de la conciencia'”. - HMDR, 907-914.

42-757. READ, M. K. - Visions in exile: The body in Spanish literature and linguistics: 1500-1800 (N. 41-856). \|KRQ 39 (1992), 505-507 (Pérez*Magallón); HR, 60 (1992), 343-345 (Whitaker).

V. también núms. 900,930 . 


\section{GÉNEROS}

42-758. JAMESON, F. - "De la sustitución de importaciones literarias y culturales en el Tercer Mundo: el caso del testimonio". - RCLL, 1992, núm. $36,117-133$.

42-759. FLORES, L. - "Ideología y cultura en la autobiografía chicana". RCLL, 1992, núm. 36, 95-107.

\section{Poesía}

42-760. Barnstone, Willis - Six Masters of the Spanish sonnet. Francisco de Quevedo, Sor Juana Inés de la Cruz, Antonio Machado, Federico García Lorca, Jorge Luis Borges, Miguel Hernández. - Southern Illinois University Press, Carbondale, 1993. $\mathrm{xix}+311 \mathrm{pp}$.

42-761. CANO, JOSÉ LUIS - Historia $y$ poesía. - Anthropos, Barcelona, 1992. 225 pp. (Ámbitos literarios, Ensayo, 44).

42-762. Gicovate, BERNARDO - El soneto en la poesia hispánica. Historia y estructura. - UNAM, México, 1992. $270 \mathrm{pp}$.

42-763. MuÑoz GarRigós, JosÉ "Poesía dialectal y connotación". LEA, 14 (1992), 257-286.

42-764. Villanueva, Darío - "Poesía lírica y realismo intencional". $B G E C, 1993$, núm. 6, 43-52.

V. también núm. 496 .

\section{Edad Media}

42-765. Bailey, MatTHew - The "Poema del Cid" and the "Poema de Fernán González": The transformation of an epic tradition. - The Hispanic Seminary of Medieval Studies, Madison, 1993. 144 pp.

42-766. BREA, MERCEDES - "Anotaciones sobre la función de los miscradores en las cantigas de amor gallego-portuguesas". - CuN, 52 (1992), 167-180.
42-767. Dagenais, JoHN - "Cantigas d'escarnho and serranillas". - BHS, 68 (1991), 247-263.

42-768. Frenk, MARGIT - “Lírica aristocrática y lírica popular en la Edad Media española". - AJMM2, 1-19.

42-769. Gradín, PILAR - La canción de mujer en la lírica medieval. - Universidad de Santiago, Santiago de Compostela, 1990. 282 pp. \| RFilR, 9 (1992), 330-331 (Ortega Román).

42-770. LÓPEZ ESTRADA, FRANCISCO, y María Teresa García Berdoy Poesía castellana de la Edad Media. Taurus, Madrid, 1991. 333 pp. \| CuLH, 1992, núm. 16, 250 (Lagos); Criticón, 1992, núm. 54, 148-149 (Loupias).

42-771. MENÉndez PidAl, Ramón La épica medieval española. Desde sus origenes hasta su disolución en el Romancero. Ed. de Diego Catalán y María del Mar de Bustos. - Espasa-Calpe, Madrid, 1992. (Obras completas de Ramón Menéndez Pidal, 13).

42-772. RICO, F. - Texto y contextos. Estudios sobre la poesía española del siglo $x v$ (N. 41-862). \| HR, 61 (1993). 549-551 (Martínez Torrejón).

42-773. ROSSELL, ANTONI - "Canción de gesta y música. Hipótesis para una interpretación práctica: cantar épica románica hoy". - CuN, 51 (1991), 207-221.

42-774. WEISs, J. - The poet's art, literary' theory in Castile c. 1400-60 (N. 41-866). || HR, 60 (1992), 81-82 (Corfis).

\section{Siglos de Oro}

42-775. DifRanco, RALPH A., y JosÉ J. LABRADOR HERRAIZ - "El manuscrito 23/4/1 de la Biblioteca de don Bartolomé March". - BHi, 94 (1992), 293-325.

42-776. García Galiano, ÁNGel - La imitación poética en el Renacimiento. Reichenberger, Kassel, 1992. 501 pp. 42-777. GONZÁlez, AURELIO - " $\mathrm{Ha}$ cia una caracterización del romancero 
rústico de los Siglos de Oro". - Reflexiones lingüisticas y literarias, $\mathrm{t} .2$, ed. $\mathbf{R}$. Olea, y J. Valender (México, 1992), 87-112.

42-778. GORNALL, JOHN (ed.) - "Ensaladas villanescas" associated with the "Romancero nuevo". - University of Exeter, Exeter, 1991. xxv + 61 pp. \| Criticón, 1992, núm. 54, 149-150 (Cazal).

42-779. GoTOR, JosÉ LUIS - "Las Rimas de casto amor del "Cavallero del Fenix en Roma, 1642"'. - NRFH, 40 (1992), 395-417.

42-780. LARSON, CATHERINE - Language and the Comedia: Theory and Practice. Bucknell University Press, Lewisburg, 1991. 181 pp. \| $B C, 44$ (1992), 271-273 (Oriel).

42-781. LÓPEz BueNo, BEGOÑa - "La implicación género-estrofa en el sistema poético del siglo XVI'". - Edad de Oro, 1992, núm. 11, 99-111.

42-782. Manero Sorolla, María PILAR - "La configuración imaginística de la dama en la lírica española del Renacimiento. La tradición petrarquista'. - BBMP, 68 (1992), 5-71.

42-783. Mas i Usó, Pascual - "La polémica sobre Francisco Jerónimo Simón (1578-1612): Milagros, fiestas, certámenes en su honor y castigos de Dios'. - EM, 1992, núm. 176, 7595.

42-784. Olivares, Julián, y ElizaBETH S. BOYCE (eds.) - Tras el espejo la musa escribe. Lírica femenina de los Siglos de Oro. - Siglo Veintiuno, Madrid, 1993. xii +706 pp.

42-785. Pérez Priego, Miguel Ángel - Cuatro comedias celestinescas. - Universidad, Valencia, 1993. 374 pp. (Textos teatrales hispánicos del siglo xvi, 3).

42-786. RIVERS, ELIAS - "Géneros poéticos en el Siglo de Oro". - NRFH, 40 (1992), 251-264.

42-787. SÁNCHEZ ROBAYNA, ANDRÉS Poetas canarios de los Siglos de Oro. Instituto de Estudios Canarios, La Laguna, 1990. 41 pp. \|BHi, 94 (1992), 362-263 (Arellano).

42-788. TERRY, ARTHUR - SeventeenthCentury Spanish poetry. The power of artifice. - Cambridge University Press, Cambridge, 1993. xv +300 pp.
42-789. TORRES, J. C. - "Una nueva relación poética (del año 1624)". RLit, 54 (1992), 667-708.

V. también núms. 504, 1004, 1488.

\section{Siglo XVIII}

42-790. Sebold, Russell P. - "Periodización y cronología de la poesía setecentista española", - $A L E, 1992$, núm. 8, 175-192.

V. también núm. 1006.

\section{Colonia}

42-791. Meo Zilio, GiovanNi - "Sobre el petrarquismo peruano". $R F E, 72$ (1992), 455-468.

42-792. Tenorio, Martha Lilia "La "Canción famosa": fama y fortuna". - NRFH, 40 (1992), 523-541.

42-793. ZaVALA, IRIS M. - "Metáforas epistemológicas coloniales: «En breve cárcel»". - HMDR, 803-815.

Siglo XIX, España

42-794. RODRÍGUEZ DE LA FLOR, JOSÉ LUIS - Un siglo de poesía satíricoburlesca periodística (1832-1932). - De la Torre, Madrid, 1993. 283 pp.

Hispanoamérica

42-795. PYM, ANTHONY - "Strategies of the frontier in Spanish-American Modernismo"'. - CL, 44 (1992), 161173. 


\section{Siglo $\mathrm{XX}$}

42-796. Alonso, MARÍA NiEVES - "¿Qué cantan los poetas de ahora? (De estética y ética, de realidad y utopía)". Atenea, 1992, núms. 465/466, 241-260. 42-797. ANTELO, RAÚL - "Veredas de enfrente: martinfierrismo, ultraísmo, modernismo". - RevIb, 58 (1992), 853-876.

42-798. ARAújo, Helena - "Poesía femenina: ¿un lenguaje traducible?". - RUAn, 1992, núm. 228, 70-76.

42-799. SALVADOR, Álvaro - "La antipoesía entre el neovanguardismo y la posmodernidad"'. - RevIb, 58 (1992), 611-622.

42-800. SHERIDAN, Guillermo - " "Los Contemporáneos" y la generación del 27'. - CuH, 1993, núms. 514/515, 185-194.

\section{Siglo XX, España}

42-801. Díez de Revenga, Francisco JAVIER - "Los poetas del 27 como críticos literarios". - CuH, 1993, núms. 514/515, 65-79.

42-802. GEIST, ANTHONY - "El 27 y la vanguardia: una aproximación ideológica”. - CuH, 1993, núms. 514/515, 53-64.

42-803. GONZÁlez, ÁNGEI - "La poesía de la generación del 27". - $\mathrm{CuH}$, 1993, núms. 514/515, 39.51.

42-804. HADZELEK, ALEKSANDRA "Imagen de América en la poesía de la generación del 27'. - CuH, 1993, núms. 514/515, 155-183.

42-805. Klengel, Susanne, y Juan JOSÉ LANZ RIVERA - "La poesía experimental en España: historia y reflexión teórica". - Ibero, 1992, núm. 45, 52-70.

42-806. Manteiga, Roberto Carlos - "La voz de la agitación en los poetas del 27". - DLit, 10 (1992-93), núm. 1, 101-117.

42-807. MARICHAL, JUAN - "Una espléndida década (1926-1936)'” -
CuH, 1993, núms. 514/515, 25-37.

42-808. MaYheW, Jonathan - "The twilight of the Avant-garde: Spanish poetry in the 1980s"'. - HR, 60 (1992), 401-411.

42-809. Provencio, Pedro - "El grupo poético de los años cincuenta". CuH, 1993, núm. 512, 55-70.

42-810. Provencio, PEdro - "La generación del 70". - CuH, 1993, núm. 522, 87-102.

V. también núm. 794 .

Hispanoamérica

42-811. Castillo Zapata, Rafael "Palabras recuperadas. La poesía venezolana de los ochenta: rescate y transformación de las palabras de la tribu. El caso "Tráfico"”. - Inti, 1993, núms. 37/38, 197-205.

42-812. FERNÁNDEZ, MIGUEL ÁNGEL, y RENÉE FERRER DE ARRELLAGA (eds.) - Poetisas del Paraguay. - Torremozas, Madrid, 1992. $88 \mathrm{pp}$. \| Carav, 1993, núm. 60, 176-178 (Castro).

42-813. FReidemberg, DANiEL - "Poesía argentina de los años setenta y ochenta"'. - CuH, 1993, núms. 517/518/519, 139-160.

42-814. GONZÁlez, MIKE, \& DAVID TREECE - The gathering of voices: The Twentieth-Century poetry of Latin America. - Verso, New York, 1992. xx + 403 pp.

42-815. Hollis, K. - "Nicaraguan poetry workshops: The democratization of poetry". - SLAPC, 11 (1992), 109122.

42-816. Malpartida, JUAN - "La poesía en Hispanoamérica. (Algunos ejemplos)"'. - CuH, 1993, núm. 513, 73-84.

42-817. OROZCO TORRE, ARTURO Poesía hispanoamericana de principios del siglo xx. - UNAM, México, 1993. $151 \mathrm{pp}$.

42-818. Pellegrino, Carlos - "Apuntes para una lectura de la poesía uruguaya contemporánea"'. - RevIb, 58 (1992), 827-839. 
42-819. PÉrez, A. J. - "Notas sobre las tendencias de la poesía postvanguardista en Hispanoamérica". - H, 75 (1992), 50-59.

42-820. PROAÑO, FrANKLIN - La poesía femenina actual de Sudamérica. - Scripta Humanistica, Potomac, 1993. 420 pp.

V. también núms. 696, 702.

\section{Prosa}

Edad Media

42-821. Avenoza, Gemma, y Manuel RAÍNDO - "Un fragmento de crónica aragonesa. El ms. 245 de la Biblioteca de Catalunya". - $C u N, 53$ (1993), 37-84.

42-822. BLAY, VicentA - "La conciencia genérica en la ficción sentimental. (Planteamiento de una problemática)". - Historias y ficciones: Coloquio sobre la literatura del siglo $x v$, eds. R. Beltrán, J. L. Canet y J. L. Sirera (València, 1992), 205-226.

42-823. Canet VAllés, José LUiS "El proceso del enamoramiento como elemento estructurante de la ficción sentimental'. - Historias y ficciones: Coloquio sobre la literatura del siglo $x v$, eds. R. Beltrán, J. L. Canet y J. L. Sirera (València, 1992), 227-239.

42-824. Deyermond, Alan D. - Tradiciones y puntos de vista en la ficción sentimental. - UNAM, México, 1993. (Pubs. de Medievalia, 5). \| Medievalia, 1993, núm. 13, 26-31 (Von der Walde Moheno).

42-825. MARIMÓN LORCA, GARMEN Prosistas castellanas medievales. - Publicaciones de la Caja de Ahorros Provincial, Alicante, 1990. 172 pp. II $A L M, 30$ (1992), 285-287 (Ontañón de Lope). [Leonor López de Córdoba, Teresa de Cartagena].

42-826. MINerVINI, LAURA - Testi giudeospagnoli medievali. (Castiglia e Aragona). - Liguori Editore, Napoli, 1992. 2 ts.: 530,285 pp. (Romanica napolitana, 27).

42-827. Popeanga, Eugenia - "Mito $y$ realidad en los libros de viajes me- dievales". - Historias y ficciones: Coloquio sobre la literatura del siglo $x v$, eds. $\mathrm{R}$. Beltrán, J. L. Canet y J. L. Sirera (València, 1992), 73-81.

V. también núm. 700 .

\section{Siglos de Oro}

42-828. Borrego Pérez, ManUel "La crítica de una nobleza irresponsable. Un aspecto de los Memoriales del Conde Duque"'. - Criticón, 1992, núm. 56, 87-101.

42-829. Ghevalier, Maxime - "Fórmulas de cuentos tradicionales en textos del Siglo de Oro". - NRFH, 40 (1992), 331-342.

42-830. FERnÁNDEZ InSUELA, ANTONIO - "Sobre la narrativa española en la Edad de Oro y sus reediciones en el siglo XVIII". - RLit, 55 (1993), 55-84. 42-831. López-Baralt, Luce - Un Kãma Sütra español. - Siruela, Madrid, 1992. $511 \mathrm{pp}$.

42-832. REED, HELEN H. - "The pleasure of the picaresque". - DLit, 11 (1993-94), núm. 1, 137-151.

\section{Siglo XVIII}

42-833. Álvarez Barrientos, J. - La novela del siglo xviii (N. 41-940). \|RLit, 54 (1992), 754-757 (Checa Beltrán).

42-834. Goldman, Peter B. - "What's in a word? "Class" and its evolution in the Eighteenth century'. - KRQ 39 (1992), 7-16.

42-835. SÁNChEz BlanCo, Francisco - Historia de la literatura española. La prosa del siglo xviii. Ed. de $\mathrm{R}$. de la Fuente. - Júcar, Madrid, 1992. $297 \mathrm{pp}$.

V. también núm. 830 . 
Colonia

42-836. BASAlisCO, LUCIO - "Culture a confronto: guaranies e yaros visti da un gesuita alla fine del Seicento". QIA, 9 (1992), 709-720.

42-837. BELLINI, GIUSEPPE - " "Il dramma del mondo azteco e $\mathrm{i}$ uDodici Apostolin". - QIA, 9 (1992), 640648.

42-838. BENSO, SILVIA - "Il silenzio e la voce di Atahualpa". - QIA, 9 (1992), 649-660.

42-839. BORRERO GARCÉS, LUIS ENRIQUE - "Aventuras y desventuras del descubrimiento". - BACol, 1992, núms. $176 / 177,65-77$.

42-840. CASTRO, Silvio - "Europa America Americhe: la geometria asimmetrica". - QIA, 9 (1992), 732742.

42-841. JákFalvi-Leiva, SuSANA "De la voz a la escritura: la Relación de Tito Cusi (1570)'”. - RCLL, 1993, núm. 37, 259-277.

42-842. LARSEN, NEIL - "En contra de la des-estetización del "discurso" colonial"'. - RCLL, 1993, núm. 37, 335342.

42-843. MÉndez, MARÍA ÁGuedA "Desvio de la oratoria en la Inquisición novohispana". - Reflexiones lingüisticas y literarias, t. 2, ed. R. Olea, y J. Valender (México, 1992), 153165.

42-844. MORA, CARMEN DE - Las siete ciudades de Cíbola. Textos y testimonios sobre la expedición de Vázquez Coronado. Alfar, Sevilla, 1992. 229 pp. (Alfar Universidad, 46).

42-845. Subirats, Eduardo - "De la polémica humanista en torno a la conquista". - Estudios, 1992, núm. 30, 27-37.

42-846. Terrones, MARÍA Eugenia "Trasgresores coloniales: malentretenidos y mendigos en la Ciudad de México en el siglo XVII"'. - Estudios, 1992, núm. 30, 39-58.

42-847. ZaVAla, IRIS M. - "El discurso canibalístico sobre el Nuevo Mundo"'. - AP, 1991, núm. 12, 5-36.

V. también núm. 555 .
Siglo XIX

42-848. Pozzi, Gabriela - Discurso y lector en la novela del xix (1834-1876). Rodopi, Atlanta-Amsterdam, 1990. 167 pp. || $K R Q, 39$ (1992), 115-116 (Baquero).

42-849. RAmos, Julio - "Cuerpo, lengua, subjetividad". - RCLL, 1993, núm. 38, 225-237.

42-850. RUBIO JIMÉNEZ, JESÚS - "El viaje artístico-literario: una modalidad literaria romántica". - KRQ, 39 (1992), 23-31.

Siglo XIX, España

42-851. BOTREL, JEAN FRANÇOIS "Narrativa y lecturas del pueblo en la España del siglo XIX”. - CuH, 1993, núm. 516, 69-91.

42-852. BRETZ, M. L. - Voices, silences and echoes. A theory of the essay and the critical reception of Naturalism in Spain. Tamesis, London, 1992. 139 pp.

42-853. BROWN, J. L. (ed.) - Women zriters of contemporary Spain. Exiles in the homeland (N. 41-975). \|| HR, 62 (1994), 138-140 (Molinaro); H, 75 (1992), 96 (Nichols).

42-854. Charnon-Deutsch, L. - Gender and representation: Women in Spanish realist fiction (N. 41-956). \| HR, 61 (1993), 106-108 (Bauer).

42-855. EZAMA GIL, Ángeles - "Algunos datos para la historia del término "novela corta» en la literatura española de fin de siglo". - RLit, 55 (1993), 141-148.

42-856. García SÁnchez, Franklin - Tres aproximaciones a la novela histórica romántica española (mimesis y fantasía en la novela histórica romántica). - Dovehouse, Ottawa, 1993. $185 \mathrm{pp}$.

42-857. GullóN, Germán - La novela moderna en España (1885-1902). Los albores de la modernidad. - Taurus, Madrid, 1992. 217 pp. (Persiles, 204). \| RHM, 46 (1993), 207-209 (Valis).

42-858. Olmos Gil, Miguel A. - "El 
prosaísmo de la incredulidad. Reflexiones sobre la poeticidad del cristianismo en los ensayistas ilustrados: 1800-1840'. - CuLH, 1992, núm. $16,57-71$.

12-859. Palenque, Marta - "El romanticismo en Sevilla: El nuevo paraíso (1839)". - BHS, 68 (1991), 455-462.

Hispanoamérica

42-860. BENÍTEZ ROJO, ANTONIO "Nacionalismo y nacionalización en la novela hispanoamericana del siglo XIX". - RCLL, 1993, núm. 38, 185-193.

42-861. BERNECKER, WALTHER L. " "Volksliteratur" und Pamphlete im Mexiko des 19. Jahrhunderts. Zu einer vernachlässigten sozialhistorischen Quellengattung'. - Ibero, 1992, núm. 46, 42-64.

42-862. ORDIZ, JAVIER - “Civilización y barbarie en la narrativa argentina del siglo XIX"'. - EHF, 15 (1993), 143-152.

42-863. SOMMER, DORIS - Foundational fictions: The national romances of Latin America. - University of California Press, Berkeley-Los Angeles-Oxford, 1991. 418 pp. \| Fil, 25 (1990), 241-245 (Kohan); RCLL, 1993, núm. 38, 399403 (Orihuela).

42-864. Williams, R. L. - The Colombian novel 1844-1987 (N. 41-968). $\| H$, 75 (1992), 100-101 (Oberhelman); $H R, 60$ (1992), 511-514 (Tittler).

42-865. ZAYAS DE LILLe, Gabriela "Los sermones políticos de José Mariano Beristáin de Souza". - NRFH, 40 (1992), 719-759.

V. también núm. 555 .

\section{Siglo XX}

42-866. Fernández Cifuentes, Luis - "Fenomenología de la vanguardia: el caso de la novela". - $A L E, 1993$, núm. 9, 45-59.
42-867. Viesca IGLesias, ANA MaRía - "Joaquín A. Bonet, Emilio Robles (Pachín de Melás) y Antonio J. Onieva. Colaboraciones periodísticas: 1931-1936"'. - BIEA, 47 (1993), 197242.

Siglo XX, España

42-868. Bergmann, Emilie L. - "'Letters and diaries as narrative strategies in contemporary Catalan women's writing'". - Critical essays on the literatures of Spain and Spanish America, eds. L. T. González del Valle \& J. Baena (Boulder, 1991), 19-28.

42-869. ESTEBAN, JosÉ - “La narrativa de la generación del 27 '. $-\mathrm{CuH}$, 1993, núms. 514/515, 81-91.

42-870. FERNÁNDEZ, LUIS Miguel El neorrealismo en la narración española de los años cincuenta. - Universidad, Santiago de Compostela, 1992. 299 pp.

42-871. Nichols, Geraldine C. Des/cifrar la diferencia. Narrativa femenina de la España contemporánea. - Siglo Veintiuno de España, Madrid, 1992. $172 \mathrm{pp}$.

42-872. SIESS, JÜRGEN - “Ansätze zum "existentialistischen" Roman in Spanien". - I, 1992, núm. 35, 50-65.

42-873. ThOMAS, GaRETH - The novel of the Spanish Civil War (1936-1975). Cambridge University Press, Cambridge; $1990 . \mathrm{xi}+273$ pp. \|KRQ 39 (1992), 123-125 (Johnson).

V. también núm. 705 .

Hispanoamérica

42-874. Acosta Ruiz, María I. "Historia y escritura femenina en Olga Nolla, Magali García Ramis, Rosario Ferré y Ana Lydia Vega"'. RevIb, 59 (1993), 265-277.

42-875. AINSA, FERNANDO - "Catarsis liberadora y tradición resumida: las nuevas fronteras de la realidad en la 
narrativa uruguaya contemporánea". - RevIb, 58 (1992), 807-825.

42-876. Alonso, C. J. - The Spanish American regional novel. Modernity and autochthony (N. 41-989). \| HR, 60 (1992), 113-115 (Aponte).

42-877. ApARICIO, Frances R. - "Entre la guaracha y el bolero: un ciclo de intertextos musicales en la nueva narrativa puertorriqueña'. - $R e v I b, 59$ (1993), 73-89.

42-878. ARAÚJO, NARA - "La escritura y la crítica feminista en el Caribe: otro espacio de la identidad'. Unión, 1993, núm. 15, 17-23.

42-879. BARRERA LINARES, LUIS "Oficio y marginalidad: tres décadas de narrativa venezolana". - EUSB, 1993, núm. 1, 131-147.

42-880. Bell, Steven M., Albert $\mathrm{H}$. LEMAY, \& LEONARD ORR (eds.) Critical theory, cultural politics, and Latin American narrative. - University of Notre Dame Press, Notre Dame, 1993. xi $+227 \mathrm{pp}$.

42-881. BobEs Naves, Jovita - "Recurrencias temáticas en la novela hispanoamericana (I)'. - ALE, 1992, núm. 8, 9-24.

42-882. Bobes NAVES, JoVITA - "Recurrencias temáticas en la novela hispanoamericana (II)"' - $-A L E, 1993$, núm. 9, 9-19.

42-883. BORELLO, R. A. - El peronismo (1943-1955) en la narrativa argentina $(\mathrm{N}$. 41-995). || HR, 61 (1993), 590-592 (Ianes).

42-884. CoRrEAS DE ZAPATA, C. (ed.) - Short stories by Latin American women: The magic and the real (N. 41-999). $\| H$, 75 (1992), 117 (Meyer).

42-885. DURÁN, GLORIA - "From victim to witch: The evolution of woman's role in Spanish American fiction as a clue to negative social change". - DLit, 10 (1992-93), núm. 2, 85-95.

42-886. GOMES, MIGUEL - "El lenguaje de las destrucciones: Caracas y la novela urbana". - Inti, 1993, núms. 37/38, 217-224.

42-887. GONZÁLEZ, EDUARDO - The monstered self: Narratives of death and performance in Latin American fiction. Duke University Press, Durham-Lon- don, 1992. xix +275 pp. $\| M L N, 107$ (1992), 1064-1067 (Black); HR, 62 (1994), 152-153 (Tittler).

42-888. GonZÁLEZ ECHEVARRÍA, R. Myth and archive: $A$ theory of Latin American narrative (N. 41-1011). \| RevIb, 58 (1992), 275-279 (Fares); HR, 60 (1992), 518-520 (Zamora).

42-889. GUERRA CUNNINGHAM, L. (ed.) - Splintering darkness: Latin American women writers in search of themselves (N. 41-1014). \|H, 75 (1992), 337 (Jehenson).

42-890. Gutiḱrrez-Jones, CarL "Rethinking the borderlands: between literary and legal discourse". - Dispositio, 1991, núm. 41, 45-60.

42-891. IbIETA, Gabriella (ed.) Latin American writers. Thirty stories. St. Marti's Press, New York, 1993. $356 \mathrm{pp}$.

42-892. Jaramillo BuEndía, Gladys, RAÚl PÉREZ TORRES Y SIMÓN ZABALA (eds.) - Índice de la narrativa ecuatoriana. - Editora Nacional, Quito, 1992. || $R C L L, 1993$, núm. 38, 413415 (Orihuela).

42-893. KERR, LUCILLE - Reclaming the author: Figures and fictions from Spanish America. - Duke University Press, Durham-London, 1992. \| RevIb, 59 (1993), 365-368 (Bacarisse).

42-894. LUDMER, JOSEFINA - "El delito: ficciones de exclusión y sueños de justicia”. - RCLL, 1993, núm. 38, 145-153.

42-895. LUKaVSKá, EVA - " ¿Lo real mágico o el realismo maravilloso?". - ERR, 21 (1991), 67-77.

42-896. MARTIN, G. - Journeys through the labyrinth: Latin American fiction in the twentieth century (N. 41-1026). \|HR, 60 (1992), 251-252 (Williams).

42-897. Marting, Diane E. (ed.) Escritoras de Hispanoamérica. - Siglo XXI, Bogotá, 1990. 638 pp. || Carav, 1992, núm. 58, 231-233 (Gilard).

42-898. Mata Gil, Milagros - “El espacio de la nostalgia en la escritura venezolana'. - Inti, 1993, núms. 37/38, 23-28.

42-899. MEnTon, S. - Narrativa mexicana. (Desde "Los de abajo" hasta "Noticias del Imperio") (N. 41-1029). || RevIb, 58 
(1992), $\bullet 283-288$ (Gordon); $H, 75$ (1992), 332 (Oropesa).

42-900. MuÑoz, Willy O. - El personaje femenino en la narrativa de escritoras hispanoamericanas. - Pliegos, Madrid, 1992. 147 pp.

42-901. ReAti, Fernando O. Nombrar lo innombrable. Violencia politica y novela argentina: 1975-1985. - Legasa, Buenos Aires, 1992. 268 pp.

42-902. RIVAS DE WESOlOWSKI, LUZ MARINA - "Ellas también contaron (cuentistas venezolanas 1940-1956)'. - EUSB, 1993, núm. 1, 95-105.

42-903. RIVERA, FrANCISCO - "Sobre narrativa venezolana: 1970-1990". Inti, 1993, núms. 37/38, 89-96.

42-904. Rodríguez CASTRO, MARía ElenA - "Las casas del porvenir: nación y narración en el ensayo puertorriqueño". - RevIb, 59 (1993), 33-54.

42-905. ROTKER, SUSANA - "Crónica y cultura urbana: Caracas, la última década". - Inti, 1993, núms. 37/38, 233-242. [También en EUSB, 1993, núm. 1, 121-130].

42-906. Simpson, Amelia S. - Detective fiction from Latin America. - University Press, Fairleigh Dickinson, 1990. 218 pp. \|KRQ, 39 (1992), 383-384 (Haberly).

42-907. SMOTHERMAN, TERESA - "La filosofía de la liberación en la nueva novela indigenista". - $C u A, 1992$, núm. 35, 145-157.

42-908. STAVANS, ILÁN - "Lust in translation. Notas sobre el boom narrativo hispánico-norteamericano". RHM , 46 (1993), 384-393.

42-909. Steele, Cynthia - Politics, gender, and the Mexican novel, 19681988: Beyond the pyramid. - University of Texas Press, Austin, 1992. xi + $209 \mathrm{pp}$.

42-910. TYLER, JOSEPH - "Represion and violence in selected contemporary Argentine stories". - DLit, 9 (199192), núm. 2, 87-97.

42-911. Verani, Hugo J. - "Narrativa uruguaya contemporánea: periodización y cambio literario"'. - RevIb, 58 (1992), 777-805.

42-912. Villanova, Ángel - "Motivo clásico y novela latinoamericana". -
NRFH, 40 (1992), 1087-1099.

42-913. WEINBERG DE MAGIS, LiLIANA

- "Diálogo sobre España y América'. - NRFH, 40 (1992), 807-821.

V. también núms. $623,698,701,702$, $864,1033$.

\section{Teatro}

42-914. GonzÁlez ECHEVARRÍA, RoBERTO - Celestina's blood: Continuities of the baroque in Spanish and Latin American literature. - Duke University Press, Durham, 1993. xi +281 pp.

42-915. Martínez, JoAQUín J. "Género y congéneres de la comedia sentimental". - AnMal, 14 (1991), 103-128.

42-916. SzMUK, SzILVIA E. et al.-“Bibliography of publications on the comedia (1991-1992)'. - BC, 44 (1992), 291-350.

42-917. VAREY, JOHN - “Los autos sacramentales como celebración regia y popular". - RCEH, 17 (1992-93), núm. 2, 357-371.

42-918. VIVIESCAS, VÍCTOR - "La historia del teatro en Medellín". RUAn, 1992, núm. 228, 84-97.

V. también núm. 513.

\section{Edad Media}

42-919. Álvarez Pellitero, Ana MARÍA (ed.) - Teatro medieval. - Espasa Calpe, Madrid, 1990. (Austral, A157).

42-920. Ferrer Valls, Teresa - “El espectáculo profano en la Edad Media: espacio escénico y escenografía". - Historias y ficciones: Coloquio sobre la literatura del siglo $x v$, eds. R. Beltrán, J. L. Canet y J. L. Sirera (València, 1992), 307-322.

42-921. Labandeira, Amancio "Más referencias sinodales sobre las actividades teatrales y parateatrales de la Edad Media'. - CuLH, 1992, 
núm. 15, 223-232.

42-922. MASSIP, FRANCESC - El teatro medieval. Voz de la divinidad, cuerpo de histrión. - Montesinos, Barcelona, 1991. (Biblioteca de divulgación temática, 52).

42-923. SuRTZ, RONALD E. (ed.) Teatro castellano de la Edad Media. Taurus, Madrid, 1992. 203 pp. (Clás. Taurus, 13). \| CuLH, 1992, núm. 16, 251-253 (González); HR, 62 (1994), 111-112 (Piera).

\section{Siglos de Oro}

42-924. AmezcuA, José - "Espacio semiótico en el teatro del siglo XVII". - PSM, 1993, núm. 1, 173-177.

42-925. BLUE, William R. - "Bibliografía" anotada sobre el teatro del Siglo de Oro (1990)". - Criticón, 1992, núm. 56, 187-196.

42-926. BRIDGES, CHRISTINe M. E. “'Las máscaras del poder". - El escritor y la escena (2), 105-114.

42-927. Buezo, Catalina - "El niño ridículo en el teatro breve, plasmación dramática de una práctica festiva". Criticón, 1992, núm. 56, 161-178.

42-928. CANET VAliés, José LUIS De la comedia humanística al teatro representable. - Universidad, Valencia, 1993. $398 \mathrm{pp}$. (Textos teatrales hispánicos del siglo $x v i, 2)$.

42-929. CÁRREÑO, ANTONIO - "Hacia una poética del final de comedia: de Lope a Calderón'. - El escritor y la escena (2), 175-199.

42-930. CASA, Frank P. - "El tema de la violación sexual en la comedia". El escritor y la escena (1), 203-212.

42-931. Davis, Charles, \& J. E. VAREY - "The taburetes and lunetas of the Madrid corrales de comedias: Origins and evolution'”. - BHS, 68 (1991), 125-138.

42-932. Domínguez Matito, FrancisCO - "Las compañías de comedias en los pueblos de La Rioja en el Siglo de Oro". - El escritor y la escena (1), 213-227.
42-933. REDONDO, AUGUSTIN - "Una curiosa relación castellana de fines del siglo XVI: el auto dramático del Corpus Christi de 1579, en Tordehumos"'. NRFH, 40 (1992), 241-250.

42-934. FALCONIERI, JOHN V. - "Comedia manuscripts in Rome, part II'. - BC, 44 (1992), 243-251.

42-935. Ferrer VAlls, Teresa - Nobleza y espectáculo teatral (1535-1622). Universidad, Valencia, 1993. 392 pp. (Textos teatrales hispánicos del siglo xvi, 1). 42-936. GiménEZ, Clara - "Comedias de magia y santos en la literatura española". - Edad de Oro, 1992, núm. 11, 195-198.

42-937. Granja, Agustín DE LA "Datos dispersos sobre el teatro en Granada entre 1585-1604', - El escritor y la escena (1), 13-28.

42-938. LAUER, A. Robert - “La Conquista de Chile en el teatro español del Siglo de Oro". - El escritor y la escena (2), 95-103.

42-939. LAUER, A. ROBERT - "La tragedia histórica del Siglo de Oro (Vinués, Lope y Calderón)". - Nóesis, 1992, núm. 8, 25-37.

42-940. Miguel Gallo, ignacio JaVIER DE - "El proceso de consolidación del teatro en Burgos (1550-1605): Miguel Giginta y la Casa de Niños de la Doctrina". - BHi, 94 (1992), 45-74.

42.941. ORIEL, CHARLES - Writing and inscription in Golden Age drama. - Purdue University Press, West Lafayette, 1992. $189 \mathrm{pp}$.

42-942. PORTES, Francisco - " Reflexiones sobre el actor". - El escritor $y$ la escena (1), 61-65.

42-943. Reyes Peña, Mercedes DE LOS, y PIEDAD Bolaños DONOSO "Presencia de comediantes españoles en el Patio de las Arcas de Lisboa '(1700-1755)"'. - El escritor y la escena (1), 229-273.

V. también núm. 1594.

Siglo XVIII

42-944. Aguilar Piñal, Francisco - 
" $L a$ noche terrible: una tragedia sentimental". - BHS, 68 (1991), 191-195.

42-945. DEACON, PHILIP - " "The removal of Louis Reynaud as director of the Madrid Theatres in 1776". - BHS, 68 (1991), 163-172.

42-946. Palacios, Emilio - "La comedia sentimental. Dificultades en la determinación teórica de un género dramático en el siglo XVIII' ' - RLit, 55 (1993), 85-112.

42-947. SÁEZ PÉrez, ISIDRo E. - “El teatro andaluz en el siglo XVIII: Granada". - BHi, 94 (1992), 141-167.

42-948. URZAINQUI, INMACULADA "Crítica teatral y secularización: el Memorial literario (1784-1797)'. BHi, 94 (1992), 203-243.

\section{Colonia}

42-949. CoRona, CARMEN - "Elementos cultos y populares en el teatro de evangelización". - El escritor y la escena (1), 69-75.

42-950. Maldonado, Humberto - " $\mathrm{La}$ evolución de la loa en la Nueva España: de González de Eslava a Sor Juana'". - El escritor y la escena (1), 77-94.

\section{Siglo XIX}

42-951. Cabrales Arteaga, José MaNUEL - "Aproximación al teatro poético modernista". - $B B M P, 68$ (1992), 211-238.

42-952. Rubio JimÉneZ, JESÚs - “Ediciones teatrales modernistas puestas en escena'. - RLit, 53 (1991), 103 150 .

Siglo XIX, España

42-953. Gies, DAvid T. - "Glorious invalid: Spanish theater in the Nine- teenth Century'". - HR, 61 (1993), 213-245.

42-954. LARRAZ, E. - Théâtre et politique pendant la guerre d'Indépendance espagnole: 1808-1814 (N. 41-1091). \| BHi, 94 (1992), 366-371 (Laffranque).

42-955. LOPE, HANS-JOACHIM - "La imagen de los franceses en el teatro español de propaganda durante La Guerra de la Independencia (18081813)"'. - BHS, 68 (1991), 219-229.

42-956. Matтauch, Hans - "Zur Situation der dramatischen Parode in Spanien (1830-1850). Ein Beitrag zur Erhellung von gatturgs- durch Theatergeschichte'. - I, 1992, núm. 35, 15-32.

42-957. Schinasi, Michael - "Two documents for the history of the Spanish theatre in the period of the Gobierno intruso". - BHS, 68 (1991), 211-217.

Siglo XX, España

42-958. DOUgherty, Dru, y María FRANCISCA Vilches de Frutos "Carnaval y teatro: de CansinosAsséns a Valle-Inclán, pasando por el teatro comercial'. - $-\mathrm{BHi}, 94$ (1992), $327-340$.

42-959. DOUGHerty, Dru, y María Francisca Vilches de Frutos (eds.) - El teatro en España. Entre la tradición y la vanguardia. 1918-1939. C.S.I.C.-Fundación García LorcaTabapress, Madrid, 1992. 513 pp. \| RLit, 54 (1992), 757-761 (García Ruiz).

42-960. KREIS, KaRL-WILHELM - Zur Ästhetik des Obszönen. Arrabals Theater und die repressive Sexualpolitik des FrancoRegimes. - Krämer, Hamburg, 1992. 490 pp. || Ibero, 1992, núm. 45, 102103 (Franzbach).

42-961. MORAL, CARMEN DEL - "La mitificación de Madrid en el género chico". - ROcc, 1992, núm. 128, 69-82.

42-962. Nieva de la Paz, Pilar "Las escritoras españolas en el teatro infantil de preguerra: Magda Donato, 
Elena Fortún y Concha Méndez'” RLit, 55 (1993), 113-128.

42-963. Oliva, CÉSAR - "El teatro de la generación del 27'. - CuH, 1993, núms. 514/515, 93-101.

42-964. PASQUARIElLo, ANTHONY M. - "The Madrid theater season of 1950: Politics of the premios". - Critical essays on the literatures of Spain and Spanish America, eds. L. T. González del Valle \& J. Baena (Boulder, 1991), 187-195.

42-965. TORRES NebrerA, Gregorio - "Don Quijote en el teatro español del siglo $\mathrm{xx”.} \mathrm{-} \mathrm{CTC,} \mathrm{1992;} \mathrm{núm.} \mathrm{7,}$ 93-140.

V. también núm. 1300.

\section{Hispanoamérica}

42-966. DubatTI, Jorge A. - "El nuevo teatro de Buenos Aires'. - CuH, 1993, núms. 517/518/519, 445-462.

42-967. LEgIDO, JUAN CARLOS "Cincuenta años de teatro en el Uruguay". - RevIb; 58 (1992), 841-851.

42-968. Messinger CyPess, SANDRA -

"Re-visión de la figura de la Malinche en la dramaturgia mexicana contemporánea”. - CuA, 1993, núm. 40, 208-222.

42-969. OBREgon, Osvaldo - "'Le théâtre latino-américain accueilli par la critique française (1958-1977)'. . Carav, 1992, núm. 58, 99-115.

42-970. OSTUNI, OMAR - Por los teatros del interior: crónicas y hechos que revelan historias desconocidas del teatro uruguayo. - Asociación de Teatros del Interior, Montevideo, 1993. $178 \mathrm{pp}$.

42-971. SANDOVAl SÁnchez; Alberto - "La puesta en escena de la familia inmigrante puertorriqueña'”. - RevIb; 59 (1993), 345-359.

42-972. TAYLOR, D. Theatre of crisis: Drama and politics in Latin America (N. 41-1106). || RCLL, 1993, núm. 38, 405-406 (Castro Urioste); $H, 75$ (1992), 339-340 (Morris).

42-973. VÉLEZ, J. F. - Dramaturgos mexicanos según ellos mismos (N. 41-1108).
|| H, 75 (1992), 332-333 (Reckley).

V. también núms. $697,707$.

\section{LITERATURA TRADICIONAL Y POPULAR}

42-974. Alín, José María - "Nuevas supervivencias de la poesía tradicional'. - $H M D R, 403-465$.

42-975. Álvarez Arias, Áurora "Romances de Boo (Aller)". BIEA, 45 (1991), 535-558.

42-976. ANAHORY-LIBROWICZ, ORO "¿Por qué un Romancero sefardí?". - HMDR, 159-170.

42-977. ANASTÁcIO, VANDA - " $A$ Condessa Traidora”. - HMDR, 209-231.

42-978. ARMistead, SAMUEl G. "Los orígenes épicos del Romancero en una perspectiva multicultural". HMDR, 3-15.

42-979. AVAlle-ARce, JuAN Bautista DE - "Sobre un romance noticiero". - NRFH, 40 (1992), 117-130.

42-980. BARRIGA VILLANUEVA, REBECA - "Tintes de subjetividad en las coplas de amor: Cancionero Folklórico de México".. - Carav, 1993, núm. 60, 59-83.

42-981. BELTRÁN, RAFAEL - "La leyenda de la doncella de las manos cor- tadas tradiciones italiana, catalana y castellana"'. - Historias y ficciones: Coloquio sobre la literatura del siglo $x v$, eds. R. Beltrán, J. L. Canet y J. L. Sirera (València, 1992), 25-36.

42-982. BELTRÁN, VICENTE - La canción tradicional de la Edad de Oro. - Planeta, Barcelona, 1990. (Clásicos Uni: versales Planeta; 194):

42-983. BETANCOURT, HELIA, AlesSANDRA BONAMORE, y HENRY COHEN - Cancionero y romancero tradicional de Heredia. - Fundación Educativa San Judas Tadeo, San José (Costa Rica), 1992. ₹ .

42-984. BOTTON-BURLA, FLORA "Las coplas de "La Llorona»". HMDR, 551-572.

42-985. BOURRET, MICHEL — "Quelques remarques sur la nature et les fonctions de l'espace dans le Romancero vie- 
jo"'. - Imprévue, 1993, núm. 1, 77-95.

42-986. BRUNeTto, WALTER - "O

Romanceiro e as cantigas da segada".

- HMDR, 171-208.

42-987. Calderón, HÉCTOR - "Texas border literature: Cultural transformation and historical reflection in the works of Américo Paredes, Rolando Hinojosa and Gloria Anzaldúa'. Dispositio, 1991, núm. 41, 13-27.

42-988. Calderón Calderón, MaNUEL - "La transmisión del romance de Flérida y don Duardos". - Incipit, 1991, núm. 11, 107-125.

42-989. Campra, Rosalba - "El discurso heterogéneo del tango". $H M D R, 707-725$.

42-990. Cándano, Graciela - "Algunos aspectos de la fidelidad e infidelidad femeninas en el romancero viejo"'. - Medievalia, 1992, núm. 10, 1420.

42-991. Cándano Fierro, Graciela - "Búsqueda y encuentro. El disfraz en tres romances". - HMDR, 147158.

42-992. Catalán, Diego - "Hallazgo de una poesía marginada: el Romancero de tradición oral". - $H M D R$, 53-94.

42-993. Catalán, Diego (ed.) - Romancero e historiografía medieval. - Centro de Estudios Ramón Areces, Madrid, 1990.109 pp. \| $A L M, 30$ (1992), 317 (Ontañón de Lope).

42-994. Chicote, Gloria Beatriz "'Oralidad y escritura en el romancero bonaerense". - Incipit, 1992, núm. 12, 181-198.

42-995. Cid, Jesús ANTONIO - “El Romancero oral en Asturias. Materiales de Josefina Sela y E. Martínez Torner: inventario, índices, antología". - RDTP, 48 (1993), 175-245.

42-996. CID, Jesús ANTONIO - "La tradición moderna y la edición del Romancero hispánico. Encuestas promovidas por Ramón Menéndez Pidal en Asturias (1911-1920)"'. - RDTP, 47 (1992), 127-154.

42-997. Costa Fontes, Manuel Da -

" Vida de freira en la tradición oral lusobrasileña". - HMDR, 641-665.

42-998. DEVOTO, DANIEL - "La lengua de las tribus. (De Guéret-Chaminadour a Santa María de los Buenos Aires)"'. - NRFH, 40 (1992), 921958.

42-999. Díaz-Mas, Paloma - "Algo más sobre romances (y canciones) en ensaladas". - NRFH, 41 (1993), 231-250.

42-1000. Espinosa, Aurelio, JR. "Algunas consideraciones sobre los temas de los cuentos tradicionales de Castilla y León'. - RDTP, 48 (1993), 143-162.

42-1001. Freire López, ANa MARÍa Poesía popular durante la guerra de independencia española. - Grant \& Cutler, London, 1993. 203 pp.

42-1002. FrenK, M. (ed.) - Corpus de la antigua lírica popular hispánica (siglos xv a xvii) (N. 41-1134). \| RPh, 45 (199192), 355-361 (Costa Fontes).

42-1003. FRENK, MARgIT - Corpus de la antigua lírica popular hispánica. Suplemento. - Castalia, Madrid, 1992. 69 pp. (Nueva biblioteca de erudición y crítica, 1).

42-1004. FrenK, MARgit - "Diez cancioncitas populares en un manuscrito valenciano del siglo $\mathrm{XVI}$ "'. $-N R F H$, 40 (1992), 187-198.

42-1005. FRENK, MARGIT - "El romance llamado El rapto". - HMDR, 257-270.

42-1006. Fuente Fernández, F. J. "Cuatro pliegos de cordel del siglo XVIII". - RLit, 54 (1992), 709-728.

42-1007. GoNZÁlez, AURELIO - “El oro en el Romancero viejo". - Nóesis, 1992, núm. 8, 11-24.

42-1008. GonzÁlez, Aurelio - "Una lectura heterodoxa del romance de $R o$ saflorida". - AJMM2, 73-81.

42-1009. GONZÁLEZ, AURELIO (coord.) - Bibliografía descriptiva de la poesía tradicional y popular de México. - El Colegio de México, México, 1993. 577 pp.

42-1010. García Collado, Marian "El cuento folklórico y sus adaptaciones. Entre la tradición oral y la fijación escrita. (Tres apropiaciones del cuento Juan el oso, cuento-tipo AT 301b)'". RDTP, 47 (1992), 179-191.

42-1011. Garza Cuarón, Beatriz "Los clichés iniciales en la lírica popular. México y otros países del mundo 
hispánico". - HMDR, 495-537.

42-1012. Garza DE Koniecki, María DEL CARMEN - "Los corridos de maldición". - HMDR, 591-640.

42-1013. GoldBerg, HARRIET - "The Judeo-Spanish proverb and its narrative context". - PMLA, 108 (1993), 106-120.

42-1014. GoNzÁl.ez COBAS, MODESTO - "En "Música y poesía popular de España y Portugal», de Kurt Schindler, se ignora la colaboración de Torner". - BIEA, 47 (1993), 111-127.

42-1015. GutiÉRrez Macías, VALERIANO - "Los motes de la comarca natural de Las Villuercas"'. - RDTP, 48 (1993), 247-252.

42-1016. HAMOS, ANDREA W. - "Romancero y tradición. Los romances bíblicos entre los sefardíes'. - $H R$, 61 (1993), 201-212.

42-1017. HERRERA-SOBEK, MARÍA "Los parricidas: el mito de Edipo y los enfrentamientos padre e hijo en el corrido" - $H M D R$, 573-590.

42-1018. HOUSE WEBBER, RUTH "Observaciones sobre los personajes del Romancero". - HMDR, 17-32.

42-1019. JIMÉNEZ OTTALENGO, REGINA - "Representaciones colectivas en torno a la mujer en expresiones de cultura popular mexicana". - $P S M$, 1993, núm. 1, 61-65.

42-1020. KATZ, ISRAEL J. - "Musical setting of the lament Vida de freira in Sixteenth- and Seventeenth-Century Spanish and Portuguese sources as well as its tunes in the modern Portuguese oral tradition'. - $H M D R, 667$ 705.

42-1021. LizarazU DE MESa, María AsUnción - "Canciones de boda en la provincia de Guadalajara. Su proceso de creación y dinámica de cambio". - RDTP, 47 (1992), 271-302.

42-1022. LÓPEZ DE LOS MOZOS, JOSÉ RAMÓN - "Realidad y ficción literaria del maranchonero: muletero, tratante y rico". - RDTP, 48 (1993), 135141.

42-1023. MARISCAL HAY, BEATRIZ "Creación y tradición en la literatura oral de México". - Reflexiones lingüísiccas y literarias, t. 2, ed. R. Olea, y J.
Valender (México, 1992), 343-354.

42-1024. MARISCAL HAY, BEATRIZ -

"En busca de El caballo robado: hacia una poética de la poesía narrativa tradicional'". - HMDR, 325-336.

42-1025. MÉndez, María Águeda -

"La metamorfosis erótica del Mambrú en el siglo XVII novohispano". HMDR, 391-400.

42-1026. MENDOZA DIAZ-MAROTO, FrANCISCO - "Una cala en el Romancero oral de la emigración hispánica en $\mathrm{Pa}$ rís"'. - HMDR, 95-125.

42-1027. NAVA, FERNANDO, y JUdiTH Orozco - "El Sistema de Cristobal Colón y la Biografía de Colón, una muestra de poesía popular mexicana". CuA, 1993, núm. 42, 203-213.

42-1028. Nava, E. FERnando - "Tonadas y valonas: música de las poesías y los decimales de la Sierra Gorda". - Reflexiones lingüísticas y literarias, t. 2, ed. R. Olea, y J. Valender (México, 1992), 355-378.

42-1029. ORduna, Germán - “¿Cuál es el texto?: del texto literario a la "puesta en canto" (a propósito del $E l$ romance de la Delfina)". - Incipit, 1992, núm. 12, 3-20.

42-1030. Paredes Jáuregui, Nancy TEÓFILA - "Análisis de la tradición oral andina a través del cuento aymara: la Qhachwa". - PSM, 1993, núm. 1, 165-172.

42-1031. Pedrosa, José Manuel "La novia exigente: de unas seguidillas del siglo XVII al ball rodó catalán y canción paralelística sefardî"'. - Criticón, 1992, núm. 56, 41-52.

42-1032. Piñero, Pedro M., y VirtuDES ATERO - "La Bella en misa gaditana: un revuelo erótico-festivo en el templo". - HMDR, 315-323.

42-1033. Piñero Ramírez, Pedro M. - "El Romancero en los poetas del 27". - CuH, 1993, núms. 514/515, 334-338.

42-1034. PRieto LASA, J. RAMón "Significado y tradición de un relato mítico. Los orígenes de la Casa de $\mathrm{Ha}$ ro"'. - RDTP, 47 (1992), 203-216.

42-1035. SALAZAR, FLOR - "La difunta pleitada (IGER 0217). Romance tradicional y pliego suelto". - HMDR, 
271-313.

42-1036. Serrano Osorio, Francisco

- "Manifestaciones de cultura popular en Huejotzingo"'. - PSM, 1993, núm. 1, 57-60.

42-1037. SiRERA, JOSEP LlUís - "Diálogo de Cancionero y teatralidad". Historias y ficciones: Coloquio sobre la literatura del siglo $x v$, eds. R. Beltrán, J. L. Canet y J. L. Sirera (València, 1992), 351-363.

42-1038. Soler, María Ángeles "Vocablos de origen náhuatl en el Cancionero folklórico de México". HMDR, 539-550.

42-1039. SOONS, ALAN - "The romances of the Cancionero de Wolfenbüttel". BHS, 68 (1991), 305-309.

42-1040. Sotomayor, Carmen - "La representación del moro en los romances de la guerra civil". - Imprévue, 1993, núm. 1, 41-54.

42-1041. Stefano, GiUseppe di "Los textos del Romance del rey moro que perdió Alhama en las fuentes del siglo XVI". - HMDR, 41-51.

42-1042. SUÁREZ LÓPEZ, JESÚs - "Una versión asturiana de Lanzarote y el ciervo de pie blanco". - RDTP, 48 (1993), 163-174.

42-1043. Trapero, Maximiano - "Los estribillos romancescos de La Gomera: su naturaleza y funcionalidad". HMDR, 127-145.

42-1044. TRejo, LaURA - “La muerte de don Beltrán: tópico y novedad', - - Medievalia, 1991, núm. 8, 13-26.

42-1045. VAlENCIANO, ANA - "Memoria, innovación y censura colectiva en la tradición oral: épica yugoslava versus Romancero hispánico". HMDR, 33-40.

42-1046. VAQUERO, MERCEDES - “Épica francesa y épica española en el Romançe del conde Dirlos'. - Historias y ficciones: Coloquio sobre la literatura del siglo $x v$, eds. R. Beltrán, J. L. Canet y J. L. Sirera (València, 1992), 93-108.

42-1047. WRIGHT, R. - Spanish ballads (N. 41-1145). \| HR, 62 (1994), 109110 (Blair Kaplan).

V. también núms. 715, 724, 739, 768, $778,829,1135,1620$.

\section{AUTORES (Y OBRAS ANÓNIMAS)} EDAD MEDIA

\author{
Alfonso $X$ el Sabio
}

42-1048. - "Espéculo". Texto jurídico atribuido al Rey de Castilla Don Alfonso X, el Sabio, ed. R. A. MacDonald (N. 411148). \| HR, 60 (1992), 79-81 (Craddock).

42-1049. Alfonso X, El SABIo - Astromagia. A cura di A. D'Agostino. Liguori, Napoli, 1992. 462 pp.

42-1050. Alfonso X, EL SABIO - Las siete partidas. Antología. Sel., pról. y notas de F. López Estrada y M. T. López García-Berdoy. - Castalia, Madrid, 1992. 465 pp. \| CuLH, 1992, núm. 16, 249-250 (Pardo).

42-1051. Alfonso X, EL SABIO - Las Siete Partidas, based on the edition of the Real Academia de la Historia, 1807. Prepared by J. R. Craddock, J. J. Nitti y J. C. Temprano. - The Hispanic Seminary of Medieval Studies, Madison, 1990. microficha.

42-1052. FERNÁNDEZ ORDÓN̄EZ, INÉS - "Las estorias" de Alfonso el Sabio. Istmo, Madrid, 1992. $256 \mathrm{pp}$.

42-1053. FunES, LEONARDO - "Un nuevo avance en el conocimiento de la historiografía alfonsí'. - Incipit, 1992, núm. 12, 209-221.

42-1054. GonZÁlez, CRISTINA - "Salvajismo y barbarie en la Estoria de España". - NRFH, 40 (1992), 63-71.

42-1055. Greenia, George D. - "The politics of poetry: Manuscript illumination and narration in the Cantigas de Santa Maria'". - HR, 61 (1993), 325344.

42-1056. Márquez VillanUeVA, F., y C. A. VeGA (eds.) - Alfonso $X$ of Castile. The Learned King (1221-1248) (N. 41-1152). \| H, 75 (1992), 556 (Darst).

42-1057. MEjía, Alma L. - “El enfrentamiento entre el caballero y el rey: el caso de Bernardo del Carpio en la Primera Crónica General'. - AJMM2, 43-50.

42-1058. MEYER-HERMANN, REINHARD - "Theorie und Empirie der Wort- 
folge im Spanischen (u. a. am Beispiel der Primera Crónica General)". - ZRPh, 107 (1991), 58-103.

42-1059. Paredes NúÑEZ, JUAN - La guerra de Granada en las "Cantigas" de Alfonso $X$ el Sabio. - Universidad, Granada, 1991.

V. también núm. 1089.

\section{Alfonso $X I$}

42-1060. Alfonso XI - Libro de la monteria. Est. y ed. de M. I. Montoya Ramírez. - Universidad, Granada, 1992. 727 pp. || CD, 206 (1993), 693694 (A[lonso] T[urienzo]).

42-1061. Montoya, María Isabel Léxico del "Libro de la montería" de Alfonso $X I$. - Universidad, Granada, 1990. (Colección Filológica, 34).

42-1062. Victorio, JUAN (ed.) Poema de Alfonso Onceno. - Cátedra, Madrid, 1991. (Letras Hispánicas, 291).

\section{Amadis de Gaula}

42-1063. RODRÍGuez DE MONTalvo, GARCI - Amadís de Gaula. Ed. de J. B. Avalle-Arce. - Espasa Calpe, Madrid, 1991. (Austral, A119 y A120).

42-1064. Gracia, Paloma - "Tradición heroica y eremítica en el origen de Esplandián". - RFE, 72 (1992), 133-148.

42-1065. RODRÍGUEz VELAsco, JEsús - "Yo soy de la Gran Bretaña, no sé si la oiste acá dezir (La tradición de Esplandián)'. - RLit, 53 (1991), 49-61.

42-1066. Sales Dasí, Emilio José "Las Sergas de Esplandián: ¿una ficción "ejemplar»?". - Historias y ficciones: Coloquio sobre la literatura del siglo $x v$, eds. R. Beltrán, J. L. Canet y J. L. Sirera (València, 1992), 83-92.
Avisaçión de la dignidad real

42-1067. BIZZARRI, HUGO ÓSCAR "Otro espejo de príncipes: Avisaçión de la dignidad real". - Incipit, 1991, núm. 11, 187-208. [Ms. 1159 de la BNM].

Berceo, Gonzalo de

42-1068. Berceo, Gonzalo de - Obra completa. Coord. de I. Uría. - Espasa-Calpe, Madrid, 1992.

42-1069. BERCEO, GONZALO DE - Vida de Santo Domingo de Silos. Poema de Santa Oria. Ed. de Aldo Ruffinato. - EspasaCalpe, Madrid, 1992. (Austral, A262). 42-1070. Álvarez Álvarez, Manuela - Estudio de la flexión verbal en la obra de Gonzalo de Berceo (siglo xiii). - Instituto de Estudios Riojanos-Universidad de Deusto, Bilbao, 1991. 273 pp. || Medievalia, 1992, núm. 11, 32-34 (Arias Álvarez).

42-1071. BURKARD, RICHARD - "Berceo's source author for the Milagro of the shipwrecked pilgrim: A contrivance based on an unused tale in thott 128?". - RNo, 33 (1992-93), 249-252.

42-1072. CARrasco, FÉLIX - "Un modelo generativo para Milagros de Nuestra Señora, de Berceo". - RCEH, 17 (1992-93), núm. 1, 1-17.

42-1073. GÓMEz SÁNCHEz-ROMATE, MARÍA JosÉ - "Mujeres cotidianas en Berceo". - Medievalia, 1992, núm. 10, 1-13.

42-1074. Grieve, Patricia E. - "The spectacle of memory/Mary in Gonzalo de Berceo's Milagros de Nuestra Señora". - $M L N, 108$ (1993), 214-229.

42-1075. NELsON, D. - Gonzalo de Berceo $y$ el "Aleixandre": vindicación de un estilo (N. 41-1166). || HR, 60 (1992), 470472 (Goldberg).

42-1076. OlivarES ZORRILlA, Rocío - La imagen luminosa en dos obras de Gonzalo de Berceo. - Universidad Autónoma de Chapingo, México, 1991. 122 pp. (Serie Humanidades, 2).

V. también núm. 734 . 


\section{Cancioneros}

42-1077. SEVERIN, DOROTHY SHERMAN (ed.) - El cancionero de Oñate-Castañeda. Introd. de M. García. - Hispanic Seminary of Medieval Studies, Madison; 1990. xxxiv + 433 pp. $\| H R, 60$ (1992), 356-358 (Burrus).

\section{Corral, Pedro del}

42-1078. Álvarez-Hesse, Gloria - La Crónica sarracina. Estudio de los elementos novelescos y caballerescos. - P. Lang, New York, 1992. 192 pp. (Romance Languages and Literatures, 124). \|EHF, 15 (1993), 225-228 (Cuesta Torre); BHi, 94 (192), 353-355 (Jardin).

42-1079. CaCho Blecua, Juan MaNUEL - "Los historiadores de la Crónica sarracina". - Historias y ficciones: Coloquio sobre la literatura del siglo $x v$, eds. R. Beltrán, J. L. Canet y J. L. Sirera (València, 1992), 37-55.

\section{Curial e Güelfa}

42-1080. BUTINYÀ I JiMÉNEZ, JÚLIA "De les fonts del Curial e Güelfa i del posat blasmador del seu autor". RFilR, 9 (1992), 181-189.

Dança de la muerte

42-1081. BASALISCO, LUCIO - "Note sulla danza della morte spagnola". QLLS, 15 (1990), 7-15.

Díaz de Toledo, Pero
Díaz de Toledo y su Diálogo e razonamiento en la muerte del Marqués de Santillana"'. - Historias y ficciones: Coloquio sobre la literatura del siglo $x v$, eds. $\mathbf{R}$. Beltrán, J. L. Canet y J. L. Sirera (València, 1992), 111-120.

\section{Escrivà, Joan}

42-1083. RiQuer, Martín de - "Los escritores mossèn Joan Escrivà y el Comendador Escrivá". - CuN, 53 (1993), 85-113.

\section{Esopete Ystoriado}

42-1084. BURRUS, Victoria A., \& HARRIET GOLDBERG (eds.) - Esopete ystoriado, Toulouse 1488 (John Rylands Library) and Ysopete ystoriado, Zaragoza 1489 (Escorial 32-I-13). The Hispanic Seminary of Medieval Studies, Madison, 1990. microficha.

42-1085. NAVARRo, Carmen - "El incunable dè 1482 y las ediciones del Isopete en España". - QLLS, 15 (1990), 157-164.

\section{Exemplario contra los engaños $y$ peligros del mundo}

42-1086. Haro, Marta - "Repercusión de elementos técnico-narrativos en el didactismo del Exemplario contra los engaños y peligros del mundo". - - Historias y ficciones: Coloquio sobre la literatura del siglo $x v$, eds. R. Beltrán, J. L. Canet y J. L. Sirera (València, 1992), 121-129. 
Flores, Juan de

42-1087. WALDE, LILLIAN VON DER "Amor cortés y cultura oficial en Juan de Flores". - AJMM2, 21-28.

\section{Gonzólez de Clavijo, Ruy}

42-1088. CARROZO RUEDA, SOFIA "Tradiciones tópicas y propósitos de objetividad en la Embajada a 'Tamorlán". - RLitMed, 4 (1992), 79 86.

Gran conquista de ultramar

42-1089. GonzÁlez, CRISTINA - La tercera crónica de Alfonso $X$ : La gran conquista de Ultramar. - Tamesis, London, $1992.165 \mathrm{pp}$.

Imperial, Francisco

42-1090. Bubnova, Tatiana - "Micer Francisco Imperial, el cuerpo desmembrado y la parodia sacra". AJMM2, 57-72.

Juan Manuel

V. núm. 1361.

Lamentación del alma ante la muerte

42-1091. CID, JeSÚs ANTONIO - " $\mathrm{La}$ mentación del alma ante la muerte. Nuevo poema medieval'. - $H M D R, 729-$ 791.
La Vida de San Alifonso por metros

42-1092. WALSH, JOHN K. (ed.) - La Vida de San Alifonso por metros (ca. 1302). - University of California Press, Berkeley-Los Angeles, 1992. xi +210 pp.

Leomarte. Sumas de la historia troyana

42-1093. BLACK, ROBERT G. (ed.) Leomarte. Sumas de la historia troyana. Ms. 9256, Biblioteca Nacional, Madrid. - HSMS, Madison, 1990. microficha.

\section{Libro de Alexandre}

42-1094. ANDRES-SUÁREZ, IRENE "Consideraciones sobre las estrofas 2.538-2.549 del Libro de Alexandre y el término tendal"'. - RFE; 72 (1992), 81-102.

42-1095. Bañeza Román, Celso "Lámek mató a su "guión". Contribución al estudio de la copla 2358 del $\mathrm{Li}$ bro de Alexandre". - RLit, 53 (1991), 153-161.

42-1096. FRAKER, CHARLES F. - The "Libro de Alexandre": Medieval epic and silver Latin. - University of North Caroline, Chapel Hill, 1993. 187 pp.

42-1097. Marcos MARÍn, Francisco - "La fecha del Libro de Alexandre y la confusión de los nombres del número". - Incipit, 1992, núm. 12, 171180.

42-1098. RUBINSTEIN, BECKY, - "E] Poema de Alexandre: matiz de un conflicto: lactancia / limpieza de sangre" . AJMM2, 101-110.

V. también núm. 710 . 


\section{Libro de Apolonio}

42-1099. BRUNO, GIOVANNI - "Tres nuevas enmiendas al Libro de Apolonio". - VR, 52 (1993), 230-236. 42-1100. CORBELla, DOLORES (ed.) Libro de Apolonio. - Cátedra, Madrid, 1992. 305 pp. (Letras Hispánicas, 348).

Libro de los gatos

42-1101. BizzarRi, Hugo Óscar "Nuevas reflexiones sobre el enigmático título Libro de los gatos". RLitMed, 4 (1992), 47-55.

Libro de miseria de omne

42-1102. Rodríguez RIVAS, GREgoRIO - "En torno a autor, lengua original y fecha de composición del Libro de miseria de omne'. - RLitMed, 4 (1992), 187-196.

\section{Libro. del Caballero Zifar}

42-1103. Gracia, PalOMA - "Varios apuntes sobe el "Cuento del caballero atrevido": la tradición del «lago solfáreo" y una propuesta de lectura". CuLH, 1992, núm. 15, 23-44.

42-1104. Lucía Megías, JosÉ MANUEL - "Un folio recuperado del Libro del cavallero Zifar (Sobre el epígrafe de los folios $17 \mathrm{v}$ y $18 \mathrm{r}$ del Ms. 11309 de la Biblioteca Nacional de Madrid)"'. RLitMed, 4 (1992), 163-175.

\section{Libro llamado de Alboraique}

conversos in the Libro llamado de Alboraique". - HR, 60 (1992), 1-17.

\section{Llull, Ramon}

42-1106. BADIA, LOLA, \& ANTHONY BONNER - Ramón Llull: vida, pensamiento y obra literaria. - Sirmio, Barcelona, 1992. $241 \mathrm{pp}$.

42-1107. RAMIS, PEDRO - Lectura del "Liber de Civitate Mundi" de Ramón Llull. - PPU, Barcelona, 1992. 441 pp. \| $C D, 206$ (1993), 257 (Álvarez Turienzo); Anthropos, 1993, núm. 144, 74 (Rivera de Ventosa).

\section{López de Ayala, Pero}

42-1108. López de Ayala, Pero - Coronica de Enrique III. Ed. de C. L. Wilkins y H. M. Wilkins. - The Hispanic Seminary of Medieval Studies, Madison, 1992. xxvi + 134 pp.

42-1109. FERRO, JORGE N. - "La elaboración de la doctrina política en el discurso cronístico del Canciller Ayala". - Incipit, 1991, núm. 11, 23-106.

42-1110. Gingras, Gerald L. - "López de Ayala's Crónica del Rey Don Pedro: The politics of chivalry"'. $R C E H, 16$ (1991-92), núm. 2, 187201.

42-1111. MOURE, JosÉ L. - "Sobre la cuestión de la prioridad de la composición en las dos versiones de las Crónicas del Canciller Ayala (evidencias textuales de un capítulo de la Crónica del dey Don Pedro)". - Incipit, 1992, núm. 12, 21-49.

42-1112. NAYLOR, ERIC W. - "Sobre la traducción de La caída de príncipes de don Pero López de Ayala". - Historias y ficciones: Coloquio sobre la literatura del siglo $x v$, eds. R. Beltrán, J. L. Canet y J. L. Sirera (València, 1992), 141-156. 
López de Córdoba, Leonor

42-1113. AyEBRE-ChaUX, REINALDO - "Leonor López de Córdoba y sus ficciones históricas". - Historias y ficciones: Coloquio sobre la literatura del siglo $x v$, eds. R. Beltrán, J. L. Canet y J. L. Sirera (València, 1992), 17-23.

\section{Manrique, Gómez}

42-1114. CAPRA, DANIEla - "La renovación del diálogo en las Preguntas $y$ Respuestas de Gómez Manrique’'. KRQ, 39 (1992), 185-198.

42-1115. DEYERMOND, AlAN - "Historia sagrada y técnica dramática en la Representación del Nacimiento de Nuestro Señor, de Gómez Manrique". - Historias y ficciones: Coloquio sobre la literatura del siglo $x v$, eds. R. Beltrán, J. L. Canet y J. L. Sirera (València, 1992), 291-305.

\section{Manrique, Jorge}

42-1116. BELTRÁN, ViCENTE - "'Tipología y génesis de los cancioneros: el caso de Jorge Manrique". - Historias y ficciones: Coloquio sobre la literatura del siglo $x v$, eds. R. Beltrán, J. L. Canet y J. L. Sirera (València, 1992), 167 188.

42-1117. López Casanova, ARcadio - "Construcción imaginativa en las Coplas de Jorge Manrique". - Historias y ficciones: Coloquio sobre la literatura del siglo $x v$, eds. R. Beltrán, J. L. Canet y J. L. Sirera (València, 1992), 197-202.

42-1118. Martínez Esteruelas, CRUZ - Cualquier tiempo pasado. Vida y melancolía de Jorge Manrique. - Rialp, Madrid, 1991.
March, Ausiàs

42-1119. MARCh, AuSiàs - Poesías. Ed. de Martín de Riquer, trad. de Jorge de Montemayor. - Planeta, Barcelona, 1990. (Clásicos Universales Planeta, H/181).

42-1120. ARCHER, ROBERT - "Tradition, genre, ethics and politics in Ausiàs March maldit'. - BHS, 68 (1991), 371-382.

42-1121. SOBRER, JOSEP MIQUEL "The architecture of Ausiàs March's "First death song" (Poem 92)". $H R, 60$ (1992), 267-284.

\section{Marin, Pedro}

42-1122. CÁtedra, Pedro (ed.) - Los sermones atribuidos a Pedro Marín. Van añadidas algunas noticias sobre la predicación castellana de S. Vicente Ferrer. Universidad, Salamanca, 1992. 182 pp. (Textos recuperados, 1). \| BHi, 94 (1992), 347-352 (Sánchez).

\section{Martínez de Toledo, Alfonso (Arcipreste de Talavera)}

42-1123. GÓmEZ REDONDO, FERNANDO - "La materia épica en la Atalaya de las crónicas del Arcipreste de Talavera: el caso de Fernán González"'. - Historias y ficciones: Coloquio sobre la literatura del siglo $x v$, eds. R. Beltrán, J. L. Canet y J. L. Sirera (València, 1992), 57-71.

42-1124. MAÑERo Rodicio, SARA "El Arcipreste de Talavera: el público cortesano como elemento configurador". - Historias y ficciones: Coloquio sobre la literatura del siglo $x v$, eds. $\mathrm{R}$. Beltrán, J. L. Canet y J. L. Sirera (València, 1992), 131-140. 
Martorell, Joanot

42-1125. AMEzcuA, JosÉ - "Notas sobre el amor en el Tirante el Blanco". AJMM2, 155-163.

42-1126. ESPADALER, ANTON M. "Una presentación del Tirant lo Blanc". - RFilR, 9 (1992), 161-166.

42-1127. GRILLI, GIUSEPPE - “Tirant: biografia y novela"'. - Medievalia, 1992, núm. 12, 1-11. [Traducción de Aurelio González].

42-1128. Oleza Simón, JOAN - "Tirant lo Blanc y la ansiedad de ficción del caballero Martorell'". - Historias y ficciones: Coloquio sobre la literatura del siglo $x v$, eds. R. Beltrán, J. L. Canet y J. L. Sirera (València, 1992), 323-335.

42-1129. RIQUER, MARTÍN DE - Aproximació al "Tirant lo Blanc". - Quaderns Crema, Barcelona, 1990. 319 pp. (Assaig, 8). \| RFilR, 9 (1992), 315318 (Butiñá Jiménez); BHi, 94 (1992), 358-361 (Heusch).

42-1130. RIQUER, MARTÍN DE - "Tirant lo Blanch", novela de historia y de ficción. - Sirmio, Barcelona, 1992. 267 pp.

42-1131. Rubiera, María Jesús - Tirant contra el Islam. - Ediciones Aitana, Altea, Alicante, 1993. (Série L'Albir, 1).

42-1132. VARgas Llosa, Mario - Carta de batalla por "Tirant lo Blanc". Seix-Barral, Barcelona, 1991. 106 pp. || RFilR, 9 (1992), 333-335 (Pozo Barrón).

V. también núm. 718 .

Mena, Juan de

42-1133. Alvar, Carlos - "A propósito del Tratado de amor, atribuido a Juan de Mena"'. - Historias y ficciones: Coloquio sobre la literatura del siglo $x v$, eds. R. Beltrán, J. L. Canet y J. L. Sirera (València, 1992), 159-165.

42-1134. MuciÑo, José A. - "Una parodia del Laberinto de fortuna de Juan de Mena". - AJMM2, 51-56.
42-1135. Pedrosa, José Manuel "El romancillo de El bonetero, Juan de Mena y la tradición oral”. $-R D T P$, 47 (1992), 155-177.

42-1136. SMITH, Colin - "Mena's Laberinto and the visual arts'. - $B H S$, 68 (1991), 297-303.

V. también núm. 678 .

Montoro, Antón de

42-1137. Montoro, A. DE - Poesía completa, ed. M. Costa (N. 41-1202). \| HR, 61 (1993), 94-95 (Corfis).

Núñez, Nicolás

42-1138. PARrilla, Carmen - “"Acrescentar lo que de suyo está crescidon: el cumplimiento de Nicolás Núñez". Historias y ficciones: Coloquio sobre la literatura del siglo $x v$, eds. R. Beltrán, J. L. Canet y J. L. Sirera (València, 1992), 241-253.

Pérez de Guzmán, Fernán

42-1139. BELTRÁN, ViCENTE - “La transmisión manuscrita de las Generaciones $y$ semblanzas". - RFE, 72 (1992), 57-80.

42-1140. López Casas, Mercè - "La técnica del retrato en las Generaciones y semblanzas de Pérez de Guzmán y las "artes poéticas medievales" ". $-R$ LitMed, 4 (1992), 145-162.

Poema del Cid

42-1141. MONTANER, Alberto (ed.) Cantar de mio Cid. Est. prelim. de F. Rico. - Crítica, Barcelona, 1993. 
$783 \mathrm{pp}$.

42-1142. HARney, MichaeI - Kinship and polity in the "Poema de mio Cid". Purdue University Press, West Lafayette, 1993. $\mathrm{x}+285 \mathrm{pp}$.

42-1143. MONTGOMERY, THOMAS -

"Interaction of factors in tense choice in the Poema del Cid"'. - BHS, 68 (1991), 355-369.

42-1144. MONTGOMERY, THOMAS "The presence of a text: The Poema del Cid". - MLN, 108 (1993), 199-213.

42-1145. MORENO Castillo, ENRIQUe - "El Cantar del Cid como obra poética". - RLit, 53 (1991), 19-48.

V. también núms. $765,1884$.

\section{Poema de Fernán González}

V. núm. 765.

Poridad de poridades / Secretum secretorum o Secreto de secretos

42-1146. PSEUDO-ARISTÓTELES - Secreto de los secretos (Ms. BNM 9428). Ed. de Hugo Ó. Bizzarri. - Secrit, Buenos Aires, 1991. || RLitMed, 4 (1992), 234-236 (Gómez Redondo).

Qüistion entre dos cavalleros

42-1147. WEISS, JULIAN - "La Qïistion entre dos cavalleros: Un nuevo tratado político del siglo $\mathrm{XV}^{\prime \prime}$. - RLitMed, 4 (1992), 9-39.

Razón de amor

42-1148. Armijo, Carmen Elena "Razón de amor: ¿cultura oficial o cultura popular". - $-A J M M 2,29-41$.
42-1149. AzUELA, MARÍA CRISTINA "La ambigüedad en la Razón de amor'. - NRFH, 41 (1993), 201-214.

42-1150. SIMÓ GOBERNA, LOURDES "Razón de amor y la lírica latina medieval'". - RLitMed, 4 (1992), 197-212.

Rodríguez del Padrón, Juan

42-1151. Serḱs, Guillermo - "La elegía de Juan Rodríguez del Padrón". - HR, 62 (1994), 1-22.

\section{Rojas, Fernando de}

42-1152. ROJAS, FERnANDO DE - Celestina. Ed. de P. M. Piñero Ramírez. Espasa-Calpe, Madrid, 1993. (Austral, A282).

42-1153. ROJAS, FERnANDO DE - Comedia o Tragicomedia de Calisto y Melibea. Ed. de P. E. Russell. - Castalia, Madrid, 1991. 634 pp. (Clásicos Castalia, 191). \| CuLH, 1992, núm. 16, 251 (Dumitru); RLitMed, 4 (1992); 236243 (Rodríguez Puértolas).

42-1154. ASKINS, ARTHUR L.-F. y VícTOR INFANTES - "Las 'coplas' celestinescas de ¿tremar?: una historia casi completa de medio pliego". - Cel, 1991, núm. 2, 31-51:

42-1155. BARANDA, Consolación "De Celestinas: problemas metodológicos"'. - Cel, 1992, núm. 2, 3-32.

42-1156. BotTA, PATrizia, e ElisABETTA VACCARO - "Un esemplare annotato della Celestine e la traduzione inglese di Mabbe". - CuN, 52 (1992), 353-419.

42-1157. Castells, Ricardo - "Los refranes y la problemática autoría de la Comedia de Calisto y Melibea". - Cel, 1992, núm. 1, 15-23.

42-1158. FAulHABer, GHarles "The Heredian-Zabalburu copy of the Tragicomedia de Calisto y Melibea, Sevilla, 1502". - Cel, 1992, núm. 1, 2534. 
42-1159. FERNÁNDEz-RIVERA, ENRIQUE J. - " "Huevos asados": nota marginal". - Cel, 1993, núm. 1, 57-60.

42-1160. FradeJas Lebrero, José "'Tres notas a la Celestina". - Cel, 1993, núm. 1, 47-56.

42-1161. Fraker, C. F. - "Celestina": Genre and rhetoric (N. 41-1229). \| BHi, 94 (1992), 355-358 (Garcia); HR, 60 (1992), 82-84 (McGrady).

42-1162. Garcí-Gómez, Miguel "Un tercer autor para la Tragicomedia. La informática al servicio de la literatura". - Cel, 1992, núm. 2, 33-62.

42-1163. GIMBER, ARNO - "Los rufianes de la primera Celestina. Observaciones acerca de una influencia literaria'. - Cel, 1992, núm. 2, 63-76.

42-1164. Gimeno CASAldUERO, JOAQUín - "El mundo de La Celestina". - NRFH, 40 (1992), 99-116.

42-1165. HATHAWAY, ROBERT L. "Concerning Melibea's breasts". Cel, 1993, núm. 1, 17-32.

42-1166. HERMENEGILDO, AlFrEDO "El arte celestinesco y las marcas de teatralidad". - Incipit, 1991, núm. $11,127-151$.

42-1167. JOSET, JACQUES - “Dulcis amaritudo: una isotopía descuidada de La Celestina"'. - Historias y ficciones: Coloquio sobre la literatura del siglo $x v$, eds. R. Beltrán, J. L. Canet y J. L. Sirera (València, 1992), 257-266.

42-1168. JOSET, JACQUES - "Una vez más el falso boezuelo". - Cel, 1992, núm. 2, 77-80.

42-1169. Lacarra, María Eugenia "El fenómeno de la prostitución y sus conexiones con La Celestina". - Historias y ficciones: Coloquio sobre la literatura del siglo $x v$, eds. R. Beltrán, J. L. Canet y J. L. Sirera (València, 1992), 267-278.

42-1170. MACPHERSON, IAN - "Celestina labrandera". - RLitMed, 4 (1992), 177-186.

42-1171. Marney, Michael - "Melibea's mother and Celestina". - Cel, 1993, núm. 1, 33-46.

42-1172. MárQUez Villanueva, FranCISCO - Orígenes y sociología del tema celestinesco. - Anthropos-Ministerio de Asuntos Exteriores, Barcelona-Ma- drid, 1993. 240 pp. (Hispanistas, 2). 42-1173. Martínez CRESPO, Alicia "Llanillas, lanillas: algo más sobre el laboratorio de Celestina". - Cel, 1993, núm. 1, 61-66.

42-1174. PENSADO, José LUIS - “"A Dios paredes"”. - Cel, 1991, núm. 2, 63-66.

42-1175. RANK, JERRY R. - "Marciales's Celestina". - $R P h, 45$ (1991-92), 149-161.

42-1176. Sabat de Rivers, Georgina - "Los problemas de La segunda Celestina". - NRFH, 40 (1992), 493-512.

42-1177. Salus, Garol - “Picasso's version of Celestina and related issues". - Cel, 1991, núm. 2, 3-17.

42-1178. SMITH, R. ROGER - "Recapitulation: A technique of character portrayal in Celestina". - Cel, 1991, núm. 2, 53-62.

42-1179. SNOW, JOSEPH T. - "Una lectura de Celestina-personaje y de la obra de Fernando de Rojas". - Historias y ficciones: Coloquio sobre la literatu$r a$ del siglo $x v$, eds. R. Beltrán, J. L. Canet y J. L. Sirera (València, 1992), 279-287.

42-1180. WHINNOM, KeITH - "The 'argumento' of Celestina', - Cel, 1991, núm. 2, 19-30. [Ed. de A. D. Deyermond].

V. también núm. 914.

Ruiz, Juan

42-1181. RUIz, JUAN - Libro de buen amor. Ed. de A. Blecua. - Cátedra, Madrid, 1992. (Letras Hispánicas, 70). 42-1182. RUIZ, JUAN - Libro de buen amor, ed. J. Joset (N. 41-1237). \| HR, 61 (1993), 275-277 (Michalski).

42-1183. DagenaIs, JOHN - "Mulberries, sloe berries; or, was Doña Endrina a mora?"'. - MLN, 107 (1992), 396-405.

42-1184. Delmar, Fernando - "Locus a tempore". - Reflexiones lingüisticas y literarias, t. 2, ed. R. Olea, y J. Valender (México, 1992), 53-66.

42-1185. Hilty, GEROLD - " Un episo- 
dio enigmático del Libro de buen amor". - VR, 52 (1993), 237-242.

42-1186. JURADO, JOSÉ - "Libro de buen amor, vv. 20a-43f: problemas de crítica textual". - RFE, 72 (1992), 117-131.

42-1187. LÓPEz-BARALT, LUCE - "La bella de Juan Ruiz tenía los ojos de huri'.' - NRFH, 40 (1992), 73-83.

42-1188. LY, NADINE - "Filiation étymologique et édition de texte (à propos du vers $390 \mathrm{a}$ du Libro de buen amor de Juan Ruiz Archiprêtre de Hita)". - BHi, 94 (1992), 673-694.

42-1189. ORDUNA, GERMÁN - "Lectura del Buen amor". - Incipit, 1991, núm. 11, 11-22.

\section{San Pedro, Diego de}

42-1190. AguirRe, J. M. - "Sobre una interpretación de "El mayor bien de quereros» de Diego de San Pedro". - HMDR, 793-801.

V. también núm. 1138 .

\section{Sánchez Calavera, Ferrán}

42-1191. BROOKS, ELAINE S. - "Rhyme, reason, and absence in Ferrán Sánchez Calavera's debate on predestination'. - $R$ No, 33 (1992-93), 161-168.

\section{Santillana, Marqués de}

42-1192. Garcia, Michel - "La ficción poética en la obra del Marqués de Santillana". - Historias y ficciones: Coloquio sobre la literatura del siglo $x v$, eds. R. Beltrán, J. L. Canet y J. L. Sirera (València, 1992), 189-195.

42-1193. GÓMEZ MORENO, ÁNGEL (ed.) - El "Proemio e carta" del Marqués de Santillana y la teoría literaria del s. $x v$. PPU, Barcelona, 1990.

42-1194. GUTIÉRREZ CAROU, JAVIER -
"Métrica y rima en los sonetos del Marqués de Santillana". - RLitMed, 4 (1992), 123-144.

Sendebar. Libro de los engaños $\varepsilon$ los assayamientos de las mugeres

42-1195. FRADEJAS LebreRo, JosÉ (ed.) - Sendebar. Libro de los engaños de la las mujeres. - Castalia, Madrid, 1990. $160 \mathrm{pp}$. (Odres Nuevos).

Siete sabios de Roma

42-1196. TORRE RODRÍGUEZ, VENTURA DE LA - "Filiación de las versiones castellanas del ciclo. Siete sabios de Roma. Variantes del Sendebar occidental". - RFE, 72 (1992), 103-115.

\section{Toledo, Alfonso de (Bachiller)}

42-1197. TOLEDO, AlFonso DE - Invencionario. Ed. de P. O. Gericke. Hispanic Seminary of Medieval Studies, Madison, 1992. xxx $+252 \mathrm{pp}$.

\section{Triste deleytaçión}

42-1198. GómEz FARgas, ROSA M. "Triste deleytacion, ¿novela de clave?". - RLitMed, 4 (1992), 101-122.

42-1199. REcio, ROXANA - "Una cuestión de título: el desfile en el paraíso de la Triste deleytación"'. - Medievalia, 1992, núm. 11, 19-26. 
Valera, Diego de

42-1200. Simó Goberna, Marfa de LOURDES - "Los manuscritos del Tratado de las armas de mosén Diego de Valera"'. - Medievalia, 1992, núm. 12, 23-29.

Valladolid, Alfonso de (Abner, rabí de Burgos)

42-1201. VAlladolid, Alfonso de (?) - Sermones contra los iudios e moros. Ms. 25-H, Biblioteca Pública y Provincial de Soria. Ed. by John Dagenais et al. - HSMS, Madison, 1991. microfilm.

\section{SIGLOS DE ORO}

Acuña, Hernando de

42-1202. MAURer, Christopher " Un monarca, un imperio y una espada: Juan Latino y el soneto de Hernando de Acuña sobre Lepanto". $H R, 61$ (1993), 35-51.

\section{Aguado, Simón}

42-1203. Castro de Moux, María E. - "Tipos de discurso teatral en el Entremés de los negros de Simón Aguado". - BC, 45 (1993), 53-66.

42-1204. POUPENEy Hart, Catherine - “El ogro, la hechicera y el rey. Cuentos e historias en las relaciones de la rebelión de Aguirre". - Nóesis, 1992, núm. 8, 105-119.
Alcázar, Baltasar de

V. núm. 1337.

Alemán, Mateo

42-1205. LAURenti, Joseph L. - "El impacto de Mateo Alemán en Norteamérica: Impresos raros de los siglos XVI y XVII'. - ALM, 30 (1992), 203232.

42-1206. MONTI, Silvia - "Istanze narrative e statuto dell'enunciazione nelle novelle interpolate del Guzmán de Alfarache". - QLLS, 15 (1990), 123141.

42-1207. WhitenaCK, JUdith A. "The alma diferente of Mateo Alemán's "Ozmín y Daraja"". - KRQ 38 (1991), 59-73.

V. también núm. 40.

Arce de Otálora, Juan

42-1208. GÓMEZ, JEsús - "Las formas del relato breve en los Coloquios de Palatino y Pinciano". - RLit, 54 (1992), 75-99.

42-1209. Ocasar Ariza, José LuIs "La tradición manuscrita de los Coloquios de Palatino y Pinciano de Juan de Arce Otálora". - Criticón, 1992, núm. 56, 81-85.

\section{Bances Candamo, Antonio}

42-1210. Bances Candamo, F. - Cómo se curan los celos y Orlando Furioso, ed. I. Arellano (N. 41-1265). \|HR, 61 (1993), 567-568 (Quintero).

42-1211. Bances Candamo, FrancisCO - Sangre, valor y fortuna. Ed. de Santiago García Castañón. - Instituto de Estudios Asturianos, Oviedo, 
1991. 197 pp. || Criticón, 1992, núm. 54, 164-167 (Arellano).

42-1212. García-Castañón, SantiaGO - "La historia como pre-texto: el caso de Por su rey y por su dama, de Bances Candamo". - BIEA, 47 (1993), 145-155.

42-1213. SUÁrEZ, ANA - "Bances Candamo: hacia un teatro ilustrado y polémico". - RLit, 55 (1993), 5-53.

V. también núm. 640 .

Boscán, Juan

42-1214. BOSCÁN, JUAN - Obras. Ed., est. y notas de C. Clavería. - PPU, Barcelona, 1993. Ixxxvii + $597 \| R L i t$, 55 (1993), 285-288 (Fortuno Lloréns).

42-1215. Clavería, Carlos - "Lastanossa no describe". - HR, 62 (1994), 53-57.

42-1216. Colombí-Monguió, Alicia DE - "Boscán frente a Navagero: el nacimiento de la conciencia humanista en la poesía española". - NRFH, 40 (1992), 143-168.

\section{Calderón de la Barca, Pedro}

42-1217. Calderón DE la Barca, PEDRO - "Auto de la Montañesa. Ed. de E. Rull y J. C. de Torres". - RLit, 53 (1991), 181-210.

42-1218. Calderón de la Barca, PEDRO - El mágico prodigioso. Ed. de $\mathbf{M}$. McKendrick y A. A. Parker. - Clarendon, Oxford, 1992. ix + 277 pp.

42-1219. CAlderón DE la Barca, PEDRO - La vida es sueño. Ed. de E. Rull. - Taurus, Madrid, 1992. 259 pp.

42-1220. AltamiRanda, DANIEL - "Una vez más sobre el problema de las dos versiones de $E l$ agua mansa de Pedro Calderón de la Barca". - Incipit, 1992, núm. 12, 223-231.

42-1221. AMadei Pulice, M. A. - Calderón y el Barroco. Exaltación y engaño de los sentidos (N. 41-1272). \| Criticón, 1992, núm. 55, 176-178 (Arellano); H, 57 (1992), 558-559 (Castañeda); HR, 61 (1993), 282-284 (Ter-Horst). 42-1222. AMEzcuA, J. - Lectura ideológica de Calderón. "El médico de su honra" (N. 41-1273). || Criticón, 1992, núm. 54, 171-173 (Déodat-Kessedjian); $B C$, 45 (1993), 149-150 (Fox).

42-1223. ARMAS, FREDERICK DE - "The king's son and the golden dew: Alchemy in Calderón's La vida es sueño". - HR, 60 (1992), 301-319.

42-1224. ARMAS, FREDERICK DE (ed.) The prince in the tower. Perception of "La vida es sueño". - Bucknell University Press, Lewisburg, 1993. 229 pp.

42-1225. BENABU, ISAAC - "Playing Calderón: Tracing as play's receptive frame". - $B C, 45$ (1993), 29-40.

42-1226. BRIDGES, Christine M. E. "El horóscopo y el vaticinio: dos mecanismos teatrales en La vida es sueño y en Eco y Narciso, de Galderón de la Barca"'. - Inti, 1991-92, núms. 34/45, 177-184.

42-1227. Bunes IbarRa, Miguel ÁNGEL - "El Islam en los autos sacramentales de Pedro Calderón de la Barca". - RLit, 53 (1991), 63-83.

42-1228. COLAHAN, ClaAk, y AlFred RODRÍGUEZ - "Una nota adicional acerca de "pues el delito mayor del hombre es haber nacidos"'. $-B C, 45$ (1993), 77-80.

42-1229. CULL, JOHN T. - "Emblematics in Calderón's $E l$ médico de su hon$r a$ '. - BC, 44 (1992), 113-131.

42-1230. FERnÁNDEZ UTRERA, MARÍA SOLEDAD - " "Juegos de lenguaje" en La dama duende". - BC, 45 (1993), 13-28.

42-1231. GREER, R. G. - The play of poweer. Mythological court dramas of Calderón de la Barca (N. 41-1288). \|| HR, 62 (1994), 119-121 (Lecumberri Cilveti); KRQ, 39 (1992), 255-256 (ter-Horst). 42-1232. HESSE, EVERETT W. - "Theme and symbol in Calderón's La hija del aire'. - BC, 44 (1992), 31-43.

42-1233. Hilder, DAvid J. - "Secuencias calderonianas de capa y espada: ¿'sucesos caseros?"'. - BC, 45 (1993), 67-75. 
42-1234. JOHNSTON, ROBERT M. "Asymmetry and the spectator'r experience in Calderón's $E l$ médico de su honra". - BC, 44 (1992), 59-71.

42-1235. KURTZ, Barbara E. - "“Cuestiones de la sacra teología»: cuestiones de la apostasía en los autos de Calderón". - El escritor y la escena (2), 165174.

42-1236. KURTZ, B. E. - The play of allegory in the "Autos sacramentales" of Pedro Calderón de la Barca (N. 41-1296). \| $H R, 61$ (1993), 412-415 (Greer).

42-1237. MORROW, GarOLYN - "Discourse and class in El alcalde de Zalamea'. - BC, 44 (1992), 133-149.

42-1238. Moulines, C. Ulises - “ ¿Es la vida sueño?”. - Diánoia, 38 (1992), 17-33.

42-1239. Niemeyer, Helga - "El alcalde de Zalamea" oder die Kunst der "comedias. Untersuchungen zum Lope de Vegas Theaterstück und vergleichende Betrachtung der Calderónschen "Alcalden-Version. Alano, Aachen, 1991. 266 pp. \|RJ, 43 (1992), 352-356 (Wogatzke-Luckow).

42-1240. Pollin, Alice M. - “Judaísmo y Sinagoga en Calderón: recreación de un tema alegórico medieval". - RLit, 54 (1992), 149-181.

42-1241. Ruano de la Haza, J. M. (ed.) - La primera versión de 'La vida es sueño", de Calderón. - Liverpool University Press, Liverpool, 1992. 354 pp. \| RLit, 54 (1992), 745-747 (De Torres).

42-1242. SERrano Deza, Ricardo -

"Estrategias para un análisis infoasistido de la "lógica del texto" en un corpus calderoniano". - El escritor y la escena (1), 189-202.

42-1243. SOONS, ALAN - "La voz afecto $y$ sus congéneres en la comedia. Lección de tres obras de Calderón sacadas de Diferentes XLII'. - NRFH, 40 (1992), 451-460.

42-1244. SOULlER, DIDIER - Caldetón de la Barca et le gran théâtre du monde. P.U.F., Paris, 1992. 392 pp.

42-1245. STrother, DARci L. - "Loving parents or cruel jailers? Towards an understanding of Calderón's Basilio and Liríope". - BC, 45 (1993), 81-92.
V. también núms. 929, 939, 1482.

Camōes, Luis de

42-1246. Ovtcharenko, Olga - "A mulher na obra camoniana". - Co, 1992, núms. 125/126, 9-13.

V. también núm. 673 .

Caro, Rodrigo

42-1247. Williamsen, Amy R. - "Rewriting in the margins: Caro's Valor, agravio $y$ mujer as challenge to dominat discourse". - BC, 44 (1992), 21-30.

Carrillo y Sotomayor, Luis de

42-1248. CARRILlO y SOTOMAYOR, L. - Obras, ed. R. Navarro Durán (N. 41-1300). \| HR, 62 (1994), 117-119 (Porqueras Mayo).

Castro y Bellvis, Guillén de

42-1249. RATClIFF, MARJORIE - "Powerless or empowered? Women in Guillén de Castro's Las mocedades del Cid and Las hazañas del Cid'. - BC, 44 (1992), 261-267.

\section{Cervantes Saavedra, Miguel de}

42-1250. Cervantes, Miguel de - Los baños de Argel. Pedro de Urdemalas. Ed. de J. Canavaggio. - Taurus, Madrid, 1992. 378 pp. (Clás. Taurus, 17).

42-1251. AlADRO, JORGE - " Entre Roque Guinart y Don Quijote, o el des- 
doblamiento de Cervantes"'. - ACerv, 30 (1992), 129-137.

42-1252. Alvar, Carlos (dir.) - Miguel de Cervantes: entremeses. - Centro de Estudios Cervantinos, Alcalá de Henares, 1992. 141 pp.

42-1253. ÁlVAREZ MARTínEz, JosÉ LUIS - "Berganza y la moza ventanera". - Cervantes, 1992, núm. 2, 63-77.

42-1254. Arata, Stefano - "La conquista de Jerusalén, Cervantes y la generación de 1580"' - Criticón, 1992, núm. 54, 9-112.

42-1255. Baras Escolá, Alfredo "Una lectura erótica del Quijote". Cervantes, 1992, núm. 2, 79-89.

42-1256. BROOKES, KRISTEN G. "Readers, authors, and characters in Don Quijote". - Cervantes, 1992, núm. 1, 73-92.

42-1257. Canavaggio, Jean - "Madrigal, bufín in partibus'. - CTC, 1992, núm. 7, 47-53.

42-1258. CaStañón, ADOLFO - "Don Quijote y la máquina encantadora". NRFH, 40 (1992), 323-330.

42-1259. Close, A. J. - Cervantes: 'Don Quixote"(N. 41-1346). \| H, 75 (1992), 91 (Urbina).

42-1260. ConTAG, KIMBERLY - "The backbone of burlesque: Vertebral jokes and hoaxes in Cervantes's Don Quijote". - Critical essays on the literatures of Spain and Spanish America, eds. L. T. González del Valle \& J. Baena (Boulder, 1991), 65-74.

42-1261. CREEL, BRYANT L. - "Theoretical implications in Don Quixote's idea of enchantment". - Cervantes, 1992, núm. 1, 19-44.

42-1262. CRUz CASADO, ANTONIO "Una recuperación: Las semanas del jardin de Miguel de Cervantes'. ACerv, 30 (1992), 163-173.

42-1263. CulL, J. T. - "Death as the great equalizer in emblems and in Don Quixote". - H, 75 (1992), 10-19.

42-1264. DÍAZ FERnÁNDEZ, JOSÉ IGNACIO, y LUISA FERNANDA AGUIRRE DE CÁNCER - "Contexto histórico y tratamiento literario de la hechicería morisca y judía en el Persiles". - Cervantes, 1992, núm. 2, 33-62.

42-1265. DunN, Peter N. - "Don Qui- jote through the looking glass'" Cervantes, 1992, núm. 1, 5-17.

42-1266. Eisenberg, Daniel - Cervantes y "Don Quijote". - Montesinos, Barcelona, 1993. 124 pp.

42-1267. EsQUVAL-HEINEMANN, BÁRBARA P. - "Some forgotten Don Quijotes'. - Cervantes, 1992, núm. 1, 45-57.

42-1268. FALlOWS, NOEL - " "Nobility of soul»: A rhetorical commonplace in Cervantes' La ilustre fregona'. $-R N o$, 33 (1992-93), 305-312.

42-1269. FELKEL, ROBERT W. - “El trastorno de la caballería en Don Quijote: el héroe cervantino a la luz de los tratados de caballería catalanes". ACerv, 30 (1992), 99-127.

42-1270. FERNÁNDEZ DE CANO Y MARTÍN, JOSÉ RAMÓN - "El vocabulario erótico cervantino: algunas "calas al aire» en el entremes de El viejo celoso". - Cervantes, 1992, núm. 2, 105-115.

42-1271. FERNÁNDEZ MORERA, DARIO - "Chivalry, symbolism, and psychology in Cervantes' Knigth of the green cloak'. - $H R, 61$ (1993), 531546.

42-1272. GonZÁlez, Aurelio - "Doble espacio teatral en El gallardo español de Cervantes"'. - El escritor y la escena (1), 95-103.

42-1273. GonzÁlez RodAs, Publio "América en la obra de Cervantes". - RUAn, 1992, núm. 229, 89-95.

42-1274. GORFKLE, LAURA - "The seduction(s) of fiction and the gendered reader in/of Don Quixote: Dorotea's tale". - RCEH, 17 (1992-93), núm. 2, 281295.

42-1275. GRAHAM-JONES, JEAN — " "Tuya soy": The economics of marriage in Cervantes's Entremés del rufián viudo llamado Trampagos". - BC, 44 (1992), 151-161.

42-1276. HART, Thomas R. - " ¿Cervantes perspectivista?". - NRFH, 40 (1992), 293-303.

42-1277. HASBROUCK, MiCHAEL - "Posesión demoníaca, locura y exorcismo en el Quijote". - Cervantes, 1992, núm. 2, 117-126.

42-1278. Huerta Galvo, Javier "Figuras de la locura en los entremeses cervantinos". - CTC, 1992, 
núm. 7, 55-68.

42-1279. Hutchinson, Steven - Cervantine journeys. - University of Wisconsin Press, Madison, 1992. xv + $271 \mathrm{pp}$.

42-1280. HUTCHINSON, STEVEN - "Las brujas de Cervantes y la noción de comunidad femenina". - Cervantes, 1992, núm. 2, 127-136.

42-1281. Illades, Gustavo - "Tres miradas a la Novela del curioso impertinente'. - Medievalia, 1992, núm. 12, 12-22.

42-1282. InAMOTO, KenjI - "La mujer vestida de hombre en el teatro de Cervantes'. - Cervantes, 1992, núm. 2, 137-143.

42-1283. JEHENSON, MYRIAM YVONNE - "The Dorotea-Fernando/Luscinda-Cardenio episode in Don Quijote: A Postmodernist play". - $M L N, 107$ (1992), 205-219.

42-1284. Johnson, C. B. - "Don Quixote"': The quest for modern fiction (N. 411383). \| Cervantes, 1992, núm. 1, 124125 (Farness).

42-1285. JOLY, MONIQUE - " Erotismo y marginación social en la novela cerrantina". - Cervantes, 1992, núm. 2, $7-19$.

42-1286. King, Willard F. - "Cervantes, el cautiverio y los renegados". - NRFH, 40 (1992), 279-291.

42-1287. LABARRE, ROLAND - "Tres entiparadojas sobre Cervantes"'. Criticón, 1992, núm. 54, .

42-1288. LASkier Martín, A. - Cervantes and the burlesque sonnet (N. 411389). \| $M L N, 107$ (1992), 410-412 (Sieber).

42-1289. Lewis-Smith, Paul - "Cervantes, on human absurdity: The unifying theme of La casa de los celos $y$ selvas de Ardenia". - Cervantes, 1992, núm. 1, 93-103.

42-1290. Lo RÉ, A. G. - Essays on the periphery of "Quijote" (N. 41-1392). II $H, 75$ (1992), 320 (Friedman); Cervantes, 1992, núm. 1, 126-127 (Sánchez).

42-1291. López Estrada, Francisco - "Vista a oriente: la española en Constantinopla'. - CTC, 1992, núm. 7, 31-46.
42-1292. Maravall, J. A. - Utopía y contrautopía en el "Quijote" (N. 261530). \| Cervantes, 1992, núm. 1, 127 129 (Baena). - V. 39-9160.

42-1293. MARTín MORÁN, José MANUEL - "Don Quijote está sanchificado; el des-sanchificador que lo requijotice...". - BHi, 94 (1992), 75118.

42-1294. Martín Morán, José MANUEL - "La función del narrador múltiple en el Quijote". - ACerv, 30 (1992), 9-65.

42-1295. Martínez García, FrancisCO - "Oralidad y lectura en el Quijote'. - EHF, 15 (1993), 101-115.

42-1296. MEREGALLI, F. - Introduzione a Cervantes (N. 41-1399). \| HR, 61 (1993), 279-281 (Damiani).

42-1297. Molho, Mauricio - " "El sagaz perturbador del género humano": brujas, perros embrujados y otras demonomanías cervantinas". Cervantes, 1992, núm. 2, 21-32.

42-1298. MONTERROSO REGUERA, JOSÉ - "El cervantismo del curso 19901991'. - Edad de Oro, 1992, núm. 11, 199-205.

42-1299. Munguía García, Víctor EDUARDO - "El Licenciado Vidriera y Don Quijote'. - ACero, 30 (1992), 157-162.

42-1300. Muñoz Carabantes, Manuel - "El teatro de Cervantes en la escena española entre 1939 y 1991'. CTC, 1992, núm. 7, 141-195.

42-1301. Nerlich, M., \& N. SPADACCINI (eds.) - Cervantes' "Exemplary novels" and the adventure of writing (N. 411403). \| $H R, 61$ (1993), 97-99 (Avalle Arce).

42-1302. O'NeIL, MARY ANNe “'Cervantes' prose epic'. - Cervantes, 1992, núm. 1, 59-72.

42-1303. Penas, Ermitas - "Discurso cervantino y novela histórica romántica". - ACerv, 30 (1992), 139-156.

42-1304. QUÉrillacQ, RENÉ - “Los moriscos en Cervantes". - ACerv, 30 (1992), 77-98.

42-1305. REED, CORY A. - "Dirty dancing: Salome, Herodias and $E l$ retablo de las maravillas". - $B C, 44$ (1992), 7-20. 
42-1306. REED, CORY A. - The novelist as playwright. Cervantes and the "entremés nuevo". - P. Lang, New York, 1993. $212 \mathrm{pp}$.

42-1307. RODRÍGUez, AlFRED, \& CAROL USNER - "Las bodas de Camacho: folklore y literatura'. $-R N o, 33$ (1992-93), 253-256.

42-1308. RODRÍGUEZ, ALFRED, y DEANNA CORNEJO-PATTERSON - "Apunte sobre Don. Quijote como narrador". - ACerv, 30 (1992), 191-197.

42-1309. SÁnchez, Alberto - "Aproximación al teatro de Cervantes"'. $C T C, 1992$, núm. 7, 11-30.

42-1310. SÁNchez, AlbERTo - "Dos notas para el Quijote". - ACerv, 30 (1992), 177-182.

42-1311. SCHLEINER, WINFRIED - "The glass graduate and the aphrodisiac that went wrong: New light from old texts"'. - FORUM, 27 (1991), 370381.

42-1312. Schuessler, Michael KARL - "The textualization of tradition: $E l$ vizcaino fingido and the developmentof the Entremés as a literary genre"'. $B C, 44$ (1992), 231-241.

42-1313. SPADACCINI, NICHOLAS, \& JENARO TALENS - Cervantes and the Self-Made world. - University of Minnesota Press, Minneapolis, 1993. xvi $+210 \mathrm{pp}$.

42-1314. TACCA, ÓscAR - "La complejidad narrativa del Quijote". $B A A L, 55$ (1990), 187-209.

42-1315. Uslar Pietri, Arturo "El reino de Cervantes". - ROcc, 1992, núm. 139, 149-163.

42-1316. WEBER, ALISON - "Pentimento: The parodic text of $L a$ Gitanilla". - HR, 62 (1994), 59-75.

42-1317. WeIGER, JOHN G. - "Prejudice in Barataria: The judgments of governor Sancho Panza". - RNo, 33 (199293), 81-87.

42-1318. WILlIAMSON, EDWIN - "El Quijote" y los libros de caballerías. Taurus, Madrid, 1991. 298 pp.

42-1319. ZaVALA, IRIS M: - "El Quijote, la uescritura desatadai y la crítica del logocentrismo"'. - NRFH, 40 (1992), 305-322.

42-1320. ZIMIC, STANISLAV - "La Gi- tanilla de Cervantes". - BBMP, 68 (1992), 29-142.

42-1321. Zimic, Stanislav - "Sobre los amores de Leandra y Vicente de la Roca (Don Quijote I, caps. 50-52)'. ACerv, 30 (1992), 67-76.

V. también núms. $645,684,965,1428$, $1443,1777,2200$.

Claramonte, Andrés de

42-1322. ARMAS, FREDERICK A. DE "Fashioning a new world: Lope de Vega and Claramonte's El nuevo rey Gallinato". - Critical essays on the literatures of Spain and Spanish America, eds. L. T. González del Valle \& J. Baena (Boulder, 1991), 1-10.

Comedia a lo pastoril para la noche de Navidad

42-1323. RODRÍGUEZ RODRÍGUEZ, JOSÉ JAVIER - "La función del componente lírico en la Comedia a lo pastoril para la noche de Navidad (1550-1575)"'. - CuLH, 1992, núm. 15, 113-127. [Ms. 16.058 BNM].

\section{Covarrubias [H]orozco, Sebastián de}

42-1324. MORREALE, MARGaRITA "Los Emblemas de Alciato en el Tesoro de la lengua castellana de Sabastián de Covarrubias". - NRFH, 40 (1992), 343-381.

Cueva, Beltrán de la

42-1325. LAURENTI, JOSEPH L. - “ una rara traduzione del Mayorazgo di Beltrán de la Cueva (1440-1492)'. QIA, 1993, núm. 73, 117-121. 


\section{Delicado, Francisco}

42-1326. IMPERIALE, LUIGI - " "Una realidad disfrazada en La Lozana andalu$z a$ '. - RFE, 72 (1992), 159-166.

42-1327. SURTZ, Ronald E. - "Texto e imagen en el Retrato de la Lozana andaluza". - NRFH, 40 (1992), 169-185.

Diálogo de las transformaciones de Pitágoras

42-1328. ViAn Herrero, ANA - "Una obra maestra del diálogo lucianesco renacentista: el anónimo Diálogo de las transformaciones de Pitágoras'. - $\mathrm{BHi}$, 94 (1992), 5-36.

\section{Encina, Juan del}

42-1329. Encina, JUAn DEL - Poesía lirica y cancionero musical. Ed., introd. y notas de $R$. O. Jones y Carolyn $R$. Lee. - Castalia, Madrid, 1990. 381 pp. (Clásicos Castalia, 62).

42-1330. PÉrez Priego, Miguel ÁNGel - "Historia y literatura en torno al príncipe D. Juan. La Representación sobre el poder del amor de Juan del Enci= na'. - Historias y ficciones: Coloquio sobre la literatura del siglo $x v$, eds. R. Beltrán, J. L. Canet y J. L. Sirera (València, 1992), 337-349.

\section{Enríquez Gómez, Antonio}

42-1331. EnRíQUeZ, ANTONIO - El siglo pitagórico y la vida de don Gregorio Guadaña. Ed. de Teresa de Santos. Cátedra, Madrid, 1991. 401 pp. || Criticón, 1992, núm. 54, 155-158 (Arellano).

42-1332. KRAMER-HellinX, Nechama - Antonio Enríquez Gómez. Literatura y sociedad en "El siglo pitagórico y Vida de don Gregorio Guadaña". - P. Lang, New York, 1992. 359 pp.

Espejo de buen biuir

42-1333. Baraja Salas, Eduardo "La primera edición del Espejo de bien biuir. Sevilla 1534 (rareza bibliográfica)". - CD, 205 (1992), 179-182. [Más facsímil en apéndice].

\section{Espinel, Vicente}

42-1334. HugheS, GeTHIN - "Marcos de Obregón: A life worth telling and the narrative frame". - $R C E H, 17$ (1992-93), núm. 1, 63-77.

\section{Estebanillo González}

42-1335. Campbell, Ysla - "Disidencia y conformismo en el Estebanillo González'. - Nóesis, 1992, núm. 8, 77-103.

Fernández de Avellaneda, Alonso

42-1336. AYLWARD, E. T. - Towards a revaluation of Avellaneda's "Quijote" (N. 41-1435). \| HR, 61 (1993), 407-408 (McGaha).

\section{Fernández de Ribera, Rodrigo}

42-1337. NúÑEZ DE Rivera, J. VALENTíN - "Rodrigo Fernández de Ribera epigramático y Baltasar de Alcázar: problemas de atribución. Descripción y estudio del manuscrito 17524 de la 
Biblioteca Nacional". - Criticón, 1992, núm. 55, 53-89.

42-1338. NÚÑEZ DE RIVERA, J. VALEN. TíN - "Rodrigo Fernández de Ribera, traductor de Marcial. Edición de la Centuria de epigramas". - RLit, 55 (1993), 169-225.

\section{Fernández, Sebastián}

42-1339. VÉlEz QUiÑoneS, HARRY "Celestina "a lo divino": el caso de la Tragedia Policiana". - Cel, 1993, núm. 1, 3-16.

V. también núm. 1448 .

\section{Garcilaso de la Vega}

42-1340. Gargano, A. - Fonti, miti, topoi: cinque saggi su Garcilaso (N. 411439). || Incipit, 1992, núm. 12, 286290 (Ciapparelli).

V. también núms. 657,670 .

\section{Godinez, Felipe}

42-1341. Godínez, FELIPE - Aún de noche alumbra el sol. Los trabajos de Job. Ed. de P. Bolaños Donoso y Pedro M. Piñero Ramírez. - ReichenbergerUniversidad de Sevilla, Kassel-Sevilla, 1991. 243 pp. \| Criticón, 1992, núm. 54, 169-171 (González).

Gómez de la Reguera, Francisco

42-1342. GómEz de la Reguera, FranCISCO - Empresas de los reyes de Castilla $y$ de León. Ed. y est. de C. Hernández Alonso. - Secretariado de Publicaciones de la Universidad, Valladolid, 1990. 284 pp. \|| $A L M, 30$ (1992), 320-
321 (Ontañón de Lope).

\section{Gómez García}

42-1343. MartíN, MELQUiAdES ANDRÉS - "Estrenuidad, severidad y benignidad, armas del caballero español, en Carro de dos vidas (1500)'". - CuLH, 1991, núm. 14, 141-153.

\section{Góngora, Luis de}

42-1344. Góngora, LuIS DE - Poesía selecta. Ed. de A. Pérez Lasheras y J. M. Micó. - Taurus, Madrid, 1991. 341 pp. (Clás. Taurus, 5). \|HR, 61 (1993), 99-100 (Rivers).

42-1345. Burton, Grace M. - "Narration and knowledge in the Soledades: The Peregrino revisited'. $-R N o, 33$ (1992-93), 3-11.

42-1346. CARREIRA, ANTONIO - "Los poemas de Góngora y sus circunstancias: seis manuscritos recuperados". - Criticón, 1992, núm. 56, 7-20.

42-1347. Colins, Marsha S. - "Antiquity and modernity in Góngora's $E l$ doctor Carlino". - RCEH, 17 (199293), núm. 1, 19-29.

42-1348. DOLAN, K. H. - Cyclopean song: Melancholy and aestheticism in Góngora's "Fábula de Polifemo y Galatea" (N. 411448). \| H, 75 (1992), 92 (McVay, Jr.).

42-1349. GAYLORD, MARY M. - "Góngora and the footprints of the voice". - $M L N, 108$ (1993), 230-253.

42-1350. Matas Caballero, Juan "La presencia de los poetas españoles en la polémica en torno a las Soledades"'. - Criticón, 1992, núm. 55, 131140.

42-1351. O'CONNOR, THOMAS AUSTIN - "Sobre el bozo de Acis: una apostilla a los versos 279-80 del Polifemo de Góngora'. - BBMP, 68 (1992), 143148.

42-1352. QUINTERO, MARÍA CRISTINA 
- Poetry as play: "Gongorismo" and the "comedia". - J. Benjamins, Amsterdam, 1991. xviii +260 pp. $\| B C, 44$ (1992), 279-281 (Collins).

42-1353. ROSES, JOAQUín - "La Apología en favor de don Luis de Góngora de Francisco Martínez de Portichuelo. (Selección anotada e introducción)". - Criticón, 1992, núm. 55, 91-130.

42-1354. Terracini, LORE - "Tres lectores para un soneto". - NRFH, 40 (1992), 265-277.

42-1355. WOOD Riveka, Alma - "Observaciones sobre el estrato fónico en un soneto de Góngora'. - $H M D R$, 817-828.

V. también núms. $640,673$.

Gracián, Baltasar

42-1356. Blanco, Mercedes - Les rhétoriques de la pointe. Baltasar Gracián et le conceptisme en Europe. - Champion, Paris, 1992. 707 pp.

42-1357. Forcione, AlbaN - "La disociación cósmica de Gracián". NRFH, 40 (1992), 419-450.

42-1358. Hidalgo-Serna, Emilio El pensamiento ingenioso de Baltasar Gracián. El "concepto" y su función lógica. Anthropos, Barcelona, 1993. 240 pp. (Autores, Textos y Temas. Humanismo, 2).

42-1359. JAMMES, ROBERT, et MARC VITSE - "Métaphore du corps dans un passage du Criticón (II, 8)”. - Le corps comme métaphore dans l'Espagne des $x v i e$ et xviie siècles, ed. A. Redondo ( $\mathrm{Pa}$ ris, 1992), 265-274.

42-1360. Neumeister, Sebastian, y DIETRICH BRIESEMEISTER (eds.) El mundo de Gracián. Actas del Coloquio Internacional Berlín 1988. - Colloquium, Berlin, 1991. || Criticón, 1992, núm. 54, 158-164 (Blanco).

42-1361. Orobitg, Christine - "Gracián lector de Don Juan Manuel a través de Argote de Molina'. - Criticón, 1992, núm. 56, 117-133.
Granada, fray Luis de

42-1362. Beuchot, MAURICIO - "Fray Luis de Granada: la retórica y el sentimiento"'. - Morphé, 1992, núm. 7, 131-139.

Guevara, Antonio de

42-1363. Blanco Gómez, Emilio "Noticia de una edición desconocida de fray Antonio de Guevara”. - $A I A$, 51 (1991), 3-9.

Herrera, Hernando Alonso

42-1364. Baranda, CONSOlaCión "Un "manifiesto" castellano en defensa del humanismo: la Breve disputa en ocho levadas contra Aristótil y sus secuaces, de Hernando Alonso Herrera (Alcalá, 1517)". - Criticón, 1992, núm. 55, 15-30.

Horozco, Sebastián de

42-1365. WEINER, JACK - “"El libro de cuentos" (1572-1579) de Sebastián Horozco (1510-1580): hacia su publicación". - NRFH, 40 (1992), 233-240.

\section{Hurtado de Mendoza, Antonio}

42-1366. Hurtado de Mendoza, ANTONIO - Ni callarlo ni decirlo. Ed., introd. y notas de E. W. Vogt. - Universidad Autónoma de Ciudad Juárez, Ciudad Juárez, 1992. 202 pp. (Co. Conmemorativa del Quinto Centenario del Encuentro de dos Mundos, 3).

42-1367. Stoll, ANita K. - "The dual 
levels of Antonio Hurtado de Mendoza's Cada loco con su tema". - $B C, 44$ (1992), 73-84.

Hurtado de Mendoza, Diego de

42-1368. RADA, INÈS - "Les métaphores du corps dans la poésie de Diego Hurtado de Mendoza". - Le corps comme métaphore dans l'Espagne des xvie et xviie siècles, ed. A. Redondo (Paris, 1992), 275-284.

\section{Jáuregui, Juan}

42-1369. PIKE, RUTH - "Converso lineage and the tribulations of the Sevillan poet Juan de Jáuregui'". - KRQ, 38 (1991), 423-429.

Jiménez de Urrea, Pedro Manuel de

42-1370. XIMÉNEZ DE URREA, PEDRO MANUEL - Penitencia de amor (Burgos, 1514). Ed. de R. L. Hathaway. University of Exeter Press, Exeter, 1990. xxxv + 75 pp. (Exeter Hispanic Texts, 49). \|| Cel, 15 (1991), núm. 2, 71-73 (Snow).

42-1371. Hathaway, Robert L. "Pedro Manuel Ximénez de Urrea, dramaturgo misántropo"'. - NRFH, 40 (1992), 131-142.

Juan de la Cruz, San

42-1372. JUAN DE LA CRUZ, SAN Obras completas. Ed. de M. Herráiz. Sigueme, Salamanca, 1991. 1160 pp. (El rostro de los santos, 9). \| EM, 1992, núm. 176, 154 (Pikaza).

42-1373. JUAN DE la CRUZ, SaN - Poe- sie, ed. P. Elia (N. 41-1474). \|HR, 60 (1992), 358-359 (Damiani); 60 (1992), $482-483$ (Rivers).

42-1374. AMRAN El MALEH, EDMOND - "Murmullo de una voz silenciosa en la noche de Úbeda". - Syntaxis, 1992, núm. 29, 3-6.

42-1375. ANDUEZA, MARÍA - "San Juan de la Cruz en México". - CuA, 1993, núm. 37, 165-179.

42-1376. BARRENA, JESÚS - Juan de la Cruz, utopía deseable. - Sígueme, Salamanca, 1991. $174 \mathrm{pp}$. (El rostro de los santos, 13). || EM, 1992, núm. 176, 152 (Pikaza).

42-1377. DEVOTO, DANIEL - "La rima: vaguedad de vaguedades, y todo variedad. (Reflexiones no ortodoxas sobre las consonancias imperfectas de San Juan de la Cruz y las rimas pobres de Fray Luis de León)". - Edad de Oro, 1992, núm. 11, 43-57.

42-1378. EstebaN, ClAdUdE - “Lugar ameno', 'lugar divino': topografia, dinámica y sublimación en el Cántico espiritual" ". - Syntaxis, 1992, núm. $29,18-31$.

42-1379. García Cuevas, Cristóbal - "Aspectos retóricos de la poesía de San Juan de la Cruz". - Edad de Oro, 1992, núm. 11, 29-41.

42-1380. JaUralde PoU, Pablo 'Las condición histórica del Cántico espiritual"'. - Edad de Oro, 1992, núm. $11,87-97$.

42-1381. JAVIER, José M. - Juan de la Cruz. Un caso límite. - Sígueme, Salamanca, 1991. 1120 pp. (El rosiro de los santos, 14). || $E M, 1992$, núm. 176, 154-155 (Pikaza).

42-1382. MANCHO, María Jesús "Simbolismo sonoro en el Cántico espiritual". - AnMal, 14 (1991), 5570.

42-1383. Nieto Sanjuán, José C. "El proceșo poético de la "Llama de amor vivas". - Edad de Oro, 1992, núm. 11, 123-132.

42-1384. RAMOS, J. - "Un acceso filosófico a la noción mística de gracia en San Juan de la Cruz". - Estudios, 1992, núm. 28, 65-77.

42-1385. SÁNCHEZ ROBAYNA, ANDRÉS - "San Juan de la Cruz: destrucción 
y destino". - Syntaxis, 1992, núm. 29, 7-12.

42-1386. SÁnchez SÁnchez, MerceDES - "San Juan de la Cruz y Fray Luis de León en su centenario". Edad de Oro, 1992, núm. 11, 211-217. 42-1387. Thompson, Colin P. - "La tradición mística occidental: dos corrientes distintas en la poesía de San Juan de la Cruz y Fray Luis de León'. - Edad de Oro, 1992, núm. 11, 187194.

42-1388. Vermeylen, A. (ed.) - Saint Jean de la Croix (1591-1991) (N. 411480). || Incipit, 1992, núm. 12, 280285 (Uriarte Rebeudi).

42-1389. ZAMBRANO, MARÍA - "San Juan de la Cruz: de la "Noche obscura” a la más clara mística"'. - RUAn, 1992, núm. 227, 43-51.

V. también núm. 751 .

\section{Lanini Sagredo, Pedro Francisco}

42-1390. Mackenzle, Ann L. - "The comedias of Don Pedro Francisco Lanini Sagredo (?1640-?1715)', - $-B H S$, 68 (1991), 139-151.

\section{Lazarillo de Tormes}

42-1391. Asensio, Manuel J. - "El Lazarillo en su circunstancia histórica'”. - RLit, 54 (1992), 101-128.

42-1392. Brenes Carrillo, Dalai "¿Quién es V. M. en Lazarillo de Tormes?". - BBMP, 68 (1992), 7388.

42-1393. RODRÍGUEz, A., y D. CORNEJO-PATTERSON - "Una nota sobre el 'padrastro' de Lazarillo". - RLit, 54 (1992), 641-644.

42-1394. YNDURÁIN, DOMINGO - “El renacimiento de Lázaro". - H, 57 (1992), 474-483.
León, fray Luis de

42-1395. LeÓn, FRAY L. DE - Poesía completa, ed. J. M. Blecua (N. 411493). \| RLit, 53 (1991), 732-735 (Martínez Soler);

42-1396. AlCALÁ, Á. - Proceso inquisitorial de fray Luis de León (N. 41-1495). ॥ $C D, 206$ (1993), 680 (González Velasco).

42-1397. BARRIENTOS GARcíA, J. "Fray Luis de León: Escritos desde la cárcel (Autógrafos del primer proceso inquisitorial)". - CD, 205 (1991), 804806.

42-1398. Castaño Navarro, ANa " La maternidad de Cristo en Los nombres de Cristo: el tema en textos anteriores y la formulación de fray Luis de León". - Medievalia, 1991, núm. 9, 18-29.

42-1399. Cillveti LeKunberri, ÁNGel - "Contexto literario y originalidad de la "Oda a Felipe Ruiz", de Fray Luis de León"'. - Edad de Oro, 1992, núm. 11, 15-28.

42-1400. Gallardo, Carmen - "Las resonancias de Horacio en Fray Luis de León". - Edad de Oro, 1992, núm. 11, 73-85.

42-1401. García de la Fuente, OleGARIO - "Traducciones y comentarios de Fray Luis de León al Cantar de los cantares". - AnMal, 14 (1991), 71 85.

42-1402. GonzÁlez Velasco, M. "El proceso de fray Luis de León (1571-1576). Notas y comentarios a Documentos y ediciones"'. - $C D, 205$ (1992), 231-237.

42-1403. González Velasco, M. "Obras latinas, nova et vetera, de fray Luis de León. Traducciones y nuevas ediciones". - CD, 206 (1993), 617 631.

42-1404. HeRnández, BEnIGNo - “El P. Cámara y las obras latinas de fray. Luis de León". - CD, 206 (1993), 203-212.

42-1405. Hildner, DAVID J. - Poetry and thruth in the Spanish works of fray Luis de León. - Tamesis, London, 1992. 177 pp. || HR, 62 (1994), 115- 
117 (Rivers).

42-1406. LazGaNo GONZÁlez, R. Fray Luis de León. Bibliografía (N. 411511). \| Edad de Oro, 1992, núm. 11, 225-231 (Ortiz).

42-1407. LÓPEZ CASTRO, ARMANDO "La armonía en fray Luis de León". - CuLH, 1992, núm. 15, 195-216.

42-1408. RODRÍGUEz DiEz, JOSÉ "Historia de la orden de San Agustín en la época de Fray Luis de León". Edad de Oro, 1992, núm. 11, 133-148.

42-1409. RUIZ PÉREZ, PEDRO - "SObre los sonetos de Fray Luis". - Edad de Oro, 1992, núm. 11, 149-160.

42-1410. SAN JOSÉ LERA, JAVIER "Creación y recreación: los versos 31 a 35 de la Oda XII, "Qué vale quanto vee», de Fray Luis de León en dos versiones". - AnMal, 14 (1991), 173-179.

42-1411. SchWARTZ, LÍA - "Fray Luis de León y las traducciones de los clásicos; la elegía II.iii de Tibulo". Edad de Oro, 1992, núm. 11, 175-186. 42-1412. Viñas ROMÁN, TEÓFILO (coord.) - Fray Luis de León. IV Centenario (1591-1991). Congreso interdisciplinar: Madrid, 16-19 de octubre 1991. Actas. Ediciones Escurialenses, 1992, Madrid, 1992.450 pp. \| CD, 206 (1993), 682-684 (González Velasco.

V. también núms. 1377, 1386, 1387.

\section{Loyola, Ignacio de}

42-1413. EICKHOFF, GEORG - "Ignacio de Loyola entre armas y letras. Los preceptos de lectura del humanismo castellano y los Ejercicios espirituales como arte de leer'. - $-I, 1992$, núm. $36,1-20$.
Mártir de Anglería, Pedro

42-1415. AlatorRe, ANTONIO - "Pedro Mártir y el Nuevo orbe". - Reflexiones lingüísticas y literarias, $t .2$, ed. $R$. Olea, y J. Valender (México, 1992), 67-85.

42-1416. CRO, STELIO - "El buen salvaje y la edad moderna: Hakluyt, Montaigne y Pedro Mártir'. CuLH, 1991, núm. 14, 173-190.

V. también núm. 1542.

Melo, Francisco Manoel de

42-1417. ESTRUCH TOBELlA, JOAN "Lusismos en Guerra de Cataluña de Francisco Manuel de Melo". - HR, 60 (1992), 457-468.

42-1418. VISTARINI, ANTONIO BERNAT - Francisco Manuel de Melo (16081666). Texios y contextos del Barroco peninsular. - Universitat de les Illes $\mathrm{Ba}$ lears, Palma, 1992. $213 \mathrm{pp}$.

Mira de Amescua, Antonio

42-1419. MIRA DE AMESCUA, ANTONIO - Callar en buena ocasión o muerto vivo y enterrado. - Reichenberger, Kassel, 1992. $102 \mathrm{pp}$.

V. también núm. 1477.

Molina, Argote de

V. núm. 1361.

Mariana, Juan de

42-1414. BARBA-MARTÍN, JOSÉ - "Las dos historias de Juan de Mariana". Estudios, 1992, núm. 29, 51-70.
Montemayor, Jorge de

42-1420. RHodes, ElizabeTH - The unrecognized precursors of Montemayor's 
"Diana". - University of Missouri Press, Columbia-London, 1992. xii + 260 pp.

V. también núm. 751 .

Muñón, Sancho de

V. núm. 1448.

Núñez de Reinoso, Alonso

42-1421. Deffis de Calvo, Emilia "El cronotopo de la novela española de peregrinación: Alonso Núñez de Reinoso y Lope de Vega'", - Criticón, 1992, núm. 56, 135-146.

Orozco, beato Alonso de

42-1422. Figura y obra de Alonso de Orozco, O.S.A. Actas de las Jomadas del IV Centenario de su muerte. - Ed. Revista Agustiniana, Madrid, 1992. \| $C D, 206$ (1993), 947-948 (Viñas).

Padilla, Juan de ("El Cartujano')

42-1423. Vicente García, Luis MIGUEL - "La astrología en Los doce triunfos de los doce apóstoles del Cartujano". - RLit, 54 (1992), 47-73.

Pérez de Montoya, Juan

42-1424. RODRÍGUEZ CACHO, LINA "Los símiles corporales entre el sermón y el coloquio misceláneo. Las Comparaciones de Pérez de Montoya". - Le corps comme métaphore dans l'Espag- ne des xvie et xviie siècles, ed. A. Redondo (Paris, 1992), 245-262.

\section{Quevedo y Villegas, Francisco}

42-1425. Quevedo, Francisco DE Execración contra los judios. Ed. de F. Cabo Aseguinolaza y S. Fernández Mosquera. - Crítica, Barcelona, 1993. 143 pp.

42-1426. ArRedondo, MARía SoleDAD - "La espada y la pluma contra Francia en el siglo XVII: cartas de Quevedo y Saavedra Fajardo". Criticón, 1992, núm. 56, 103-115.

42-1427. Artal, Susana G. - “Quevedo y las doncellas de Lucifer. Nuevo intento de apertura de un pasaje penado". - HR, 61 (1993), 175-184.

42-1428. BONIFACI, SOL - "La premática de los coches". - EM, 1992, núm. 177, 5-62.

42-1429. Chevalier, MAXIME - Quevedo y su tiempo: la agudeza verbal. Crítica, Barcelona, 1992. 266 pp. \| LBM, 1992, núm. 23, 124-126 (Bozal); Syntaxis, 1992, núms. 30/31, 189191 (Díaz Armas).

42-1430. Clamurro, W. H. - Language and ideology in the prose of Quevedo (N. 41-1555). \| H, 75 (1992), 320-322 (Bleznick); HR, 61 (1993), 564-566 (Ricapito).

42-1431. Fernández Mosquera, SanTIAGo, y ANTONio AzUSTRe GaliaNA - "Índices de la poesía de Quevedo". - BBMP, 68 (1992), 293-304.

42-1432. González, Mirta Aurora

- La distorsión de la lógica y la polifonía en la prosa de Quevedo. - P. Lang, New York, 1993. $140 \mathrm{pp}$.

42-1433. GonZÁlez Ollé, F. - "Interpretación de una sátira quevedesca: las octavas contra Morovelli''. - Incipit, 1992, núm. 12, 51-70.

42-1434. Jauralde Pou, Pablo "Quevedo, voces poéticas en conflicto. (Acerca de la metáfora corporal)". - Le corps comme métaphore dans l'Espagne des xvie et xvize siècles, ed. A. Redondo (Paris, 1992), 285-293. 
42-1435. KuUSusto, SHARON, y ÁNGel SÁNCHEZ - "El sueño del Infierno según Quevedo: discurso de un infierno mercantil". - DLit, 11 (1993-94), núm. 1, 81-93.

42-1436. LÓPEZ POZa, SAgRario Francisco de Quevedo y la literatura patrística. - Universida da Coruña, La Coruña, 1992. $301 \mathrm{pp}$.

42-1437. RIANDIËRE LA ROCHE, JOSETTE - "Corps politique et corps mystique dans "La política de Dios" de Quevedo". - Le corps comme métaphore dans l'Espagne des xvie et xvïe siècles, ed. A. Redondo (Paris, 1992), 115-139.

42-1438. SCHWARTZ, Lía - "Prisión y desengaño de amor: dos topoi de la retórica amorosa en Quevedo y en Soto de Rojas". - Criticón, 1992, núm. 56, 21-39.

42-1439. SMIth, PaUl J. - Quevedo: "El Buscón". - Grant \& Cutler, London, 1992. (Critical guides to Spanish texts, 51).

V. también núm. 760 .

\section{Quiñones de Benavente, Luis}

42-1440. ESTEPA, LUIS - "Versiones primeras de dos obras de Quiñones de Benavente". - RLit, 54 (1992), 335362.

42-1441. Lobato, María Luisa - " "E] testamento de Luis Quiñones de Benavente". - BC, 44 (1992), 253-259.

Saavedra Fajardo, Diego de

V. núm. 1426.

Sánchez de Badajoz, Diego

42-1442. Copello, Fernando - "Le corps comme métaphore dans le thé- âtre de Diego Sánchez de Badajoz". - Le corps comme métaphore dans l'Espagne des xvie et xviie siècles, ed. A. Redondo (Paris, 1992), 301-309.

\section{Sandoval y Rojas, Bernardo de}

42-1443. VÁzQUEZ, Luis - "El testamento de un gran Mecenas: Don Bernardo de Sandoval y Rojas, "El Otro» del Viaje del Parnaso, confundido con Tirso de Molina". - EM, 1992, núm. 177, 131-174.

42-1444. VÁzQUEZ, LUIS - "Los Apotegmas del Cardenal de Toledo Don Bernardo de Sandoval y Rojas". $E M, 1992$, núm. 177, 175-187.

\section{Santa Cruz, Alonso de}

42-1445. Pérez Tomás, Eduardo E. - "A propósito de una reciente edición del Islario general de todas las islas del mundo de Alonso de Santa Cruz". Incipit, 1992, núm. 12, 233-241.

Sigüenza, José de

42-1446. Ozaeta, José M. - "Dictamen del $P$. Sigüenza sobre la venida del apóstol Santiago a España". $C D, 206$ (1993), 899-910.

42-1447. OzaEta, José M. - "Erasmo de Rotterdam y fray José de Sigüenza". - CD, 206 (1993), 5-45.

Silva, Feliciano de

42-1448. ESTEBAN MARTín, LUIS MARIANO - "Muerte, resurrección y muerte de Celestina: tres autores ante 
un personaje"'. - CuLH, 1992, núm. $15,103-111$.

Soto de Rojas, Pedro

V. núm. 1438 .

Teresa de Jesús

42-1449. Polo, JosÉ - "Santa Teresa y el lenguaje: a propósito del juicio, más bien negativo, de Américo Castro (1959) sobre un libro póstumo (1915) de Antonio Sánchez Moguel"'. BHi, 94 (1992), 603-618.

42-1450. Velasco Kindelán, M. -

"Motivaciones y destinatarios del $\mathrm{Li}$ bro de la Vida de Santa Teresa de Jesús'. - RLit, 54 (1992), 645-651.

Tirso de Molina

42-1451. Molina, Tirso DE - El melancólico. Ed., est. y notas de A. Hualde Juvera. - Revista Estudios, Madrid, 1992. 260 pp.

42-1452. AlbRECHT, J. W. - "Irony in four comedies by Tirso de Molina". - H, 75 (1992), 260-265.

42-1453. Altamiranda, Daniel “ ¿Hacia una edición crítica "definitiva» de El burlador de Sevilla? A propósito de dos ediciones recientes del Burlador'. - Incipit, 1991, núm. 11, 175-185.

42-1454. DOLFI, LAURA - "Léxico culto y funcionalidad dramática en Por el sótano y el torno de Tirso". - EM, 1992, núm. 176, 5-32.

42-1455. TOFAYA, JESÚs - "El fingimiento como instrumento de liberación en Marta la piadosa". - Nóesis, 1992, núm. 8, 69-75.

42-1456. VÁzQUEz, LUIS - “Boletín de noticias tirsianas". - EM, 1992, núm. 176, 97-108.
42-1457. VÁZQUEZ, LUIS - "El testamento de doña María de Olalde y el de Juan Fernández, amigo de la Merced $y$ de Tirso (documentos inéditos)". - EM, 1992, núm. 176, 109135.

V. también núms. 662, 1428, 1443.

42-1458. Turriano, Juanelo (PseuDO) - Los veintiún libros de los ingenios y de máquinas. Pról. de J. A. García-Diego, transcripción y notas por María de los Santos. - Turner, Madrid, 1993. 635 pp. \|| $C D, 206$ (1993), 691-692 (T.).

Valdés, Alfonso de

42-1459. Valdés, Alfonso de - Diálogo de las cosas acaecidas en Roma. Ed. de R. Navarro Durán. - Cátedra, Madrid, 1992. 236 pp.

Valdivielso, José de

42-1460. ARIAS, RICARDO - "Reflexiones sobre $E l$ peregrino de José de Valdivielso". - Criticón, 1992, núm. 56, 147-160.

Vega Carpio, Lope de

42-1461. VEGA, FÉLIX LOPE - La moza de cántaro. Ed. de J. M. Díez Borque. - Espasa-Calpe, Madrid, 1990. 243 pp. \|| $C u L H, 1991$, núm. 14, 336-337 (Rodríguez).

42-1462. Ames, Debra Collins "Love melancholy in La quinta de Florencia'. - $B C, 44$ (1992), 45-58. 
42-1463. CAMPBELL, YSLA - "Continuidad y ruptura en La pobreza estimada de Lope de Vega". - El escritor y la escena (1), 105-114.

42-1464. CAMPBELL, YSLA - "Las conquistas del oro: honor y apariencia en Pobreza no es vileza de Lope de Vega'. - El escritor y la escena (2), 115-123.

42-1465. CANONICA DE ROCEHEMONTEIX, E. - El poliglotismo en el teatro de Lope de Vega (N. 41-1597). \| Criticón, 1992, núm. 55, 170-172 (Cazal); $B C$, 45 (1993), 163-165 (Lihani); $E M$, 1992, núm. 177, 207 (Vázquez).

42-1466. CARREÑo, ANTONIO - "Lo que se calla Diana: El perro del hortelano de Lope de Vega"'. - El escritor y la escena (1), 115-128.

42-1467. CASA, FranK P. - "Justicia y poder en El mejor alcalde, el rey". - El escritor y la escena (2), 125-133.

42-1468. CASE, Thomas E. - Lope and Islam. Islamic personnages in his "comedias". - Juan de la Cuesta, Newark, 1993. $187 \mathrm{pp}$.

42-1469. Case, Thomas E. - "Lope and the moriscos". $-B C, 44$ (1992), 195-216.

42-1470. Delgado Morales, Manuel - "Palabra y ornato en la puesta en escena de Peribáñez y Fuenteovejuna". $H R, 61$ (1993), 345-361.

42-1471. FERNÁNDEZ GUILLERMO, LEONOR - "La versificación en El castigo sin venganza de Lope de Vega"'. - El escritor y la escena (2), 135-142.

42-1472. García VARELA, Jesús "La dinámica del discurso dramático en La estrella de Sevilla". - BC, 44 (1992), 85-102. [Obra atribuida a Lope de Vega, Claramonte y Vélez de Guevara].

42-1473. Gitlitz, DAVID - "El mejor mozo de España de Lope: montaje de un mito nacional'". - El escritor y la escena (1), 129-135.

42-1474. GonZÁlez, Aurelio - "Las bizarrias de Belisa: texto dramático y texto espectacular". - El escritor y la escena (2), 143-153.

42-1475. Grieve, Patricia E. - "Point and counterpoint in Lope de Vega's Rimas and Rimas sacras". - HR, 60 (1992), 413-434.
42-1476. Hermenegildo, ALFREDO "Volumen textual y función dramática de los personajes ancilares: El acero de Madrid, de Lope de Vega'. - El escritor y la escena (1), 137-157.

42-1477. HERNÁNDEZ GONZÁLEZ, ERASMO - "La edición princeps de El palacio confuso no es de 1634". - RFE, 72 (1992), 179-181.

42-1478. HERnÁNDEZ GonZÁlez, ERASMO - "Una desconocida parte de comedias de Lope (Parte XXIII, Valencia, 1629)". - Criticón, 1992, núm. $56,179-186$.

42-1479. HERnÁNDEZ VAlcárcel, CARMEN - Los cuentos en el teatro de Lope de Vega. - Universidad de Murcia-Edition Reichenberger, Murcia-Kassel, 1992. 445 pp. || Anthropos, 1993, núm. 150, 77 (Estepa).

42-1480. Hicks, MARGARET R. - "Stage darkness in the early plays of Lope de Vega". - BC, 44 (1992), 217-230.

42-1481. KIRSCHNER, TERESA J. "Exposición y subversión del discurso hegemónico en pro de la Conquista en El Nuevo Mundo de Lope de Vega'. El escritor y la escena (1), 45-58.

42-1482. KÜPPER, J. - Diskurs-Renovatio bei Lope de Vega und Calderón. Untersuchungen zum spanischen Barockdrama (N. 41-1607). || HR, 60 (1992), 359-362 (Neumeister).

42-1483. Labarre, Françoise, y RoLAND LABARRE - "Sobre la fecha de Peribánez y el Comendador de Ocaña”. Criticón, 1992, núm. 54, 123-126.

42-1484. MACKENZIE, ANN L. - "Some comments upon two recent critical editions of El castigo sin venganza". BHS, 68 (1991), 503-506.

42-1485. MARTíneZ DE LA EsCalera, JoSÉ - "La circunstancia toledana de una "tragedia" de Lope de Vega y el nombre de Tirso (1596)". - RLit, 53 (1991), 631-639.

42-1486. MCCRARY, SUSAN N. - " "La noche de San Juan", as the temporal coordinate in El último godo". - DLit, 11 (1993-94), núm. 1, 113-126.

42-1487. MOUX, MARÍA - "La Política de Aristóteles en Fuente Ovejuna". Nóesis, 1992, núm. 8, 39-68.

42-1488. Novo, YOLANDA - "Sobre el 
marbete Rimas, a propósito de Lope, y el estatuto de la poesía lírica en el Siglo de Oro". - RLit, 54 (1992), 129 148.

42-1489. Pérez Pisonero, Arturo "El romance como estructura dramática en Peribáñez y el Comendador de Ocaña"'. - El escritor y la escena (1), 159165.

42-1490. Primorac, Berislav - "Agresión sexual y castigo en Audiencias del rey don Pedro". - El escritor y la escena (2), 155-163.

42-1491. Profeti, Maria Grazia "I bambini di Lope: tra committenza e commozione". - QLLS, 15 (1990), 187-206.

42-1492. RABELl, CARMEN R. - Lope de Vega. El arte nuevo de hacer "novellas". - Tamesis, London, 1992. 86 pp.

42-1493. Rozas, J. M. - Estudios sobre Lope de Vega, ed. J. Cañas Murillo (N. 41-1613). \|| Edad de Oro, 1992, núm. 11, 219-224 (Martínez Comeche); HR, 61 (1993), 562-564 (McGrady).

42-1494. Soufas, Teresa S. - "The receptive circuit and the mise en scene in/of La estrella de Sevilla". - MLN, 107 (1992), 220-234.

42-1495. SWIETLICKI, C. - " Close cultural encounters: Speech and writing in Fuenteovejuna"' - HR, 60 (1992), 33-53.

42-1496. TORRes, Milagros - "Métaphores corporelles et corps métaphoriques dans El maestro de danzar (1594) de Lope de Vega'. - Le corps comme métaphore dans l'Espagne des xvie et xviie siècles, ed. A. Redondo (Paris, 1992), 311-323.

V. también núms. $635,654,677,678$, $684,929,939,1322,1421$.

\section{Vélez de Guevara, Luis}

42-1497. KENNEDY, RUTH L. - "La estrella de Sevilla as a mirror of the courtly scene-and of its anonymus dramatist (Luis Vélez???)'. - BC, 45 (1993), 103-143. [Pref. de G. Peale].
Vicente, Gil

42-1498. GARAY, R. P. - Gil Vicente and the development of the Comedia (N. 411622). \| H, 75 (1992), 556-557 (Ihrie).

Villalón, Cristóbal de

V. núm. 73 .

Virués, Cristóbal de

V. núm. 939.

Vives, Juan Luis

V. núm. 1566.

Zapata de Chaves, Luis de

V. núm. 730 .

\section{SIGLO XVIII}

Álvarez de Cienfuegos, Nicasio

42-1499. Loureiro, ÁNGEL G. - "La poesía de la muerte de Álvarez de Cienfuegos: el deseo de la razón produce monstruos'”. $-H R, 60$ (1992), 435-456. 
Cadalso; José de

42-1500. CADÁlso, JosÉ DE - Noches lúgubres. Ed. de R: P. Sebold. - Taurus, Madrid, 1993. $215 \mathrm{pp}$.

42-1501. FERnández Díaz, M. CARMEN - "Sobre algunos galicismos de las Cartas marruecas". - IFE, 1992, núm. $6,105-112$.

42-1502. LAMA, Miguel ÁNGEL - "Las Noches lúgubres de Cadalso, o el teatro a oscuras"?. - HR, 61 (1993), 1-13.

V. también núm. 685 .

\section{Comella, Luciano}

42-1503. Huerta, Fernando - “El comediógrafo mal-tratado: Luciano Comella y la Ilustración". - BHS, 68 (1991), 183-189.

\section{Cruz, Ramón de la}

42-1504. CRUZ, R. DE LA - Sainetes, ed. F. Lafraga (N. 41-1630). \| H, 75 (1992), 321-322 (Goughlin).

42-1505. DOWIING, JOHN - "Ramón de la Cruz: libretista de zarzuelas". - BHS, 68 (1991), 173-182.

42-1506. SAla Valldaura, Josep MARÍA - "Bases - y: tópicös morales de los sainetes de Ramón de la Cruz". $A L E, 1992$, núm. 8, 157-174.

Feijoo, Jerónimo Benito

42-1507. VARgas Martínez, Gustavo - "Introducción a Feijoo, apologista de América". - CuA, 1992, núm. 31, 214-229.

V. también núms. $41 ; 1534$
Fernández de Moratín, Leandro

42-1508. FERNÁNDEZ DE MORATÍN, L. - Viage a Italia, ed. B. Tejerina (N. 41-1634). || HR, 61 (1993), 415-416 (Pérez Magallón).

42-1509. Demerson, JORGE - "Leandro Fernández de Moratín y José de Lugo en Londres (1792-1793)'”. ALE, 1992, núm. 8, 53-61.

42-1510. Pérez Magallón, Jesús "Moratín, neoclásico de una armonía ya 'imposible". - RCEH, 17 (199293), núm. 2, 343-356.

42-1511. Pérez-Magallón, Jesús "Realidades poéticas y ámbitos poemáticos en Moratín". - $B H i, 94$ (1992), 169-201.

\section{Fernández de Moratín, Nicolás}

42-1512. FERNÁNDEZ DE MORATÍN, N. - El arte de las putas, ed. E. Velázquez (N. 41-1637). \|| HR, 60 (1992), 362364 (Gies).

42-1513. TEJERINA; BELÉN - "La obra de Nicolás Fernández de Moratín revisada por su hijo Leandro: el autógrafo de las obras póstumas conservado en la biblioteca madrileña de Bartolomé March"'. $-A L E, 1993$, núm. 9, 155 180.

Floranes, Rafael

42-1514. ROUND, NICHOLAS G. - "The antiquary reassessed: Floranes and the liberal tradition'. - $B H S, 68$ (1991), 107-123.

García de la Hueria, Vicente.

42-1515. KaPLAN, GREgORY B. - "The other major source of Huerta's Raquel: 
Esther'. - $A L E, 1992$, núm. 8, 109117.

42-1516. Llama, Miguel Ángel - La poesía de Vicente García de la Huerta. Universidad, Extremadura, 1993. 271 pp.

Iglesias de la Casa, José

42-1517. Díez Fernández, José IGNACIO - "La obra poética impresa de José Iglesias de la Casa”. - RLit, 54 (1992), 575-597.

Iriarte y Oropesa, Tomás de

42-1518. IRIARTE, TOMÁS DE - Fábulas . literarias. Ed. de A. L. Prieto de Paula. - Cátedra, Madrid, 1992. 262 pp. \| RLit, 55 (1993), 299-300 (Ríos).

Isla, José Francisco de

42-1519. ISLA, JOSÉ FRANCISCO DE Historia del famoso predicador Fray Gerundio de Campazas, alias zotes. Ed. de J. Jurado. - Gredos, Madrid, 1992. 975 pp.

Jovellanos, Gaspar Melchor de

42-1520. Jovellanos, Gaspar MelCHOR DE - Poesía. Teatro. Prosa literaria. Ed. de J. H. R. Polt. - Taurus, Madrid, 1993. 518 pp.

42-1521. Caso González, José MIGUEL - “Jovellanos y su tiempo". - BHS, 68 (1991), 91-105.
León y Mansilla, José de

42-1522. GLendinNing, Nigel - "La Soledad tercera de José de León y Mansilla (1718)". - BHS, 68 (1991), 13-24.

Lobo, Eugenio Gerardo

42-1523. Arellano, IgNACIO - " $E l$ triunfo de las mujeres, loa mariana y sacramental del poeta dieciochesco Eugenio Gerardo Lobo. (Materiales para el estudio del género y su evolución)"'. - Criticón, 1992, núm. 55, 141-161.

López, Juan

42-1524. PatTier TorRes, Felicidad - "Juan López, autor de la primera versión española de los Idilios (1797) de Gessner'. - RLit, 54 (1992), 231245.

Meléndez Valdés, Juan

42-1525. Froldi, Rinaldo - "Una carta inédita de Juan Meléndez Valdés al Padre Andrés'’. - $B H S, 68$ (1991), 33-36.

42-1526. WALTERS, D. GaReth - "In praise of inconstancy: The Odes to Lisi of Meléndez Valdés"'. - BHS, 68 (1991), 25-32.

Montengón y Paret, Pedro

42-1527. HAFTER, MONROE Z. - "Montengón's $E l$ mirtilo in its Eighteenthcentury context". - BHS, 68 (1991), 37-46. 
Montiano y Luyando, Agustín de

42-1528. SHAW, D. L. - "Montiano's Atoulpho". - BHS, 68 (1991), 153161.

Trigueros, Cándido María

V. núm. 660 .

Valladares y Sotomayor, Antonio

V. núm. 661.

\section{COLONIA}

Aguirre, Lope de

42-1529. PASTOR, BEATRIZ - "Las metamorfosis de Lope de Aguirre". EUSB, 1993, núm. 1, 107-120.

\section{Alva Lxtlilxóchitl, Fernando de}

42-1530. BAUDOT, GEORGES - "Sentido de la literatura histórica para la transculturación en el México del siglo XVII: Fernando de Alva Ixtlixóchitl"'. - Reflexiones lingüisticas y literarias, t. 2, ed. R. Olea, y J. Valender (México, 1992), 125-137.

42-1531. CALVI, MARIA VITTORIA ‘El diálogo entre españoles e indígenas en la XIII Relación de Fernando de Alva Ixtlilxóchitl'. - QIA, 9 (1992), 621-639.
Barco Centenera, Martín del

42-1532. Verdesio, Gustayo - "La Argentina: tipología textual y construcción de los referentes". - RCLL, 1993, núm. 38, 345-360.

\section{Benavente, fray Toribio de ("Motolinia")}

42-1533. Crovetto, Pierluigi - I segni del Diavolo e i segni di Dio. La Carta al Emperador Carlos V (2 gennaio 1555) di fray Toribio Motolinía. - Bulzoni, Roma, 1992. || QIA, 1993, núm. 73, 133134 (Giletti Benso).

Carrió de la Vandera, Alonso

42-1534. RODRIGO, ENRIQUE - "Carrió de la Vandera y Feijoo: el papel de la historia en el exordio de El lazarillo de ciegos caminantes". - BIEA, 47 (1993), 259-268.

\section{Castro, Francisco de}

42-1535. Buezo, Catalina - "Apuntes sobre el ritual expulsión del mal en la plaza pública y edición de $E l$ antojo de la gallega, mojiganga de Francisco de Castro". - RDTP, 48 (1993), 81102.

\section{Cervantes de Salazar, Francisco}

42-1536. BONO, DiAnNe M. - Cultural diffusion of Spanish :humanism in New Spain. Francisco de Salazar's 'Diálogo de la dignidad del hombre". - P. Lang, New York, 1991. || QIA, 1993, núm. 
73, 139-140 (Damiani).

Cieza de León, Pedro

42-1537. Castillo, Nicolás del "Quechuismos en la Crónica del Perú de P. Cieza de León (1550-1554) (conclusiones)". - ALHis, 8 (1992), 43-46.

Cobo, fray Bernabé

42-1538. Olmo Pintado, Margarita DEL - "La historia natural en la $H$ istoria del Nuevo Mundo, del P. Cobo". - RIM, 52 (1992), 795-823.

\section{Colón, Cristóbal}

42-1539. ARROM, JOSÉ JUAN - “En demanda de Cathay: lo real y lo imaginario en el Diario del primer viaje de Colón'. - CuA, 1992, núm. 33, 3147.

42-1540. BOREllo, RODOlFO - "Los diarios de Colón y el padre Las Casas"'. - CuH, 1993, núm. 512, 7-22.

42-1541. Chiareno, Osvaldo - "Altre postille linguistiche al testo del $\mathrm{Li}$ bro de la Primera Navegación'”. - QIA, 9 (1992), 564-570.

42-1542. DURÁN LUZIO, JUAN "Cuatro versiones de un curioso incidente ocurrido en la playa de Limón [antes Cariai] un día de septiembre de 1502"'. - HR, 62 (1994), 93-104.

42-1543. HEYDENREICH, TITUS (Hrsg.) - Columbus zwischen zwei Welten. Historische und literarische Wertungen aus fünf Jahrhunderten. 2 Bde. - Vervuert, Frankfurt/M, 1992. 1008 pp. (Erlanger Lateinamerika-Studien, 30).

42-1544. JARA, RENÉ, \& Nicholas SPADACCINI (eds.) - Amerindian images and the legacy of Columbus. - University of Minnesota Press, Minneapolis,
1992. $\mathrm{xi}+75 \mathrm{ep}$.

42-1545. Marino, Ruggero - "IInnocenzo VIII, il papa di Cristoforo Colombo". - QIA, 9 (1992), 595-602.

42-1546. Martinengo, Alessandro - “La utopía de Cristóbal Colón". - QIA, 9 (1992), 554-563.

42-1547. MOLlat, MiCHEL - Los exploradores del siglo xiii al xvi. Primera miradas sobre nuevos mundos. - F.C.E., México, 1990. 214 pp. || Medievalia, 1991, núm. 9, 42-43 (González).

\section{Colón, Hernando}

V. núm. 1542.

Cortés, Hernán

42-1548. Enguita UTRILla, José MaRÍA - "Voces amerindias en las Relaciones de Hernán Cortés'” - RFE, 72 (1992), 379-398.

42-1549. MORINO, ANGELO - "Hernán Cortés e la regina Calafia”. QIA, 9 (1992), 603-620.

\section{Diaz del Castillo, Bernal}

42-1550. Alvar, Manuel - Americanismos en la "Historia" de Bernal Díaz del Castillo. - Ediciones de Cultura Hispánica, Madrid, 1990. 121 pp. ॥ ZRPh, 107 (1991), 810 (Baldinger).

42-1551. MENDIOla Mejía, AlFonso - Bernal Díaz del Castillo: verdad romancesca y verdad historiográfica. - Gobierno del Estado de Puebla-Universidad Iberoamericana, México, 1991. 146 pp. \| Morphé, 1992, núm. 6, 175-178 (Velázquez). 
Durán, fray Diego

42-1552. FLORES ORTIZ, ROBERTO El amor de las razones. Saber $\varepsilon$ interacción en la "Historia de las Indias de Nueva España" de Fray Diego Durán. - UAM, México, 1991. 318 pp. (Cruce de Frontera, Historia, 1). \| Morphé, 1992, núm. 6, 171-174 (Castillo Rojas).

Ercilla y Zúñiga, Alonso de

42-1553. ERcilla, AlONSO DE - La Araucana. Ed. de I. Lerner, - Cátedra, Madrid, 1993. 1026 pp.

Espinosa Medrano, Juan de

42-1554. CisNeros, LUIS JAIME - "Itinerario y estructura del Apologético de Espinosa Medrano". - LexisL, 16 (1992), 123-188.

\section{Fernández de Oviedo, Gonzalo}

42-1555. FERnÁNDEZ DE OVIEDO, G. Batallas y quinquagenas, ed. J. B. Avalle-Arce (N. 41-1677). || HR, 61 (1993), 95-97 (Félix Bolaños).

42-1556. BOLAÑos, ÁlVARO FÉLIX "Panegírico y libelo del primer cronista de Indias Gonzalo Fernández de Oviedo"'. - BICC, 45 (1990), 577 649.

Garcilaso de la Vega, el Inca

42-1557. CORNEJO POLAR, ANTONIO "El discurso de la armonía imposible. (El Inca Garcilaso de la Vega: discurso y recepción social)". - RCLL,
1993, núm. 38, 73-80.

42-1558. Hilton, Sylvia, y AMANCio LABANDEIRA - "La sensibilidad cromática y estética del inca Garcilaso": - RIM, 52 (1992), 529-558.

González de Eslava, Fernán

42-1559. GonZÁleZ DE EsLAVA, F. Villancicos, romances, ensaladas $y$ otras canciones devotas, ed. M. Frenk (N. 41 1680). || Fil, 25 (1990), 216-218 (Chicote); LMM, 3 (1992), 195-203 (García de Enterría).

V. también núm. 950 .

\section{Hernández, Francisco}

42-1560. Bustamante García, Jesús - "De la naturaleza y los naturales americanos en el siglo XVI: algunas cuestiones críticas sobre la obra de Francisco Hernández"'. - RIM, 52 (1992), 297-328.

\section{Hojeda, Diego de}

42-1561. Peinador MARÍN, LuIS J. "Narración y diálogo en La Cristíada de Hojeda". - EM, 1992, núm. 176, 33-41.

Juana Inés de la Cruz, Sor

42-1562. BAUdOT, GeORges - "La trova náhuatl de Sor Juana Inés de la Cruz"'. - HMDR, 849-859.

42-1563. DÍAZ BALSERA, VIVIANA "Los empeños de una casa: el sujeto colonial, y las burlas al honor" . - El escritor y la escena (2), 61-73.

42-1564. Hensey, Fritz G. - "Syntzx, 
text processing, and translation ordo artificialis in Sor Juana Inés' Primero sueño". - $H L, 4$ (1992), 389-410.

42-1565. Hernández ARAICO, Susana - "El código festivo renacentista barroco y las loas sacramentales de Sor Juana: des/re/construcción del mundo europeo". - El escritor y la escena (2), 75-93.

42-1566. Howe, Elizabeth Teresa "Sor Juana Inés de la Cruz and Juan Luis Vives"'. - DLit, 11 (1993-94), núm. 1, 63-72.

42-1567. Long, PAmela H. - "Sor Juana as composer: A reappraisal of the villancicos"'. - Critical essays on the literatures of Spain and Spanish America, eds. L. T. González del Valle \& J. Baena (Boulder, 1991), 161-169.

42-1568. MCDONALD, ROBERT - “An incredible graph: Sor Juana's Respuesta". - RCEH, 17 (1992-93), núm. 2, 297-318.

42-1569. MERKL, HEINRICH - "Juana Inés de la Cruz y Carlos de Sigüenza y Góngora en 1680'. - I, 1992, núm. 36, 21-37.

42-1570. Urbano, V. - Sor Juana Inés de la Cruz: amor, poesía, soledumbre, ed. A. López de Martínez (N. 41-1699). ॥ $H, 75$ (1992), 329 (Lewis).

V. también núms. $662,722,760,950$.

Las Casas, fray Bartolomé de

42-1571. Helminen, Juha PeKka "Las Casas, los judíos, los moros y los negros". - CuH, 1993, núm. 512, 23-28.

42-1572. Jalif de Bertranou, Glara Alcicia, y Gustavo González "Conflicto y discurso sobre el hombre americano. La polémica Las Casas-Sepúlveda". - CuA, 1992, núm. $35 ; 21-42$.

42-1573. Ortega, José - "Las Casas, un reformador social "por abajo"”. CuH, 1993, núm. 512, 29-38.

42-1574. Parish, HELEN Rand, y HaROLD E. WEIDMAN - Las Casas en
México. Historia y obra desconocidas. F.C.E., México, 1992. 409 pp.

42-1575. SAINT LU, ANDRÉ - "Bartolomé de las Casas et la traite des nègres'. - BHi, 94 (1992), 37-43.

42-1576. Soria, Giuliano - "Echi della conquista nella Torino del ' 600 : Valerio Fulvio Savoiano e Bartolomé de Las Casas'. - QIA, 9 (1992), 721731.

V. también núms. 1540, 1542.

Núñez Cabeza de Vaca, Alvar

42-1577. Champion, James J. - "Verb frequency in La Relación of Alvar Núnez Cabeza de Vaca'. - RNo, 33 (1992-93), 25-32.

42-1578. GlantZ, MARGo (coord.) Notas y comentarios sobre Alvar Núnez Cabeza de Vaca. - Grijalbo, México, 1993.

42-1579. RIVERA MARTÍNEZ, EDGARDO - "Singularidad y carácter de los Naufragios de Alvar Núñez Cabeza de Vaca". - RCLL, 1993, núm. 38, 301-315.

42-1580. SPITTA, SilviA - "Chamanismo y cristiandad: una lectura de la lógica intercultural de los Naufragios de Cabeza de Vaca". - RCLL, 1993, núm. 38, 317-330.

\section{Olmos, fray Andrés de}

42-1581. BAUdOT, GEORGES - "Fray Andrés de Olmos y la penetración del luteranismo en México. Nuevos datos y documentos". - NRFH, 40 (1992), 223-232.

Oña, Pedro de

42-1582. MEjIas-Lopez, William "Principios indigenistas de Pedro de 
Oña presentes en Arauco domado"'. QIA, 1993, núm. 73, 77-94.

\section{Poma de Ayala, Felipe Guamán}

42-1583. Cánovas, Rodrigo - Felipe Guamán Poma: escritura y censura en el nuevo mundo. - Francisco Zegers, Santiago de Chile, 1993. 112 pp.

42-1584. ORTEGA, JULIO - "Guamán Poma y el discurso de los alimentos". - Reflexiones lingüisticas y literarias, t. 2, ed. R. Olea, y J. Valender (México, 1992), 139-152.

?-1585. SCARAMUZZA VIDONI, MARIAROSA - "La ritrattistica nella Nueva Corónica di Guamán Poma de Ayala". - QIA, 9 (1992), 682-694.

\section{Rodríguez Freile, Juan}

42-1586. HERMAN, SUSAN - "Conquest and discovery: Subversion of the fall in El carnero". - $M L N, 108$ (1993), 283-301.

\section{Romero, Francisco}

42-1587. ALBònICO, ALDO - "Un'ope$\mathrm{ra}$ in difesa degli indi nella Milano del Seicento: il Llanto sagrado de la América meridional". - QIA, 9 (1992), 695 708.

Rosas de Oquendo, Mateo

42-1588. LASARTE, P. (ed.) - Sátira hecha por Mateo Rosas de Oquendo a las cosas que pasan en el Pirú, año de 1598 (N. 41-1712). || RCLL, 1992, núm. 35, 159-160 (Cornejo-Polar); HR, 60 (1992), 483-485 (Schwartz Lerner).
Ruiz de Alarcón, Juan

42-1589. AmEzcuA, José - "La verdad sospechosa y la poética del desenlace". - $H M D R, 829-847$

42-1590. AMEZCUA, J., y S. GONZÁleZ (eds.) - Espectáculo, texto y fiesta. Juan Ruiz de Alarcón y el teatro de su tiempo (N. 41-1713). \| H, 75 (1992), 569-570 (Mejías-López).

42-1591. Castelis, RiCARDO - "García's love melancholy and the banquet scene in Ruiz de Alarcón's La verdad sospechosa". $-B C, 45$ (1993), 93-101.

42-1592. FIORE, ROBERT L. - "Alarcón's El dueño de las estrellas: Hero and Pharmakos"'. - HR, 61 (1993), 185199.

42-1593. García-VARELA, Jesús "El anticrisio de Juan Ruiz de Alarcón: de la hagiografía al Apocalipsis". El escritor y la escena (2), 39-44.

42-1594. HALPERN, CYNTHIA LEONE The political theater of early SeventeenthCentury Spain, with special reference to Juan Ruiz de Alarcón. - P. Lang, New York, 1993. $\mathrm{x}+179 \mathrm{pp}$.

42-1595. KING, W. F. - Juan Ruiz de Alarcón, letrado y dramaturgo. Su mundo mexicano y español (N. 41-1715). \|RLit, 53 (1991), 257-259 (Campo Gómez); $H R, 61$ (1993), 288-290 (Stern).

42-1596. PEÑA, MARGARITA - "Juan Ruiz de Alarcón ante la crítica". NRFH, 40 (1992), 383-393.

42-1597. PEÑA, MARgarita - "Juan Ruiz de Alarcón en el espejo de la crítica". - El escritor y la escena (1), 177-187.

42-1598. PRIMORAC, BERISLAV - "Las luchas literarias y el estreno de $E l$ Anticristo de Alarcón". - El escritor y la escena (1), 167-175.

42-1599. SERRANO DEZA, RICARDO "La verdad sospechosa y su uintención" a la luz del análisis infoasistido". - $E l$ escritor y la escena (2), 45-59.

42-1600. VEga GarcíA-LuEngos, GerMÁN - "Alarcón y el sorprendente retorno de don Domingo de Don Blas". - El escritor y la escena (2), 13-36. 
Ruiz de León, Francisco

42-1601. Peña, Margarita - "Luces dieciochescas sobre la conquista de México: la crónica rimada de Ruiz de León". - Nóesis, 1992, núm. 8, 121131.

Sepúlveda, Juan Ginés de

42-1602. Castilla Urbano, Frnacis$\mathrm{CO}$ - "Juan Ginés de Sepúlveda: en torno a una idea de civilización". RIM, 52 (1992), 329-348.

V. también núm. 1572.

Sigüenza y Góngora, Carlos de

42-1603. SAlCIDO ROMERO, Alberto - "La ambigüedad genérica de los Infortunios de Alonso Ramirez como producto de la dialéctica entre discurso oral y discurso escrito". - $\mathrm{BHi}, 94$ (1992), 119-139.

V. también núm. 1569.

Tejeda, Luis de

42-1604. Castiñeira, José María "Luis José de Tejeda y Guzmán, el primer poeta argentino'. - BAAL, 57 (1992), 101-112.

Valle Caviedes, Juan del
"Historiografia, discurso e contradiscurso na Colônia: Gregório de Matos e Juan del Valle y Caviedes'. - $H$, 57 (1992), 508-515.

\section{SIGLO XIX}

\section{España}

Alarcón, Pedro Antonio de

42-1606. Florensa, Eva F. - "El niño de la bola y la fisiología de la novela decimonónica (II)"'. - ALE, 1992, núm. 8, 63-81.

$$
\text { Alas, Leopoldo "Clarín" }
$$

42-1607. Alas, L. - Apolo en Pafos, ed. A. Sotelo Vásquez (N. 41-1724). \| $H R, 60$ (1992), 497-498 (Bauer).

42-1608. Alas, L. - Nueva campaña, ed. A. Vilanova (N. 41-1727). \| HR, 61 (1993), 112-113 (Lozano Marco).

42-1609. Carlson, Janina - "Siguiendo las huellas de La Regenta". BIEA, 47 (1993), 323-329.

42-1610. Dobón, María Dolores "Tema e imagen en Superchería. Naufragio en Guadalajara". - ALE, 1993, núm. 9, 21-29.

42-1611. FERnÁNDEZ, M. S. - "Estra tegias de poder en el discurso realista: La Regenta y Fortunata y Jacinta'. - $-H$, 75 (1992), 266-274.

42-1612. Miller, STEPHEN - "Intertexts, contexts and the Clarinian canon: The place of «El cura de Vericueto"'. - BHS, 68 (1991), 463-477.

42-1613. ONTAÑóN DE LOPE, PACIENCIA - "Dos viajes de bodas: el de la Regenta y el de Clarín”. - $A L M, 30$ 
(1992), 191-195.

42-1614. Sieburth, Stephanie A. Reading "La Regenta": Duplicitous discourse and the entropy of structure. - J. Benjamins, Amsterdam-Philadelphia, 1990. 127 pp. (Purdue University Monographs in Romance Languages, 29)). \| $R J, 43$ (1992), 356-359 (WogatzkeLuckow).

42-1615. Sotelo, A. - Leopoldo Alas y el fin de siglo (N. 41-1732). \| $H R, 60$ (1992), 234-236 (Valis).

42-1616. SOTELO, ADOLFO - "Leopoldo Alas "Clarín" en Nueva York (1894-97): las novedades de Hispanoamérica'”. - CuH, 1993, núm. 511, 115-123.

42-1617. VALIS, NOËL - "Clarín y la vida cultural del extranjero: tres artículos desconocidos (Miscelánea, 1900)"'. - BIEA, 47 (1993), 157-178.

42-1618. VALIS, N. - "Malevolent insemination" and other essays on Clarin ( $\mathrm{N}$. 41-1733). || H, 75 (1992), 323-324 (Gullón); KRQ, 39 (1992), 502-504 (Wietelmann Bauer).

42-1619. Viñuales, Pedro Pablo "Mi entierro de Clarín: un cuento raro'. - $A L E, 1992$, núm. 8, 193-206.

V. también núms. 644, 680, 1628, 1652.

Alvarado, Francisco de

42-1620. ARROYO RODRÍGUEZ, LUIS AnTONIO - "Cuentos folklóricos en las Cartas críticas de Francisco de Alvarado". - RDTP, 47 (1992), 365-370.

Bécquer, Gustavo Adolfo

42-1621. BÉCQUER, G. A. - Rimas, ed. R. P. Sebold (N. 41-1734). \|RCEH, 17 (1992-93), núm. 1, 207-211 (Del Vecchio); HR, 62 (1994), 123-126 (González Troyano).

42-1622. Hastings, Eugene B. - Bécquer, su proyección y sus huellas. Pról. de R. Montesinos. - University of
North Carolina, Chapel Hill, 1992. 119 pp.

42-1623. LARUBIA-PRADO, FRANCISCO - "La función intencional del apóstrofe en la rima 35/LII de Gustavo Adolfo Bécquer'. - RNo, 33 (199293), 231-238.

42-1624. Rodríguez FER, Cllaudio -

"Das lendas de Bécquer ás lendas de Fole". - RCEH, 18 (1993-94), núm. $1,67-80$.

V. también núms. $647,655,659$.

Blanco White, José María

42-1625. Blanco WHITE, José MaRÍA - Diálogos argelinos y otros ensayos. Ed. de M. Moreno Alonso. - Alfar, Sevilla, 1992. 149 pp.

V. también núm. 648 .

Blasco Ibáñez, Vicente

42-1626. Fox, A. A. - "Estructuras totémicas en La barraca de Blasco Ibánez". - $-H, 75$ (1992), 275-280.

V. también núm. 1652.

Castillo-Puche, José Luis

42-1627. Belmonte-SERRANO, José "Un oscuro pasaje en la vida de José Luis Castillo-Puche". - KRQ, 39 (1992), 211-220.

Castro, Rosalía de

V. núm. 659. 
Echegaray, José

42-1628. Hernández, LibradA - “Clarín, Galdós y Pardo Bazán frente al teatro de José Echegaray". - $A L E$, 1992, núm. 8, 95-108.

42-1629. SAMPER, EDGARD - "La vision de l'Espagne à travers la critique théâtrale française (1883-1916): le case Echegaray". - IFE, 1993, núm. 9, 139-152.

\section{Espronceda, José de}

42-1630. Larubia-Prado, Francisco - "Texto y tiempo en El estudiante de Salamanca. La impostura de la historia literaria y del romanticismo español'.

- RHM, 46 (1993), 3-18.

\section{Estébanez Calderón, Serafín}

V. núm. 527.

Foz, Braulio

42-1631. AMORES GarcíA, MONTSERRAT - "Del folclor a la literatura: Vida de Pedro Saputo". - RDTP, 48 (1993), 103-123.

Ganivet, Ángel

42-1632. SUBIRATS, EDUARDO - "Cuarteto español". - Estudios, 1992, núm. 29, 15-32. [Sobre Ganivet, Unamuno, Ortega, Castro].
Gil y Carrasco, Enrique

42-1633. Ríos-FONT, WADDA C. " "Encontrados afectos": El señor de Bembibre as a Self-Conscious novel". - HR, 61 (1993), 469-482.

Larra, Mariano José de

42-1634. ROSENBERG, JOHN R. - "Between delirium and luminosity: Larra's ethical nightmare"' - HR, 61 (1993), 379-389.

42-1635. Sherman, Alvin F., JR. "Larra vs. El jorobado: Spanish society and the debate over Anthony (1836)". - ALE, 1993, núm. 9, 129-139.

León, Ricardo

V. núm. 638.

Lista y Aragón, Alberto

42-1636. MartíNEz TORRón, Diego - Ideología y literatura en Alberto Lista. - Alfar, Sevilla, 1993. 488 pp.

\section{López Soler, Ramón}

42-1637. Rubio Cremades, Jesús "La narrativa de Ramón López Soler: ficción y realidad". - KRQ 39 (1992), 17-21.

Menéndez Pelayo, Marcelino

42-1638. Laín Entralgo, Pedro "Revisión de Menéndez Pelayo". BBMP, 68 (1992), 391-398. 
Menéndez Pidal, Juan

42-1639. Cid, JESÚS-ANTONIO - "Ensayo de una bio-bibliografía de Juan Menéndez Pidal. La Unión Católica y el periodismo ultramontano en la Restauración". - BIEA, 46 (1992), 7-43.

\section{Mesonero Romanos, Ramón}

42-1640. MESONERO ROMANOS, RAMÓN DE - Escenas y tipos matritenses. Ed., est. prelim. y notas de E. Rubio Cremades. - Cátedra, Madrid, 1993. $511 \mathrm{pp}$.

\section{Moría Delgado, Martín}

42-1641. Williams, LoRNA V. - "Morúa Delgado and the Cuban slave narrative". - MLN, 108 (1993), 302313.

\section{Palacio Valdés, Armando}

42-1642. BARBIERI, MARIE E. - "La visión de Armando Palacio Valdés: unas notas sobre sus escritos teóricos". - KRQ, 39 (1992), 81-86.

42-1643. Cuenca, José Manuel, y SoLEDAD MIRANDA GARcía - "La Andalucía dè Palacio Valdés". $B I E A, 46$ (1992), 163-177.

42-1644. Dendle, BRIAN J. - "Diez cartas inéditas de Armando Palacio Valdés a Edmundo Gosse y a William Heinemann". - BIEA, 47 (1993), 303-313.

42-1645. Dendle, BRIAN J., \& STEPHEN MILlLER (eds.) - Estudios sobre Armando Palacio Valdés. - Dovehouse, Ottawa, 1993. 141 pp.
Pardo Bazán, Emilia

42-1646. PARDO BAZÁN, E. - Cuentos completos, ed. J. Paredes Núñez (N. 411762). \| $H, 75$ (1992), 324-325 (Miller). 42-1647. PARdo BAZÁN, EMILIA - La madre naturaleza. Ed. de I. J. López. Taurus, Madrid, 1992. 383 pp. (Clás. Taurus, 16).

42-1648. BIEDER, MARYELLEN - "Emilia Pardo Bazán and literary women: Women reading women's writing in late 19th-century Spain". - RHM, 46 (1993), 19-33.

42-1649. Cate-ARries, Francie "Murderous impulses and moral ambiguity: Emilia Pardo Bazán's crime stories.'. $-K R Q, 39$ (1992), 205-210.

42-1650. Charnon-DeUtsch, LOU 'Feitas's decision: Pardo Bazán's exploration of female identity in Memorias de un solterón"'. - DLit, 11 (199394), núm. 1, 25-50.

42-1651. DeCoster, Cyrus - "Pardo Bazán: Art and music critic". RNo, 33 (1992-93), 223-229.

42-1652. EBERENZ, R. - Semiótica y morfologia textual del cuento naturalista $E$. Pardo Bazán, L. Alas "Clarín", V. Blasco Ibáñez) (N. 41-1765). \| HR, 60 (1992), 367-369 (Valis).

42-1653. GonZález ARIAS, Francisca - Portrait of a woman as artist. Emilia Pardo Bazán and the modern novel in France and Spain. - Garland, New YorkLondon, 1992. xxiii $+230 \mathrm{pp}$.

42-1654. HENN, DAvid - "Issues and individuals: Pardo Bazán's La piedra angular'. - Forum, 27 (1991), 358-369.

42-1655. LLÁcer, EuSEBIO - "Análisis microestructural de Los pazos de Ulloa"'. - KRQ, 38 (1991), 431-436. V. también núms. $656,1628$.

\section{Pereda, José María de}

42-1656. García Castañeda, SalvaDOR - "Del periodismo al costumbrismo: la obra juvenil de Pereda"'. KRQ 39 (1992), 33-39. 


\section{Pérez Galdós, Benito}

42-1657. PÉREz Galdós, Benito -

Fortunata y Jacinta. Ed., introd. y notas de A. Sotelo Vásquez. - Planeta, Barcelona, 1993. lxxi + 1046 pp.

42-1658. ANDERSON, FARRIS - "Madrid y el espacio de Miau'. - $\mathrm{CuH}$, 1993, núm. 521, 23-36.

42-1659. Beltrán Almería, L., y J. VARGAS GaRcÍA - "El discurso del personaje en la novela galdosiana'. - RLit, 53 (1991), 513-533.

42-1660. BENÍTEZ, RUBÉN - La literatura española en las obras de Galdós. (Función y sentido de la intertextualidad). - Universidad, Murcia, 1992. 271 pp. \| RHM, 46 (1993), 397-398.

42-1661. Bravo-Villasante, Carmen - "El último amor de Galdós". CuH, 1993, núm. 521, 37-40.

42-1662. BRownLOW, JEANnE P. “Epochal allegory in Galdós's Torquemada: The Ur-text and the episteme". - PMLA, 108 (1993), 294-307.

42-1663. Cabrejas, Gabriel - "Galdós y el suicidio". - CuLH, 1991, núm. 14, 191-201.

42-1664. Cabrejas, Gabriel - "Los niños de Galdós". - NRFH, 41 (1993), 333-351.

42-1665. Castaño Navarro, Ana "Las narraciones de viajes en Galdós'. - AP, 1991, núm. 12, 37-51.

42-1666. Cuenca Toribio, José Manuel - "Galdós, cronista parlamentario". CuH, 1993, núm. 521, 41-46.

42-1667. Dendle, BRIAN J. - Galdós $y$ la ndvela histórica. - Dovehouse, Ottawa, 1992. $106 \mathrm{pp}$.

42-1668. GOLD, HAZEL - The reframing of Realism. Galdo's and the discourses of the Nineteent-Century novel. - Duke University Press, Durham, 1993. x + 244 pp.

42-1669. GOLDMAN, PETER B., y ANDRÉs VILLAGRÁ - "Personajes y transformaciones en Fortunata y Jacinta". KRQ, 39 (1992), 61-70.

42-1670. Hoddie, JaMES H. - "Reexamen de un enigmático texto galdosiano: $E l$ doctor Centeno". - $\mathrm{CuH}, 1993$, núm. 521, 47-67.

42-1671. HOYLE, ALAN - "El trasfon- do irónico y económico de Miau". RLit, 53 (1991), 85-102.

42-1672. JAGOE, CATHERINE - "Krausism and the Pygmalion motif in Galdós's La familia de León Roch"'. - KRQ 39 (1992), 41-52.

42-1673. KIRSNER, ROBERT - "Catalonia en la obra de Galdós". - DLit, 11 (1993-94), núm. 1, 73-80.

42-1674. Montero-Paulson, Daría "El grupo de la mujer "natural" en la obra de Pérez Galdós". - CuH, 1993, núm. 521, 7-22.

42-1675. ONTAÑóN DE LOPE, PACIENCIA - “Lo prohibido, prólogo y epílogo de otras obras galdosianas". - NRFH, 40 (1992), 779-790.

42-1676. RibBans, GeOFFrey - History and fiction in Galdo's narratives. - Clarendon Press, Oxford, 1993. xvii +310 pp. 42-1677. Romero PÉrez, Francisco - "Abnormality as revealed in a structural analysis of Galdós' Fortunata $y$ Jacinta". - DLit, 10 (1992-93), núm. 1, 137-150.

42-1678. SCHNEPF, MichaEL A. - "From Galdós's La desheredada manuscript: Male characters in transition". KRQ, 39 (1992), 53-60.

42-1679. Sotelo VÁzQuez, M. "Ángel Guerra" de Benito Pérez Galdós y sus críticos (1891) (N. 41-1797). \|HR, 61 (1993), 110-112 (Tsuchiya).

42-1680. Toscano Lira, Teresa Retórica e ideología de la Generación de 1868 en la obra de Galdós. - Pliegos, Madrid, 1993. 224 pp.

42-1681. Ullman, Pierre L. - "A contrapuntal and Spenglerian approach to Misericordia". - $-H R, 60$ (1992), 321-339.

42-1682. VALIS, NOËL - "Fabricating culture in Cánovas". - $M L N, 107$ (1992), 250-273.

42-1683. Vilarós, Teresa M. - "La apropiación del cuerpo femenino: usura y avaricia en Fortunata y Jacinta'. KRQ, 39 (1992), 71-79.

42-1684. WIETELMANN BAUER, BETH - "For love and money: Narrative economies in Misericordia". $-M L N$, 107 (1992), 235-249.

42-1685. Willem, Linda M. (ed.) $-A$ sesquicentennial tribute to Galdós. 1843- 
1993. - Juan de la Cuesta, Newark, 1993. $360 \mathrm{pp}$.

42-1686. WILLEM, LINDA M. - "The narrative premise of Galdós's Lo prohibido"'. - KRQ, 38 (1991), 189-196.

V. también núms. $680,1611,1628$.
Querol, Vicente Wenceslao

42-1687. GRACIA, JORDI - "Ingredientes modernistas de un post-romántico: V. W. Querol'". - $A L E, 1992$, núm. 8, 83-94.

Rueda Santos; Salvador

42-1688. Aguilar Piñal, Francisco - "Una carta de Manuel Reina a Salvador Rueda"'. - RLit, 55 (1993), 161-166.

Rusiñol, Santiago

42-1689. MaRco García, ANTONIO "El modernismo, heredero de la estética romántica. A propósito de dos cartas de Santiago Rusiñol a Víctor Balaguer'. - ALE, 1992, núm. 8, 133-156.

Saża, Alejandro

42-1690. BORDONADA, ÁNGELA ENA "Alejandro Sawa: canto al sol de un escritor ciego"' - CuLH, 1991, núm. 14, 315-324.
Solis, Dionisio

42-1691. Gies, DAvID T. - "Hacia un catálogo de los dramas de Dionisio Solís (1774-1834)'. - BHS, 68 (1991), 197-210.

\section{Valera, Juan}

42-1692. VALERA, JUAN - Cartas a sus hijos. Ed. de M. Galera Sánchez. Publicaciones de la Diputación, Córdoba, 1991. 344 pp. (Estudios cordobeses). \| $B H i, 94$ (1992), 371-373 (Pageard).

42-1693. MolinA, José LuIS - "Las cartas inéditas de Juan Valera a Fernando A. del Olmet"'. - CuH, 1993, núm. 520, 45-54.

42-1694. NAVARRO, ANA - "Don Juan - Valera en Viena. Expediente diplomático y correspondencia política". - CuLH, 1991, núm. 14, 7-78.

42-1695. Ara Torralba, J. C., y D. HÜBNER TEICHGRÄBER - "Estrategias de la enunciación en las novelas de Juan Valera". - RLit, 54 (1992), 599-618.

42-1696. THURSTON-GRISWOLD, H. El idealismo sintético de don Jüan Valera: teoría y práctica (N. 41-1801). || RLit, 54 (1992), 427-430 (Díaz-Aguilar Pérez); $H R, 60$ (1992), 494-495 (DeCoster).

42-1697. THURSTON-GRISWOLD, 'HENRY - "Idealist bashing in Juan Valera's early novels". - KRQ 39 (1992), 467-474.

\section{Zayas y Beaumont, Antonio de}

42-1698. MANSBERGER AMORÓs, R:"Un parnasiano español bajo el signo de Heredia: Antonio de Zayas y Beaumont, duque de Amalf"': - RLit, 54 (1992), 619-637. 
Zorrilla, José

42-1699. ZoRrilla, JosÉ - Antología poética. Ed. de R. de la Fuente Ballesteros. - Espasa-Calpe, Madrid, 1993. 436 pp.

42-1700. ZORRILlA, José - Don Juan Tenorio. El capitán Montoya. Ed. de J. L. Picoche. - Taurus, Madrid, 1992. 351 pp. (Clás. Taurus, 15)

42-1701. ARIAS, JUDITH H. - "The Devil at Heaven's door: Metaphysical desire in Don Juan Tenorio". - HR, 61 (1993), 15-34.

\section{Hispanoamérica}

Alberdi, Juan Bautista

42-1702. Bueno, Mónica L. - "Lectura de una lectura: Juan Bautista Alberdi y el Facundo"'. - CuLH, 1992, núm. 15, 217-222.

Altamirano, Ignacio $M$.

42-1703. Rivas VelázQUez, AlejanDRO - "Altamirano y su nueva visión de la novela en El Zarco". - Reflexiones lingüísticas y literarias, t. 2, ed. R. Olea, y J. Valender (México, 1992), 169-185.

Bello, Andrés

42-1704. Berríos, MARIO - "El acto como fundación. Comentario a la Introducción de la filosofía del entendimiento de Andrés Bello". - CuA, 1992, núm. 34, 141-148.

42-1705. Cussen, ANTONIO - Bello and Bolivar. Poetry and politics in the Spanish American Revolution. - Cambridge
University Press, Cambridge, 1992. xiii + 208 pp. $\| M L N, 108$ (1993), 372-375 (Pratt).

Blest Gana, Alberto

42-1706. QUeR ANTICH, SANTIAGO "Chilenos y españoles en Durante la Reconquista". - LyL, 1992, núm. 5, 93-116.

Cambaceres, Eugenio

42-1707. Cambaceres, Eugenio - Sin rumbo. Ed. de R. Gnutzmann. - Universidad del País Vasco, Bilbao, 1993. 172 pp.

42-1708. Geirola, Gustavo - "Cuerpo, violencia y terrorismo en la escritura irónica del Eugenio Cambaceres". - CuLH, 1992, núm. 16, 111-144.

Carrasquilla, Tomás

V. núm. 1748 .

\section{Cisneros, Luis Benjamin}

42-1709. DiAZ, LISIAK-LAND - “Denuncia social de un romántico, a través de sus personajes, en Julia o escenas de la vida en Lima, de Luis Benjamín Cisneros, Perú, 1860"'. - Inti, 1991-92, núms. 34/35, 37-48.

\section{Darío, Rubén}

42-1710. DARÍO, RUBÉN - Autobiografía. Oro de Mallorca. Introd. de A. Piedra. 
- Mondadori España, Madrid, 1990. || RCLL, 1993, núm. 38, 411-413 (Montaldo).

42-1711. ACEREDA, ALBERTO - Rubén Dario, poeta trágico. Una nueva visión. - Teide, Barcelona, 1992. 188 pp. (El escritor y su literatura). || Anthropos, 1993, núms. 142/143, 167-168 (Mantero).

42-1712. LlOPESA, R. - "Las fuentes literarias de "La ninfa" de Rubén Darío". - RLit, 54 (1992), 247-255.

42-1713. MatTalía, SONIA - "El canto del "auran: autonomía y mercado literario en los cuentos de $\mathrm{Azul}$..." RCLL, 1993, núm. 38, 279-292.

42-1714. PÉREZ, ALBERTO JULIÁN - La poética de Rubén Dario. Crisis postromántica y modelos literarios modernistas. - Orígenes, Madrid, 1992. $218 \mathrm{pp}$.

V. también núm. 2028.

\section{Díaz Mirón, Salvador}

42-1715. DELGado JenKins, HumberTO - "Realismo y poesía en "Ejemplon". - DLit, 9 (1991-92), núm. 2, 49-53.

Fernández de Lizardi, José Joaquín

42-1716. FERNÁNDEZ DE LIZARDI, JOSÉ JOAQUín - Don Catrín de la Fachenda y Noches tristes y día alegre. E. de J. Rea Spell. $9^{a}$ ed. - Porrúa, México, 1994. xxiii +220 pp.

42-1717. FLORES, ENRIQUe - "El loro de Lizardi. Lectura en voz alta del $P_{e}$ riquillo Sarniento". - LMM, 3 (1992), 7-39.

\section{Gómez de Avellaneda, Gerirudis}

42-1718. Garfield, E. P. - "Periodi- cal literature for women in midnineteenth century Cuba: The case of Gertrudis Gómez de Avellaneda's Álbum cubano de lo bueno y lo bello". SLAPC, 11 (1992), 13-28.

42-1719. LÁZARO GURTABAY, REYES "La naturaleza como espejo de contradicciones del discurso abolicionista en Sab". - DLit, 11 (1993-94), núm. 1, 51-62.

42-1720. VOLEK, EMIL - "Cartas de amor de la Avellaneda". - CuH, 1993, núm. 511, 103-113.

\section{González, Juan Vicente}

42-1721. UNZUETA, FernANDO - "Juan Vicente González: de la biografía a la escritura de la nación". - EUSB, 1993, núm. 1, 19-27.

\section{Gutiérrez Nájera, Manuel}

42-1722. GutiÉrREz NÁJERA, MaNuEL - Cuentos frágiles. Ed. y pról. de A. Bustos Trejo. - UNAM, México, 1993. $139 \mathrm{pp}$.

42-1723. ClaARK DE LARA, BELEM "Paréntesis (1882), cuento parisiense de Manuel Gutiérrez Nájera". $L M M, 3$ (1992), 171-179.

Hernández, José

42-1724. WEINBERg DE MAgis, LiLIANA - "Encuentro de dos mundos: voces y silencios en el Martín Fierro". - Reflexiones lingüísticas y literarias, t. 2, ed. R. Olea, y J. Valender (México, 1992), 187-206.

V. también núm. 1826. 
Herrera y Reissig, Julio

V. núm. 1817.

\section{Mansilla, Lucio Victorio}

42-1725. Montero, María L. - "Lucio V. Mansilla y sus bibliotecas". $B A A L, 56$ (1991), 103-128.

\section{Martí, José}

42-1726. MARTí, José - La edad de oro. Ed. de F. Escobar. - San Judas Tadeo, San José (Costa Rica), 1993. 168 pp.

42-1727. CRUZ, J. - “"Esclava vencedora»: la mujer en la obra literaria de José Martí"'. - H, 75 (1992), 30-37. 42-1728. EтTE, OTTMAR - José Martí. Apostel - Dichter - Revolutionär. Eine Geschichte seiner Rezeption. T. 1. - M. Niemeyer, Tübingen, 1991. $\mathrm{x}+457$ pp. \|RJ, 43 (1992), 360-363 (MeyerMinnemann); RCLL, 1993, núm. 38, 406-411 (Morales Saravia).

42-1729. ETTE, OTTMAR - "La polisemia prohibida: la recepción de José Martí como sismógrafo de la vida política y cultural'. - CuA, 1992, núm. 32, 196-211.

42-1730. FERnández REtamar, RoBERTO - "Más de cien años de previsión. Algunas reflexiones sobre el concepto martiano de Nuestra América'. - CuA, 1993, núm. 40, 65-77.

42-1731. FERnÁNDEZ RETAMAR, Ro. BERTO - "Nuestra América: cien años". - NRFH, 40 (1992), 791-806.

42-1732. FERNÁNDEZ RETAMAR, RoBERTO - "Sobre la edición cubana de Martí, el apóstol". - RCLL, 1993, núm. 37, 345-351.

42-1733. Fornet Betancourt, Raúl - "La Conquista: ¿una desdicha his- tórica? Una aproximación al problema desde José Martî'. - CuA, 1992, núm. 32, 186-195.

42-1734. Giorgis, Liliana - "José Martí y la utopía de un "humanismo social»". - CuA, 1992, núm. 34, 157163.

42-1735. Mestas, JUAN E. - El pensamiento social de José Martí: ideología y cuestión obrera. - Pliegos, Madrid, 1993. $175 \mathrm{pp}$.

42-1736. TEJA, A. M. - La poesía de José Martí entre naturaleza e historia. Estudios sobre la antitesis y la sintesis (N. 411857). \| HR, 60 (1992), 514-516 (González).

V. también núms. $642,647,655,683$, 1824.

Mateos, Juan A.

42-1737. Mateos, Juan A. - El sol de mayo. Memorias de la Intervención. Est. prelim. de C. Díaz y de Ovando. $3^{\text {a }}$ ed. - Porrúa, México, 1993. (Sepan cuantos, 197).

Palma, Ricardo

42-1738. ANDreU, Alicia G. - " "Amor de madre»: paradigma intertextual en la obra de Ricardo Palma". DLit, 10 (1992-93), núm. 2, 9-22.

Riva Palacio, Vicente

42-1739. Riva Palacio, Vicente Monja y casada, virgen y mártir. Ed. y pról. de A. Castro Leal. $6^{\text {a }}$ ed. - Porrúa, México, 1993. 2 ts.: xii +703 pp. (Colección de escritores mexicanos, 1819). 
Ros de Olano, Antonio

42-1740. HaFter, MONROE Z. - "Magnetism and corn plaster in El doctor Lanuela". - KRQ 38 (1991), 175-188.

Sarmiento, Domingo Faustino

42-1741. Alonso, Carlos J. - " Reading Sarmiento: Once more, with passion". - HR, 62 (1994), 35-52.

42-1742. CRiscenti, JosePH T. (ed.) Sarmiento and his Argentina. - Lynne Rienner, Boulder, 1993. 216 pp.

42-1743. GARRELS, ElizABETH "Traducir a América: Sarmiento y el proyecto de una literatura nacional". - RCLL, 1993, núm. 38, 269-278.

42-1744. PAgÉS LARRAYA, ANTONIO "El adiós de Sarmiento". - $B A A L$, 56 (1991), 341-394.

42-1745. Pellicer, James O. - "Vicente Fidel López en el Facundo". $B H S, 68$ (1991), 489-501.

\section{Senillosa, Felipe}

42-1746. Curia, BEATrIZ - "Una loa desconocida de Felipe Senillosa: Al héroe de los Andes. Cuadro alegórico de la Revolución de Américas para el 25 de mayo del año 90 de nuestra libertad. Buenos Aires, 1819". - Incipit, 1992, núm. 12, 71-96.

Sierra O'Reilly, Justo

42-1747. POOT HERRERA, SARA - “ $L a$ hija del judío, entre la Inquisición y la imprenta'. - NRFH, 40 (1992), 761 . 777.
Silva, José Asunción

42-1748. NARANJO MESA, JORgE AlberTO - "Silva y Carrasquilla". RUAn, 1992, núm. 227, 52-63.

- 42-1749. Villaverde, Girilo - Cecilia Valdés o La Loma del Ángel. Ed. de J. Lamore. - Cátedra, Madrid, 1992. 638 pp. (Letras hispánicas, 345).

42-1750. SOMMER, DORIS - "Cecilia no sabe, o los bloqueos que bloquean". - RCLL, 1993, núm. 38, 239-248.

\section{SIGLO XX}

Argentina

Aira, César

42-1751. Fernández, NANCy P. "Juegos y pasajes en Ema, la cautiva, de César Aira”. - CuLH, 1992, núm. 15, 233-236.

Aloisi, Enzo

42-1752. Troiano, James - "Life as theater in Aloisi's Nada de Pirandello, por favor". - Inti, 1991-92, núms. 34/35, 159-168.

Arlt, Roberto

42-1753. CORRAL, ROSE - El obsesivo circular de la ficción. Asedios a "Los siete locos" y "Los lanzallamas". - F.C.E.El Colegio de México, México, 1992. $119 \mathrm{pp}$. 
42-1754. Mattalia, Sonia - "Modernización y desjerarquización cultural: el caso Arlt (de La vida puerca a El amor brujo)". - RevIb, 58 (1992), 501-516.

V. también núms. $653,1831$.

Arrieta, Rafael Alberto

42-1755. HerRera, Ricardo H. "Cuatro poemas y una imagen de $\mathrm{Ra}$ fael Alberto Arrieta". - Incipit, 1992, núm. 12, 199-208.

\section{Asis, Jorge}

42-1756. KATRA, W. H. - "Novelizando el proceso argentino: La calle de los caballos muertos de Jorge Asís". $R C L L, 1992$, núm. 35, 147-153.

\section{Banchs, Enrique}

42-1757. Meo Zilio, Giovanni - “A propósito de ecos petrarquistas en el argentino Enrique Banchs'. - NRFH, 40 (1992), 909-920.

\section{Bioy Casares, Adolfo}

42-1758. Barrera, TRINIDAD - "Adolfo Bioy Casares, la aventura de vivir'. - RevIb, 58 (1992), 343-355.

42-1759. DOWLING, LEE H. - "Derridean "traces" in La invención de Morel by Bioy Casares"'. - DLit, 9 (199192), núm. 2, 55-66.

V. también núm. 1772.

\section{Borges, Jorge Luis}

42-1760. Aizenberg, E. (ed.) - Borges and his successors: The Borgesian impact on literature and the arts (N. 41-1929). $\| H$, 75 (1992), 331-332 (Lindstrom).

42-1761. AIZENBERG, EDNA - “Borges, precursor postcolonial". - Fil, 25 (1990), 3-23.

42-1762. Ammon, Theodore G. "A note on a note in "The library of Babel"'. - RNo, 33 (1992-93), 265269.

42-1763. BALderston, DANIEL - Out of context: Historical reference and the representation of reality in Borges. - Duke University Press, Durham, NC, 1993. $216 \mathrm{pp}$.

42-1764. BALMASEDA MAESTU, ENRIQUE - "Borges: el poeta y la poesía en sus versos". - CuIF, 18 (1992), 159-180.

42-1765. BARRENEchea, ANA María - "Jorge Luis Borges y la ambivalente mitificación de su abuelo paterno". - NRFH, 40 (1992), 1005-1024.

42-1766. BERG, WALTER BRUNO "Neue Welt und alter Buchstabe, oder: Ist Borges ein lateinamerikanischer Schriftsteller?' '. $-I, 1992$, núm. 35, 84-97.

42-1767. BLÜHER, KARL ALFRED, y ALFONSO DE TORO - Jorge Luis Borges. Variaciones interpretativas sobre sus procedimientos literarios y bases epistemológicas. - Vervuert, Frankfurt/M, 1992. $228 \mathrm{pp}$. (Teoría y crítica de la cultura y literatura, 2).

42-1768. BORELLO, RODOLFO A. - "Situación, prehistoria y fuentes medievales: "El aleph» de Borges". - $B A A L$, 57 (1992), 31-48.

42-1769. BRODZKI, BELLA - "Borges and the idea of woman". - DLit, 10 (1992-93), núm. 2, 33-51.

42-1770. Cervera Salinas, Vicente - La poesía de Jorge Luis Borges: Historia de una eternidad. - Universidad, Murcia, 1992. 243 pp. (Cuadernos, 43).

42-1771. FishburN, E., \& P. HuGHES (eds.) $-A$ dictionary of Borges. Forewords by $\mathbf{M}$. Vargas Llosa and $A$. Burgess (N. 41-1936). \| HR, 60 (1992), 390-391 (Alazraki); H, 75 (1992), 330-331 (Woods).

42-1772. Gambetta, AídA - "Entre el espejo y la máscara: H. Bustos Do- 
mecq". - Morphé, 1993, núm. 8, 99110.

42-1773. Guitarte, Guillermo L. "Obras de Borges que pertenecían a Amado Alonso en Harvard University. (Reimpresión)'”. - Incipit, 1992, núm. 12, 143-156.

42-1774. GUitarte, GuILlermo L. "Obras de Borges que pertenecieron a Amado Alonso en Harvard University'. - Incipit, 1991, núm. 11, 161174.

42-1775. LOEWENSTEIN, C. JARED Descriptive catalogue of the Jorge Luis Borges collection at the University of Virginia Library. - University Press of Virginia, Charlottesville, 1993. xvi +254 pp.

42-1776. MENESES, CARLOS (coord.) Jorge Luis Borges. Una teoría de la invención poética del lenguaje. - Anthropos, Barcelona, 1993. $191 \mathrm{pp}$.

42-1777. NÁllim, Carlos ORLando - "Borges y Cervantes, Don Quijote y Alonso Quijano"'. - NRFH, 40 (1992), 1047-1056.

42-1778. Olea Franco, Rafael “Borges, ¿civilización o barbarie?”. - Reflexiones lingüisticas y literarias, t. 2, ed. R. Olea, y J. Valender (México, 1992), 225-250.

42-1779. Olea Franco, RAFAel - El otro Borges. El primer Borges. - El Colegio de México-F.C.E., México, 1993. $300 \mathrm{pp}$.

42-1780. PAOLI, ROBERTO - Tre saggi su Borges. - Bulzoni, Roma, 1992.

42-1781. PASTERNAC, NORA - "El anticervantismo de Borges: de Paul Groussac a Pierre Menard'. - Estudios, 1992, núm. 31, 51-66.

42-1782. PLANELLS, ANTONIO - "Jorge Luis Borges y el tótem canadiense". - RCEH, 16 (1991-92), núm. 2, 293-306.

42-1783. RODRÍGUEZ-LUIS, JULIO "Los borradores de Pierre Menard". - NRFH, 40 (1992), 1025-1045.

42-1784. ROJAS, SANTIAGO - "El desdoblamiento creador-personaje en Borges: usos y logros de creación". DLit, 10 (1992-93), núm. 2, 141-153.

42-1785. SARLO, BEATRIZ - Jorge Luis Borges. A writer on the edge. Ed. by J. King. - Verso, London, 1993. xvii
$+148 \mathrm{pp}$.

42-1786. SGARANO, TOMMASO, e MANUELA SASSI - Concordanze per lemma dell'opera in verso di J. L. Borges: Mauro-Baroni, Viareggio-Lucca, 1992. $955 \mathrm{pp}$.

42-1787. SiEBENMANN, GuSTAV - “Ein deutsches Requiem für Borges. Feststellungen und Materialen zu seiner Rezeption". - I, 1992, núm. 36, 52-72.

42-1788. STABB, M. - Borges revisited (N. 41-1949). \| HR, 61 (1993), 594596 (Bosteels).

42-1789. STANDish, PeTER - "On lexical clues to reading Borges"' $R C E H, 16$ (1991-92), núm. 2, 340344.

42-1790. STEPHENS, CYNTHIA - "Borges, De Quincey and the interpretation of words". - KRQ, 39 (1992), 481-487.

42-1791. TENORio, Martha Lilia "Primeras inquisiciones. Teoria y práctica de la metáfora en el primer Borges'. - Reflexiones lingüísticas y literarias, t. 2, ed. R. Olea; y J. Valender (México, 1992), 207-224.

42-1792. URRACA, BEATRIZ - "Wor(1)ds through the looking-glass: Borges's mirrors and contemporary theory". - RCEH, 17 (1992-93), núm. 1, 153176.

V. también núms. $637,674,679$; 688, $760,1831$.

\section{Cortázar, Julio}

42-1793. Berg, WALTER BRUNO Grenz-Zeichen Cortázar; Leben und Werk eines argentinischen Schriftstellers der $\mathrm{Ge}$ genwart. - Vervuert, Frankfurt am Main, 1991. 424 pp. || Carav, 1992, núm. 58, 216-220 (Hina).

42-1794. BOCCHINO, ADRIANA A. "La estrategia del híbrido: realidad/la otra realidad en Rayuela de Julio Cortázar'. - I, 1992, núm. 36, 107-112.

42-1795. CUNNINGHAM, RODGER "Falling into heaven: Pre-adamism and paradox in Rayuela". - Inti, 
1991-92, núms. 34/35, 93-106.

42-1796. FERNÁNDEZ FERRER, ANTONIO - "El "disparate claro" en Cortázar y Piñera”. - RevIb, 58 (1992), 423-436.

42-1797. GnutzmanN, Rita - "Los "autores" de Rayuela". - CuLH, 1991, núm. 14, 181-189.

42-1798. JUAN-NAVARRO, SANTIAGO "Un tal Morelli: teoría y práctica de la lectura en Rayuela, de Julio Cortázar'. - RCEH, 16 (1991-92), núm. 2, 235-252.

42-1799. KNICKERBOCKER, DALE - "La teoría literaria implícita en "Diario para un cuento" de Julio Cortázar'. - Inti, 1991-92, núms. 34/35, 151158.

42-1800. LindSTROM, NAOMI - "Cortázar's books of juxtaposition: Clues from Adorno". - DLit, 9 (1991-92), núm. 2, 67-74.

42-1801. MORA, CARMEN DE - "Aproximación a la poética de Cortázar a partir de sus cuentos". - Syntaxis, 1992, núms. 30/31, 119-126.

42-1802. Nifantani, Marco - "El concepto de juego en Cortázar', Fstudios, 1993, núm. 34, 69-76S.

42-1803. PEAVLER, T. J. - Julio Cortázar (N. 41-1966). \| KRQ 39 (1992), 382-383 (Llácer); HR, 61 (1993), 310312 (Mac Adam).

42-1804. YOUNG, RICHARD A. - "La poética de la flor en "El otro cielo", de Julio Cortázar', - KRQ 39 (1992), 347-354.

42-1805. YOUNG, Richard A. - ' $O c$ taedro" en cuatro tiempos (texto y tiempo en un libro de Cortázar). - Dovehouse, Ottawa, 1993. 265 pp.

V. también núms. $688,693$.

\section{Fernández Moreno, César}

42-1806. MARTÍNEZ, JUANA - “Una lectura con ambages (sobre Ambages de César Fernández Moreno)"'. - RevIb, 58 (1992), 477-487.

\section{Gálvez, Manuel}

42-1807. Dellepiane, Ángela B. "Tránsito Guzmán: una olvidada novela de Gálvez”. - BAAL, 57 (1992), 49-86.

42-1808. WALKeR, JOHN - "Manuel Gálvez y la novela de la confesión". -DLit, 9 (1991-92), núm. 2, 99-113.

Gambaro, Griselda

42-1809. TOMPKINS, CYNTHIA - “El poder del horror: abyección en la narrativa de Griselda Gambaro y Elvira Orphée". - RHM, 46 (1993), 179192.

\section{Gerchunoff, Alberto}

42-1810. Salgado Gordon, M. - "Alberto Gerchunoff and the "Bridge" on the River Plate". - $H, 75$ (1992), 287-293

Girondo, Oliverio.

42-1811. ANDERSON IMBERT, ENRIQUe - "El Girondo que conocí". - $B A$ $A L, 56$ (1991), 503-512.

42-1812. Castagnino, Raúl H. "Oliverio Girondo". - BAAL, 56 (1991), 495-501.

42-1813. JUZYN-AMEstoy, Olga "Oliverio Girondo: la otra cara del carnaval'. - DLit, 10 (1992-93), núm. 1, 69-91.

42-1814. Veiravé, AlFredo - "El universo poético de Oliverio Girondo'. - BAAL, 56 (1991), 513-532. 
Güiraldes, Ricardo

42-1815. GüIRALDES, R. - Don Segundo Sombra, ed. A. B. Dellepiane (N. 411973). \| H, 75 (1992), 99-100 (Lichtblau).

42-1816. SPICE, JuAN Pablo - "Don Segundo Sombra: en busca del "otro»". - RCLL, 1993, núm. 38, 361-373.

V. también núm. 1819.

\section{Lugones, Leopoldo}

42-1817. KIRKPATRICK, G. - The dissonant legay of modernismo. Lugones, Herrera $y$ Reissig, and the vocies of modern Spanish American poetry (N. 41-1980). || Ibero, 1992, núm. 45, 83-87 (Niemeyer).

42-1818. NaHarro Calderón, JosÉ MARÍA - "Escritura fantástica y destruccióry' realista en Las fuerzas extrañas de Leopoldo Lugones". - $H R, 62$ (1994), 23-34.

42-1819. VIDELA DE RIVERO; GLORIA - "Textualización de la montaña andina en poemas de Lugones, Güiraldes y Ramponi". - Incipit, 1992, núm. 12, 123-141.

\section{Marasso, Arturo}

42-1820. Calyetti, Jorge - "La poética de Arturo Marasso". - $B A A L$, 55 (1990), 285-294.

42-1821. PELTZER, Federico - " "Arturo Marasso, ensayista y crítico literario". - BAAL, 55 (1990), 295-301:

Martínez Estrada, Ezequiel

42-1822. BuRgOS, NIDIA - "Un documento inédito de Martínez Estrada". - CuA, 1993, núm. 42; 157-164.

42-1823. EARLE, PETER G. - "Las so- ledades de Martínez Estrada". CuA, 1993, núm. 42, 148-156.

42-1824. FERNÁNDEZ RETAMAR, RoBERTO - "Desde Martí de Ezequiel Martínez Estrada”. - CuA, 1993, núm. 42, 131-147.

42-1825. WEINBERG, LILIANA IRENE "Ezequiel Martínez Estrada y el universo de la paradoja". - CuA, 1993, núm. 42, 165-199.

42-1826. WEINBERG DE MAGIS, LILIANA

- Ezequiel Martinez Estrada y la interpretación del "Martín Fierro". - UNAM, México, 1992. 217 pp. \| CuA, 1993, núm. 40, 229-234 (Andueza).

V. también núm. 913 .

\section{Martínez, Tomás Eloy}

42-1827. Berc, AdGardo H.- - "Pensar la historia a través de la ficción: $L a$ novela de Perón de Tomás Eloy Martínez'’. - CuLH, 1992, núm. 16, 105109.

\section{Moyano, Daniel}

42-1828. ROCA MARTÍNEZ, JOSÉ LUIS, y Virginia Gil AMATE - "Exilio, emigración y destierro en la obra de Daniel Moyano". - RevIb, 58 (1992), 581-596.

Mujica Láinez, Manuel

42-1829. Fernández Ariza, GuadaluPE - "El unicornio de Manuel Mujica Láinez: tradición literaria y constantes genéricas". - RevIb; 58 (1992), 407421 .

42-1830. FERrari, Alcira RaQUel "Un cuento de Manuel Mujica Láinez de Misteriosa Buenos Aires (1952): análisis de la operatoria de los intertextos en la creación narrativa". - 
Incipit, 1992, núm. 12, 97-122.

Orphee, Elvira

V. núm. 1809.

Piglia, Ricardo

42-1831. GNutzmanN, Rita - "Homenaje a Arlt, Borges y Onetti de Ricardo Piglia'. - RevIb, 58 (1992), 437-448.

42-1832. GRANDIS, RITA - "La cita como estrategia narrativa en Respiración artificial'. - RCEH, 17 (199293), núm. 2, 259-269.

42-1833. Romano Thuesen, Evelia A. - "Marcelo: el presente sin presencia en Respiración artificial de Ricardo Piglia'. - NRFH, 41 (1993), 279291.

\section{Puig, Manuel}

42-1834. BACARISSE, PAMELA - Impossible choice: The implications of the cultural references in the novels of Manuel Puig. University of Calgary Press, Calgary, 1993. x + 172 pp.

42-1835. Cuervo Hewitt, Julia "El texto ausente: silencios y reticencias de una época en El beso de la mujer araña de Manuel Puig'. - DLit, 10 (1992-93), núm. 2, 63-72.

42-1836. Drucaroff, Elsa - "Para escribir una novela familiar: sobre $L a$ traición de Rita Hayworth de Manuel Puig". - Fil, 25 (1990), 111-132.

42-1837. Herrero Olaizola, AlejanDRO - "Condenados por leer: lectura y lectores de Puig en Maldición eterna a quien lea estas páginas'. - HR, 61 (1993), 469-482.

42-1838. HunTer, Priscilla - "Molina and the heaving goddesses: Thread imagery in Manuel Puig's El beso de la mujer araña". - Critical essays on the literatures of Spain and Spanish America, eds. L. T. González del Valle \& J. Baena (Boulder, 1991), 133-144.

42-1839. Robles, Mireya - “Evasión testimonial y constancia eterna de una angustia: un título kitsch para Manuel Puig. In memoriam"'. - CuLH, 1992, núm. 16, 175-180.

\section{Ramponi, Jorge Enrique}

V. núm. 1819.

Sábato, Ernesto

42-1840. BACH, C. - "Ernesto Sábato, palabras de la conciencia. Un existencialista argentino sondea la tenebrosidad en la naturaleza humana". - Rev$I b, 58$ (1992), 45-51.

42-1841. Botero, J. C. - “La lucidez salvadora de Ernesto Sábato". - RevIb, 58 (1992), 61-67.

42-1842. Dellepiane, A. - "Ernesto Sábato o la historia de una pasión". - RevIb, 58 (1992), 217-222.

42-1843. Ferreira, A. P. - "El túnel de Ernesto Sábato en busca del origen". - RevIb, 58 (1992), 91-103.

42-1844. FIGUEIREDO, G. - "Humilde apología de Ernesto Sábato". - RevIb, 58 (1992), 247-251.

42-1845. HolzaPFEL, T. - "Sobre héroes y tumbas: novela del siglo". - ReoIb, 58 (1992), 177-181.

42-1846. KASNER, N. M. - "Metafísica y soledad: un estudio de la novelística de Ernesto Sábato'. - RevIb, 58 (1992), 105-113.

42-1847. LOJO DE BEUTER, M. R. "La mujer simbólica en Abaddón el exterminador". - RevIb, 58 (1992), 183-192.

42-1848. MATURO, G. - "Vida y obra: la poética humanista de Ernesto Sábato". - RevIb, 58 (1992), 53-59. 
42-1849. MONTIEL, L. - "Sábato, Sum$m a "$. - RevIb, 58 (1992), 233-245.

42-1850. MújICA, H. - "Ernesto Sábato: la humilde esperanza de otro mañana". - Rev1b, 58 (1992), 153-160.

42-1851. Roggiano, AlFredo - "Crono bio-bibliografía seleccionada y comentada de Ernesto Sábato. Itinerario del hombre y del escritor'. - RevIb, 58 (1992), 15-32.

42-1852. SAUTER, S. - "Proceso creativo en la obra de Ernesto Sábato". RevIb, 58 (1992), 115-151.

42-1853. Scarano, Mónica Elsa "El tema de la argentinidad en la obra de Ernesto Sábato. La inclusión del discurso ensayístico en la prosa de ficción". - CuLH, 1992, núm. 15, 129156.

42-1854. SEgrE, C. - "Ernesto Sábato o la lucha por la razón'. - RevIb, 58 (1992), 223-232.

42-1855. SEgUI, A. F. - "Los cuatro sueños de Castel en El túnel de Ernesto Sábato'. - RevIb, 58 (1992), 69-80.

42-1856. STEENMEIJER, M. - "Neurosis epistemológica. El túnel como novela modernista". - RevIb, 58 (1992), 81-90.

42-1857. URBINA, N. - "La estructura narrativa de Sobre héroes y tumbas de Ernesto Sábato: aplicación de un método"'. - RevIb, 58 (1992), 161-176.

V. también núms. 674,749 .

\section{Saer, Juan José}

42-1858. CROCE, MARCEla - "Las cicatrices repetitivas de la tradición: la narrativa de Juan José Saer'. - Fil, 25 (1990), 49-110.

\section{Traba, Marta}

42-1859. García Serrano, M. VictoRIA - "Incompatibilidades: existencialismo y feminismo en "La identificación" de Marta Traba". - Inti,
1991-92, núms. 34/35, 131-140.

$$
\text { Ugarte, Manuel }
$$

V. núm. 642.

Valenzuela, Luisa

42-1860. CORDONES-COOK, JUANAMARíA - "Como en la guerra, en busca del Otro". - RCEH, 16 (1991-92), núm. 2, 171-185.

42-1861. MuÑoz, Willy O. - "Luisa Valenzuela: tautología lingïística y/o realidad nacional". - $R C E H, 17$ (1992-93), núm. 2, 333-342.

Bolivia

$$
\text { Arguedas, Alcides }
$$

V. núm. 1862.

\section{Tamayo, Franz}

42-1862. IRUROZQUI VICTORIANO, MARTA - "¿Qué hacer con el indio? Un análisis de las obras de Franz Tamayo y Alcides Arguedas". - RIM, 52 (1992), 559-587.

\section{Chile}

\section{Allende, Isabel}

42-1863. GaMaCHO-GINGERICH, ALINA - "La mujer ante la dictadura en las 
dos primeras novelas de Isabel Allende"'. - DLit, 9 (1991-92), núm. 2, 13-25.

42-1864. Carval.ho, Susan DE - " Escrituras y escritoras: The artistprotagonists of Isabel Allende', DLit, 10 (1992-93), núm. 1, 59-67.

42-1865. PARKINSON ZAMORA, LOIS -

"The magical tables of Isabel Allende and Remedios Varo". - CL, 44 (1992), 113-143.

Blanco, Guillermo

42-1866. BLANCO MARTÍNEZ, GUILleRMO - "Camisa limpia, sus yos y sus circunstancias". - $L y L$, 1992, núm. $5,13-24$.

Bombal, María Luisa

42-1867. TOlliver, JOYCE - " OOtro modo de ver": The gaze in La última niebla'. - RCEH, 17 (1992-93), núm. 1, 105-121.

Donoso, José

42-1868. GonZÁlez, Flora - "'Masking history in Donoso's Taratuta". RCEH, 17 (1992-93), núm. 1, 47-62. 42-1869. LEMOGODEUC, JEAN MARIE - "Las máscaras y las marcas de la autobiografía. La cuestión del narrador en El jardín de al lado de José Donoso". - - RCLL, 1993, núm. 38, 383392.

42-1870. MAGNARELli, SHaRON - Understanding José Donoso. - University of South Carolina Press, Columbia, 1993. xii +192 pp.

42-1871. MURPHY, MARIE - Authorizing fictions: José Donoso's "Casa de campo". - Tamesis, London, 1992. $113 \mathrm{pp}$.
Edwards Bello, Joaquín

42-1872. JONES, JULIE - "The hero as flâneur: Edwards Bello's Criollos en París". - Inti, 1991-92, núms. 34/35, 141-148.

Edwards, Jorge

42-1873. EDWARDS, J. - Adiós, poeta. . (N. 41-2014). \| CuLH, 1992, núm. 15, 240-241 (Gnutzmann).

\section{Eltit, Diamela}

42-1874. LÉRtora, JUAN CARlos "Categorías posmodernistas y la narrativa de Diamela Eltit”. - $L y L$, 1992, núm. 5 , 65-73.

\section{Hahn, Óscar}

42-1875. LASTRA, P., y E. LiHN (eds.) - Asedios a Oscar Hahn (N. 41-2015). \| $R C L L, 1992$, núm. 35, 175-176 (Uribe).

\section{Huidobro, Vicente}

42-1876. Huidobro, ViCENTE - "Jimena”. - Atenea, 1993, núm. 467, 97-99.

42-1877. AguirRe, Mariano - " Huidobro narrador'. - Atenea, 1993, núm. 467, 101-102.

42-1878. Arenas, Braulio - "Vicente Huidobro y el creacionismo". Atenea, 1993, núm. 467, 23-63.

42-1879. Astorga, Luz María "Rasgos humanos de un gran poeta". - Atenea, 1993, núm. 467, 81-96. 
42-1880. Castro Morales, Belén " "Os traigo los recuerdos de Altazor". Creacionismo y metapoesía en Ver $y$ palpar, de Vicente Huidobro". RevIb, 58 (1992), 379-392.

42-1881. ECHEVERRÍA, LIDIA NEGHME - "Vicente Huidobro: su obra vanguardista inicial". - $H R, 60$ (1992), 285-299.

42-1882. ESPINOSA, ISMAEL - "Las ediciones originales de Vicente Huidobro. (Ensayo de una bio-bibliografía)". - Atenea, 1993, núm. 467, 103122.

42-1883. ESPINOSA, ISMAEL - "Significàdo de Altazor". - Atenea, 1993, núm. 467, 123-125.

42-1884. GeLADO, V. - "La apropiación como operación de la cultura: el Mio cid Campeador de Vicente Huidobro". - RCLL, 1992, núm. 35, 2131.

42-1885. HAHN, OSCAR - "Huidobro: un niño de cien años". - Atenea, 1993, núm. 467, 67-74.

42-1886. MONTES BRUNET, HUGO "La maestría de Huidobro". Atenea, 1993, núm. 467, 137-141.

42-1887. QUIROGA, JosÉ - "El entierro de la poesía: Huidobro, Nietzsche y Altazor". - MLN, 107 (1992), 342-362.

42-1888. QUIROGA, JOSÉ - "Vicente Huidobro: The poetics of the invisible texts". - H, 57 (1992), 516-526.

42-1889. ROJAS, GoNZALO - "Huidobro de repente". - Atenea, 1993, núm. 467, 65-66.

42-1890. VAldovinos, HeRNÁN "Vicente Huidobro y Altazor". Atenea, 1993, núm. 467, 127-136.

V. también núms. $636,652,690$. trar unas fotografias de San Antonio de Atitlán” de Enrique Lihn". - Inti, 1991-92, núms. 34/35, 79-92.

V. también núms. 686,687 .

\section{Mistral, Gabriela}

42-1893. ARrigoitia, LUIS DE - Pensamiento y forma en la obra de Gabriela Mistral (N. 41-2029). \| ALM, 30 (1992), 311-313 (Silva Aldrete).

42-1894. DAYDí-TOLSON, S: - El último viaje de Gabriela Mistral (N. 41-2031). ॥ $H R, 60$ (1992), 252-253 (Mora).

42-1895. ZAÏTZEFF, SERge I. - "Cartas de Gabriela Mistral a Genaro Estrada". - CuA, 1993, núm. 37, 115131.

\section{Neruda, Pablo}

42-1896. Blume SÁNChez, JAIME "El tema de la mujer en Canto General de Neruda". - LyL, 1992, núm. 5, 27-37.

42-1897. GutiÉRrez RevUelta, PEDRo - "Fernando Villalón, el amigo desconocido de Pablo Neruda". - $\mathrm{CuH}$, 1993, núms. 514/515, 307-311.

42-1898. MELIS, ANTONIO - "Poesía y política en Las uvas y el viento". RCLL, 1993, núm. 38, 123-130.

42-1899. VARELA, JOSÉ R. - "El tema de la alienación en La rosa separada de Pablo Neruda"'. - RCEH, 17 (199293), núm. 1, 177-206.

V. también núms. 636, 652, 687, 728.

\section{Parra, Nicanor}

42-1891. Ostria GonzÁlez, M. "Enrique Lihn o la desdicha sin respuesta". - RCLL, 1992, núm. 35, 49-60.

42-1892. SARMIENTO, ÓSCAR D.- "Ironía de la lectura en "Versos para ilus-
42-1900. PARRa, NicANOR - Poemas para combatir la calvicie; muestra de antipoesía. Comp. de Julio Ortega. Consejo Nacional para la Cultura y las Artes, México, 1993. 
42-1901. Lafuente, Silvia - "Presencia de lo popular en el itinerario poético de Nicanor Parra'. - QIA, 1993, núm. 73, 49-64.

42-1902. ORTEGA, JULIO - "Voces de Nicanor Parra". - H, 75 (1992), 601-602.

Prado, Pedro

42-1903. Massone, JuAn Antonio "Poesía y anécdota de Pedro Prado (1886-1952)'. - L LL, 1992, núm. 5, 75-92.

Rojas, Gonzalo

42-1904. ARAYA, JUAN GABriel "Conversaciones con Gonzalo Rojas". - Atenea, 1992, núms. 465/466, 269-280.

42-1905. GIORDANO, JAIME - "Más allá de las palabras: Gonzalo Rojas”'. - Atenea, 1993, núm. 467, 187-196.

\section{Valdivieso, Mercedes}

42-1906. Fuente, JOSÉ AlBERTO DE LA - "La narrativa de Mercedes Valdivieso: de La brecha a la Tatamai”. $L y L, 1992$, núm. 5, 39-51.

Colombia

Echeverri Mejia, Arturo

42-1907. Escobar Mesa, Augusto “Arturo Echeverri Mejía”. - RUAn, 1992, núm. 232, 75-87.

\section{García Márquez, Gabriel}

42-1908. BARRERA, TrINIDAD - "Lectura de Buen viaje, señor presidente". QIA, 1993, núm. 73, 29-36.

42-1909. Совo, Juan Gustavo (ed.) Gabriel García Márquez: Testimonios sobre su vida. Ensayos sobre su obra. - Siglo del Hombre, Bogotá, 1992. 424 pp.

42-1910. Fernández, Gastón J. "La función de la muerte en El amor en los tiempos del cólera". - DLit, 10 (1992-93), núm. 2, 97-105.

42-1911. HOOD, EDWARD WATERS La ficción de Gabriel García Márquez: repetición e intertextualidad. - P. Lang, New York, 1993. 229 pp.

42-1912. KOOREMAN, THOMAS E. "Poetic vision and the creation of character in El coronel no tiene quien le escri$b a$ ". - RNo, 33 (1992-93), 271-277.

42-1913. LÓPEZ MEjf́A, ADELAIDA "Burying the dead: Repetition in $E l$ otoño del patriarca". - MLN, 107 (1992), 298-320.

42-1914. MADrid, Lelia M. - "Cien años de soledad: deseo y repetición". $I, 1992$, núm. 36, 95-106.

42-1915. URBINA, NICASIO - "Cien años de soledad: un texto lúdico con implicaciones muy serias". - RCEH, 17 (1992-93), núm. 1, 137-152.

42-1916. URBINA, NiCASIO - "Las mily una noches y Cien años de soledad: falsas presencias e influencias definitivas". - MLN, 107 (1992), 321-341.

42-1917. WoOD, M. - García Márquez: "100 years of solitude" (N. 41-2048). \| H, 75 (1992), 101 (Hood).

42-1918. YAMAL, RICARDO - "El carnaval en Los funerales de la Mamá Grande de Gabriel García Márquez". - $L y L$, 1992, núm. 5, 149-162.

V. también núms. 749, 1922.
42-1919. Posada, JaIme - "Pedro Gómez Valderrama: las ideas y las le- 
tras"'. - BACol, 1992, núms. 176/177, 7-14.

Mutis, Álvaro

42-1920. MUTIS, Álvaro - Abdul Bashur, soñador de navios. - Eds. Siruela, Madrid, 1991. 180 pp. \|CuLH, 1992, núm. 16, 245-246 (Gnutzmann).

42-1921. BALZA, JOSÉ - "Mutis: disoluciones y mudanzas". - Inti, 199192, núms. 34/35, 193-198.

42-1922. STACKELBERG, JÜRGEN VON - "El que sirve a una revolución ara en el mar: Simón Bolívar bei Álvaro Mutis und Gabriel García Márquez' . - I, 1992, núm. 36, 38-51.

Rivera, José Eustasio

42-1923. CAMARERO ARRIBAS, TOMÁs - "De los lectores y el metalector en La vorágine de J. E. Rivera". NRFH, 41 (1993), 251-262.

42-1924. SchulmaN, IVAN A. - " $L a$ vorágine: contrapuntos y textualizaciones de la modernidad". - NRFH, 40 (1992), 875-890.

Valencia, Gerardo

42-1925. HeRnández DE MEndoza, CECilia - "La poesía de Gerardo Valencia. Temas y motivos'”. $B A C o l, 1992$, núm. 175, 39-67.

Acosta, Agustín

42-1926. Capote, M. - Agustín Acosta. El modernista y su isla (N. 41-2052). \|H,
75 (1992), 329-330 (RodríguezFlorido).

42-1927. FEBLES, JORGE - "Un pueblo: menosprecio de corte y alabanza de aldea en la poesía de Agustín Acosta'. - ALM, 30 (1992), 133-152.

Arenas, Reinaldo

42-1928. ARENAS, R. - El portero (N. 41-2054). \|H, 75 (1992), 103-105 (Zalacaín).

42-1929. ARENAS, R. - Viaje a la Habana (N. 41-2055). \| H, 75 (1992), 103105 (Zalacaín).

42-1930. ETTE, OTTMAR (ed.) - La escritura de la memoria. Reinaldo Arenas: Textos, estudios y documentación. - Vervuert, Frankfurt/M, 1992. 231 pp. (Americana eystettensia, 3 ).

42-1931. García SÁNCHEZ, FrankLIN B. - "El dionisismo paródico-grotesco en La loma del ángel, de Reinaldo Arenas'. - RCEH, 17 (1992-93), núm. 2, 271-279.

42-1932. HERNÁNDEZ MIYARES, J. E., \& P. ROzENCVAIG (eds.) - Reinaldo Arenas: alucinaciones, fantasias y realidad (N. 41-2057). \| H, 75 (1992), 105-106 (Ocasio).

42-1933. Sото, F. - "Celestino antes del alba, El palacio de las blanquísimas mofetas, and Otra vez el mar: The struggle for self-expression". - $H, 75$ (1992), 60-68.

Cabrera Infante, Guillermo

42-1934. Polo García, Victorino "De Tres tristes tigres a La Habana para un infante difunto, un espejo para el camino". - RevIb, 58 (1992), 557-566. V. también núm. 658 . 
Carpentier, Alejo

42-1935. Díaz Ruiz, IGNacio - “El recurso de la Historia. (A propósito de Carpentier)". - NRFH, 40 (1992), 1073-1086.

42-1936. GonzÁlez ECHEVERRÍA, RoBERTO - Alejo Carpentier: el peregrino de su patria. - UNAM, México, 1993. 414 pp.

42-1937. JAECK, LOIS MARIE - “The lost steps: Goodbye Rousseau and into the funhouse!'. - H, 57 (1992), 534542 .

Cruz, Soledad

42-1938. Riccio, AleSSANDRA - "Soledad Cruz: la otredad militante". Inti, 1991-92, núms. 34/35, 49-60.

Fernández Retamar, Roberto

42-1939. Gordon, SAMUEL - " to Fernández Retamar: ensayo conversado". - RevIb, 58 (1992), 675690.

\section{Guillén, Nicolás}

42-1940. Alberti, Rafael, Eliseo DiEgo et al. - "Sobre Nicolás Guillén'. - Unión, 1993, núm. 16, 74-81. [Entrevistas realizadas por Silvia Berros].

42-1941. ÁlVAREz Álvarez, LuIS “Diálogo y sueño en Nicolás Guillén”. - Unión, 1993, núm. 16, 70-74.

42-1942. Mullen, EDWARD J. - "Some early readings of Motivos de son". $K R Q 39$ (1992), 221-230.
Lezama Lima, José

42-1943. BeJEL, E. - José Lezama Lima, poet of the image. Illust. by V. Dopico. - University of Florida Press, Gainesville, 1992. xi $+178 \mathrm{pp}$ (University of Florida Monographs, Humanities, 64). \| H, 75 (1992), 102-103 (Hall).

42-1944. BeutLeR, Gisela - "José Lezama Lima, Pensamientos en La Habana (1944). Versuch einer Annäherung und Kommentare'. - $R J, 43$ (1992), 296-317.

42-1945. LeVINSON, BRETT - “Possibility, ruin, repetition: Rereading Lezama Lima's "American expression"". - RCEH, 18 (1993-94), núm. 1, 4966.

42-1946. MOLINERo, R. V. - José Lezama Lima o el hechizo de la búsqueda (N. 41-2111). || H, 75 (1992), 102-103 (Hall).

42-1947. SuÁrez GalbáN, Eugenio Lima, Lezama. - El Cazerón, Madrid, 1993. 37 pp.

42-1948. Teuber, Bernardo - " $O$ felix lapsus! Autobiografia, crítica genética y genealogía del sujeto en Paradiso de José Lezama Lima". $M L N, 108$ (1993), 314-330.

\section{Loynaz, Dulce María}

42-1949. SMITH, VERITY - “"Eva sin paraíson: una lectura feminista de Jardin de Dulce María Loynaz'. NRFH, 41 (1993), 263-277.

Piñera, Virgilio

V. núm. 1796. 
Ramos Otero, Manuel

42-1950. CRUz Malavé, ARNaldo -

"Para virar al macho: la autobiografía como subversión en la cuentística de Manuel Ramos Otero". - RevIb, 59 (1993), 239-263.

Sarduy, Severo

42-1951. Sarduy, Severo - Cocuyo. Tusquets, Barcelona, 1990. 209 pp. ॥ $H, 75$ (1992), 335-336 (Oberhelman). 42-1952. SARDUY, SeVEro - De donde son los cantantes. Ed. de R. González Echevarría. - Cátedra, Madrid, 1993. $237 \mathrm{pp}$.

42-1953. GOSSER, MARY ANN - "Cobra: Writing is the art of ellipsis and digression". - Critical essays on the literatures of Spain and Spanish America, eds. L. T. González del Valle \& J. Baena (Boulder, 1991), 111-120.

42-1954. ULLOA, LEONOR A., y JUSTO C. ULLOA - "La manipulación del fragmento en Colibri de Sarduy". Critical essays on the literatures of Spain and Spanish America, eds. L. T. González del Valle \& J. Baena (Boulder, 1991), 215-223.

V. también núm. 646 .

Vázquez Díaz, René

42-1955. Martínez, Elena M. "Función y mecanismos del humor en La era imaginaria de René Vázquez Díaz'. - Inti, 1991-92, núms. 34/35, 119-130.
Ecuador

Estupiñán Bass, Nelson

42-1956. RichardS, HENRY J. - "Mimesis of product and process in Nelson Estupiñán Bass's Senderos brillantes'. - DLit, 10 (1992-93), núm. 1, 119-135.

Gangotena, Alfredo

42-1957. CASTILLO DE BERChENKO, ADRIANA - Alfredo Gangotena, poéte équatorien (1904-1944) ou l'Ecriture partagée. - Presses Universitaires de Perpignan, Perpignan, 1992. 298 pp. || Carav, 1993, núm. 60, 170-172 (Arenas).

España

Alberti, Rafael

42-1958. AlBERTI, RAFAEL - De un momento a otro. El adefesio. Ed. de G. Torres Nebrera. - Cátedra, Madrid, 1992. $319 \mathrm{pp}$.

42-1959. BARDI, UBALDO - "Note sulla fortuna dell'opera di Rafael Alberti in Italia"'. - QIA, 9 (1992), 496592.

42-1960. BRIAN MORRIS, C. - "Alberti en la generación del 27'. - CuH, 1993, núms. 514/515, 251-271.

42-1961. BUSQUETS, LORETO - "El Renacimiento italiano en $A$ la pintura de Alberti". - QIA, 9 (1992), 460489.

42-1962. ChIAPPINI, GaETANo - "Mare e memoria nei Retornos de los vivo lejano di Rafael Alberti (Due chiavi di 
lettura e proposte per une estudio)". - QIA, 9 (1992), 430-439.

42-1963. Ciceri, MARCELLA - "Metamorfosi del toro". - QIA, 9 (1992), 424-429.

42-1964. MACRÌ, ORESTE - "Saggio sulla poesia di Rafael Alberti (Marinero en tierra e Retornos)'”. - QIA, 9 (1992), 372-418.

42-1965. Paltrinieri, Elisabetta "Ascesa negata in Sobre los Ángeles". - QIA, 9 (1992), 490-495.

42-1966. Profeti, Maria Grazia "Romeo y Julieta: illustrazione grafica ed avanguardie"'. - QIA, 9 (1992), 419-423.

42-1967. SantonJa, Gonzalo - "Alberti y las publicaciones "comprometidas" durante los años treinta". CuH, 1993, núms. 514/515, 352-360. 42-1968. SCARAMUZZA VIDONI, MARIAROSA - "Rittrato di gruppo in paradiso. La arboleda perdida e la memorialistica della generazione del '27', QIA, 9 (1992), 447-459.

42-1969. SERAFIN, Silvana - 'L'Argentina di Rafael Alberti, tra invenzione ed esperienza". - QIA, 9 (1992), 440-446.

V. también núms. 1982, 2065.
Alfau, Felipe

V. núm. 694.

Alonso, Dámaso

42-1974. GrigGS, JOHN W. - "La soledad en la poesía de Dámaso Alonso"'. - DLit, 10 (1992-93), núm. 2, 107-117.

V. también núm. 2065.

Altolaguirre, Manuel

42-1975. Santonja, Gonzalo - "Manuel Altolaguirre, de un mundo a otro"'. - CuH, 1993, núm. 522, 19 27.

\section{Alvarez, Valentín Andrés}

V. núm. 1993.

Arrabal, Fernando

42-1970. Aleixandre, V. - Ámbito, ed. A. Duque Amusco (N. 41-2165). \| CuLH, 1992, núm. 15, 242 (Lagos).

42-1971. Charry LARA, FERNANDO "Vicente Aleixandre y la poesía hispanomericana". - BACol, 1992, núms. 176/177, 23-34.

42-1972. Díez de Revenga, Francisco JAVIER - "Vicente Aleixandre: de la poesía pura al surrealismo”'. - IFE, 1992, núm. 6, 185-197.

42-1973. SCHÄRER-NUSSBERGER, MAYA - Vicente Aleixandre. Création et poétique.

- Eds. de la Baconnière, BoudryNeuchâtel, 1992. 232 pp.
42-1976. Tirado, Pilar del Carmen - "El espectador en El cementerio de automóviles". - Inti, 1991-92, núms. 34/35, 169-176.

$A u b, \operatorname{Max}$

42-1977. García Antón, Gecilia "Max Aub. La epopeya del hombre desterrado. Sobre Morir por cerrar los ojos'. - RLit, 55 (1993), 129-138. 
42-1978. Monti, Silvia - Sala d'attesa. Il teatro incompiuto di Max Aub. - Bulzoni, Roma, 1992.

Ayala, Francisco

42-1979. Ayala, Francisco - Los usurpadores. Ed. de C. Richmond. Cátedra, Madrid, 1992.

42-1980. CORNEJO-PARRIEGO, ROSALÍA V. - "Muertes de perro: revisionismo historiográfico en la ficción postmoderna". - RCEH; 17 (1992-93), núm. 1, 31-46.

42-1981. FORTES, JOSÉ ANTONIO (coord.)

- Francisco Ayala. Una literatura y un pensamiento que investigan lingüisticamente el ámbito estético y moral de la condición humana. - Anthropos, Barcelona, 1992. 95 pp.

42-1982. García MONTERO, LUIS "Memoria viva del 27. Conversación con Francisco Ayala, José Bello, Rosa Chacel y Rafael Alberti". - CuH, 1993, núms. 514/515, 11-22.

\section{Azorín (José Martinez Ruiz)}

42-1983. García, Carlos Javier "Intertexto, indeterminación y reconocimiento en Doña Inés de Azorín". - RNo, 33 (1992-93), 289-296.

42-1984. NieVa DE LA PAZ, PilaR "Crónica de un estreno: Lo invisible (1928), de Azorín". - ALE, 1993, núm. 9, 103-113.

42-1985. SERVODIDIO, MIRELLA "Rereading Azorín". - RHM, 46 (1993), 369-374.

\section{Bacarisse, Mauricio}

42-1986. PÉREZ, ROBERTO - "Sufragismo, drama inédito de Mauricio Bacarisse". - RLit, 54 (1992), 363-383.
Baroja, Pio

42-1987. URDÍROZ VILIANUEVA, NIEVA - "El léxico francés en la obra barojiana”. - IFE, 1993, núm. 9, 99-137.

Benavente, Jacinto

V. núm. 665 .

Benet, Juan

42-1988. MARGENOT III, JOHN B. Zonas y sombras: Aproximaciones a "Región" de Juan Benet . - Pliegos, Madrid, 1991. 201 pp. \|| RRo, 28 (1993), 315-316 (Grubbe).

V. también núm. 645 .

Bergamin, José

42-1989. FERNÁNDEZ SÁNCHEZ-ALARCOS, RAÚL - "La poesía humanizada de Bergamín y algo más sobre Los filólogos". - CuH, 1993, núms. 514/515, 221-226.

Buero Vallejo, Antonio

42-1990. MIZRAHI, IRENE - "Razón y sensibilidad en la obra En la ardiente oscuridad de Buero Vallejo'. - RHM, 46 (1993), 117-130.

\section{Burgos, Carmen de} ("Colombine")

42-1991. Caballero: Wangǘmert, 
MARÍA M. - "Rodríguez Juliá: una ojeada sobre Puerto Rico, entre la burla y la compasión"'. - ReoIb, 58 (1992), 367-378.

\section{Casona, Alejandro}

42-1992. DíEz TABOADA, JUAN MARÍA — "El teatro de Alejandro Casona antes del exilio (1925-1937)'. - RLit, 54 (1992), 269-279.

42-1993. FERnÁNDEZ INSUELA, ANTONIO - "Textos poco conocidos de y sobre autores asturianos: Alejandro Casona y Valentín Andrés Álvarez". - BIEA, 46 (1992), 473-511.

\section{Castro, Américo}

V. núm. 1632.

\section{Cela, Camilo José}

42-1994. MAINER, JOSÉ-CARLOS - “"Por un pensamiento que a lo mejor es mentira": la guerra civil en la obra de Camilo José Cela". - BHi, 94 (1992), 245-261.

42-1995. MARÍN-MINGUILLÓN ADOLFO - "La familia de Pascual Duarte y el efecto esquizo"'. - Critical essays on the literatures of Spain and Spanish America, eds. L. T. González del Valle \& J. Baena (Boulder, 1991), 171-179.

\section{Cernuda, Luis}

42-1996. AMOR Y VÁzQUEZ, José "Máscaras mexicanas en la poesía de Cernuda y Moreno Villa: Quetzalcóatl y Xochipilli'. - NRFH, 40 (1992), 1057-1072.
42-1997. ANCET, JACQUES - "El deseo, lo negro. (Sobre Luis Cernuda)". CuH, 1993, núms. 514/515, 215-200.

42-1998. DomínGuez, José ANTONIO (ed.) - Luis Cernuda para niños. - De la Torre, Madrid, 1992. 128 pp.

42-1999. LONDERO, RENATA - "Aspetti delle teorie romantiche inglesi in Cernuda". - $A L E, 1992$, núm. 8, 119-131.

42-2000. VALENDER, JAMES - "Luis Cernuda y sus Estudios sobre poesía española contemporánea"'. - Reflexiones lingüisticas y literarias, t. 2, ed. R. Olea, y J. Valender (México, 1992), 323-339.

V. también núms. $659,675,682$.

\section{Chacel, Rosa}

42-2001. Ghacel, Rosa - Poesía (19311991). Ed. de Antoni Marí. - Tusquets, Barcelona, 1992. 265 pp. (Marginales, 119).

42-2002. Porlan, Alberto - "Apunte sobre Rosa Chacel'. - CuH, 1993, núms. 514/515, 285-288.

42-2003. RODRÍGUEZ, ESPERANZA "En respuesta y homenaje a Rosa Chacel". - CuH, 1993, núms. 514/515, 273-284.

V. también núm. 1982.

Ciria y Escalante, José de

42-2004. LóPEz LleRA, CÉSAR - "Un pombiano de Santander: José de Ciria y Escalante". - CuLH, 1991, núm. 14, 241-256.

Delibes, Miguel

42-2005. Gelz, ANDREAS - "No me lie, Doctor. . . : diskursanalytische Bemerkungen zu Las guerras de nuestros antepasados von Miguel Delibes"'. - I, 
1992, núm. 35, 66-83.

\section{Diego, Gerardo}

42-2006. BeRnal, JOSÉ LUIS (ed.) -

Gerardo Diego y la vanguardia hispánica.

- Universidad de Extremadura, Cáceres, 1993. $235 \mathrm{pp}$.

42-2007. LÓPEZ CASTRO, ARMANDO -

"Gerardo Diego y la búsqueda de la totalidad". - CuLH, 1991, núm. 14, 257-297.

V. también núm. 2065.

Donato, Magda

V. núm. 962.

\section{Espinosa, Miguel}

42-2008. FLOR, FERNANDO DE LA "Miguel Espinosa: de la narrativa posmoderna al discurso neobarroco" - ALE, 1993, núm. 9, 61-78.

\section{Felipe, León}

42-2009. Ortiz De Montellano, BerNARDO - "León Felipe y Juan Larrea". - CuA, 1992, núm. 31, 16-40. 42-2010. WEINBERG, LILIANA IRENE "León Felipe y Cuadernos Americanos" - CuA, 1993, núm. 41, 187-189.

Fortún, Elena

V. núm. 962.
Fortún, Fernando

42-2011. PHillips, Allen W. - "Fernando Fortún: su obra y su persona". - NRFH, 40 (1992), 823-842.

Gamoneda, Antonio

42-2012. CAnDAU, AnTONio - "Antonio Gamoneda: la conciencia y las formas de la ironía". - HR, 62 (1994), 77-91.

Garcia Hortelano, Juan

42-2013. García Hortelano, J. Tormenta de verano, ed. A. Gómez Yebra (N. 41-2228). \| HR, 61 (1993), 120-122 (Alborg).

\section{García Lorca, Federico}

42-2014. García LORCA, Federico Amor de don Perlimplín con Belisa en su jardin. Ed. de M. Ucelay. - Red, México, 1992. 296 pp.

42-2015. GARcía LORCA, F. - Diván del Tamarit. Seis poemas gallegos. Llanto por Ignacio Sánchez Mejías. Poemas sueltos, ed. A. Anderson (N. 41-2233). \|HR, 61 (1993), 114-115 (Cate-Arries).

42-2016. García LORCA, FEderico Romancero gitano. Poeta en Nueva York. El público. Ed. de D. Harris. - Taurus, - Madrid, 1993. 379 pp.

42-2017. ANDERSON, ANDREW A. "Bibliografia lorquiana reciente". $F G L, 1992$, núms. 10/11, 237-261.

42-2018. ANDERSON, ANDREW A. "Las peripecias de Poeta en Nueva York". - FGL, 1992, núms. 10/11, 97-123.

42-2019. ANDERSON, A. A. - Lorca's late poetry: A critical study (N. 41-2240). 
\|HR, 60 (1992), 377-379 (Sibbald). 42-2020. ANDERSON, ANDREW A. " "Un dificilísimo juego poético": Theme and symbol in Lorca's El público". - KRQ 39 (1992), 331-346.

42-2021. Bauer, Garlos - "Cómo traducir a Lorca: algunas ideas sueltas"'. - FGL, 1992, núms. 10/11, 4143.

42-2022. Cisneros, Luis JaIME "Dos notas sobre el epistolario de García Lorca". - BAAL, 56 (1991), 329-340.

42-2023. DOUGHERTY, DRU - "Lorca y las multitudes: Nueva York y la vocación teatral de Federico García Lorca'. - FGL, 1992, núms. 10/11, 7584.

42-2024. Esteban Martín, Luis MARIANO - "La Poncia, personaje esencial en La casa de Bernarda Alba". CuLH, 1992, núm. 16, 155-164.

42-2025. FEAL, C. - Lorca: tragedia $y$ mito (N. 41-2252). \| RLit, 53 (1991), 272-275 (Rodríguez).

42-2026. FERNÁNDEZ-CIFUENTES, LUIS - "Lorca en Nueva York: arquitecturas para un poeta'. - FGL, 1992, núms. 10/11, 125-135.

42-2027. FORMAN, SANDRA, \& ALLEN JOSEPHS - Only mystery: Federico Garcia Lorca's poetry in word and image. - University Press of Florida, Gainsville, 1992. $144 \mathrm{pp}$.

42-2028. García-Posada, Miguel -

"El homenaje neoyorquino de García Lorca a Rubén Darío". - FGL, 1992, núms. 10/11, 139-145.

42-2029. Gerling, DAVID R. - "Amor de Don Perlimplín con Belisa en su jardín. Aleluya erótica en cuatro cuadros y un prólogo. Síntesis de las farsas de Federico García Lorca". - DLit, 10(1992-93), núm. 1, 151-165.

42-2030. GREenfield, Sumner - "El poeta de vuelta en España: lo neoyorquino en el teatro de Lorca. 199336 '. - FGL, 1992, núms. 10/11, 8593.

42-2031. Halliburton, Lloyd "Manhattan transfer: The "clandestine" influence on Lorca's Poeta en Nueva York". - $A L E, 1993$, núm. 9, 79-84. 42-2032. HIRSCH, EDWARD - "Apren- diendo de Lorca". - FGL, 1992, núms. 10/11, 47-51.

42-2033. HoNIG, EDWIN - "Traducción y transfiguración: Apartes sobre Poeta en Nueva York'. - FGL, 1992, núms. 10/11, 19-22.

42-2034. KLEIN, D. A. - "Blood wedding", "Yerma", and "The house of Bernarda Alba". García Lorca's tragic trilogy (N. 41-2260). $\| H R, 62$ (1994), 135138 (Fernández Cifuentes).

42-2035. LeVINe, PhiliP - "Poeta en Nueva York en Detroit". - FGL, 1992, núms. 10/11, 53-58.

42-2036. Logan, WilliaM - "El amigo de lo efable". - FGL, 1992, núms. 10/11, 23-25.

42-2037. MAURer, Christopher "Traduciendo a García Lorca". FGL, 1992, núms. 10/11, 15-17.

42-2038. Menarini, Piero - "La danza de la muerte de Poeta en Nueva York"'. - FGL, 1992, núms. 10/11, 147-163.

42-2039. MORRIS, C. B. - García Lorca: "La casa de Bernarda Alba"' (N. 412263). \|HR, 61 (1993), 581-583 (Wilcox).

42-2040. Newton, Candelas - Lorca, una escritura en trance. Libro de poemas y "Diván del Tamarit". - J. Benjamins, Amsterdam-Philadelphia, 1992. 249 pp. (Purdue University monographs in Romance languages, 40).

42-2041. PAEPE, C. DE (dir.) - Catálogo general de los fondos documentales de la Fundación Federico García Lorca. T. 1: Manuscritos de la obra poética de madurez, ed. C. de Paepe. Con la colab. de R. M. Illán de Haro y S. González García. - Ministerio de Cultura-Dirección de Archivos Estatales-Fundación Federico García Lorca, Madrid, 1992. $201 \mathrm{pp}$.

42-2042. PERRI, DENNIS - "Fulfillment and loss: Lorca's view of communication in the Twenties"'. - H, 75 (1992), 484-491.

42-2043. Perri, Dennis - "Lorca's suite Palimpsestos: Keeping the reader at bay". - KRQ 38 (1991), 197-211. 42-2044. POLlin, Alice - "Whitman y Lorca". - FGL, 1992, núms. 10/11, 181-190. 
42-2045. RंOTHENBERG, JEROME "Algunas palabras por y para García Lorca en el 50 aniversario de Poeta en Nueva York". - FGL, 1992, núms. $10 / 11,59-61$.

42-2046. SIMON, GREG - "Sobre dos palabras: norma y hueco". - FGL, 1992, núms. 10/11, 27-29.

42-2047. SMITH, ALAN - "Cómo se anda en un sueño: el Romance sonámbulo de Federico García Lorca". - RHM, 46 (1993), 65-72.

42-2048. STAINTON, LESLIE - " " $\mathrm{j} \mathrm{Oh}$ Babilonia! ¡Oh Cartago! ¡Oh Nueva York!!: El europeo ante Manhattan, Manhattan ante el europeo". $-F G L$, 1992, núms. 10/11, 191-212.

42-2049. Trueblood, Allan S. "Reflexiones críticas del traductor. (Dos poemas de Canciones)". - FGL, 1992, núms. 10/11, 31-35.

42-2050. Walters, D. Gareth " "Comprendí. Pero no explico". Revelation and concealment in Lorca's Canciones". - BHS, 68 (1991), 265. 279.

42-2051. White, STEVEN - "Miseria y esplendor en la traducción de Poèta en Nueva York'. - FGL, 1992, núms. 10/11, 37-39.

42-2052. YAGǗE BOSCH, JAVIER "Huir de Nueva York: Whitman y Lorca en un dibujo". - FGL, 1992, núms. 10/11, 213-233.

V. también núms. 692,760 .

\section{Garfias, Pedro}

42-2053. Matas Caballero Juan "Teoría y práctica del exilio: Primavera en Eaton Hastings, de Pedro Garfias". - CuLH, 1991, núm. 14, 155-172. nero. - Consell Valencià de Cultura, Valencia, 1993. 355 pp.

Gil de Biedma, Jaime

V. núm. 686.

42-2055. BOU, ENRIC (coord.) - Pere Gimferrer. Una poética del instante. Anthropos, Barcelona, 1993. 95 pp.

\section{Gómez de la Serna, Ramón}

42-2056. CHARPENTIER, H. - Las "Novelle" de Ramón Gómez de la Serna (N. 41-2274). \| HR, 60 (1992), 102-104 (Hartfield-Mendez).

42-2057. Marimón Llorca, Carmen - "El delirio en soledad. Análisis del drama del Palacio Deshabitado de Ramón Gómez de la Serna". - CuIF, 18 (1992), 5-18.

\section{Gómez Ojea, Carmen}

42-2058. BOScheTTO, SANDRA M. "Double-voiced tales in Carmen Gómez Ojea's La novela que Marien no termino" . - H, 75 (1992), 500-507.

\section{González, Ángel}

Gil-Albert, Juan

42-2054. GIL-ALBERT, JUAN - Racimo de los dioses. Antología poética. Sel., est. prelim., notas y variantes de G. Car-

42-2059. Benson, Douglas K. - "Heteroglossia en la poesía de Ángel González". - Critical essays on the literatures of Spain and Spanish America, eds. L. T. González del Valle \& J. Baena (Boul- 
der, 1991), 11-18.

42-2060. Fisher, Diane R. - "The deconstruction of irony in the poetic trajectory of Ángel González'. - - RHM, 46 (1993), 141-156.

Goytisolo, Juan

42-2061. BARrio, ARIEL DEL - Dialogismo y novela. El principio dialógico en las novelas de Juan Goytisolo. - Ediciones Documentas, Santiago, 1990. $\| L y L$, 1992, núm. 5, 285-287 (Saldes Báez).

42-2062. EPPS, BRAD - "The politics of ventriloquism: Cava, revolution and sexual discourse in Conde Julián'. $M L N, 107$ (1992), 274-297.

42-2063. SIX, A. L. - Juan Goytisolo.

The case of chaos (N. 41-2298). $\| H R, 60$ (1992), 502-505 (Herzberger); $H, 75$ (1992), 325-326 (Pérez); MLN, 107 (1992), 415-417 (Valis).

V. también núm. 2092.

\section{Guillén, Jorge}

42-2064. Díez de Revenga, Francisco. JAVIER - Jorge Guillén. El poeta y nuestro mundo. - Anthropos, Barcelona, 1993. 239 pp.

42-2065. Díez De Revenga, F. J. - Poesía de senectud: Guillén, Diego, Alonso y Alberti en sus mundos poéticos terminales (N. 41-2300). \| HR, 60 (1992), 245247 (Wilcox).

V. también núm. 648 .

Hernández, Antonio

42-2066. Scarano, LAURA Rosana "La poesía de Antonio Hernández: tránsito del "yo" al "nosotros"”. CuLH, 1991, núm. 14, 203-239.
Hernández, Miguel

42-2067. Hernández, Miguel - Obra completa. Ed. de A. Sánchez Vidal y J. C. Rovira. - Espasa Calpe, Madrid, 1992. 2 ts.

42-2068. Hernández, Miguel - Viento del pueblo. Ed. de J. C. Rovira y C. Alemany Bay. Ed. facsímil. - De la Torre-Instituto de Cultura Juan Gil Albert, Madrid, 1992. 174 pp.

42-2069. Balcells, José MARía - Miguel Hernández. - Teide, Barcelona, 1990. 138 pp. || Anthropos, 1992, núms. 134/135, 139 (Paco).

V. también núm. 760 .

Hierro, José

42-2070. Ferrari, Marta Beatriz "Análisis de los "metatextos" en la poesía de José Hierro. En torno a 25 años de silencio"' - CuLH, 1992, núm. 16, 199-217.

Janés, Clara

42-2071. PÉREZ, JANET - "The novels of a poet: Clara Janés"'. - Critical essays on the literatures of Spain and Spanish America, eds. L. T. González del Valle \& J. Baena (Boulder, 1991), 197-207.

Jarnés, Benjamín

42-2072. Sabugo Abril, Amancio "Benjamín Jarnés y su teoría de la novela". - CuH, 1993, núms. 514/515, 289-292. 
Jiménez, Juan Ramón

42-2073. JIMÉNEZ, JUAN RAMÓN Cartas. Antología. Ed. de F. Garfias. Espasa-Calpe, Madrid, 1992. 367 pp. (Austral, 251).

42-2074. JiMÉNEZ, JUAN RAMÓN - Ideología (1897-1957). Ed. de A. Sánchez Romeraldo. - Anthropos, Barcelona, 1990. cl + 762 pp. \| CuLH, 1991, núm. 14, 334-335 (Barquilla).

42-2075. JAFFE, CATHERINE - "Reading Juan Ramón Jiménez's “Espacio»: intersubjectivity and intertextuality". - Critical essays on the literatures of Spain and Spanish America, eds. L. T. González del Valle \& J. Baena (Boulder, 1991), 145-151.

42-2076. Juliá, M. - El universo de Juan Ramón Jiménez. (Un estudio del poema "Espacio") (N. 41-2310). \| HR, 60 (1992), 374-375 (Young).

42-2077. LÓPEz Castro, ARMANDO "Lo sarto en Juan Ramón Jiménez". - BBMP, 68 (1992), 239-267.

42-2078. ROMERO LÓPEZ DE LAS HAZAS, DOLORES - "Juan Ramón Jiménez 1900: hallazgo del eslabón perdido entre la silva modernista y el verso libre hispánico". - CuIF, 18 (1992), 99-107.

42-2079. Villar, ARTURO DEL - "Las cartas abiertas de Juan Ramón". CuH, 1993, núm. 513, 103-107.

42-2080. Vitier, CinTiO - "Juan Ramón Jiménez en Cuba". - Unión, 1993, núm. 15, 2-11.

\section{Laforet, Carmen}

42-2081. JORDAN, BARRY - “Looks that kill: Power, gender and vision in Laforet's Nada', - RCEH, 17 (199293), núm. 1, 79-104.

42-2082. JORDAN, BARRY - "Narrators, readers and writers in Laforet's Nada". - RHM, 46 (1993), 87-102.

42-2083. SOUFAS, C. CRISTOFER "Narrative form as feminist ideology: Feminist consciousness/criticism in
Laforet's Nada, Matute's Primera memoria and Moix's Julia"'. - DLit, 11 (1993-94), núm. 1, 153-161.

Larrea, Juan

42-2084. DíAz DE Guereñu, J. M. La poesía de Juan Larrea. Creación y sentido (N. 41-2312). \| HR, 60 (1992), 247249 (Bary).

42-2085. DOLFI, LAURA - "Versión celeste secondo Larrea (lettere inedite)". - QIA, 1993, núm. 73, 5-28.

V. también núm. 2009.

Llamas Aguilaniedo, José María

42-2086. Calvo Carilla, José Luis "La heroína modernista. (La mujer finisecular en las novelas de Llanas Aguilaniedo)"'. - $A L E, 1992$, núm. 8, 25-35.

Machado, Antonio

42-2087. Chicharro, D. - "El teatro de los Machado: revisión crítica de la bibliografía tras el aluvión del cincuentenario". - RLit, 54 (1992), 653-664.

V. también núm. 659,760 .

Machado, Manuel

42-2088. BARÓN, EMILIO - Lirismo y humor. Manuel Machado y la poesía irónica moderna. - Alfar, Sevilla, 1992. 157 pp.

42-2089. García-Abad García, TereSA - "La crítica teatral de Manuel Machado en La Libertad (1920-1926)". - RLit, 53 (1991), 535-554. 
V. también núm. 2087.

Matute, Ana María

V. núm. 2083.

Marquina, Eduardo

V. núm. 2173.

$$
\text { Méndez, Concha }
$$

V. núm. 962.

\section{Martín Gaite, Carmen}

42-2090. Calvi, M. V. - Dialogo e conversazione nella narrativa di Carmen Martín Gaite (N. 41-2330). \| H, 75 (1992), 564-566 (Servodidio).

42-2091. CHOWN, LiNDA - "Palimpsestic biography: The back room". Critical essays on the literatures of Spain and Spanish America, eds. L. T. González del Valle \& J. Baena (Boulder, 1991), 57-64.

42-2092. EPPS, BRAD - "The space of sexual history: Reading position in $\mathrm{El}$ cuarto de atrás and Reivindicación del conde Don Julián". - Critical essays on the literatures of Spain and Spanish America, eds.

L. T. González del Valle \& J. Baena (Boulder, 1991), 75-87.

Martinez Mencheni, Antonio

42-2093. ORTEGA, JOSÉ - "'Sicopatología del fascismo: Pro patria mori de Martínez Mencheni'. - DLit, 11 (1993-94), núm. 1, 127-136.

Millás García, Juan José

42-2094. Holloway, Vance R. "The pleasure of oedipal discontent and $E l$ desorden de tu nombre, by Juan José Millás García". - RCEH, 18 (1993-94), núm. 1, 31-47.

\section{Miró, Gabriel}

42-2095. JOHNSON, ROBERTA - “El abuelo del rey: Gabriel Miró's saga of the Spanish Nineteenth century". $K R Q, 39$ (1992), 101-108.

42-2096. LARSEN, KeVIN S. - " "Más lejos, negreaban los pavos»: Implications of an aspect of Gabriel Miró's animal imagery"'. - RNo, 33 (199293), 45-52.

42-2097. MACDONALD, IAN R. - "Miró y Freud: Una nota en torno a la biblioteca de Gabriel Miró". - $A L M$, 30 (1992), 197-199.

42-2098. MÁrQuez Villanueva, F. La esfinge mironiana $y$ otros estudios sobre Gabriel Miró (N. 41-2339). \| HR, 60 (1992), 371-374 (Lozano Marco); $A L M, 30$ (1992), 307-311 (Ontañón de Lope).

Martínez Sierra, Gregorio

V. núm. 2173. 
Montero, Rosa

42-2099. Zatlin, Phylils - "Gothic inversion of the future: Rosa Montero's Temblor', - $-R N o, 33$ (1992-93), 119-123.

Morales, José Ricardo

42-2100. AzNar SOler, MANUEl (coord.) - José Ricardo Morales. Un dramaturgo del destierro. Creación dramática y pensamiento crítico. - Anthropos, Barcelona, 1992. 95 pp.

Morales, Rafael

42-2101. ROMARÍS PAIS, ANDRÉS "Paralelismo e imagen en Prado de serpientes, de Rafael Morales". - CuLH, 1992, núm. 16, 43-56.

Moreno Villa, José

42-2102. ROMOJARO, ROSA - "La segunda poética de José Moreno Villa. (Jacinta la pelirroja, Carambas, Puentes que no acaban, Salón sin muros)" . - AnMal, 14 (1991), 129-140.

V. también núm. 1996.

Ortega y Gasset, José

42-2103. ORTEGA Y GASSET, JosÉ "El estilo de una vida (notas de trabajo)". - ROcc, 1992, núm. 132, 51-68. 42-2104. Dust, P. H. (ed.) - Ortega y Gasset and the question of modernity (N. 41-2343). \|| HR, 61 (1993), 433-435 (Raley).

42-2105. Molinuevo, José Luis -
"Literatura y filosofía en Ortega y Gasset". - ROcc, 1992, núm. 132, 69-94.

42-2106. ORtega, Soledad - "Las "notas" de Ortega". - ROcc, 1992, núm. 132, 49-50.

42-2107. SENABRE, RICARDO - "Ortega y Gasset y la generación del 27". - CuH, 1993, núms. 514/515, 197207.

V. también núm. 1632.

Ortiz, Lourdes

42-2108. TAlbot, LyNn K. - "Lourdes Ortiz's Urraca: A re-vision/revision of history". - KRQ 38 (1991), 437-448.

Panero, Leopoldo

42-2109. Hueta Calvo, Javier "Poesía y política en la España de Posguerra. La polémica en torno a Canto personal, de Leopoldo Panero". - CuLH, 1992, núm. 16, 7-31.

\section{Pérez de Ayala, Ramón}

42-2110. ABDEL-Rahman, Gamal "Sobre Tinieblas en las.cumbres, de Ramón Pérez de Ayala". - BIEA, 46 (1992), 211-217.

42-2111. Friera SuÁrez, Florencio - "Ramón Pérez de Ayala: el interés de su biografía y el placer de la lectura de su obra". - BIEA, 47 (1993), 719.

42-2112. ViÑuela, Miguel - Desmitificación y esperanza en la obra de Pérez de Ayala. - Instituto de Estudios Asturianos, Oviedo, 1991. \| BIEA, 45 (1991), 794.

V. también núm. 665 . 
Prados, Emilio

42-2113. LÓPEz dE ABIADA, José MANUEL - "La poesía política de Emilio Prados anterior a la guerra civil: de los poemas de adhesión al movimiento revolucionario, de No podréis (19301932) a los romances elegiacos y de denuncia de Llanto de octubre'. HMDR, 861-873.

42-2114. Santos Silva, Loreina -

"Los romances de Emilio Prados: dos compromisos". - HMDR, 875-886.

42-2115. VAlENDER, JAMES - “Emilio Prados y la Guerra Civil Española: dos prosas olvidadas'. - NRFH, 40 (1992), 989-1003.

\section{Quiroga, Elena}

42-2116. BARNEY, KRISTEN R. - " "The quiet revolution of Elena Quiroga'. - RHM, 46 (1993), 103-116.

Riera, Carmen

42-2117. JOHNSON, ROBERTA - "Voices and intersubjectivity in Carmé Riera's narratives'”. - Critical essays on the literatures of Spain and Spanish America, eds. L. T. González del Valle \& J. Baena (Boulder, 1991), 153-159.

\section{Rodríguez, Claudio}

42-2118. García JAMBrina, LUIS "Claudio Rodríguez: bibliografia" - RHM, 46 (1993), 343-368.

42-2119. García JAMBRINA, LUIS "La "prehistoria" literaria de Claudio Rodríguez": - RHM, 46 (1993), 237-257.

42-2120. LaFollette Miller, MarTHA - "Oracular lyricism and ele- ments of Romance in the poetry of Claudio Rodríguez', - - RHM, 46 (1993), 321-331.

42-2121. MAYHew, J. - Claudio Rodriguez and the language of poetic vision (N. 41-2361). \|KRQ 39 (1992), 110-111 (Debicki); $M L N, 108$ (1993), 369-372 (Lorenzo-Rivero); H, 75 (1992), 327328 (Wilcox).

42-2122. MayheW, Jonathan- "Claudio Rodríguez and the writing of the masculine body". - RHM, 46 (1993), 268-274.

42-2123. Mudrovic, W. Michel "Dreams, frames and impromptu stages: Quotidian spectacle in poems of Claudio Rodríguez'. - RHM, 46 (1993), 313-321.

42-2124. Prieto de Paula, Ángel L. - "Claudio Rodríguez: visión y contemplación". - RHM, 46 (1993), 289-302.

42-2125. Siebenmann, Gustav "Otro elogio de la sombra: interpretación de "La mañana de búho", de Claudio Rodríguez". - RHM, 46 (1993), 332-339.

42-2126. Silver, PHILIP W. - "Poesía última de Claudio Rodríguez: "Casi una leyendan". - RHM, 46 (1993), 340-342.

42-2127. Sobejano, Gonzalo - " "Espuma», de Claudio Rodríguez"'. RHM , 46 (1993), 303-312.

42-2128. Suñén, Juan Carlos "Notas para un mapa semántico de Claudio Rodríguez". - $R H M, 46$ (1993), 258-267.

V. también núm. 681 .

\section{Salinas, Pedro}

42-2129. Salinas, Pedro - Prelude to pleasure. A bilingual edition of "Visperas del gozo". Tr. by N. Valis. - Bucknell University Press, Lewisburg, 1993. 100 pp.

42-2130. Salinas, PEdRo - Teatro completo. Ed. crítica e introd. de Pilar Moraleda García. - Alfar, Sevilla, 1992. 440 pp. (Alfar Universidad, 41). 
42-2131. Carreño, Antonio - "Los mitos del yo lírico: La voz a ti debida de Pedro Salinas". - Inti, 1991-92, núms. 34/35, 3-20.

42-2132. MORÓN ARROYO, Ciriaco, y MaNuel ReVuelta Sañudo (eds.) - Pedro Salinas. Estudios sobre su praxis y teoria de la escritura. - Sociedad Menéndez Pelayo, Santander, 1992. 224. $\mathrm{pp}$.

42-2133. Peltzer, Federico - " "En el Centenario de Pedro Salinas". - BA$A L, 56$ (1991), 559-571.

42-2134. Pozuelo Yvancos, José MARía - "La huella de Nebrija: Pedro Salinas y su Defensa del lenguaje". - ALM, 31 (1993), 313-332.

42-2135. Pozuelo Yvancos, José MARÍA - "Pedro Salinas, crítico literario". - LEA, 14 (1992), 107-125.

42-2136. Scarano, LaURA R. - "La función del arte en el fin de siglo hispánico y su derivación en la obra de Pedro Salinas". - CuLH, 1992, núm. 16, 165-173.

42-2137. SOTELO VÁZQUEZ, ADOLFO "Pedro Salinas entre el joven Eliot y el joven Unamuno". - CuH, 1993, núms. 514/515, 239-245.

V. también núm. 2235.

\section{Sánchez Ferlosio, Rafael}

42-2138. JORDAN, BARRY - "Back to the future. Recontextualising El Jara$m a "$. - KRQ, 38 (1991), 213-225.

\section{Sastre, Alfönso}

42-2139. SASTRE, ALFONSO - La taberna fantástica. Tragedia de la gitana Celestina. Ed. de M. de Paco. - Gátedra, Madrid, 1990. 270 pp. \| CuLH, 1991, núm. 14, 338-340 (Morillas).

42-2140. SIEBURTH, RENÉE - "What's in a name: ambiguity in La mordaza". - KRQ 39 (1992), 475-479.
Savater, Fernando

42-2141. HART, PATricia - "Charon still waiting: Narrative techniques in Caronte aguarda, by Fernando Savater". - DLit, 10 (1992-93), núm. 2, 119-128.

Sedano, Dora

42-2142. O'GONNOR, PATRICIA W. "The "dark double" and the patriarch in Dora Sedano's La diosa de arena". Critical essays on the literatures of Spain and Spanish America, eds. L. T. González del Valle \& J. Baena (Boulder, 1991), 181-186.

\section{Sender, Ramón J.}

42-2143. KRow-Lucal, Martha G. "El esperpento de Mosén Millán: A reflection of Valle-Inclán in Sender". - HR, 61 (1993), 391-402.

42-2144. VÁzQUEZ, MARY S. - "Ramón Sender and wartime defenses: Contraataque as fictive autobiography".

- Critical essays on the literatures of Spain and Spanish America, eds. L. T. González del Valle \& J. Baena (Boulder, 1991), 225-233.

\section{Torrente Ballester, Gonzalo}

42-2145. SPANG, KURT - "Novela y metanovela. Observaciones acerca de Fragmentos de Apocalipsis de Gonzalo Torrente Ballester". - RLit, 53 (1991), 555-581. 
Tusquets, Esther

42-2146. VÁzQuez, M. S. (ed.) - The sea of becoming: Approaches to the fiction of Esther Tusquets (N. 41-2377). \| H, 75 (1992), 326-327 (Jones).

Unamuno, Miguel de

42-2147. Unamuno, Miguel DE $-E l$ otro. Misterio en tres jornadas y un epilogo. Ed. de R. de la Fuente Ballesteros. Colegio de España, Salamanca, 1993. $148 \mathrm{pp}$.

42-2148. AbelláN, José LUIS - “El uso mitológico del mar en Unamuno". - CuA, 1992, núm. 36, 185195.

42-2149. BRETZ, MARY L. - “"The role of negativity in Unamuno's La tía Tula'. - RCEH, 18 (1993-94), núm. 1, 17-30.

42-2150. Martínez, Alejandro "La ideología patriarcal y el estado de la mujer en la obra de Unamuno". $R C E H, 16$ (1991-92), núm. 2, 253265.

42-2151. NúÑez, D., y P. Ribas Unamuno. Política y filosofía. Artículos recuperados (1886-1924). - Fundación Banco Exterior, Madrid, 1992. 235 pp. \| Anthropos, 1992, núm. 136, 77 (Mora García).

42-2152. RibBans, GeOfFrey - "Unamuno in England: Four unpublished articles (1909), Part I''. - BHS, 68 (1991), 383-394.

42-2153. Ribbans, Geoffrey - "Unamuno in England: Four unpublished articles (1909), Part II'. - BHS, 68 (1991), 479-488.

42-2154. SCHÄFfaVER, MARKuS KLAUS - "Algunos aspectos de oralidad en la obra de Unamuno". - I, 1993, núm. 37, 106-115.

V. también núms. 669, 1632, 2137.
Valente, José Angel

42-2155. López CASTRO, ARMANDO "José Ángel Valente y la búsqueda del centro". - EHF, 15 (1993), 65-77.

\section{Valle-Inclán, Ramón del}

42-2156. VALLE-INCLÁN, RAMÓN DEL - El ruedo ibérico. Ed. de J. M. García de la Torre. - Espasa-Calpe, Madrid, 1990-1992. 3 ts. || Anthropos, 1993, núms. 142/143, 164 (Abad).

42-2157. VALLE-INCLÁN, RAMÓN DEL - Tablado de marionetas para educación de príncipes. Ed. de C. Oliva. - EspasaCalpe, Madrid, 1990. 294 pp. (Austral, 129). \| CuLH, 1992, núm. 15, 239 (Lagos).

42-2158. Baamonde Traveso, GloRIA - Función del esperpento en "Tirano Banderas". - Reichenberger, Kassel, 1993. $182 \mathrm{pp}$.

42-2159. GONZÁlez DEL VALLE, LUIS T. - "La prolepsis disonante de Tirano Banderas": - HR, 61 (1993), 501518.

42-2160. Greenfield, S. M. - ValleInclán: Anatomía de un teatro problemático (N. 41-2408). \| $H R, 60$ (1992), 236238 (Ramón Resina).

42-2161. GÜNTERT, GeORges - "De Femeninas a las Sonatas. Evolución del arte narrativo de Valle-Inclán". RLit, 54 (1992), 257-268.

42-2162. JEREZ FARRÁN, C.. - El expresionismo en Valle-Inclán. Una reinterpretación de su visión esperpéntica (N. 412409). \| HR, 61 (1993), 296-297 (Dougherty).

42-2163. LAFollette Miller, MaRTHA - "The feminization and emasculation of Galicia in Valle-Inclán's Jardín umbrío". - KRQ 39 (1992), 87-92.

42-2164. LAVAUd-FAGE, Eliane - $L a$ singladura narrativa de Valle-Inclán (1888-1915). - Fundación Pedro Barrié de la Maza, Conde de Fenosa, La Coruña, 1991. 603 pp. \| Anthropos, 
1992, núms. 134/135, 137 (Estepa).

42-2165. Loureiro, ÁNGel G. - "'La estética y la mirada de la muerte: Sonata de otoño". - RHM, 46 (1993), 3450.

42-2166. Ramos, Rosa Alicia "Valle-Inclán's "Beatriz»: A tale of the symbolist fantastic". - DLit, 9 (1991-92), núm. 2, 75-86.

42-2167. Saldes BÁEZ, Sergio - “ "Hacia la especificidad textual de los Esperpentos de Ramón del Valle Inclán: entre el teatro y el cine"'. - LyL, 1992, núm. 5, 117-147.

42-2168. SANTOS ZAS, MARGaRITA Tradicionalismo y literatura en Valle-Inclán (1889-1910). - Society of Spanish and Spanish American Studies, Boulder, 1993. xiii + 410 pp.

42-2169. Schiavo, LEDA - "El bestiario en el jardín modernista: La marquesa Rosalinda de Valle-Inclán". KRQ, 39 (1992), 93-100.

42-2170. SCHNEIDER, LUIS MARIO Todo Valle-Inclán en México.-UNAM, México, 1992. 223 pp.

42-2171. ZaVALA, I. M. - La musa funambulesca. Poética de la carnavalización en Valle-Inclán (N. 41-2416). \| HR, 61 (1993), 579-581 (Greenfielf); $M L N$, 108 (1993), 363-365 (Moreiras).

V. también núms. 958, 2143.

Vázquez Montalbán, Manuel

42-2172. RESINA, JOAN RAMON "Desencanto y fórmula en las novelas policiacas de Manuel Vázquez Montalbán". - MLN, 108 (1993), 254282.

Villaespesa, Francisco

42-2173. MORENO HERNÁNDEZ, CARLOS - "Neorromanticismo, modernismo y cursilería: Villaespesa, Marquina y los Martínez Sierra". CuLH, 1992, núm. 16, 33-42.
Villalón, Fernando

42-2174. Moyano, P. - Fernando Villalón. El poeta y su obra (N. 41-2420). \| KRQ, 38 (1991), 505-506 (Díez de Revenga); RLit, 53 (1991), 749-752 (Montaraz Olivas).

V. también núm. 1897.

Zambrano, María

42-2175. Clavo Sebastián, María JOSÉ - "El tema del hombre en María Zambrano". - CuIF, 18 (1992), 129-148.

42-2176. Peñalver, Mariano "María Zambrano, el exilio y la lucidez". - CuH, 1993, núms. 514/515, 247-250.

42-2177. PUjalÁ, Grisel - "Centro, método y poesía en Claros del bosque de María Zambrano"'. - ALE, 1993, núm. 9, 115-127.

Estados Unidos

Anzaldúa, Gloria

V. núm. 987.

Hinojosa, Rolando

V. núm. 987 .

Paredes, Américo

V. núm. 987. 
Guatemala

$$
\text { Asturias, Miguel Ángel }
$$

42-2178. Prieto, ReNÉ - Miguel Ángel Asturias's archaeology of return. - Cambridge University Press, Cambridge, 1993. 307 pp.

42-2179. UNRUH, VICKY - "Double talk: Asturias's America in Cuculcán”'. - H, 75 (1992), 527-533.

\section{Cardoza y Aragón, Luis}

42-2180. MONTIEL, Edgar - "Confidencias de Luis Cardoza y Aragón. Vallejo, soledad llena de mundo". CuA, 1992, núm. 34, 27-34.

Monterroso, Augusto

42-2181. OGNO, LíA - "Augusto Monterroso". - CuH, 1993, núm. 511, $33-42$.

México

Agustín, José

42-2182. MÜLLER, INKE - " "Realismo estilo kódacn: José Agustín (La tumba 1964/1966) y Gustavo Sainz (Gazapo 1965), iniciadores de la literatura de la cultura juvenil en el México de los años sesenta y setenta"' - Ibero, 1992, núm. 46, 65-83.
Aridjis, Homero

42-2183. McMurray, George R. "A Mexican novel about 1492". H, 75 (1992), 600-601.

Arreola, Juan José

42-2184. Pellicer, RosA - "La confabulación de Juan José Arreola". RevIb, 58 (1992), 539-555.

Azuela, Mariano

42-2185. Griffin, Clive - Azuela: "Los de abajo". - Grant \& Cutler, London, 1993. 107 pp.

42-2186. JIMÉNEZ DE BÁEZ, YVETTE "Los de abajo de Mariano Azuela: escritura y punto de partida". NRFH, 40 (1992), 843-874.

42-2187. Martínez, José LuIs - “Revisión de Mariano Azuela'. - $L M M$, 2 (1992), 41-61.

Castellanos, Rosario

42-2188. LAVOU, ViCTORIEN - "El juego de los programas narrativos en Oficio de tinieblas de Rosario Castellanos". - RCLL, 1993, núm. 37, 319332.

42-2189. López González, ARAlia La espiral parece un círculo. La narrativa de Rosario Castellanos. Análisis de "Oficio de tinieblas" y "Álbum de familia". UAM-I, México, 1991. (Textos y contextos, 3). I| $L M M, 3$ (1992), 220-227 (Jiménez de Báez). 
Estrada, Genaro

42-2190. ZAÏTZEFF, SERGE - "Genaro Estrada y España". - LMM, 3 (1992), 125-134.

V. también núm. 1895.

Fuentes, Carlos

42-2191. Fuentes, Carlos - La campaña. - Mondadori, Madrid, 1990. 241 pp. || CuLH, 1992, núm. 16, 247 248 (Gnutzmann).

42-2192. FUENTES, CARLOS - Valiente Mundo Nuevo: Epica, utopia y mito en la novela hispanoamericana. - F.C.E., México, 1990. 295 pp. \| $L y L, 1992$, núm. 5, 273-278 (Fuente).

42-2193. BOLDY, STEPHEN - "Intertextuality in Carlos Fuentes's Gringo viejo". - KRQ, 39 (1992), 489-500.

42-2194. DeLDEN, MAarten VAN "Carlos Fuentes: From identity to alternativity". - MLN, 108 (1993), 331-346.

42-2195. ECHEGOYEN, REGINA N. "La función intertextual de las crónicas en Terra nostra". - CuA, 1992, núm. 33, 108-114.

42-2196. Garcia GutiḱrRez, GeORgiNA - "'Terra Nostra: crónica universal del orbe. (Apuntes sobre intertextualidad)"'. - NRFH, 40 (1992), 11351148.

42-2197. García NúÑEZ, Fernando "La poética narrativa de Carlos Fuentes'. - BHi, 94 (1992), 263-291.

42-2198. HerRera, BERNAL - "Aspectos del deseo en la obra de Carlos Fuentes"'. - Inti, 1991-92, núms. 34/35, 107-118.

42-2199. IBSEN, KRISTINE - "Narrative perspective and the role of the reader in Fuentes's Cristóbal Nonato". $R N_{0}, 33$ (1992-93), 313-317.

42-2200. LAPUENTE, FELIPE A. -

"Cervantes en la perspectiva de Fuentes". - CuA, 1993, núm. 39, 228 242.

42-2201. MÉchoulan, ERIC - "Le travail de la fiction: Carlos Fuentes, Terra nostra". - Imprévue, 1993, núm. $1,25-40$.

42-2202. ORdiz VÁzQUez, Francisco JAVIER - "Carlos Fuentes y la identidad de México". - RevIb, 58 (1992), 527-538.

42-2203. PORTAL, MARTA - "Gringo viejo: diálogo de culturas". - CuA, 1993, núm. 39, 217-227.

42-2204. RUIZ BASTO, JORGE - De la modernidad $y$ otras creencias. (En torno a "Cambio de piel" de Carlos Fuentes). UNAM, México, 1992. 114 pp.

Galindo, Sergio

42-2205. ANHALT, NEDDA G. DE - Allá donde ves la neblina. Un acercamiento a la obra de Sergio Galindo. - UNAM, México, 1992. $125 \mathrm{pp}$.

42-2206. PATÁn, FEDERICo - "De una mirada puesta en el pasado: Otilia Rauda". - Escritos, 1992, núm. 8, 2333.

42-2207. PAVÓN, ALFREDO - "Otilia Rauda: los años maravillosos". Escritos, 1992, núm. 8, 35-47.

42-2208. Prada Oropeza, Renato "De los cuentos iniciales a Otilia Rauda: algunas "recurrencias" simbólicas en la narrativa de Sergio Galindo". - Escritos, 1992, núm. 8, 7-21.

\section{Garro, Elena}

42-2209. LEÓN VEGA, MARgarita "El discurso de la memoria como estrategia del sujeto". - $A P, 1991$, núm. 12, 169-178.

42-2210. ROJAS TREMPE, LADY - "Expatriación, locura y escritura en los cuentos de Elena Garro". - Escritos, 1992, núm. 8, 61-84.

42-2211. ROJAS TREMPE, LADY "Historia narrativa de la conquista de los indígenas mexicanos: Elena Garro". - LMM, 3 (1992), 157-168. 
V. también núm. 643 .

Gorostiza, José

42-2212. Garza Guarón, Beatriz "La poética de José Gorostiza y el "grupo sin grupo" de la revista Contemporáneos". - NRFH, 40 (1992), 891-907.

\section{Huerta, Efrain}

42-2213. Ocampo, Aurora M., y LaURA NavarRete Maya - "Aportación bibliográfica. Efraín Huerta (1914-1982). I'. - LMM, 3 (1992), 237-261.

\section{Maples Arce, Manuel}

\section{2-2214. Meyer Minnemann, Klaus} - "Manuel Maples Arce, pre-estridentista: Rag. Tintas de abanico, 1920". - LMM, 3 (1992), 151-156.

42-2215. Meyer-Minnemann, Klaus - "Una pequeña joya bibliográfica: Rag. Tintas de abanico (1920) de Manuel Maples Arce'. - LMM, 3 (1992), 181-192.

\section{Mastretta, Ángeles}

42-2216. Llarena, Alicia - "Arráncame la vida, de Ángeles Mastretta: el universo desde la intimidad". RevIb, 58 (1992), 465-475.

Monsiváis, Carlos
TO VALVERDE - "Boleros. Entrevista con Carlos Monsiváis"' - LBM, 1993, núms. 26/27, 57-62.

\section{Muñiz-Huberman, Angelina}

42-2218. Mateo Gambarte, Eduardo - "Angelina Muñiz-Huberman: escritora hispano-mexicana". - CuIF, 18 (1992), 65-83.

\section{Paso, Fernando del}

42-2219. RuIZ RIVAS, HÉctor "Francia en México: la expresión de lo local y lo foráneo en Noticias del Imperio de Fernando del Paso". - Carav, 1992, núm. 58, 49-63.

\section{Paz, Octavio}

42-2220. Paz, Octavio - Convergencias. - Planeta, México, 1992. 155 pp.

42-2221. DURÁN, Richard - "The gran chingón: Pedro Páramo from the perspective of Octavio Paz's El laberinto de la soledad"'. - RNo, 33 (1992-93), 169-177.

42-2222. Earle, Peter G. - "Octavio Paz: poesía e historia". - NRFH, 40 (1992), 1101-1112.

42-2223. Malpartida, JUAN (coord.)

- Octavio Paz. Creación, historia y pensamiento. Una poética de la reconciliación. Nueva edición. - Anthropos, Barcelona, 1992. $94 \mathrm{pp}$.

42-2224. MEyer-MinNEMANN, Klaus - "Octavio Paz: Topoemas. Elementos para una lectura". - NRFH, 40 (1992), 1113-1134.

42-2225. Stanton, ANTHONY - "Octavio $\mathrm{Paz}$, Alfonso Reyes y el análisis del fenómeno poético". - $H R, 61$ (1993), 363-378.

42-2226. STANTON, ANTHONY - "Una lectura de El arco y la lira”. - Reflexio- 
nes lingüisticas y literarias, t. 2, ed. $\mathrm{R}$. Olea, y J. Valender (México, 1992), 301-322.

V. también núm. 666 .

\section{Pellicer, Carlos}

42-2227. JIMÉNEZ DE BÁEZ, YVETTE "Carlos Pellicer, contemporáneo". Reflexiones lingüisticas y literarias, t. 2, ed. R. Olea, y J. Valender (México, 1992), 269-299.

V. también núm. 683 .

\section{Poniatowska, Elena}

42-2228. AMAR SÁNCHEZ, ANA MARÍA - "Las voces de los otros. El género de no-ficción en Elena Poniatowska". - Fil, 25 (1990), 161-174.

42-2229. STEEle, CYNTHIA - "Testimonio y autor/idad en Hasta no verte Jesús mío, de Elena Poniatowska". $R C L L, 1992$, núm. 36, 155-180.

\section{Revueltas, José}

42-2230. NEGRÍN, EDITH - "Dos canciones populares en una novela de José Revueltas: las expresiones de la mexicanidad". - HMDR, 887-905.

42-2231. NEGRÍN, EDITH - "El luto humano y la narrativa mexicana que lo procede". - LMM, 3 (1992), 93-122.

Reyes, Alfonso

42-2232. REYES, ALFONSO - Una ventana abierta al infinito. Antología poética. Sel. de G. Deniz. Pról. de O. Paz. Vuelta, México, 1993. 271 pp.

42-2233. Alvar, MaNUEL - "Alfonso
Reyes y España". - NRFH, 40 (1992), 959-987.

42-2234. NaVAscuÉs Martín, JaVier DE - "Hacia una estilística de la jitanjáfora"’. - RLit, 53 (1991), 641652.

42-2235. ROBB, JAMES W. - "Amistades literarias: Alfonso Reyes y Pedro Salinas. (Un mexicano en España / un español en América)".- RHM, 46 (1993), 375-383.

42-2236. ZAÏTZEFF, SERGE I. (ed.) - De casa a casa. Correspondencia entre Manuel Toussaint y Alfonso Reyes. - El Colegio Nacional, México, 1990. \| LMM, 3 (1992), 214-220 (Curiel).

V. también núm. 2225.

\section{Rulfo, Juan}

42-2237. DíAz de Guereñu, JuAN MANUEL - "Pedro Páramo: murmullos de entre las grietas". - I, 1992, núm. 35, 98-108.

42-2238. JiMÉNEZ DE BÁEZ, Y. - Juan Rulfo, del páramo a la esperanza (una lectura crítica de su obra) (N. 41-2587). \|HR, 61 (1993), 312-314 (Leal); I, 1993, núm. 38, 144-145 (López de Abiada); RCEH, 17 (1992-93), núm. 1, 223225 (Madrid).

42-2239. PIMENTEL, LUZ AURORA " "Los caminos de la eternidad": el valor simbólico del espacio en Pedro Páramo". - RCEH, 16 (1991-92), núm. 2, 267-291.

42-2240. ROFFÉ, REINA - Juan Rulfo. Autobiografia armada. - Montesions, Barcelona, 1992. $65 \mathrm{pp}$.

42-2241. ROMANO-THUESEN, EVELIA - "El personaje femenino: un sol para develar en dos cuentos de Rulfo". - LMM, 3 (1992), 135-149.

42-2242. SACRISTÁN, MARÍA CRISTina - "Locura y realismo mágico en $P_{e}$ dro Páramo". - Estudios, 1993, núm. 32, 61-72.

42-2243. UZQUIZA GONZÁlEZ, JosÉ IGNACIO - "Simbolismo e historia en Juan Rulfo". - RevIb, 58 (1992), 639-655. 
42-2244. Vital Díaz, Alberto - "Estructura apelativa en Juan Rulfo". LMM, 3 (1992), 63-91.

V. también núms. 643, 2221.

Sainz, Gustavo

V. núm. 2182.

Torres Bodet, Jaime

42-2245. TORRES BODET, JAIME - “ $E l$ juglar y la domadora." y otros relatos desconocidos. Recop. y pról. de L. M. Schneider. - El Colegio de México, México, 1992. 154 pp. (Serie Literatura mexicana, Cátedra Jaime Torres Bodet, 1). 42-2246. UNRUH, VICKY - "Art's "Disorderly Humanity" in Torres Bodet's La educación sentimental' . - RCEH, 17 (1992-93), núm. 1, 123-136.

Usigli, Rodolfo

42-2247. Beardsell, Peter - $A$ theatre for Cannibals: Rodolfo Usigli and the Mexican stage. - Fairleigh Dickinson University, Rutherford, 1992. 242 pp. \| $H R$, 61 (1993), 306-308 (Dauster).

Vasconcelos, José

42-2248. SÁNCHEZ MACGRÉGOR, JOAQUín - "Las ideas estéticas de José Vasconcelos como proyecto utópico"

- CuA, 1992, núm. 31, 246-251.

42-2249. ZEA, LEOPOLDO - "Vasconcelos y la utopía de la raza cósmica"

- CuA, 1993, núm. 37, 23-36.
Vicens, Josefina

42-2250. Vela, María Halina - “La pasión por la existencia en la obra de Josefina Vicens"'. - Estudios, 1993, núm. 33, 91-98.

Villaurrutia, Xavier

V. núm. 675.

Xirau, Ramón

42-2251. TERry, ARTHUR - "Ramón Xirau: decir y describir". - Syntaxis, 1992, núms. 30/31, 77-99.

Yáñez, Agustín

42-2252. Franco, J. - Lectura sociocritica de la obra novelística de Agustín Yáñez (N. 41-2610). \|RCLL, 1992, núm. 35, 184-185 (Lavou).

Nicaragua

Belli, Gioconda

42-2253. Cohen, Henry - "A feminist novel in Sandinista Nicaragua: Gioconda Belli's La mujer habitada' . DLit, 9 (1991-92), núm. 2, 37-48.

42-2254. MOYANO, PILAR - "La transformación de la mujer y la nación en la poesía comprometida de Gioconda Belli'. - RCEH, 17 (1992-93), núm. 2, 319-331.

42-2255. Richards, TIMOTHY A. B. "Resistance and liberation: The mystic voice and textual authoriry in 
Belli's La mujer habitada". - Critical essays on the literatures of Spain and Spanish America, eds. L. 'T. González del Valle \& J. Baena (Boulder, 1991), 209-214.

\section{Cardenal, Ernesto}

42-2256. Cardenal, ERnesto "Vénganos a la tierra de la República de los Cielos". - CuA, 1993, núm. 40, 35-52.

42-2257. MinARD, EVELYNE - "Un exemple d'utilisation de l'historie par Ernesto Cardenal: El estrecho didoso". - Carav, 1993, núm. 60, 101-121.

42-2258. PAILlER, GLAIRE - "Avatares del tiempo histórico en dos poetas nicaragüenses de hoy: Ernesto Cardenal y Pablo Antonio Cuadra". - Carav, 1993, núm. 60, 85-99.

42-2259. SAlomon, Russell O. - "E] proceso poético: entrevista con Ernesto Cardenal'. - CuA, 1993, núm. 40, 99-109.

Cuadra, Pablo Antonio

42-2260. Cobo Borda, Juan Gustavo - "Pablo Antonio Cuadra". CuH, 1993, núm. 522, 7-17.

V. también núm. 2258.

Paraguay

Roa Bastos, Augusto

42-2261. BALDERSTON, DANiEL -

"Cuerpo presente: restos corpóreos en Yo el Supremo". - DLit, 10 (1992-93), núm. 1, 51-57.

42-2262. SICARD, ALAIN - "Poder de la escritura: ¿el crepúsculo de los chamanes?". - RCLL, 1993, núm. 38, 155-162.
42-2263. Weldt Basson, Helene CAROL - Augusto Roa Bastos's "I the Supreme". A dialogic perspective. - University of Missouri Press, Columbia, 1993. $247 \mathrm{pp}$.

V. también núm. 728 .

Perú

Adán, Martin

42-2264. VÉLEZ, JULIO - “Martín Adán: la palabra y el laberinto". RevIb, 58 (1992), 657-671.

Arguedas, José Maria

42-2265. BOREllo, RODOlFO A. "Raza de bronce y la novela indigenista”. - BAAL, 56 (1991), 9-43.

42-2266. CRUz LeAL, Petra IRAIDES “'Los horizontes de Arguedas: apuntes para una valoración crítica". RevIb, 58 (1992), 393-406.

42-2267. ROVIRA, JOSÉ CARLOS (coord.) - José Maria Arguedas. Indigenismo y mestizaje cultural como crisis contemporánea hispanoamericana. - Anthropos, Barcelona, 1992. $95 \mathrm{pp}$.

Belli, Carlos Germán

42-2268. CÁnePa, Mario A. - "Del canzoniere a la "canción coja» de Belli". - DLit, 9 (1991-92), núm. 2, 27-35.

Bryce Echenique, Alfredo

42-2269. ORTEGA, JULIO- - "Alfredo Bryce Echenique y la estética de la 
exageración'. - CuH, 1993, núm. $521,71-86$.

\author{
Eguren, José María
}

42-2270. Rodríguez ReA, Miguel ÁNGEL - "Una carta desconocida de Eguren'. - LexisL, 16 (1992), 113115.

Ferrari, Américo

42-2271. Teja, Ada MARÍA - “La poesía de Américo Ferrari: oscilaciones entre el fracaso y la esperanza. Configuración de una lucha'. - Inti, 199192, núms. 34/35, 61-78.

\section{Mariátegui, José Carlos}

42-2272. Fernández Díaz, Osvaldo - "El discurso peruano de José Carlos Mariátegui'”. - CuA, 1992, núm. $33,115-124$.

Ortega, Julio

42-2273. Cánovas, Rodrigo - "Lectura de Diario imaginario de Julio Ortega”. - Inti, 1991-92, núms. 34/35, 199-206.

Scorza, Manuel

42-2274. Escorza Cecilia - "Suplemento a la bibliografía sobre Manuel Scorza'. - RCLL, 1993, núm. 37, 361-364.

42-2275. SCHMIDT, FriedHELM - “Bi- bliografía de y sobre Manuel Scorza. Nuevas aportaciones". - $R C L L$, 1993, núm. 37, 355-359.

\section{Vallejo, César}

42-2276. Chirinos, JORge PRADO "Una carta desconocida de César Vallejo sobre su prisión en Trujillo". LexisL, 16 (1992), 259-266.

42-2277. GUZMÁN, JORGE - "César Vallejo: el acento me pende del zapato". - CuA, 1992, núm. 34, 180-185.

42-2278. MAYOR ZARAGOZA, FEDERICO

- "Transpirar la miseria del otro".

- CuA, 1992, núm. 34, 14-16.

42-2279. MONTIEL, EdGAR - “César Vallejo, "igracias por la tristeza!"”. - CuA, 1992, núm. 34, 11-13.

42-2280. NÁJAR, JORGE — "César Vallejo: homenaje(s) \& epitafio". CuA, 1992, núm. 34, 21-26.

42-2281. SillaAto, MARÍA DEL CARMEN

- "César Vallejo: en la encrucijada de la fe". - Unión, 1993, núm. 15, 28-36.

V. también núms. 667, 682, 2180.

Vargas Llosa, Mario

42-2282. BOLAND, R. - Mario Vargas Llosa: Oedipus and the "Papa'" state. A study of individual and social psychology in Mario Vargas Llosa's novels of Peruvian reality, from "La ciudad y los perros" to "Historia de Mayta" (N. 41-2723). \|H, 75 (1992), 333-334 (McMurray).

42-2283. Calabrese, Elisa - " $\mathrm{El}$ hablador de Vargas Llosa o la imposibilidad de la utopía'. - DLit, 10 (199293), núm. 2, 53-62.

42-2284. DE Grandis, Rita - "La problemática del conocimiento histórico en Historia de Mayta de M. Vargas Llosa'". - RCLL, 1993, núm. 38, 375-382.

42-2285. ReVERTE Bernal, CONCEPCIÓN - "Elogio de La madrastra de 
Mario Vargas Llosa, un relato modernista"'. - RevIb, 58 (1992), 567-580.

42-2286. RIVERA RODAS, ÓSCAR - El metateatro y la dramática de Vargas Llosa. Hacia una poética del espectador. J. Benjamins, Amsterdam, 1992. $213 \mathrm{pp}$.

42-2287. Schulz-BuschHaus, UlRICH - "Verrätselung und Ambivalenz. Funktionen des KriminalromanSchemas bei Mario Vargas Llosa (insbesondere in La ciudad y los perros)' '. $R J, 43$ (1992), 318-335.

42-2288. STANdish, Peter - "Contemplating your own novel: The case of Mario Vargas Llosa”. - $H R, 61$ (1993), 53-63.

V. también núm. 676 .

Zavaleta, Carlos E.

42-2289. GonZÁLEZ MONTES, ANTONIO - "Notas sobre Vestido de luto de C.E. Zavaleta". - LexisL, 16 (1992), 255258.

Puerto Rico

Burgos, Julia de

42-2290. Caulfield, Carlota "Canción de la verdad sencilla: Julia de Burgos y su diálogo erótico-místico con la naturaleza". - RevIb, 59 (1993), 119-126.

Casas, Myrna

42-2291. Aguilú DE MURPHY, RAQUEL - "Hacia una teorización del absurdo en el teatro de Myrna Casas". RevIb, 59 (1993), 169-176.
Collado Martell, Alfredo

42-2292. ROSA, WILLIAM - "Ciencia y literatura en Alfredo Collado Martell: un primer caso de inseminación artificial'. - RevIb, 59 (1993), 111-118.

Díaz Valcárcel, Emilio

42-2293. BÉJAR, EDUARDO C. - "Harlem todos los días: el exilio del nombre/el nombre del exilio". - RevIb, 59 (1993), 329-343.

\section{Ferré, Rosario}

42-2294. GutiérREZ, MARiela "Rosario Ferré y el itinerario del deseo: un estudio lacaniano de Cuando las mujeres quieren a los hombres"'. RCEH, 16 (1991-92), núm. 2, 203217.

42-2295. ROSES, LORRAINE ElenA "Las esperanzas de Pandora: prototipos femeninos en la obra de Rosario Ferré". - RevIb, 59 (1993), 279-287.

V. también núm. 874.

\section{Garcia Ramis, Magali}

42-2296. SOTOMAYOR, ÁUREA MARÍA - "Si un nombre convoca un mundo..., Felices días, tío Sergio en la narrativa puertorriqueña contemporánea". - RevIb, 59 (1993), 317-327.

\section{González, José Luis}

42-2297. DÍAZ, LUIS FELIPE - " "En el fondo del caño hay un negrito» de José Luis González: estructura y discurso 
narcisita". - RevIb, 59 (1993), 127 143.

\section{Lugo Filippi, Carmen}

42-2298. UMPIERRE, LUZ MARÍA "Incitaciones lesbianas en "Milagros, calle Mercurio" de Carmen Lugo Filippi". - RevIb, 59 (1993), 309316.

Marqués, René

42-2299. Caballero Wangüemert, MARía M. - "Discurso histórico y carnavalización de la historia: "El juramento" de René Marqués". ReoIb, 59 (1993), 145-156.

42-2300. Castillo, Jorge Luis "De la guerra a las sombras: sobre los pasos de Peregrinación de René Marqués". - RevIb, 59 (1993), 157-167.

Rodríguez Juliá, Edgardo

42-2301. Duchesne Winter, JUAN "Multitud y tradición en El entierro de Cortijo de Edgardo Rodríguez Juliá" - RevIb, 59 (1993), 221-237.

42-2302. Ríos Ávila, RuBÉN - "La invención de un autor: escritura y poder en Edgardo Rodríguez Juliá". - RevIb, 59 (1993), 103-219.

Sánchez, Luis Rafael

42-2303. CacháN, Manuel - "En cuerpo de camisa de Luis Rafael Sánchez: la antiliteratura alegórica del otro puertorriqueño'. - RevIb, 59 (1993), 177-186.

42-2304. Gelpí, JUAN - “El clásico y la reescritura: Insularismos en las páginas de La guaracha del Macho Camacho"'. Revlb, 59 (1993), 55-71.

42-2305. Tineo, GABRIELA - "La "negritudn: memoria y olvido en los cuentos de Luis R. Sánchez''. - $\mathrm{CuLH}$, 1992, núm. 16, 73-77.

42-2306. VÉlez, DiANA - "Bakhtin and Puerto Rican narrative: heteroglossia in Luis Rafael Sánchez's $L a$ importancia de llamarse Daniel Santos'. —Dispositio, 1991, núm. 41, 133-144.

V. también núm. 691 .

$$
\text { Silen, Iván }
$$

42-2307. MARTÍN-Rodríguez, M. M. - "Iván Silén: una poética de la alteridad". $-H, 75$ (1992), 301-309.

Soto Vélez, Clemente

42-2308. CatAlÁ, Rafael - "La vanguardia atalayista y la obra de Clemente Soto Vélez". - RevIb, 59 (1993), 101-109.

Vega, Ana Lydia

42-2309. Captain-Hidalgo, YVonne - "El espíritu de la risa en el cuento de Ana Lydia Vega". - RevIb, 59 (1993), 301-308.

42-2310. GonZÁlez, ANíbAl - "Ana Lydia Pluravega: unidad y multiplicidad caribeñas en la obra de Ana Lydia Vega". - RevIb, 59 (1993), 289-300. 
Uruguay

\section{Amorim, Enrique}

42-2311. Rojas, Santiago - “El gaucho en Amorim: progreso y folklore vistos desde un ángulo social' '. $K R Q, 38$ (1991), 85-93.

\section{Benedetti, Mario}

42-2312. Benedetti, Mario - Despistes y franquezas. - Patria-Nueva Imagen, México, 1989. 261 pp. \| RCLL, 1992, núm. 35, 181-182 (Castro Urioste).

42-2313. Caballe, ANNA - "Las fronteras del lenguaje en La tregua, de Benedetti". - RevIb, 58 (1992), 357366.

42-2314. Campanella, Hortensia (coord.) - Mario Benedetti. Literatura y creación social de la realidad. - Anthropos, Barcelona, 1992. 95 pp.

42-2315. DEHENNIN, ELSA - "A propósito del realismo de Mario Benedetti'. - RevIb, 58 (1992), 1077-1090.

42-2316. GoNZÁlez, F. - "Primavera con una esquina rota de Mario Benedetti: de la novela del exilio a la representación comprometida'. - H, 75 (1992), 38-49.

\section{Casaravilla Lemos, Enrique}

42-2317. Apratto, Roberto - "Casaravilla: la práctica de los sentidos". - RevIb, 58 (1992), 947-952.

Da Rosa, Julio C.

42-2318. ROMITI, ElenA - "La devolución del pensamiento a la vida: Julio
C. Da Rosa". - RevIb, 58 (1992), 1091-1101.

\section{Di Giorgio Medicis, Marosa}

42-2319. EchEVARREN, ROBERTo "Marosa Di Giorgio, última poeta del Uruguay'. - RevIb, 58 (1992), 11031115 .

\section{Espinola, Francisco}

42-2320. Visca, Arturo Sergio "Francisco Espínola, narrador". RevIb, 58 (1992), 975-999.

\section{Galmés, Héctor}

42-2321. Raviolo, Heber - "Héctor Galmés, o la paradójica invención del imperfecto cuentista". - RevIb, 58 (1992), 1059-1064.

\section{Hernández, Felisberto}

42-2322. Graziano, FranK - "La lujuria de ver: la proyección fantástica en "El acomodador» de Felisberto Hernández'’. - RevIb, 58 (1992), 1027-1039.

42-2323. TRIGO, ABRIL - "Un texto antropológico de Julio Herrera y Reissig". - CuA, 1992, 32, 212-227.

\section{Márquez, Selva}

42-2324. EsPiNA, EdUARDO - "De la jungla de Lautréamont a Selva Márquez: el (casi) inexistente surrealismo 
uruguayo"'. - Rè Ib, 58 (1992), 933945.

\section{Martínez Moreno, Carlos}

42-2325. Fontana, Hugo - “Carlos Martínez Moreno, testigo de cargo" - RevIb, 58 (1992), 1049-1057.

\section{Onetti, Juan Carlos}

42-2326. Gilio, María Esther, y CaRLOS MARÍA DOMÍnguez Construcción de la noche: la vida de Juan Carlos Onetti. - Planeta, Buenos Aires, 1993. $378 \mathrm{pp}$.

42-2327. Mattalia, Sonia - La figura en el tapiz. Teoría y práctica narrativa en Juan Carlos Onetti. - Tamesis, London, 1990. 193 pp. \| HR, 60 (1992), 392-393 (Shaw).

42-2328. Petit, María Angélica, y OMAR PREgo Gadea - "Los adioses de Juan Carlos Onetti. Un modelo de escritura hermética-abierta'" RevIb, 58 (1992), 1117-1132.

42-2329. Renart, J. Guillermo "Bases narratológicas para una nueva lectura de "El infierno tan temido" de Onetti'. - RevIb, 58 (1992), 11331151.

V. también núms. 653,1831 .

\section{Oribe, Emilio}

42-2330. Albistur, JORGE - "Emilio Oribe, o la hoguera hecha estatua”. - RevIb, 58 (1992), 1001-1013.

\section{Quiroga, Horacio}

42-2331. Liano, Dante - "Estilo y técnica en El salvaje de Horacio Quiroga”. - QIA, 1993, núm. 73, 3748.

42-2332. NGOM, MBARÉ - "Autoritarismo y creación literaria en el Río de la Plata: Horacio Quiroga". CuLH, 1992, núm. 15, 97-102.

42-2333. PAOLI, ROBERTO - "El perfecto cuentista: comentario a tres textos de Horacio Quiroga'. - RevIb, 58 (1992), 953-974.

\section{Rama, Ángel}

42-2334. ZANETTI, SUSANA - "Ángel Rama y la construcción de una literatura latinoamericana'. - RevIb; 58 (1992), 919-932.

Real de Azúa, Carlos

42-2335. Halperín Donghi, Tulio "Carlos Real de Azúa: la ávida curiosidad por el mundo"'. - RevIb, 58 (1992), 893-902.

Ricci, Julio

42-2336. UlLA, NoEmí - “'Tradición y transgresión en los cuentos de Julio Ricci". - RevIb, 58 (1992), 10651076.

42-2337. WALKER, JOHN - "From maniáticos to mareados: The fictional world of Julio Ricci'. - RCEH, 18 (1993-94), núm. 1, 91-106.

Rodriguez Monegal, Emir

42-2338. RODRÍGUEZ-CARRANZA, LUZ - "Emir Rodríguez Monegal, o la construcción de un mundo (nuevo) 
posible'. - RevIb, 58 (1992), 903917.

Venezuela

Álvarez, María Auxiliadora

42-2339. Ghacón, Alfredo - "María Auxiliadora Álvarez: cuerpo y ca(z)a de palabras". - Inti, 1993, núms. 37/38, 207-214.

V. también núm. 2355.

42-2340. APONTE DE ZACKLIN, LydiA _ "Escritura, exactitud y fascinación en la narrativa de José Balza". - Inti, 1993, núms. 37/38, 171-177.

42-2341. Noguera, Carlos - "La convergencia múltiple. (Una aproximación a la narrativa de José Balza)". - Inti, 1993, núms. 37/38, 179-185.

Chocrón, Isaac

42-2342. YOUNOSZAI, BARBARA, \& ROSSI IRAUSQUIN - "Not establishing limits: The writing of Isaac Chocrón'. - Inti, 1993, núms. 37/38, 155-161.

Crespo, Luis Alberto

V. núm. 2346.
Diaz Rodríguez, Manuel

42-2343. Álvarez, AleXANDRA-“Ídolos rotos de Manuel Díaz Rodríguez. Una tropical "novela de artista»". NRFH, 41 (1993), 293-331.

Garmendia, Julio

42-2344. MORA, CARMEN DE - "Ironía y ficción en la narrativa de Julio Garmendia". - RevIb, 58 (1992), 517526. [También en EUSB, 1993, núm. $1,85-94]$.

Garmendia, Salvador

42-2345. GARMENDIA, SALVAdOR "Por qué escribo". - Inti, 1993, núms. 37/38, 263-272.

Gerbasi, Vicente

42-2346. GUZMÁN PATRICIA - "El lugar como absoluto. (Vicente Gerbasi, Ramón Palomares, y Luis Alberto Crespo)"'. - Inti, 1993, núms. 37/38, 107-115.

Liscano, Juan

42-2347. Doudoroff, Michael "Nuevo mundo orinoco, de Juan Liscano: reflexiones sobre sus contextos". - Inti, 1993, núms. 37/38, 81-87. 


\section{Madrid, Antonieta}

42-2348. Cunha-Giabbai, Gloria DA - "La problemática de la mujer hispanoamericana como reflejo del conflicto social: No es tiempo para rosas de Antonieta Madrid". - Inti, 1993, núms. 37/38, 145-153.

Márquez, Miguel

V. núm. 2355.

\section{Montejo, Eugenio}

42-2349. EyZAGUIRRE, LUIS - "Eugenio Montejo: poeta de fin de siglo" - Inti, 1993, núms. 37/38, 123-132. 42-2350. Hernández, Consuelo "La arquitectura poética de Eugenio Montejo”. - Inti, 1993, núms. 37/38, 133-143.

Palomares, Ramón

V. núm. 2346.

Pantín, Yolanda

42-2351. Pantín, Yolanda - "De Casa o Lobo al Cielo de París: el futuro imposible". - Inti, 1993, núms. 37/38, 47-55.

Parra, Teresa de la

42-2352. LASARTE VALCÁRCEL, JAVIER - "Nostálgicos e irracionalistas: his- toria y modernidad en Las memorias de mamá Blanca y Las lanzas coloradas"'. EUSB, 1993, núm. 1, 69-83.

Ramos Sucre, José Antonio

42-2353. RUIz BARRIONUEVO, CARMEN - "Juegos del espacio y estrategias del personaje en José Antonio Ramos Sucre". - RevIb, 58 (1992), 597609.

42-2354. Ruiz Barrionuevo, Carmen - "Modernismo versus modernidad en José Antonio Ramos Sucre'. EUSB, 1993, núm. 1, 61-67.

Rojas Guardia, Armando

42-2355. Ramírez QUiNTERo, GonZALO - "La poesía venezolana actual: tres ejemplos". - Inti, 1993, núms. 37/38, 187-195.

\section{Strepponi, Blanca}

42-2356. Strepponi, Blanca - "El mal, los verdugos y sus víctimas: acerca de una escritura compartida en el Diario de John Robertson". - Inti, 1993, núms. 37/38, 61-68.

Trejo, Oswaldo

42-2357. BARRERA LiNARES, LUIS "La narrativa breve de Oswaldo Trejo: más allá del textualismo”. - Inti, 1993, núms. 37/38, 97-106. 
Uslar Pietri, Arturo

42-2358. Ferreira de Cassone, FloRENCIA - "Arturo Uslar Pietri. Historia y pasión de América". - CuA, 1993, núm. 40, 125-145.
42-2359. LÓPEZ MARROQUín, RUBÉN - "Arturo Uslar Pietri: una biografía intelectual". - $C u A, 1993$, núm. 40, 146-163.

V. también núm. 2352. 